\title{
EFEITOS DO CLORETO DE SÓDIO NO CRESCIMENTO, CONCENTRAÇÃO DE NUTRIENTES E DE SÓDIO, E NAS CARACTERISTICAS TECNOLÓGICAS DE SEIS CULTIVARES DE SORGO SACARINO [Oorghum bioolor (L.) Moench]
}

ALCIONEAUREA QUEIROZ DA SILVA

Orientador: Prof. Dr. EURIPEDES MALAVOLTA

Tese apresentada à Escola Superior de Agricultura "Luiz de Queiroz", da Universidade de São Paulo, para obtenção do Título de Doutor em Agronomia, Área de Concentração: Solos $\theta$ Nutrição de Plantas.

PIRACICABA

Estado de São Paulo - Brasil

Dezembro - 1983 
A mamãe,

Severina,

A papai,

Alfredo (in memorian).

A minha irmã,

Célia,

OFEREC $O$

A Humberto, meu esposo, pela

colaboração, compreensão e

incentivos constantes,

carinhosamente

$D E D I C O$ 
Ac Prof. Dr. Eurípedes Malavolta, pela orientação, amizade e inesti mável apoio;

Ao Prof. Dr. Henrique Viana Amorim;

Ao Prof. Dr. Edvaldo Mesquita Beltrão;

Ao Prof. Dr. Henrique Paulo Haag;

Ao Prof. Dr. Takashi Muraoka;

Ao Prof. Dr. Franciscọ Josē Krug;

Ao Eng:-Florestal Valter João Dieh1;

Aos Acadêmicos Mārio Lücio Roque e Ivo Luiz;

Aos cidadãos Luiz Veríssimo, Euridice Amaral Mello e Romeu R. Rocha;

Ao Prof. Dr. Francisco de Assis Ferraz de Mel1o;

As Laboratoristas Yolanda Aparecida Ruffini e Cleusa Pereira Cabral;

A Srta. Maria Izalina Ferreira Alves;

A Escola Superior de Agricultura "Luiz de Queiroz" - USP;

Ao Centro de Ciências Agrārias da Universidade Federal da Paraíba;

Ao Departamento de Química - Área de Bioquímica da Escola Superior de Agricultura "Luiz de Queiroz" - USP;

A Seção de Radioquímica e Química Analítica do CENA/ESALQ/USP;

A Fermentec S/C Ltda. Assessoria em Fermentação Alcoólica, Piracicaba, SP;

A Empresa Pernambucana de Pesquisa Agropecuāria - IPA;

A EMBRAPA; 
Ao CNPq, CAPES, FAPESP, BNDE, CNEN, IIPF (EUA) e IIP (Suiça);

Ao Departamento de Matemática e Estatistica da ESALQ/USP;

A Biblioteca do PLANALSUCAR - Piracicaba;

Aos amigos Isabel E. Eimori, Denise Hellu Silva, Lauro Humberto Silva, Maria Teresa C. Pinto, Julieta M. Collonnese, José Carlos Collonese, Isa D.P. Morillas, Josē P. Morillas Jr., José Boteon, Lucia H.

G. Chaves, Iêde B. Chaves, Jūlio C.A.A. Magalhães e Marisa.

Ao funcionārio Gabriel Toledo e Silva ("in memorian").

A todos que contribuiram com dedicação e/ou estima para a realização deste trabalho,

Sinceros agradecimentos. 
Pảg.

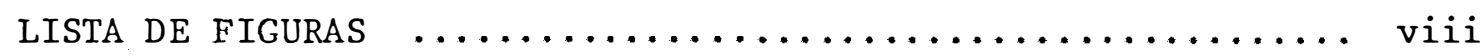

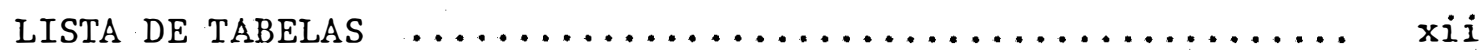

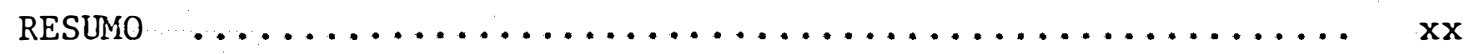

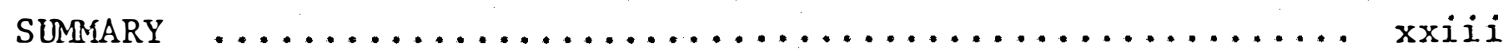

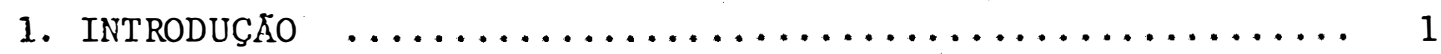

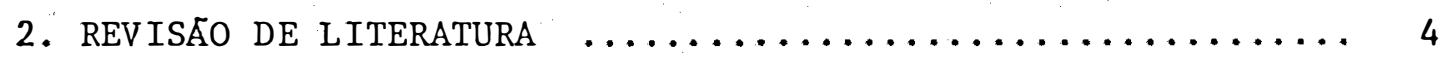

2.1 - Tolerāncia à Salinidade $\ldots \ldots \ldots \ldots \ldots \ldots \ldots \ldots \ldots, 4$

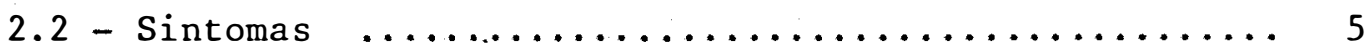

2.3 - Salinidade e Crescimento $\ldots \ldots \ldots \ldots \ldots \ldots \ldots \ldots \ldots \ldots$

2.4 - Salinidade e Composição Mineral $\ldots \ldots \ldots \ldots \ldots \ldots . .6$

2.5 - Salinidade e Características Tecnológicas ........ 13

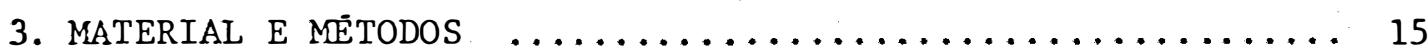

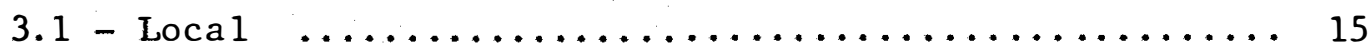

3.2 - Cultivar Utilizado $\ldots \ldots \ldots \ldots \ldots \ldots \ldots \ldots \ldots \ldots \ldots \ldots \ldots \ldots \ldots$

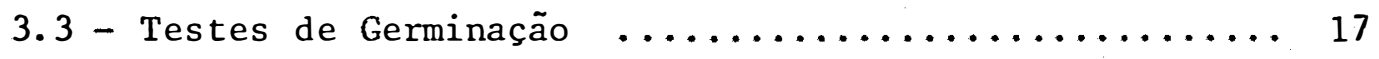

3.4 - Instalação e Condução do Experimento Preliminar ... 17

3.4 .1 - Obtenção de mudas $\ldots \ldots \ldots \ldots \ldots \ldots \ldots \ldots \ldots \ldots \ldots \ldots$

3.4.2 - Instalação em vasos e condução ......... 18

3.4 .3 - Tratamentos utilizados $\ldots \ldots \ldots \ldots \ldots \ldots \ldots 20$

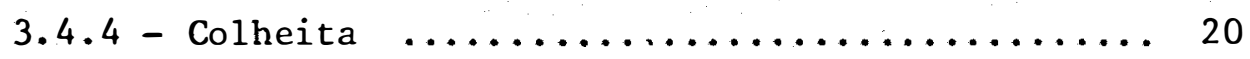

3.5 - Instalação e condução do Segundo Experimento ....... 21

3.5 .1 - Obtenção de mudas $\ldots \ldots \ldots \ldots \ldots \ldots \ldots \ldots \ldots \ldots \ldots \ldots$

3.5 .2 - Instalação em vasos e condução $\ldots \ldots \ldots \ldots .21$ 
Pāg.

3.5 .3 - Tratamentos utilizados ............. 21

3.5.4 - Colheita e preparo do material para anālise 22

3.5.5 - Anālises químicas da matéria seca e do caldo 22

3.5 .6 - Anālises tecnológicas ............... 24

3.5 .7 - Produção estimada de ālcool ......... 25

3.5 .8 - Tolerância relativa $\ldots \ldots \ldots \ldots \ldots \ldots \ldots \ldots \ldots$

3.5.9 - Planejamento experimental e anälises estatís

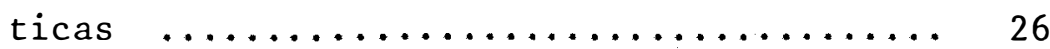

4. RESUltados E discUSSÃo ...................... 29

4.1 - Experimento Preliminar .................. 29

4.2 - Segundo Experimento $\ldots \ldots \ldots \ldots \ldots \ldots \ldots \ldots \ldots \ldots \ldots \ldots$

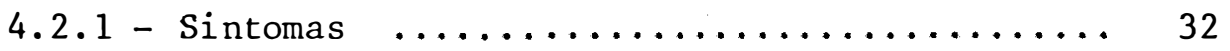

4.2 .2 - Crescimento da planta ............ 35

4.2.2.1 - Altura, comprimento da panícula e diâmetro do colmo .......... 35

4.2.2.2 - Produção de matéria seca ...... 38

4.2.2.3 - Produção de colmos frescos ..... 40

4.2.2.4 - Comentārio geral .......... 43

4.2.3 - Teores de nutrientes e de sódio na matéria sẹ ca $\ldots \ldots \ldots \ldots \ldots \ldots \ldots \ldots \ldots \ldots \ldots \ldots \ldots$

4.2 .3 .1 - Nitrogēnio ............. 46

4.2.3.2 - Fösforo .................. 49

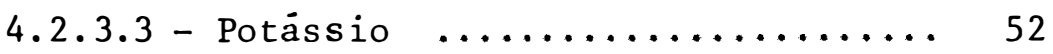

4.2 .3 .4 - Cälcio $\ldots \ldots \ldots \ldots \ldots \ldots \ldots \ldots \ldots \ldots$

4.2 .3 .5 - Magnésio $\ldots \ldots \ldots \ldots \ldots \ldots \ldots \ldots . \ldots . \ldots . \ldots$

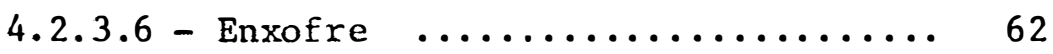

4.2 .3 .7 - Boro .................. 64 
vii.

Pāg.

4.2.3.8 - Cobre $\ldots \ldots \ldots \ldots \ldots \ldots \ldots \ldots \ldots 66$

4.2 .3 .9 - Ferro $\ldots \ldots \ldots \ldots \ldots \ldots \ldots \ldots \ldots 67$

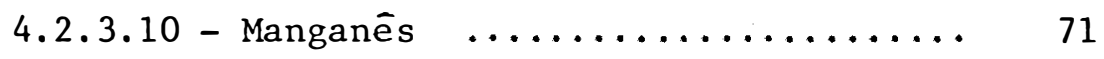

4.2 .3 .11 - Zinco $\ldots \ldots \ldots \ldots \ldots \ldots \ldots \ldots \ldots . \ldots \ldots$

4.2.3.12 - Cloro $\ldots \ldots \ldots \ldots \ldots \ldots \ldots \ldots \ldots . \ldots 77$

4.2 .3 .13 - Sódio $\ldots \ldots \ldots \ldots \ldots \ldots \ldots \ldots \ldots . \ldots$

4.2 .4 - Teores de nutrientes no caldo .......... 84

4.2.4.1 - Nitrogênio .............. 85

4.2.4.2 - Fósforo $\ldots \ldots \ldots \ldots \ldots \ldots \ldots \ldots . \ldots \ldots$

4.2 .4 .3 - Potàssio $\ldots \ldots \ldots \ldots \ldots \ldots \ldots \ldots$

4.2 .4 .4 - Cálcio $\ldots \ldots \ldots \ldots \ldots \ldots \ldots \ldots \ldots$

4.2 .4 .5 - Magnésio $\ldots \ldots \ldots \ldots \ldots \ldots \ldots \ldots . \ldots 9$

4.2 .4 .6 - Enxofre $\ldots \ldots \ldots \ldots \ldots \ldots \ldots \ldots .91$

4.2 .4 .7 - Boro $\ldots \ldots \ldots \ldots \ldots \ldots \ldots \ldots \ldots . \ldots \ldots$

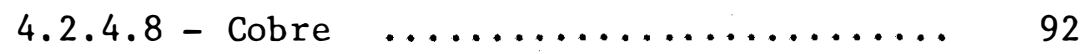

4.2 .4 .9 - Ferro $\ldots \ldots \ldots \ldots \ldots \ldots \ldots \ldots . \ldots \ldots$

4.2.4.10 - Manganēs ............... 95

4.2.4.11-Zinco $\ldots \ldots \ldots \ldots \ldots \ldots \ldots \ldots . \ldots 6$

4.2 .4 .12 - Cloro $\ldots \ldots \ldots \ldots \ldots \ldots \ldots \ldots \ldots . \ldots . \ldots 9$

4.2 .4 .13 - Sódio $\ldots \ldots \ldots \ldots \ldots \ldots \ldots \ldots \ldots \ldots$

4.2.5 - Caracteristicas Tecnológicas ........... 100

$4.2 .5 .1-{ }^{o} \operatorname{Brix} \ldots \ldots \ldots \ldots \ldots \ldots \ldots \ldots \ldots 1$

4.2.5.2 - Açúcares Redutores Totais (ART) .. 102

4.2.5.3 - Açücares Totais (AR) ......... 103

4.2.5.4 - Sacarose ................... 104

4.2 .5 .5 - Fibra $\ldots \ldots \ldots \ldots \ldots \ldots \ldots \ldots \ldots$

4.2 .6 - Produção estimada de álcool ........... 109

4.2 .7 - Tolerância relativa $\ldots \ldots \ldots \ldots \ldots \ldots \ldots \ldots \ldots 112$ 
viii.

Pāg.

5. CONCLUSÕES ................................ 115

6. LITERATURA CITADA ......................... 120

7. APENDICE $\ldots \ldots \ldots \ldots \ldots \ldots \ldots \ldots \ldots \ldots \ldots \ldots \ldots \ldots \ldots \ldots \ldots \ldots$ 


\section{LISTA DAS FIGURAS}

FIGURA

Pág.

1 Variação das temperaturas máximas e mínimas no interior da casa-de-vegetação e fora da mesma, no período de condução do 2 e experimento $\ldots \ldots \ldots \ldots \ldots \ldots \ldots$

2 Matéria seca ( $g$ ) do colmo de sorgo sacarino, em função dos niveis de cloreto na solução nutritiva ....

3 Altura da planta (m), comprimento da panícula ( $\mathrm{cm}$ ) e diāmetro do colmo (cm), em função dos níveis de cloreto na solução nutritiva $\ldots \ldots \ldots \ldots \ldots \ldots \ldots \ldots$

4 Matéria seca ( $g$ ) de raiz, de colmo e de folhas, em função dos niveis de cloreto na solução nutritiva ..

5 Matéria seca (g) de panícula, matéria seca (g) total e matéria fresca ( $g$ ) de colmo, em função dos niveis de cloreto na solução nutritiva

6 Concentração de nitrogēnio (\%) no colmo, nas folhas com sintomas leves e nas folhas com sintomas acentua dos, em função dos niveis de cloreto na solução nu-

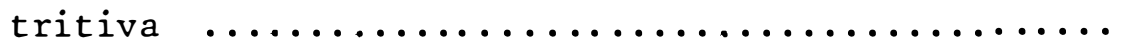

7 Concentração de fósforo (\%) no colmo, nas folhas com sintomas leves e nas folhas com sintomas acentuados, em função dos niveis de cloreto na solução nutritiva

8 Concentração de potássio (\%) no colmo, nas folhas com sintomas leves e nas folhas com sintomas acentuados, em função dos níveis de cloreto na solução nutritiva 
9 Concentração de cálcio (\%) no colmo, nas follhas com sintomas leves e nas folhas com sintomas acentuados, em função dos niveis de cloreto na solução nutritiva

10 Concentração de magnésio (\%) no colmo, nas folhas com sintomas leves e nas folhas com sintomas acentua dos, em função dos níveis de cloreto na solução nu-

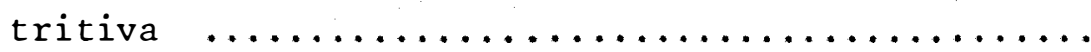

11 Concentração de enxofre (\%) no colmo, nas folhas com sintomas leves e nas folhas com sintomas acentuados, em função dos niveis de cloreto na solução nutritiva

12 Concentração de boro (ppm) no colmo, nas folhas com sintomas leves e nas folhas com sintomas acentuados, em função dos níveis de cloreto na solução nutritiva

13 Concentração de cobre (ppm) no colmo, nas folhas com sintomas leves e nas folhas com sintomas acentuados, em função dos niveis de cloreto na solução nutritiva

14 Concentração de ferro (ppm) no colmo, nas folhas com sintomas leves e nas folhas com sintomas acentuados, em função dos níveis de cloreto na solução nutritiva

15 Concentração de manganès (ppm) no colmo, nas folhas com sintomas leves e nas folhas com sintomas acentua dos, em função dos niveis de cloreto na solução nutritiva 
16 Concentração de zinco (ppm) no colmo, nas folhas com sintomas leves e nas folhas com sintomas acentuados, em função dos niveis de cloreto na solução nutritiva

17 Concentração de cloro (ppm) no colmo, nas folhas com sintomas leves e nas folhas com sintomas acentuados, em função dos niveis de cloreto na solução nutritiva

18 Concentração de sódio (ppm) no colmo, nas folhas com sintomas leves e nas folhas com sintomas acentuados, em função dos níveis de cloreto na solução nutritiva

19 Correlação entre teores de sódio (\%) e de cloro (\%) no colmo e nas folhas, e matéria seca ( $g$ ) de folhas e de colmo

20 Concentrações de nitrogēnio (ppm), fósforo (ppm) e de potássio (ppm), no caldo do sorgo sacarino, em função dos niveis de cloreto na solução nutritiva ....

21 Concentrações de cālcio (ppm), magnésio (ppm) e de enxofre (ppm), no caldo do sorgo sacarino, em função dos niveis de cloreto na solução nutritiva ....

22 Concentrações de boro (ppm), cobre (ppm) e de ferro (ppm), no caldo do sorgo sacarino, em função dos niveis de cloreto na solução nutritiva $\ldots \ldots \ldots \ldots \ldots$

23 Concentrações de manganês (ppm) e de zinco (ppm), no caldo do sorgo sacarino, em função dos niveis de clo reto na solução nutritiva $\ldots \ldots \ldots \ldots \ldots \ldots \ldots \ldots$ 
xii.

FIGURA

Pảg.

24 Concentrações de cloro (ppm) e de sōdio (ppm), no cal do do sorgo sacarino, em função dos niveis de cloreto na solução nutritiva $\ldots \ldots \ldots \ldots \ldots \ldots \ldots \ldots$

$25{ }^{0} \operatorname{Brix}(v / v)$, teores (\%) de açücares redutores totais (ART) e de açúcares redutores (AR) do caldo de sorgo sacarino, em função dos niveis de cloreto na solução

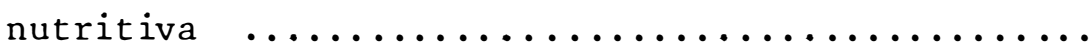

26 Teores (\%) de sacarose no caldo e de fibra no colmo, do sorgo sacarino, em função dos níveis de cloreto na solução nutritiva $\ldots \ldots \ldots \ldots \ldots \ldots \ldots \ldots \ldots \ldots$

27 Produção do colmo ( $t / h a)$, produção estimada de äl$\operatorname{coo} 1$ ( $1 /$ t de colmo e em $1 /$ ha), em função dos niveis de cloreto na solução nutritiva 
xiii.

\section{LISTA DAS TABELAS}

TABELA

Pàg.

1 Solução nutritiva usada em plantas de sorgo sacarino, durante o período de condução do experimento ..... 19

2 Métodos analíticos usados na determinação de nutrientes contidos nas diferentes cultivares de sorgo saca-

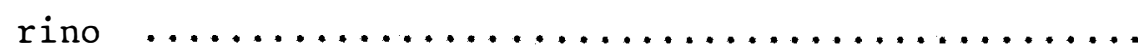

3 Anālise de variância para o delineamento inteiramente

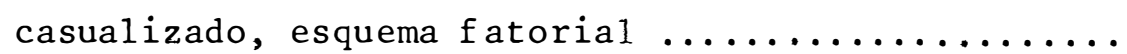

4 A anālise de variância para o delineamento inteiramen te casualizado, em esquema de parcela subdividida ...

5 Produção de matéria seca (g/planta) do colmo de diferentes cultivares de sorgo sacarino em função dos niveis de cloreto na solução nutritiva ............ 134

6 Altura (m) de diferentes cultivares de sorgo sacarino, em função dos níveis de cloreto na solução nutritiva.. 134

7 Comprimento da panícula (cm) de diferentes cultivares de sorgo sacarino em função dos níveis de cloreto na solução nutritiva $\ldots \ldots \ldots \ldots \ldots \ldots \ldots \ldots \ldots \ldots \ldots$

8 Diâmetro do colmo (cm) de diferentes cultivares de sor go sacarino, en função dos níveis de cloreto na soluçao nutritiva ......................... 135 
xiv.

TABELA

Pàg.

9 Produção de matéria seca (g/planta) das raízes de diferentes cultivares de sorgo sacarino, em função dos niveis de cloreto na solução nutritiva .......... 136

10 Produção de matéria seca (g/planta) dos colmos de diferentes cultivares de sorgo sacarino, em função dos niveis de cloreto na solução nutritiva $\ldots \ldots \ldots \ldots . . .136$

11 Produção de matéria seca (g/planta) das folhas de diferentes cultivares de sorgo sacarino, em função dos niveis de cloreto na solução nutritiva ..........

12 Produção de matéria seca (g/planta) das paniculas de diferentes cultivares de sorgo sacarino, em função dos niveis de cloreto na solução nutritiva ......... 137

13 Produção de matéria seca total (g/planta) de diferentes cultivares de sorgo sacarino, em função dos. niveis de cloreto na solução nutritiva $\ldots \ldots \ldots \ldots \ldots$

14 Produção de colmos (g/planta) de diferentes cultivares de sorgo sacarino, em função dos niveis de cloreto na solução nutritiva $\ldots \ldots \ldots \ldots \ldots \ldots \ldots \ldots \ldots$

15 Concentração de nitrogênio (\%) nos colmos de diferentes cultivares de sorgo sacarino, em função dos niveis de cloreto na solução nutritiva $\ldots \ldots \ldots \ldots \ldots$

16 Concentração de nitrogênio (\%) nas folhas de diferentes cultivares de sorgo sacarino, em função dos níveis de cloreto na solução nutritiva $\ldots \ldots \ldots \ldots \ldots$ 
17 Concentração de fósforo (\%) nos colmos de diferentes cultivares de sorgo sacarino, em função dos níveis de cloreto na solução nutritiva $\ldots \ldots \ldots \ldots \ldots \ldots \ldots$

18 Concentração de fösforo (\%) nas folhas de diferentes cultivares de sorgo sacarino, em função dos niveis de cloreto na solução nutritiva ..............

19 Concentração de potássio (\%) nos colmos de diferentes cultivares de sorgo sacarino, em função dos niveis de cloreto na solução nutritiva $\ldots \ldots \ldots \ldots \ldots$

20 Concentração de potássio (\%) nas folhas de diferentes cultivares de sorgo sacarino, em função dos niveis de cloreto na solução nutritiva $\ldots \ldots \ldots \ldots \ldots$

21 Concentração de cálcio (\%) nos colmos de diferentes cultivares de sorgo sacarino, em função dos niveis de cloreto na solução nutritiva $\ldots \ldots \ldots \ldots \ldots \ldots$

22 Concentração de cálcio (\%) nas folhas de diferentes cultivares de sorgo sacarino, em função dos níveis de cloreto na solução nutritiva $\ldots \ldots \ldots \ldots \ldots \ldots$

23 Concentração de magnésio (\%) nos colmos de diferentes cultivares de sorgo sacarino, em função dos niveis de cloreto na solução nutritiva $\ldots \ldots \ldots \ldots \ldots$

24 Concentração de magnésio (\%) nas folhas de diferentes cultivares de sorgo sacarino, em função dos niveis de cloreto na solução nutritiva 
xvi.

TABELA

Päg:

25 Concentração de enxofre (\%) nos colmos de diferentes cultivares de sorgo sacarino, em função dos niveis de cloreto na solução nutritiva $\ldots \ldots \ldots \ldots \ldots \ldots \ldots$

26 Concentração de enxofre (\%) nas folhas de diferentes cultivares de sorgo sacarino, em função dos niveis de cloreto na solução nutritiva ...............

27 Concentração de boro (ppm) noscolmcs de diferentes cul tivares de sorgo sacarino, em função dos níveis de cloreto na solução nutritiva $\ldots \ldots \ldots \ldots \ldots \ldots \ldots \ldots$

28 Concentração de boro (ppm) nas folhas de diferentes cultivares de sorgo sacarino, em função dos niveis de cloreto na solução nutritiva $\ldots \ldots \ldots \ldots \ldots \ldots$

29 Concentração de cobre (ppm) nos colmos de diferentes cultivares de sorgo sacarino, em função dos niveis de cloreto na solução nutritiva

30 Concentração de cobre (ppm) nas follhas de diferentes cultivares de sorgo sacarino, em função dos niveis de cloreto na solução nutritiva ..............

31 Concentração de ferro ( cultivares de sorgo sacarino, em função dos níveis de cloreto na solução nutritiva $\ldots \ldots \ldots \ldots \ldots \ldots$

32 Concentração de ferro (ppm) nas folhas de diferentes cultivares de sorgo sacarino, em função dos niveis de cloreto na solução nutritiva 
33 Concentração de manganês (ppm) nos colmos de diferen tes cultivares de sorgo sacarino, em função dos niveis de cloreto na solução nutritiva $\ldots \ldots \ldots \ldots \ldots$

34 Concentração de manganês (ppm) nas folhas de diferen tes cultivares de sorgo sacarino, em função dos niveis de cloreto na solução nutritiva $\ldots \ldots \ldots \ldots \ldots$

35 Concentração de zinco (ppm) nos colmos de diferentes cultivares de sorgo sacarino, em função dos niveis de cloreto na solução nutritiva $\ldots \ldots \ldots \ldots \ldots \ldots$

36 Concentração de zinco (ppm) nas folhas de diferentes cultivares de sorgo sacarino, em função dos níveis de cloreto na solução nutritiva $\ldots \ldots \ldots \ldots \ldots \ldots$

37 Concentração de cloro (ppm) nos colmos de diferentes cultivares de sorgo sacarino, em função dos niveis de cloreto na solução nutritiva ...............

38 Concentração de cloro (ppm) nas folhas de diferentes cultivares de sorgo sacarino, em função dos niveis de cloreto na solução nutritiva $\ldots \ldots \ldots \ldots \ldots \ldots \ldots$

39 Concentração de södio (\%) nos colmos de diferentes cultivares de sorgo sacarino, em função dos niveis de cloreto na solução nutritiva $\ldots \ldots \ldots \ldots \ldots \ldots \ldots$

40 Concentração de södio (\%) nas folhas de diferentes cultivares de sorgo sacarino, em função dos niveis de cloreto na solução nutritiva 
41 Concentração de nitrogênio (mg/1) no caldo de diferen tes cultivares de sorgo sacarino, em função dos niveis de clcreto na solução nutritiva $\ldots \ldots \ldots \ldots \ldots$

42 Concentração de fósforo ( $\mathrm{mg} / 1$ ) no caldo de diferentes cultivares de sorgo sacarino, em função dos niveis de cloreto na solução nutritiva ............. 166

43 Concentração de potảssio (mg/1) no caldo de diferentes cultivares de sorgo sacarino, em função dos niveis de cloreto na solução nutritiva $\ldots \ldots \ldots \ldots \ldots$

44 Concentração de cálcio (mg/1) no caldo de diferentes cultivares de sorgo sacarino, em função dos níveis de cloreto na solução nutritiva ............. 16

45 Concentração de magnésio (mg/1) no caldo de diferentes cultivares de sorgo sacarino, em função dos niveis de cloreto na solução nutritiva $\ldots \ldots \ldots \ldots \ldots$

46 Concentração de enxofre (mg/1) no caldo de diferentes cultivares de sorgo sacarino, em função dos niveis de cloreto na solução nutritiva $\ldots \ldots \ldots \ldots \ldots$

47 Concentração de boro (mg/1) no caldo de diferentes cultivares de sorgo sacarino, em função dos níveis de cloreto na solução nutritiva $\ldots \ldots \ldots \ldots \ldots \ldots \ldots$

48 Concentração de cobre (mg/1) no caldo de diferentes cultivares de sorgo sacarino, em função dos niveis de cloreto na solução nutritiva 
49 Concentração de ferro (mg/1) no caldo de diferentes cultivares de sorgo sacarino, em função dos niveis de cloreto na solução nutritiva $\ldots \ldots \ldots \ldots \ldots \ldots \ldots$

50 Concentração de manganês (mg/1) no caldo de diferen tes cultivares de sorgo sacarino, em função dos niveis de cloreto na solução nutritiva $\ldots \ldots \ldots \ldots$

51 Concentração de zinco (mg/1) no caldo de diferentes cultivares de sorgo sacarino, em função dos níveis de cloreto na solução nutritiva $\ldots \ldots \ldots \ldots \ldots \ldots$

52 Concentração de cloro ( $\mathrm{mg} / 1)$ no caldo de diferentes cultivares de sorgo sacarino, em função dos níveis de cloreto na solução nutritiva $\ldots \ldots \ldots \ldots \ldots \ldots$

53 Concentração de sódio $(\mathrm{mg} / 1)$ no caldo de diferentes cultivares de sorgo sacarino, em função dos niveis de cloreto na solução nutritiva $\ldots \ldots \ldots \ldots \ldots \ldots \ldots$

54 Teores de sólidos solüveis ( $\left.{ }^{\mathrm{O}} \mathrm{Brix} \mathrm{v} / \mathrm{v}\right)$ no caldo de diferentes cultivares de sorgo sacarino, em função dos niveis de cloreto na solução nutritiva ......

55 Teores de açücares redutores totais (ART\%) no caldo de diferentes cultivares de sorgo sacarino, em função dos niveis de cloreto na solução nutritiva ...

56 Teores de açücares redutores (AR\%) no caldo de dife rentes cultivares de sorgo sacarino, em função dos niveis de cloreto na solução nutritiva ......... 
57 Teores de sacarose no caldo de diferentes cultivares de sorgo sacarino, em função dos niveis de cloreto na solução nutritiva $\ldots \ldots \ldots \ldots \ldots \ldots \ldots \ldots \ldots$

58 Teores de fibra no colmo de diferentes cultivares de sorgo sacarino, em função dos níveis de cloreto na solução nutritiva ..................... 174

59 Efeitos da salinidade na produção de colmos frescos e produção estimada de àlcool em diferentes cultivares de sorgo sacarino

60 Tolerância relativa das cultivares, considerando-se o ciclo ou não, com base no peso seco de colmos e de grãos, no nível 2.000 ppm ................ 114 
xxi.

EFEITOS DO CLORETO DE SŌDIO NO CRESCIMENTO, CONCENTRAÇAO DE NUTRIENTES E DE SODDIO, E NAS CARACTERISTICAS TECNOLOGICAS DE SEIS CULTIVARES DE SORGO SACARINO [Sorghum bicolor (L.) Moench]

Autora: Alcionesurea Queiroz da Silva Orientador: Prof. Dr. Euripedes Malavolta

Plantas de sorgo sacarino [Sorghrom bicolor (L.) Moench] pertencentes às cultivares Ample $\mathrm{H}-0-\mathrm{K}$, CMS-XS-616, $\mathrm{Br}-501, \mathrm{Br}-$ 503, Br-602 e IPA-7301218, foram cultivadas em solução nutritiva em casa - de - vegetação, em dois experimentos, sob condições salinas. No experimento preliminar, foram fornecidos $0,3.000$ e 6.000 ppm de cloreto na solução nutritiva, na forma de cloreto de sódio, tendo como objetivo eleger níveis de discriminação, permanecendo as cultivares apenas 30 dias sob tratamento.

No segundo experimento as cultivares foram submetidas aos níveis: $0,2.000$ e $4.000 \mathrm{ppm}$ de cloreto, fornecido como cloreto de sódio, sendo colhidas no final do ciclo, o qual foi variável con- 
forme a cultivar, com os objetivos de estudar a salinidade provocada pelo cloreto de sódio, com relação aos seguintes aspectos: a) sintomatologia: b) crescimento das cultivares, avaliados através da altura, diâmetro do colmo e comprimento da panícula, produções de matéria seca e de matéria fresca; c) teores de nutrientes e de sódio nas folhas, no colmo e no caldo; d) características tecnológicas [ ${ }^{\mathrm{O}} \mathrm{Brix}$, ART (açūcares redutores totais), AR (açúcares redutores), sacarose e fibra] e produção estimada de álcool; e) tolerância relativa das cul tivares.

Com base nos resultados obtidos, pode-se concluir que os sintomas de toxidez provocados pelo cloreto de sódio nas cultivares Ample-H-0-K, CMS-XS-616, Br-501, Br-503, Br-602 e IPA-7301218 são concordantes com a literatura. A dose 4.000 ppm retardou o florescimento e causou abortamento de flores, além de secamento rápido das folhas mais velhas em todas as cultivares. A presença de cloreto de sōdio reduziu a altura, o comprimento da panícula, diâmetro docolmo, produção de colmos frescos e produção de matéria seca de todas as par tes da planta, de cada cultivar, na seguinte ordem: panícula > raíz $>$ colmo > folhas. Com relação às características tecnológicas das cultivares, o aumento de salinidade causou redução no ${ }^{\circ} \mathrm{Brix}$, ART, AR\%, sacarose \%, bem como aumento na porcentagem de fibra, das cultivares, sendo afetadas de forma negativa, consequentemente, a produ ção estimada de ālcool em $1 /$ t de colmo e em $1 /$ ha.

Com respeito à nutrição mineral, houve comportamento diferenciado entre as cultivares, em função dos níveis desalinidade. 
xxiii.

Os teores de nutrientes nas folhas, no colmo e no caldo foram afetados. Entretanto, foram mais consistentes quando se analisou o caldo, embora os nutrientes aí contidos tenham se mostrado em concentrações inferiores àquelas correspondentes às demais partes amostradas. No caldo, os teores de N, Ca, Mg, S e Fe foram reduzidos em função da salinidade, enquanto os de $\mathrm{K}$ e Cu sofreram aumentos. Por sua vez, os demais nutrientes variaram irregularmente em função da cultivar utilizada.

o cloro e o sódio acumularam-se em maiores quantidades nasfolhas, sendo que o primeiro mostrou-se menos tóxico.

As cultivares Ample-H-O-K e Br-503 foram as mais tole rantes. 
EFFECTS OF SODIUM CHLORIDE ON GROWTH, CONCENTRATION OF NUTRIENTS AND OF SODIUM, AND ON TECHNOLOGICAL CHARACTERISTICS OF SIX CULTIVARS OF SWEET SORGHUM [Sorghum bicolor (L.) Moench)]

Author: Alcioneaurea Queiroz da Silva

Adviser: E. Malavolta

Sweet sorghum plants, cultivars Ample-H-O-K, CMS-XS616, $\mathrm{Br}-501, \mathrm{Br}-503, \mathrm{Br}-602$, and IPA-7301218, were grown in nutrient solution under conditions of induced salinity, caused by sodium chloride. In a preliminary trial the salt was supplied at the levels of $0,3,000$ and $6,000 \mathrm{ppm}(\mathrm{w} / \mathrm{v})$ with the goal of selecting, after one month, the rates which better discriminate those to be used in the second experiment.

The second trial was carried out employing the levels of $0,2,000$ and 4,000 ppm, the plants being grown until the end of the life cycle whose duration varied according to the cultivars. The following objectives were sought: (1) symptomatology of salinity; effect on growth parameters; (3) variation in the concentration of nutrients and of sodium; (4) influence on technological characteristics, and on estimated alcohol content of the expressed juice; 
assessment of the relative tolerance of the cultivars to salinity.

It was verified that observed symptoms of salinity agree with those described in the literature. The higher rate delayed flowering and caused abortion of flowers, as well as fast desiccation of the older leaves. Sodium chloride, besides reducing height, length of panicle, stalk diameter and fresh weight, affected also dry weight of the various plant organs according to the following decreasing order: panicle > root > stalk > leaves. Increasing the salinity caused reduction in Brix, Total Reducing Sugars (TRS), Reducing Sugars (RS), sucrose content, as well as an increase in fibers percent. As a consequence there was a decrease in the estimated alcohol production.

The level of nutrients in the leaves, stalk and juice was affected by the treatments, the expressed juice being particularly sensitive. Salinity decreased the contents of $\mathrm{N}, \mathrm{Ca}, \mathrm{Mg}, \mathrm{S}$ and $\mathrm{Fe}$, and increased those of $\mathrm{K}$ and $\mathrm{Cu}$. $\mathrm{Na}$ and $\mathrm{Cl}$ accumulated preferential1y in the leaves.

Regression analyses showed that the toxic effect of $\mathrm{Na}$ was higher than that of $\mathrm{C} 1$.

Ample-H-O-K and $\mathrm{Br}-503$ were the more tolerant varieties under the experimental conditions. 


\section{INTRODUÇAO}

o sorgo sacarino [Sorghum bicolor (L.) Moench] è cultivado nos Estados Unidos da América desde a segunda metade do sécu1o passado, onde foi introduzido da Africa e da India (COLEMAN, 1975). Pesquisas visando sua utilização como nova opção para a produção do açúcar foram incentivadas no início deste século, sendo usado posteriormente como matéria prima na produção de àlcool combustivel na Itälia (SCHAFFERT e BORGONOVI, 1980). No Brasil os primeiros trabalhos parecem ter sido desenvolvidos no Instituto Agronōmico de Campí nas na década de 50 (TEIXEIRA et alii, 1977).

A criação do PRÓ-ÁLCOOL em 1975, motivada pela atual crise de energia, despertou interesse da pesquisa por novas fontes renováveis. Entre estas, o sorgo sacarino surge como cultura em potencial para a produção de etanol, constituindo-se em mais uma alter nativa energética nacional. Isto tem sido confirmado pelos resulta- 
dos dos experimentos feitos nas condições brasileiras, demonstrando ser o caldo excelente matēria prima para multiplicação de leveduras e produção de álcool por via fermentativa (ARAUJO et alii, 1977; SER RA, 1977; SILVA, 1983) com resultados altamente satisfatórios, agricola e industrialmenie (ESTEVES et alii, 1981).

A viabilidade de implantação do sorgo sacarino vem se desenvolvendo consideravelmente com os estudos realizados pelo Centro Nacional de Pesquisas de Milho e Sorgo - EMBRAPA, para obtenção de cultivares com boas caracteristicas agronômicas e sistemas de pro dução adaptados às diferentes regiões do País.

Embora os Estados mais produtores encontrem-se nas re giões Sul e Sudeste (FIBGE, 1978), esta cultura mostra-se também pro missora para as condições do Nordeste semi-ärido, em virtude de sua capacidade de tolerância à seca.

Entre os possiveis fatores limitantes de produção des ta cultura, relacionados à nutrição mineral, destaca-se a salinidade, reconhecidamente adversa à maioria das culturas, e que merece maiores considerações, principalmente no Nordeste, onde o problema existe.

No Brasil, embora sejam conhecidos värios trabalhos re ferentes à nutrição do sorgo sacarino (ROSOLEM, 1979; MALAVOLTA et alii, 1979; COUTINHO, 1983; SILVA, 1983), pouco se sabe sobre a interferência da salinidade nesta cultura, apesar de sua importância.

Este trabalho tem como objetivo estudar a salinidade provocada por cloreto de sódio em seis cultivares de sorgo sacarino, com relação aos seguintes aspectos: 
- Sintomatologia;

- Crescimento das cultivares avaliadas através da altura, produ ções de matéria seca e de matéria fresca;

- Teores de nutrientes e de sódio, nas folhas, no colmo e no cal do;

- Características tecnológicas ( ${ }^{\mathrm{B}} \mathrm{Brix}, \mathrm{ART}, \mathrm{AR}$, sacarose e fibra) e produção estimada de álcool;

- Tolerância relativa das cultivares. 


\section{REVISAOO DE LITERATURA}

O efeito da salinidade sobre o desenvolvimento das plantas é discutido por pesquisadores do mundo inteiro, principalmen te nos países que apresentam regiões äridas e semi-áridas, em função dos problemas sócio-econōmicos por ela causados. No Brasil o assunto torna-se importante na região Nordeste, conforme se pode constatar nas informações dadas por FRANCISCO (1959), MATSUI (1978) e SALATI et $a$ Zii (1979).

\section{1 - Tolerância à Salinidade}

De um modo geral, as espécies de crescimento rápido são menos tolerantes aos sais do que as de crescimento lento. Basean do-se em experimentos de campo, Bonnet (1960), citado por CROCOMO et alii (1965), classifica o sorgo como planta semi-tolerante a condi- 
ções salinas, concordando com RICHARDS (1974), que o considera media namente tolerante.

De acordo com TAYLOR et alii (1975), poucas pesquisas têm sido feitas sobre tolerāncia à salinidade, evidenciando diferenças entre cultivares de sorgo; em contraste, existem muitos traba1hos mostrando resposta varietal ao sal com as culturas do trigo, ar roz, cevada, aveia, alfafa e milho. Estes autores, no Texas, testando 48 cultivares de sorgo granifero cultivados em solução nutritiva contendo as concentrações $3.000,5.000$ e 7.000 ppm de sais fornecidos como $\mathrm{NaCl}$ e $\mathrm{CaCl}_{2}$, observaram que as cultivares diferiram significativamente entre as mesmas, embora tenham mostrado baixos niveis de tolerância. O mesmo foi constatado por Maliwal (1967), citado por TAYLOR et alii (1975) e por OGRA e BAIJAL (1978), testanto 18 e 22 cultivares de sorgo granífero, respectivamente.

PATHAMANABHAN e RAO (1976), na India, testaram 20 cul tivares de sorgo sob condições salinas, utilizando as concentrações: $1.000,2.000,3.000,4.000$ e $5.000 \mathrm{ppm}$ de sais fornecidos como NaC1 e $\mathrm{CaCl}_{2}$ na proporção molecular de 1:1. Baseando-se no teor de potássio da planta, estes autores constataram que as variedades toleran tes tinham mais alto teor desse elemento do que aquelas moderadamente tolerantes ou susceptiveis.

\section{2 - Sintomas}

O nivel de acumulação de cloreto que desenvolve sinto mas típicos não é bem definido. Algumas espécies podem acumular até 
$4 \%$ ou mais deste ion sem evidenciar sintomas especificos da queima (BERNSTEIN e AYERS, 1953). Folhas não injuriadas de uma mesma espëcie podem, algumas vezes, ter maior teor de cloreto do que folhas in juriadas (BROWN et alii, 1953).

De acordo com RICHARDS (1974), plantas em ambiente sa lino mostram uma coloração verde azulada nas folhas, decorrente de um acúmulo no teor de clorofila e recobrimento mais espesso da cuticula. Entretanto, os sintomas de queima de folhas são os mais caracteristicos em plantas sob condições salinas. Conforme FENN et alii (1970), o movimento de ions promovido pela transpiração faz com que o excesso de sal se mova em direção ao ápice e margens foliares, cau sando quebra no gradiente de pressão osmötica necessārio para manter a pressão da turgor, deixando uma necrose caracteristica do ápice e margens foliares, associada à acumulação excessiva de cloreto.

Em cana-de-açücar, HUMBERT (1973) comenta que a salinidade queima a ponta das folhas jovens e as margens das folhas velhas, alëm de encurtar os entrenōs; quando em estādio mais avançado, as folhas mais velhas secam seguidas das mais novas, até que ocorre finalmente seca do palmito e morte da planta.

Segundo BERNSTEIN (1974), teores de $\mathrm{Na}^{+}$compreendido na faixa de 0,25 a $0,50 \%$ e $\mathrm{Cl}^{-}$de 0,5 a $1,0 \%$ causam secamento foliar em arroz. Em cana-de-açücar, CLEMENis (1980) relata que folhas com sintomas moderados continham de 853-1.085 ppm de cloreto, enquanto aquelas comsintomas severos contiveram 3.459 a 3.924 ppm deste ion. 
que a salinidade provocada pelo cloreto de sódio nesta cultura causou secamento dos bordcs foliares, alèm de clorose internerval; ot de cloro nestas folhas foi de 0,29\%. Ainda conforme este autor, plan tas contendo teores foliares correspondentes a $0,95 \%$ de cloro estavam quase mortas por ocasião da colheita, a qual foi antecipada em um mēs.

MALAVOLTA et alii (1979), cultivando sorgo sacarino, cultivar Brandes, em solução nutritiva contendo $50 \mathrm{~m} 1 / 1$ de $\mathrm{NaCl} \mathrm{M}$, constataram que a presença deste sal causou inicialmente amaralecimento ao longo das margens e àpices das folhas mais velhas; o limite externo destas faixas tornava-se necrótico, assumindo uma coloração pardo-avermelhada. Observaram, ainda, redução no crescimento e ausēn cia de perfilhos. Conforme estes autores, folhas inferiores contive ram $3,85 \%$ de cloreto, enquanto as superiores contiveram $2,37 \%$ deste íon.

Redução no crescimento provocado pela salinidade na cultura do sorgo granífero foi também constatado por SEIFERT Jr.etalii (1975), PRISCO et alii (1975) e GARCIA E MORARD (1976).

\section{3 - Salinidade e Crescimento}

A salinidade afeta ocrescimento deplantas emgrandes $\underline{a}$ reas do mundo, mais do que faz qualquer outra substânciainibidoraque elas possam encontrar no ambiente normal (EPSTEIN, 1975). Se para a1 gumas plantas a salinidade chega a ser benéfica e até mesmo essencial 
(LUNT, 1966; EATON, 1966; JOHNSON et alii, 1957), para a maioria das plantas cultivadas é considerada não desejável ao seu deserrvolvimen to satisfatório (RICHARDS, 1974), haja visto os distürbios anátomo-morfológicos causados pela mesma como reflexo das alterações ocorri das na fotossintese, respiração, metabolismo do nitrogênio e carboidratos e atividade de reações enzimáticas (STROGONOV, 1964).

$\mathrm{Na}$ tentativa de explicar os efeitos danosos da salini dade sobre o crescimento das plantas, existem algumas teorias. Desse modo, tem-se: o efeito osmótico (EATON, 1941; BERNSTEIN e HAYAWARD, 1958), o efeito do ajustamento osmótico (SLATYER, 1961; BERNSTEIN, 1961) e o efeito tóxico (ALLISON,1964) somados ao desequilíbrio nutriciona1 (RAINS, 1972). Todavia, a redução no crescimento da planta sob condições salinas ocorre conforme sua tolerância, que por sua vez depende de suas características genéticas (HEILMAN, 1974; EPSTEIN et alii, 1980).

EATON (1942), nos Estados Unidos, cultivando sorgo gra nifero em substrato arenoso, contendo os niveis 50 e $150 \mathrm{meq} / 1 \mathrm{de}$ clo reto fornecidos como $\mathrm{NaCl}$, encontraram redução no crescimento de 37 e $85 \%$, respectivamente.

SEIFERT Jr. et alii (1975), no Texas, trabalhando com sorgo granifero submetido a $450,800,1.600$ e 2.400 ppm de sais na ägua de irrigação fornecidos como $\mathrm{NaCl}, \mathrm{CaCl}_{2}$ e $\mathrm{MgSO}_{4}$, obtiveram re dução significativa no crescimento e produção de matéria seca das plantas. 
HEILMAN (1974), no Texas, estudando o comportamento das cultivares de sorgo granifero ATX-399 (ineficiente em ferro) e RS-671 (eficiente em ferro), cultivadas em substrato contendo salini dade como $\mathrm{NaCl}$, observou que a produção de ambas diminuiu à medida que a condutividade alétrica aumentou de 0,3 para 9 mmos/cm.

GARCIA e MORARD (1976), na França, constataram redução no crescimento de sorgo granífero com os niveis 36 e 72 meq/1 de $\mathrm{NaCl}$ no substrato de crescimento das plantas.

No Brasil, PRISCO et alii (1975), trabalhando com os potenciais de $-2,-3,-4,-5$ e -6 bares fornecidos como $\mathrm{NaCl}$ e $\mathrm{Na}_{2} \mathrm{SO}_{4}$ isoladamente, em solução, tendo como substrato papel, na germinação de sementes de sorgo granífero, observaram diminuição no vigor e redução no crescimento das plântulas à medida que se aumentava a salinidade.

De acordo com HAN et alii (1965), na Argentina, solos contendo condutividade elétrica de 4,7 mmos/cm e $11,8 \%$ como sódio trocāvel, permitem desenvolvimento aceitāvel de sorgo sacarino, cultura considerada de moderada tolerância à salinidade.

\section{4 - Salinidade e Composição Mineral}

o desequilíbrio iônico alterando o aspecto nutricional da planta como consequéncia de condições salinas tem sido enfocado por BERNSTEIN e HAYWARD (1958), enquanto RAINS (1972) discute o transporte de sais pelas plantas em relação à salinidade. Certos 
íns podem ter efeito especifico tóxico ou causar deficiência de outros nutrientes (ALLISSON, 1964; EPSTEIN, 1975).

Entre os ions que contribuem para a salinidade do so1o, encontram-se o ānion $\mathrm{Cl}^{-}$e o cátion $\mathrm{Na}^{+}$. O clnro é elemento essencial ao desenvolvimento das plantas (JOHNSON et alii, 1957; EATON, 1966), mas sua presença em concentrações elevadas no substratode cul tivo são drästicas. Por sua vez, o sódio, apesar de não ser considerado elemento essencial, quando em pequenas concentrações, pode esti mular a produtividade de algumas culturas (LEHR, 1942; LUNT, 1966), enquanto que em doses excessivastraz sērios problemas. Frequentemente, a toxidez pode sercausada, pelomenos emparte, através dos efeitos sobre a absorção ou o metabolismo de nutrientes essenciais (RICHARDS, 1974). Devidoàbaixa relação $\mathrm{K} / \mathrm{Na}$ existente em condições salinas, pode haver trocas do potássio pelo sódio em função do efeito competití vo do ültimo e, em consequência, ocorre deficiência do primeiro (EPS TEIN, 1975; MENGEL e KIRKBY, 1982). A relação K/Na em plantas cultivadas em meio salino tem sido discutida também por RATHER (1982), SMI TH et alii (1980a) e SMITH et alii (1980b), trabalhando com diversas culturas, e por BOURRIER et alii (1974), GULO et alii (1972) e JANAR DHAN et alii (1979), trabalhando com sorgo granifero.

Em geral o aumento no teor de sódio no substrato resulta em redução na acumulação de cálcio,magnésio e potássio na plan ta, conforme RICHARDS (1974). BANGE (1959) menciona que o aumento na absorção do sódio reduz a absorção do potāssio. 
EVANS (1959) cita que, sob condições salinas, os baixos teores foliares de nitrogēnio e fösforo encontrados são resultan tes do efeito inibidor do ion cloreto sobre estes íns.

A presença de cloreto de sódio no substrato, em níveis elevados, diminuem cs àcidos orgānicos das plantas de sorgo (Garcia, 1975, citado por GARCIA e MORARD, 1976), os quais são importantes em manter o equilibrio interno entre cátions e ānions (MORARD et alii , $1974)$.

GARCIA e MORARD (1976), estudando a influēncia do clo reto de södio na cultura do sorgo gramifero submetido aos níveis 0 , 6, 36 e $72 \mathrm{meq} / 1$, verificaram que o nivel 6 meq/1 favoreceu a acumulação dopotássio naparte aérea (sinergismo). As plantas cujtivadas nos dois ültimos niveis contiveram teores mais elevados de magnésio, fösforo, enxofre, södio e cloro, quando comparados ao controle; por sua vez, houve diminuição nos teores de potāssio, cảlcio e nitrogênio.

Pesquisas feitas por MORARD (1981) sobre a distribuição do sōdio radioativo nos vários órgãos de plantas de sorgo após absorção radicular, constataram que este elemento foi rapidamente translocado para todos os órgãos, se acumulando no tecido condutor e particularmente raízes, acarretando baixos teores de sódio na folha. Por sua vez, o cloreto acumula-se principalmente na parte aérea(FENN et alii, 1970; CLEMENTS, 1980). MARTIN e BINGHAM (1954) informam que a adição de sódio pode resultar em grande transferēncia de potássio das raizes para a parte aērea das plantas. 
PATHMANABHAN e RAO (1976, 1977), analisando a salinida de provocada pelo $\mathrm{NaCl}$ e $\mathrm{CaCl}_{2}$ na proporção $1: 1$ nos níveis $0,1.000$, $2.000,3.000,4.000$ e 5.000 ppm, em 20 cultivares de sorgo, observaram que a absorção do cálcio, magnèsio, potássio, sódio e cloro foi maior em plantas tolerantes e moderadamente tolerantes ao sal.

PATEL (1973), estudando interações salinidade-fertili dade em cinco culturas, inclusive sorgo, com relação à produção e com posição química, observou que os teores de nitrogēnio, magnésio e potássio foram reduzidos em função da salinidade, enquanto aqueles referentes ao fósforo, cálcio, cloro e sódio aumentaram.

HEILMAN (1974), trabalhando com as cultivares de sorgo granífero ATX-399 e RS-671, observou que a salinidade causada pe1o NaCl afelou a absorção de nutrientes, de forma diferente, nos vários niveis estudados. A concentração de ferro aumentou com o aumento de salinidade, embora a absorção total tenha diminuido em função da redução no crescimento. O zinco acumulou-se na parte aérea da 'ATX-399' e diminuiu na 'RS-671', enquanto a concentração de fósforo cresceu com o aumento da salinidade na raiz e parte aérea de ambas. Conforme IVENGAR et alii (1977), as cultivares de cana-de-açúcar Co-419 e Co-577 mostraram aumentos nos teores foliares de potāssio, cálcio e magnésio em função da adição de sódio na solução nutritiva.

WEBER (1983), estudando os efeitos da salinidade em cana-de-açúcar, observou que na presença do $\mathrm{NaCl}$ os teores foliares de fósforo, manganês e boro aumentaram nas cultivares RB 70194, RB 725828, Na 56-79 e CP-5122, e constatou igualmente aumento no teor 
de potássio nas duas primeiras cultivares e na CB45-3, a qual também mostrou maiores teores de manganés e boro. Por sua vez, os teores de enxofre e nitrogénio sofreram decréscimos nas folhas de todas as cul tivares, com exceção da RB 70194, que não apresentou redução na con centração de nitrogênio.

RIZK e NORMAND (1969) comentam que o maior grau de to xidez de um sal pode ser devido a fatores do meio ambiente e inerentes à cultivar. Segundo estes autores, em cana-de-açúcar o $\mathrm{Na}^{+}$foi mais tóxico que o $\mathrm{Cl}^{-}$, o que tem sido confirmado por JOSHI e NAIK (1980)

\section{5 - Salinidade e Características Tecnolōgicas}

Informações sobre este assunto são escassas na litera tura, nada tendo sido encontrado com relação ao sorgo sacarino.

Em Porto Rico, ZERBAN (1913), trabalhando com cana-de-açücar, constatou que aumentando-se a porcentagem de sais no solo de 0,23 para 0,46, os valores do ${ }^{\circ}$ Brix baixavam de 21,0 para 19,3 en quanto os tores de sacarose se reduziam de 18,3 para 15,5.

Na Argentina, MANOFF (1939), estudando os efeitos de salinidade em cana-de-açücar, observou que às porcentagens de sais no solo: $0,025,0,090,0,120$ e 0,245 , corresponderam respectivamente, re duções nos valores de sölidos solúveis $\left({ }^{\circ} \mathrm{Brix}\right)$, seguintes: 17,26 , $16,73,16,37,15,92 \%$, e por outro 1ado, houve também diminuição nos teores de sacarose, a saber: $14,38,13,83,13,28$ e 12,78\%. 
POEY (1942), em Cuba, desaconselha o plantio desta cul tura em locais com teores de cloreto de södio superiores a 0,15\%, em virtude dos danos causados às suas características tecnolögicas. Este autor informa que porcentagens de sais no solo de 0,062, 0,145 e $0,147 \%$ correspondem, respectivamente, valores de ${ }^{O_{B r i x}} ; 21,2,21,0$ e 19,0, ocorrendo igualmente reduções nos teores de sacarose: 20,14, 19,18 e $16,08 \%$, respectivamente.

Na Argentina, FOGLIATA e ASO (1964) relatam que o teor de sacarose não foi afetado quando a porcentagem de sais no so10 era inferior a $0,043 \%$, entretanto, esta caracteristica se reduzia quando a porcentagem de sais no solo era superior a $0,102 \%$. MARETZKI et alii (1972) comentam que diminuindo-se o potencial osmótico do so 1o, ocorreu elevação no acúmulo de sacarose, acompanhada pela baixa concentração de açūcares redutores e decréscimo na atividada da invertase. 


\section{1 - Local}

0 presente trabalho consta de dois experimentos condu zidos em vasos contendo solução nutritiva, em casa-de-vegetação do Centro de Energia Nuclear na Agricultura (CENA), da Escola Superior de Agricultura "Luiz de Queiroz" - USP, em Piracicaba, São Paulo.

Durante o periodo de condução do segundo experimento foram tomadas temperaturas máximas e minimas diärias, dentro da casa-de-vegetação. Fora da mesma as temperaturas foram observadas no Posto Agrometeorológico do Departamento de Física e Meteorologia da E.S.A. "Luiz de Queiroz". Na Figura 1. tem-se as variações das temperaturas observadas, onde se percebe que as máximas e minimas no interior da casa-de-vegetação são superiores àquelas registradas fora do referido ambiente. 

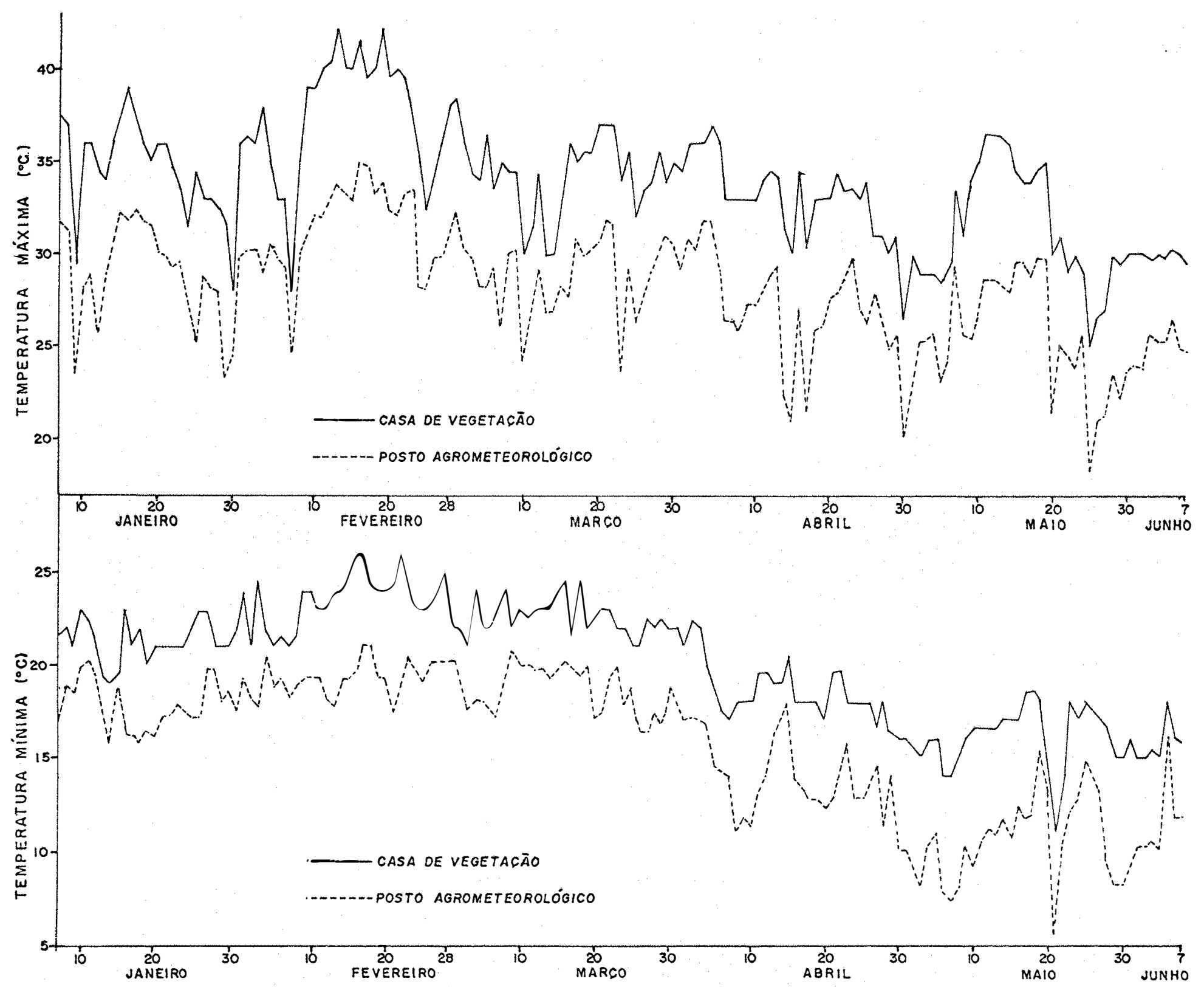

Figura 1 - Variação das temperaturas máximas e minimas no interior da casa-de-vegetação e fora da mesma, no periodo de condução do 2 experimento. 


\section{2 - Cultivares Utilizadas}

Nos dois experimentos realizados foram utilizadas sementes pertencentes 3 seis cultivares de sorgo sacarino, a saber: Br-501 (Brandes), Br $503, \mathrm{Br}-602$, CMS-XS-616, cedidas pelo Centro Na cional de Pesquisa de Milho e Sorgo, da EMBRAPA, Ample-H-O-K, recebi. da dos Estados Unidos e IPA-7301218, cedida pela Empresa Pernambucana de Pesquisa Agropecuária - IPA.

\section{3 - Testes de Germinação}

Em setembro de 1981, antes da instalação dos ensaios, fez-se teste de germinação em câmara apropriada para comprovação da viabilidade das sementes em estudo, obtendo-se um porcentual de ger minação superior a $95 \%$ para todas.

\section{4 - Instalação e Condução do Experimento Preliminar}

\subsection{1 - Obtenção de mudas}

Em setembro de 1981 as sementes foram colocadas para germinar em bandejas plásticas rasas, contendo uma camada de vermicu lita, umedecida com uma solução de $\mathrm{CaSO}_{4}{ }_{4} \mathrm{H}_{2} \mathrm{O} 10^{-4} \mathrm{M}$, com uma profundi dade de cinco centimetros, sendo cobertas com um centimetro de vermi culita. Fez-se irrigação periódica com a referida solução até as plân tulas mostrarem-se aptas ao transplante. Ao atingirem aproximadamen- 
te $10 \mathrm{~cm}$ de altura, foram retiradas cuidadosamente, sendo seleciona das e submetidas à lavagem radicular em àgua de torneira e em àgua destilada, e a seguir, transplantadas para bandejas plästicas de 30 litros de capacidade, contendo solução nutritiva completa nọ 2 de Hoagland e Arnon (1950), conforme MALAVOLTA (1975), diluída a 1:5 da concentração usual. Foi fornecido arejamento contínuo através de capilares acoplados a tubos de borracha.

\subsection{2 - Instalação em vasos e condução}

Após quinze dias do último transplante, foram selecio nadas quarenta e cinco plantinhas por cultivar, sendo então transpor tadas para vasos plásticos com capacidade de 2 litros, pintados externamente com tinta aluminizada, contendo solução nutritiva no 2 de Hoagland e Arnon (1950) completa, citada por MALAVOLTA (1975), conforme Tabela 1 .

Colocou-se uma planta por vaso, fixando-a na região do colo com auxílio de una espuma plástica em um dos orifícios da tampa do recipiente. Foi fornecido arejamento contínuo, e fez-se renovação das soluções quinzenalmente. Semanalmente fez-se medição do pH da solução. Não se fez necessārio trato fitossanitário. 
19.

Tabela 1 - Solução nutritiva usada em plantas de sorgo sacarino, durante o periodo de condução do experimento.

$\mathrm{NH}_{4} \mathrm{H}_{2} \mathrm{PO}_{4} \mathrm{M}$

$\mathrm{Ca}\left(\mathrm{NO}_{3}\right)_{2}{ }_{4}^{4} \mathrm{H}_{2} \mathrm{O} \mathrm{M}$

4

$\mathrm{KNO}_{3} \mathrm{M}$

6

$\mathrm{MgSO}_{4} 7 \mathrm{H}_{2} \mathrm{O} \quad \mathrm{M}$

Solução $a^{*}$

Solução $b * *$

* Dissolver e completar a 1 1itro: $2,86 \mathrm{~g} \mathrm{H}_{3} \mathrm{BO}_{3}+1,81 \mathrm{~g} \mathrm{MnCl}_{2}$ + $+0,22 \mathrm{~g} \mathrm{ZnSO}_{4} \cdot 7 \mathrm{H}_{2} \mathrm{O}+0,08 \mathrm{~g} \mathrm{CuSO}_{4} \cdot 5 \mathrm{H}_{2} \mathrm{O}+0,02 \mathrm{~g} \mathrm{H}_{2} \mathrm{MoO}_{4} \cdot \mathrm{H}_{2} \mathrm{O}$.

** Dissolver em $700 \mathrm{~m} 1$ de àgua deionizada: 33,2 g EDTA + 89,2 m1 $\mathrm{NaOH} \mathrm{N}+24,9 \mathrm{~g} \mathrm{FeSO}_{4} \cdot 2 \mathrm{H}_{2} \mathrm{O}$. Arejar durante uma noite, protegendo da luz: completar a 1 litro e conservar em escuro na geladeira. 


\subsection{3 - Tratamentos utilizados}

Decorridos 30 dias do transplante para os vasos, foram fornecidos os tratamentos de salinidade, cuja fonte foi o $\mathrm{NaCl}$. As concentrações de $\mathrm{Cl}^{-}$estudadas foram: 0, 3.000 e $6.000 \mathrm{ppm}$, o que

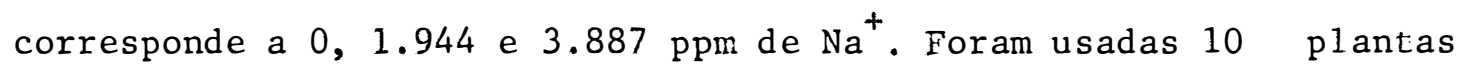
para o primeiro tratamento e quinze plantas em cada um dos demais. Isto foi efetuado para cada cultivar.

\subsection{4 - Colheita}

Após 30 dias sob condições salinas, fez-se medição da altura das plantas (docolo até a exerção da panícula) e procedeu - se à colheita. As plantas foram separadas em raiz, colmo, folhas com sintomas leves, folhas com sintomas acentuados e panícula, colocadas em sacos de papel e levadas para secagem em estufa de circulação for çada de ar a $70^{\circ} \mathrm{C}$, onde permaneceram até peso constante. Após a secagem, obteve-se o peso da matéria seca das diferentes partes amostradas. Entretanto, será discutido apenas o que se refere a colmo, com o objetivo de eleger os níveis de salinidade a serem utilizados no segundo experimento. 


\section{5 - Instalação e Condução do Segundo Experimento}

\subsection{1 - Obtenção das mudas}

Idem ao item 3.4.1, sendo o plantio efetuado em janei ro de 1982 .

\section{5 .2 - Instalação em vasos e condução}

Semelhante ao item 3.4 .2 , sendo a capacidade do vaso de 3 litros. Desta vez, tornou-se necessärio o controle fitossanitário contra um ataque generalizado do pulgão (Aphis maidis), sendo usa do para isto Gusathion na dosagem de $0,1 \%$. Os sintomas resultantes da concentração de sais na planta foram acompanhados diariamente desde o surgimento até o final do ciclo da cultura, o qual foi variável conforme a cultivar.

\subsection{3 - Tratamentos utilizados}

Neste experimento, os niveis de $\mathrm{Cl}^{-}$estudados foram: 0, 2.000, 4.000 ppm, fornecidos como NaC1, o que corresponde a 0 , 1.296 e $2.592 \mathrm{ppm} \mathrm{de} \mathrm{Na}^{+}$respectivamente. Os tratamentos foran aplicados 30 dias após a instalação em vasos, tendo sido mantidos até o final do ciclo de cada cultivar e renovados quinzenalmente. Em cada cultivar foram tomadas doze plantas para o tratamento 0 (zero) e dezoito plantas para cada um dos demais tratamentos. 
3.5.4 - Colheita e preparo do material para análise

Por ocasião da maturação da panícula do tratamento 0 (zero) de cada cultivar, foram tomados ao acaso quatro plantas, para cada tratamento dentro de cada cultivar, nas quais foram efetuadas me dições dos seguintes parâmetros: altura, diâmetro do colmo a $10 \mathrm{~cm}$ do colo e comprimento da panicula. A seguir foram colhidas e colocadảs a secar, de modo semelhante ao item 3.4.4. Após obtenção do peso da matéria seca das diferentes partes da planta, realizou-se a moagem em moinho tipo "Willey" equipado com peneira 40 mesh, sendo o re ferido material guardado em sacos impermeáveis, para análise mineral.

- Nas demais plantas foi tomado o peso dos colmos fres$\cos$ e a seguir foram desintegrados em microdesfibrador para extração do caldo, segundo o método da prensa descrito conforme TANIMOTO(1964). o caldo obtido foi acondicionado em frascos de vidro e congelado até o momento das análises.

\subsection{5 - Anālises quîmicas da matéria seca e do caldo}

As amostras moidas foram submetidas às digestões nitrico perclórica e sulfürica, obedecendo orientação dada na Seção de Radioquímica e Quimica Analitica do CENA, onde foram determinadas as concentrações de elementos nos extratos obtidos conforme os métodos citados na Tabela 2, descritos em ZAGATTO et alii (1981). 
Tabela 2 - Métodos analiticos usados na determinação de elementos contidos nas diferentes cultivares de sorgo sacarino, pela Seção de Radioquímica e Química Analitica do CENA.

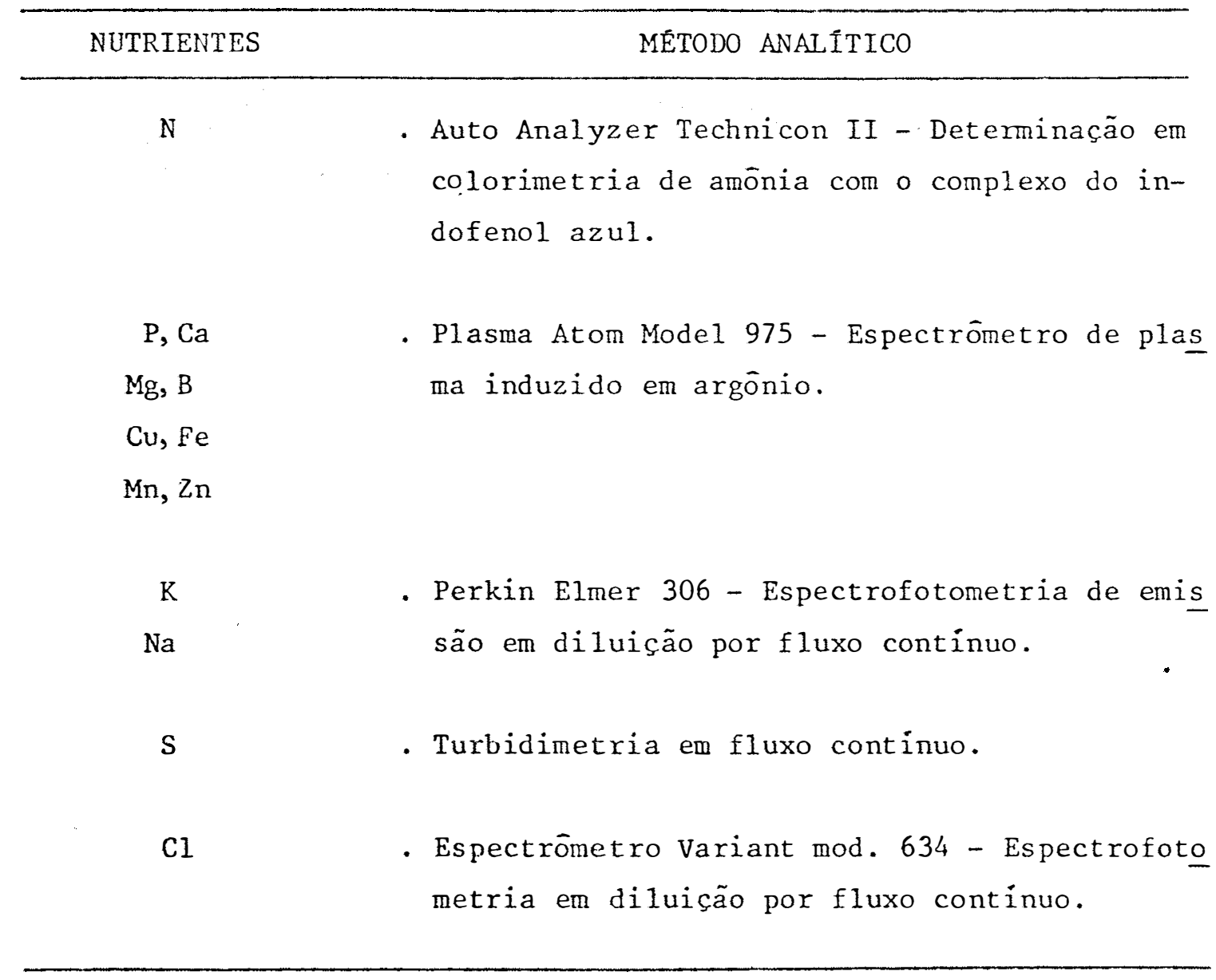


No caldo, o nitrogēnio foi deteminado com auxilio do micro Kjeldahl, cujo procedimento analitico è encontrado em SARRUGE e HAAG (1974). Os demais elementos foram dosados conforme os métodos anteriormente citados, com exceção do cloro, o qual foi calculado com base nos resultados de södio.

\subsection{6 - Anālises tecnológicas}

No caldo foram realizadas as seguintes anālises: açücares redutores totais (ART), açúcares redutores (AR) e sacarose dosadas pelo método colorimétrico de Somogy-Nelson, seguindo-se o procedimento analitico expresso em AMORIM et alii (1983) e o ${ }^{\circ}$ Brix, pelo densimetro digital de ANTON-PAAR mod. DMA-46.

A sacarose foi calculada utilizando-se os resultados obtidos do ART e AR, de acordo com a fórmula:

$$
\text { Sacarose }=0,95(\mathrm{ART}-\mathrm{AR}) \text {. }
$$

Determinou-se a porcentagem de fibra conforme TANIMOTO (1964), através da förmula:

$$
F=\frac{100 \cdot R_{2}-R_{1} \cdot B \% C E}{5(100-B \% C E)},
$$

onde:

$$
F=\text { fibra \% do sorgo; }
$$

$B \% C E=$ Brix \% do caldo extraido;

$$
\begin{aligned}
& \mathrm{R}_{1}=\text { peso do residuo do bagaço úmido; } \\
& \mathrm{R}_{2}=\text { peso do residuo do bagaço seco. }
\end{aligned}
$$




\subsection{7 - Produção estimada de āicool}

Para este cálculo, determinou-se o ART (açúcares redu tores totais) do caldo e se considerou uma eficiēncia de $90 \%$ do rendimento em àlcool na fermentação. Conhecendo-se o ART, o peso do cal do extraído e o rendimento baseado no teórico (100 kg de açúcares re dutores totais produzem no máximo 64,7 litros de álcool, 100\% puro a $20^{\circ} \mathrm{C}$ ), calculou-se a produção estimada de álcool mediante a utilização da fórmula sugerida por SILVA* (informação pessoal):

1 de àlcool/t de colmo $=\mathrm{kg}$ caldo/t de colmo $\times$ ART $\times 0,005823$.

\subsection{8 - Tolerāncia relativa}

Para cálculo da tolerância relativa das cultivares, utilizaram-se as förmulas seguintes:

$$
\begin{aligned}
& \text { Tolerância relativa }=\frac{\text { matéria seca }\left(+\mathrm{Cl}^{-}\right)}{\text {matéria seca }\left(-\mathrm{Cl}^{-}\right)} \times 100 \\
& \text { Tolerância relativa }=\frac{\text { matéria seca }(+\mathrm{Cl})}{\text { matéria seca }(-\mathrm{Cl})} \times 100 \times \frac{1}{\text { ciclo }}
\end{aligned}
$$

A matéria seca (g/planta) usada, foi referente a colmo, e grãos, obtida no nível zero $\left(-\mathrm{Cl}^{-}\right)$, e no nível $2.000 \mathrm{ppm}(+\mathrm{Cl})^{-}$). o ciclo é dado em dias, ou sejja, refere-se ao período compreendido en tre o plantio e a colheita.

\footnotetext{
* Prof. Dr.Humberto Silva, CCA/UFPb - Areia, Pb.
} 


\section{6 - Planejamento Experimental e Anālises Estatísticas}

As anālises estatisticas dos dados de produção de matéria seca, matéria fresca do colmo, altura da planta, diâmetro do colmo, comprimento da panícula, anālises químicas e anālises tecnoló gicas, foram realizadas obedecendo ao modelo matemático próprio para o delineamento inteiramente casualizado, em esquema fatorial $3 \quad \mathrm{x}$ 6; conforme descrito por PIMENTEL GOMES (1973), com 18 trata mentos, fazendo-se o desdobramento quando a interação dose $\mathrm{x}$ cultivar foi significativa. Os cinco primeiros parämetros foram repetidos qua tro vezes, enquanto os demais o foram apenas trēs vezes. As anālises estatísticas das anälises químicas referentes às folhas seguiram o modelo anteriormente citado, em esquema de parcela subdividida, fazendo-se o desdobramento quando a interação cultivar $\mathrm{x}$ dose $\mathrm{x}$ sintoma foi significativo.

Foram determinadas, para cada cultivar, as regressões linear e quadrätica.

Os esquemas de análise de variância adotados são apre sentados a seguir. 
Tabela 3 - Análise de variância adotada para o delineamento intei ramente casualizado, esquema fatorial.

\begin{tabular}{lc}
\hline Causa da Variação & G.L. \\
\hline Cultivares (C) & C-1 \\
Doses (D) & D-1 \\
C x D & $($ C-1) (D-1) \\
Residuo & por diferença \\
\hline Total & $\mathrm{N}-1$ \\
\hline
\end{tabular}

Tabela 4 - Análise de variância adotada para o delineamento intẹ ramente casualizado com esquema emparcelas subdivididas.

\begin{tabular}{lc}
\hline Causa da Variação & G.L. \\
\hline Cuítivares (C) & C-1 \\
Doses (D) & D-1 \\
C $\times$ D & (C-1) (D-1) \\
Residuo (a) & por diferença \\
\hline Parcelas & CD-1 \\
\hline Sintomas & S-1 \\
C x S & (C-1) (S-1) \\
D XS & (D-1) (S-1) \\
C x D X S & (C-1) (D-1) (S-1) \\
Residuo (b) & por diferença \\
\hline Total & $\mathrm{N}-1$ \\
\hline
\end{tabular}


As comparações entre as médias dos tratamentos foram efetuadas pelo teste de Tukey, ao nível de $5 \%$ de probabilidade. As anālises dos dados foram realizadas através do com putador eletrônico IBM-1130 do Departamento de Matomática e Estatística da ESALQ/USP, e os gräficos confeccionados através do Microcomputador HP 85-A da FERMENTEC S/C Ltda. - Assessoria em FermentaçãoAl coōlica, Piracicaba, SP. 


\section{1 - Experimento Preliminar}

Na Tabela 5 (Apêndice) encontram-se as médias referentes ao peso da matéria seca $(g)$ de colmo, onde, mediante a utilização do teste de Tukey a $5 \%$, permitiu constatar que a adição de clore to de sỏdio causou mudanças significativas em todas as cultivares. Houve efeito de nivel, cultivar e interação.

Na Figura 2 pode ser observada a relação entre produção de matéria seca do colmo das diferentes cultivares e os tratamen tos estudados. A equação de regressão obtida para cada cultivar mostra que o peso da matéria seca sofreu redução em função dos níveis de cloreto usados na solução nutritiva, tendo o efeito sido de natureza linear negativo, para todas as cultivares estudadas. No nível zero as maiores produções referem-se às cultivares IPA-7301218, Br-602 e 
30.

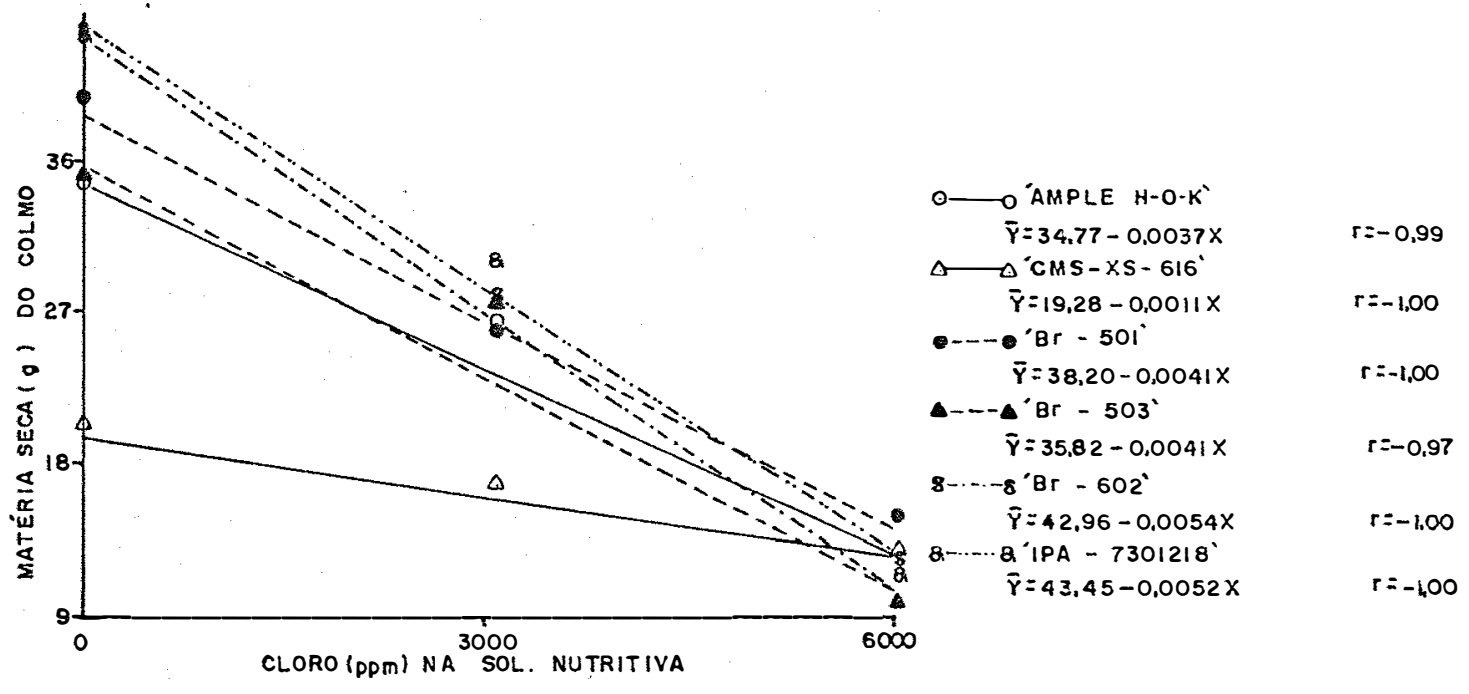

Figura 2 - Matéria seca ( $g$ ) do colmo de sorgo sacarino em função dos niveis de cloreto na solução nutritiva. 
$\mathrm{Br}-501$, que não diferem entre si estatisticamente, sendo esta ültima similar às cultivares $\mathrm{Br}-503$ e Ample-H-0-K, ambas superiores à culti var CMS-XS-616 (Tabela 5 do Apêndice). No tratamento com 3.000 ppm de cloreto, esta últimá cultivar apresentou menor produção, diferindo estatisticamente das demais, que por sua vez, foram similares. No tratamento com 6.000 ppm não houve diferença de produção entre as cul tivares. Segue-se dai que a concentração de cloreto com 3.000 ppm dis crimina cultivares quanto à tolerância à salinidade, enquanto o nível superior não o faz.

Comparando-se o tratamento controle com os demais, den tro de cada cultivar, percebe-se que apenas 30 dias sob condições sa linas causaram redução de 24 e $65 \%, 17$ e $36 \%, 35$ e 63\%, 21 e 72\%, 36 e 76\%, 31 e 73\% para as cultivares Ample H-0-K, CMS-XS-616, Br-501, $\mathrm{Br}-503, \mathrm{Br}-602$ e IPA-7301218, respectivamente. O efeito depressivo da salinidade sobre a produção de matéria seca obtido neste trabalho con corda com os resultados obtidos por TAYLOR et alii (1975), SEIFERT Jr. et alii (1975), HEILMAN (1974), todos trabalhando com sorgo granifero sob condições salinas. Embora o cloreto seja reconhecidamente mais tóxico do que o ín sódio (STROGONOV, 1964), este último também exer ce efeito negativo sobre o crescimento da planta quando em altas con centrações, conforme observado por LUNT (1966), e também por HAJRASUIHA (1980), trabalhando com feijão, e WEBER (1983), trabalhando com cana-de-açúcar. Com esta última cultura, JOSHI e NAIK (1980) observa ram que a toxidez causada pelo $\mathrm{Na}^{+}$foi mais intensa que aquela provo cada pelo cloreto nas condições estudadas. Portanto, é provāvel que 
a redução de matéria seca obtida no presente trabalho seja resultado - de efeito conjunto dos ions $\mathrm{Cl}^{-}$e $\mathrm{Na}^{+}$.

\section{2 - Segundo Exnerimento}

\subsection{1 - Sintomas}

Os sintomas de toxidez provocados pelo cloreto de sódio nas cultivares de sorgosacarino surgiraminicialmente nonível. mais elevado de salinidade. Após 24 horas sob condições salinas as folhas mais velhas das plantas correspondentes ao nivel mais alto tornaram-se cloróticas (manchas pequenas verde azuladas). Esta clorose iniciou-se pelo ápice progredindo em direção à base através dos bordos. Após 4 dias observou-se nitidamente que as äreas atingidas tornaram-se avermelhadas (vermelho ferrugem) havendo início de necrose,e coa lescência das manchas. Após 15 dias, as folhas mais velhas mostraram-se ressecadas, senescentes, enquanto as mais novas permaneciam com coloração verde escuro azulado com bordos e ápices necrosados, enrolando-se em forma de cartucho. Condições salinas reduzem a sintese de citocinina nas raízes e sua translocação para a parte aérea pode ser inibida; por outro lado, a síntese de àcido abscísico è promovida (MENGEL e KIRKBY, 1982) favorecendo a senescência.

As plantas sob nível mais baixo de salinidade $(2.000$ ppm) mostraram-se com aspecto semelhante ao controle, mas decorridos 35 dias surgiu leve necrose nos äpices e bordos das folhas mais ve1has, e a tonalidade das mesmas tornou-se verde azulada. Conforme RI 
CHARDS (1974), esta tonalidade deve-se a um aumento em clorofila.

o crescimento das plantas, bem como o seu florescimen to, foram retardados, e as paniculas mostraram abortamento de flores prejudicando a produção. Estes sintomas foram mais acentuados no nive1 $4.000 \mathrm{ppm}$, cujas plantas apresentaram enrosetamento de folhas ter minais, em virtude do intenso encurtamento de internódios. 0 sistema radicular das plantas também foi afetado, havendo escurecimento de raizes mais finas e morte posterior. Por ocasião da colheita, algumas cultivares mostravam-se com quase $2 / 3$ das folhas totalmente ressecadas. A 'Br-501' foi a mais afetada.

EATON (1942), pesquisando salinidade provocada pelo NaC1 em sorgo, também observou secamento dos bordos foliares. Segundo este autor, as plantas que estavam submetidas ao nivel mais alto de salinidade (150 meq/1) estavam quase mortas por ocasião da colhei ta, a qual foi antecipada em um mês.

MALAVOLTA et alii (1979), cultivando sorgo sacarino cultivar Brandes, em solução nutritiva contendo $50 \mathrm{~m} 1 / 1$ de $\mathrm{NaCl} \mathrm{M}$, ob servaram que a presença deste sal causou inicialmente amarelecimento ao longo das margens e ápices das folhas mais velhas; o limite exter no destas faixas tornava-se necrótico, assumindo uma coloração pardo-avermelhada. Houve também redução no crescimento das plantas. BERNSTEIN e HAYWARD (1958) relatam que o atraso no de senvolvimento vegetativo devido à salinidade provavelmente retardará o florescimento, bem como pode afetar a produção de grãos. MElJEIROS 
(1982), trabalhando com cinco cultivares de feijão macassar [Viana un guiculata (L.) Walpl, sob condições salinas provocadas pelo cloreto de sódio, concluiu que a salinidade retardou o florescimento de todas as cultivares. A redução em ärea fotossintética en função de salinidade é apontada por FENN et alii (1968) como um dos fatores de redução no crescimento da planta. Conforme FENN et alii (1970), devi do ao movimento de ions pela transpiração, o excesso de $\mathrm{Cl}^{-}$(sal extra-celular) move-se em direção ao ápice e margens das folhas, causando perda de pressão de turgor destas células que, por sua vez, produz característica desidratação das células marginais e necrose do tecido. Consequentemente, como o tecido marginal encontra-se ne crosado, o sal move-se progressivamente em direção à nervura central com eventual morte da planta, se o substrato contiver cloreto em alta quantidade. Além disso, à medida que o transporte de sais dentro do vacúolo celular da folha aumenta, energia metabölica adicional é usada para os processos de transporte, ficando portando indisponivel para o crescimento. HELAL (1980), discutindo o mecanismo de exclusão do sódio nas células, comenta que, sob condições salinas, a disponibilidade de energia metabólica deve tornar-se fator limitante para atividade biossintētica e crescimento. Segundo STROGONOV (1964), o $\mathrm{Cl}^{-}$reduz o diāmetro interno dos vasos da planta, além de diminuir a diferenciação do tecido condutor de água, dificultando, portanto,suas atividades fisiológicas.

Em plantas de sorgo granifero, HEILMAN (1974) verificou que o $\mathrm{NaCl}$ causou desarranjamento das células foliares, as quais 
mostravam-se com paredes mais finas e menor dimensão. Observou ainda constrição em torno dos feixes vasculares e consequente atrofia foliar.

E provável que os sintomas observados neste trabalho seja resultado do efeito conjunto dos íons $\mathrm{Cl}^{-}$e $\mathrm{Na}^{+}$, cujos teores nas folhas mostraram-se superiores aos niveis considerados tóxicos por LUNT (1966), EATON (1942) e CLEMENTS (1980).

\subsection{2 - Crescimento da planta}

4.2.2.1 - Altura, comprimento da panícula e diāmetro do colmo

As análises da variāncia da altura, comprimento da pa nícula e diâmetro do colmo revelaram valores de F significativos para cultivares, níveis e interação (Tabelas 6 a 8 ).

A relação entre niveis de cloreto e os parâmetros ací ma mencionados encontram-se na Figura 3. Percebe-se que em todas as cultivares houve uma redução en todos os parāmetros com o aumento de sal na solução nutritiva, tendo isto ocorrido linearmente, com altos coeficientes de correlação.

Dentro do nivel zero, as maiores alturas foram verifi cadas nas cultivares Br-503 e IPA-7301218 que não diferiram entre si, vindo a seguir as cultivares $\mathrm{Br}-602$ e Ample-H-O-K, esta ültima sendo semelhante à cultivar CMS-XS-616, a qual não diferiu da Br-501 (Tabe la 6 do Apēndice). Dentro da concentração de $2.000 \mathrm{ppm}$, a redução de 
crescimento obedeceu esta mesma ordem. Entretanto, dentro da dose 4.000 ppm, as quatro primeiras cultivares não diferiram estatisticamente entre si, sendo superiores às duas ültimas, as quais foram semelhantes. Analisando-se ainda a Tabela 6 , constata-se que as reduções porcentuais nos niveis 2.000 ppm e 4.000 ppm com relação ao con trole foram: 15 e $29 \%, 11$ e $34 \%, 18$ e $41 \%, 16$ e $34 \%, 14$ e $30 \%$, 19 e 40\% para os cultivares Ample $\mathrm{H}-0-\mathrm{K}$, CMS-XS-616, $\mathrm{Br}-501, \mathrm{Br}-503, \mathrm{Br}-$ -602 e IPA-7301218, respectivamente.

Na Tabela 7 (Apēndice) tem-se os dados médios referen tes ao comprimento da panícula. Nota-se que em todos os niveis estudados as cultivares IPA-7301218 e CMS-XS-616 destacaram-se com maior e menor altura, respectivamente. Houve reduções porcentuais de 21 e $47 \%, 14$ e $51 \%, 13$ e $21 \%, 12$ e $44 \%, 16$ e $33 \%, 19$ e $18 \%$, para as culti vares, na ordem anteriormente citada.

Com relação ao diâmetro do colmo (Tabela 8 do Apēndice), percebe-se que nos niveis zero e $2.000 \mathrm{ppm}$ de cloreto as cultivares Br-602 e IPA-7301218 apresentaram maior diāmetro, enquanto a cultivar CMS-XS-616 mostrou o menor valor. Dentro do nivel 4.000 ppm as cultivares $\mathrm{Br}-503$ e CMS-XS-616 foram similares estatisticamente, apresentando os menores diāmetros, diferindo das demais, que por sua vez foram iguais do ponto de vista estatistico.

A argumentação destes dados com a literatura será fẹ ta no item 4.2.2.4 (Comentário Geral), ou seja, no final do item 4.2 .2 . 

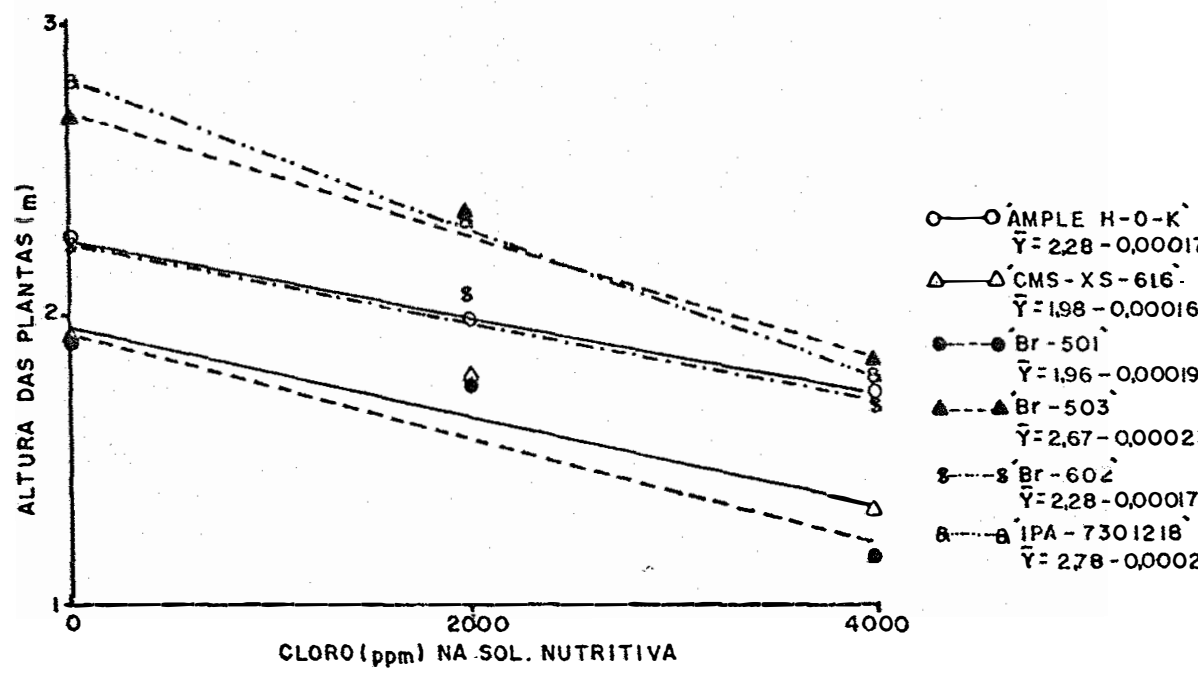

$\bar{Y}=2,28-0,00017 X$

$r=-1,00$

$\triangle \Delta^{\circ} C M S-X S-616^{\circ}$

$\bar{Y}=1.98-0.00016 X$

$r=-0,98$

- $-\mathrm{Br}-501^{\circ}$

$\bar{Y}=1,96-0,00019 \mathrm{X}$

$r=-0,94$

$\mathrm{Br}-503^{\circ}$

$\bar{\gamma}=2.67-0.00023 x$

$r=-0,99$

8-...- $-8^{\circ} \mathrm{Br}-60 \mathrm{~L}^{\circ}$

$\bar{Y}=2,28-0,00017 X$

$r=-0,99$

a- $-0^{\circ} \mathrm{PPA}-7301218^{\circ}$

$\bar{\gamma}=2,78-0,00027 x$

$r=-1,00$

CLORO (DPM) NA SOL. NUTRITIVA

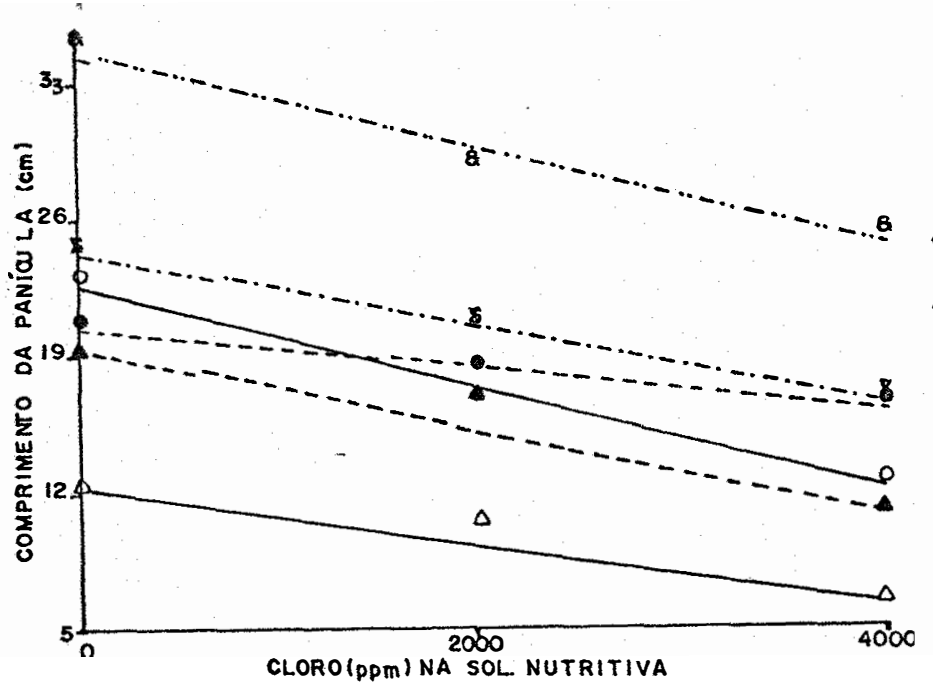

$\bigcirc$ O

$\overline{\mathrm{Y}}=22.53-0,0026 \mathrm{X}$

$r=-100$

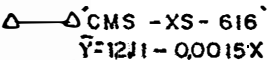

$r=0.98$

-... Br - 501

$\bar{Y}=20,00-0,0011 x$

$r=-0.99$

$\triangle B \mathrm{Br}-503$

$\overline{\mathbf{Y}}=1,8.93-0,0020 \mathrm{X}$

$r=-0.97$

8-.. $88_{B r}-602$

$\bar{\gamma}=23,86-00019 x$

$r=-1,00$

8-- 8 iPA - 7301218

$\bar{\gamma}=3.3,94-0,0024 \mathrm{X}$

$r=-098$

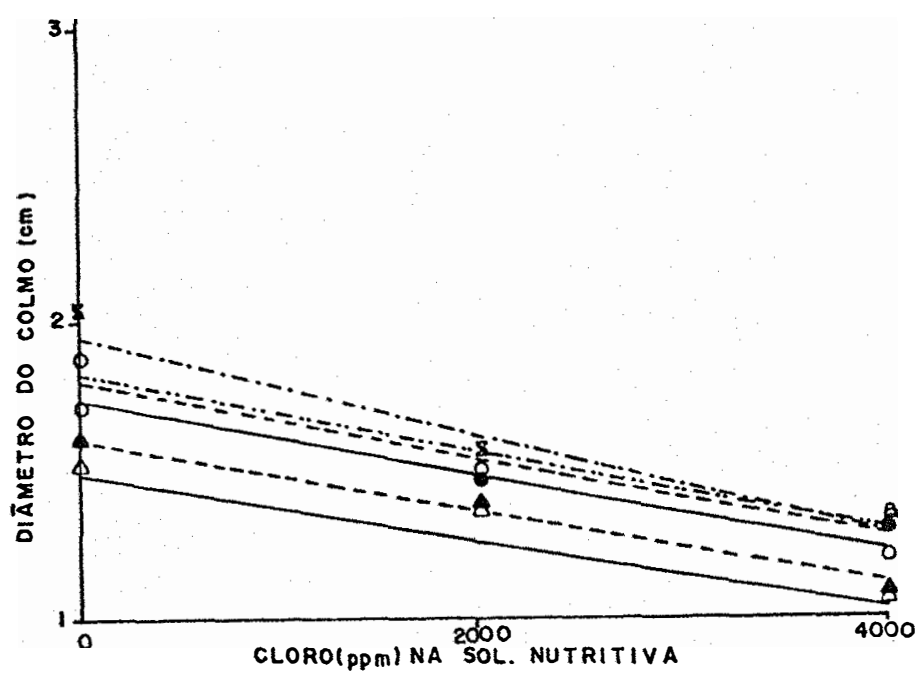

$O$ OAMPLE $H-O-K$

$\bar{\gamma}=1,07-0,00012 \mathrm{X}$

$\triangle \triangle \dot{C M S}-X S-616^{\circ}$

$\bar{\gamma}=1,49-0,00012 x$

$\bullet-\cdots \mathrm{Br}^{2}-501^{\circ}$

$\bar{\gamma}=180-0.00014 x$

$\triangle-\cdots B_{r}-503^{\circ}$

$\bar{Y}=156-0,00012 X$

\&-...-si $8 r-602^{\circ}$

$\bar{Y}=1.96-0.00018 \mathrm{X}$

a. - IPA $^{\circ} 7301218^{\circ}$

$\bar{\gamma}=183-0,00014 X$

Figura 3 - Altura da planta (m), comprimento da panícula (cm) e diâmetro do colmo (cm) em função dos niveis de cloreto na so lução nutritiva. 


\subsubsection{2 - Produção de matéria seca}

Os resultados da produção de matéria seca de raiz,col mo, folhas, panicula e matéria seca total encontram-se respectivamen te nas Tabelas 9,10,11, 12 e 13 (Apêndice). As respectivas anälises de variāncia indicam valores de F significativos para cultivar, níve1 e interação.

Mediante a utilização da anālise de regressão polinomial do 19 grau, foram obtidas as Figuras 4 e 5, nas quais se observa a ocorrência de uma redução linear na produção de matéria seca das diferentes partes da planta, e consequentemente, matéria seca total, para todas as cultivares estudadas, à medida que se aumentou a concentração salina na solução nutritiva, com altos coeficientes de cor relação.

Analisando-se a Tabela 9 percebe-se que em todos os niveis, Ample-H-0-K e Br-602, mostraram maior peso de matéria seca de raiz, enquanto a cultivar CMS-XS-616 conteve a menor produção radicu lar, embora que no nive1 $2.000 \mathrm{ppm}$ tenha sido similar estatisticamen te às cultivares IPA-7301218 e Br-501, e no nive1 4.000 ppm isto tenha ocorrido também para a cultivar Br-503, além das duas jả citadas. Houve reduções porcentuais com relação ao controle, nos niveis 2.000 e 4.000 ppm de: 20 e $48 \%, 31$ e $61 \%, 45$ e $61 \%, 28$ e $66 \%, 41$ e $64 \%, 39$ e $62 \%$, do peso da matéria seca de raiz das cultivares Ample-H-0-K, CMS-XS-61 6, Br-501, Br-503, Br-602, IPA-7301218, respectivamente. 
Analisando-se a Tabela 10 (Apêndice), verifica-se que dentro do nivel zero, as cultivares Ample-H-0-K, IPA-7301218, Br-503 e Br-602 apresentaram maior peso de matéria seca de colmo, sendo similares entre si, ao passo que no nivel 2.000 ppm isto ocorreu apenas com relação às três primeiras cultivares e no nivel 4.000 ppm foi verdadeiro para as duas primeiras. Com relação ao controle, constata-se reduções porcentuais nos niveis 2.000 e 4.000 ppm de: 23 e 51\%, 31 e 55\%, 38 e $62 \%, 27$ e 68\%, 47 e 64\%, 30 e 50\%, nas cultivares Ample $\mathrm{H}-0-\mathrm{K}, \mathrm{CMS}-\mathrm{XS}-616, \mathrm{Br}-501, \mathrm{Br}-503, \mathrm{Br}-602$ e IPA-7301218, respectivamente.

Examinando-se a Tabela 11 nota-se que a cultivar IPA-7301218 mostrou maior peso de matéria seca de folhas em todos os ni veis estudados. A redução porcentual no peso da matéria seca das folhas para os niveis 2.000 e 4.000 ppm, com relação ao controle, foram respectivamente: 11 e $35 \%, 15$ e $34 \%, 23$ e $33 \%, 10$ e $32 \%, 10$ e $32 \%$, 22 e 30\%, nas cultivares Ample-H-0-K, CMS-XS-616, Br-501, Br-503, Br-602 e IPA-7301218, respectivamente.

Analisando-se a Tabela 12 percebe-se que dentro do ni vel zero as cultivares $\mathrm{Br}-503$ e $\mathrm{Br}-501$ foram semelhante, contendo o maior peso de matéria seca de panicula, enquanto no nivel $2.000 \mathrm{ppm}$ isto se verificou apenas com relação à primeira cultivar e em ambos os niveis a cultivar CMS-XS-616 mostrou-se inferior. No nivel 4.000 houve superioridade da cultivar Br-503. Com relação ao controle, hou ve reduções porcentuais nos niveis 2.000 e $4.000 \mathrm{ppm}$, de: 26 e $87 \%$, 
45 e $83 \%, 38$ e $74 \%, 16$ e $48 \%, 33$ e $80 \%, 31$ e $76 \%$, para as cultivares Ample-H-0-K, CMS-XS-616, Br-501, Br-503, Br-602 e IPA-7301218, respectivamente.

Com relação à produção de matéria seca total das cultivares, verifica-se que no nivel 0, as cultivares IPA-7301218 e Br-602 mostraram-se superiores às demais, enquanto as cultivares Ample-H-0-K, Br-503 e Br-501 foram semelhantes estatisticamente, sendo intermediárias. Dentro do nível $2.000 \mathrm{ppm}$, as quatro primeiras culti vares foram semelhantes e superiores à cultivar Br-501, enquanto no níve1 4.000 ppm apenas a primeira mostrou maior produção, havendo se melhanças entre as cultivares Ample-H-0-K, Br-501, Br-503, Br-602. Em todos os niveis a CMS-XS-616 foi a menos produtiva. Com relação ao controle, houve redução porcentual nos niveis 2.000 e 4.000 ppm de: 22 e $58 \%, 30$ e $56 \%, 37$ e $61 \%, 22$ e $59 \%, 37$ e $65 \%, 30$ e $55 \%$ para as cultivares Ample-H-0-K, CMS-XS-616, Br-501, Br-503, Br- 602 e: IPA-7301218 , respectivamente.

Em última análise, a panícula foi o órgão que melhor indicou o efeito da salinidade no presente trabalho.

\subsubsection{3 - Produção de colmos frescos}

Nà Tabela 14 (Apêndice), tem-se os resultados médios obtidos para produção de matéria fresca de colmo, e na Figura 5 encontra-se a relação entre estes dados e niveis de cloreto na solução nutritiva. 


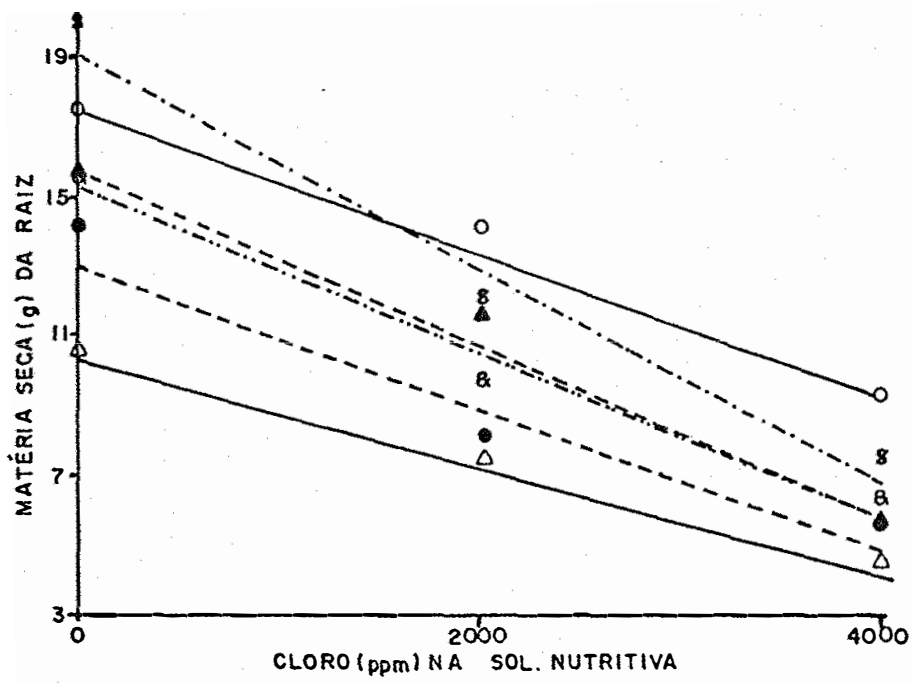

O- OAMPLE $H-0-K^{\circ}$ $\bar{\gamma}=17,27-0,0021 X$

$r=-0,99$

$\triangle C M S-X S-616$

$\bar{\gamma}=10,11-0,0015 x$

$r=-1,00$

-...

$\bar{\gamma}=13,13-0,0021 X$

$r=-0,97$

$\triangle \mathrm{Br}-503^{\circ}$

$\bar{Y}=15,52-0,0025 x$

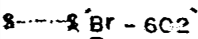

$\bar{Y}=19,06-0,0031 X$

Q-... IPA - 7301218

$\bar{\gamma}=14,9 \%-0,0024 X$

$r=-100$

$r=-0,99$

$r=-0,99$

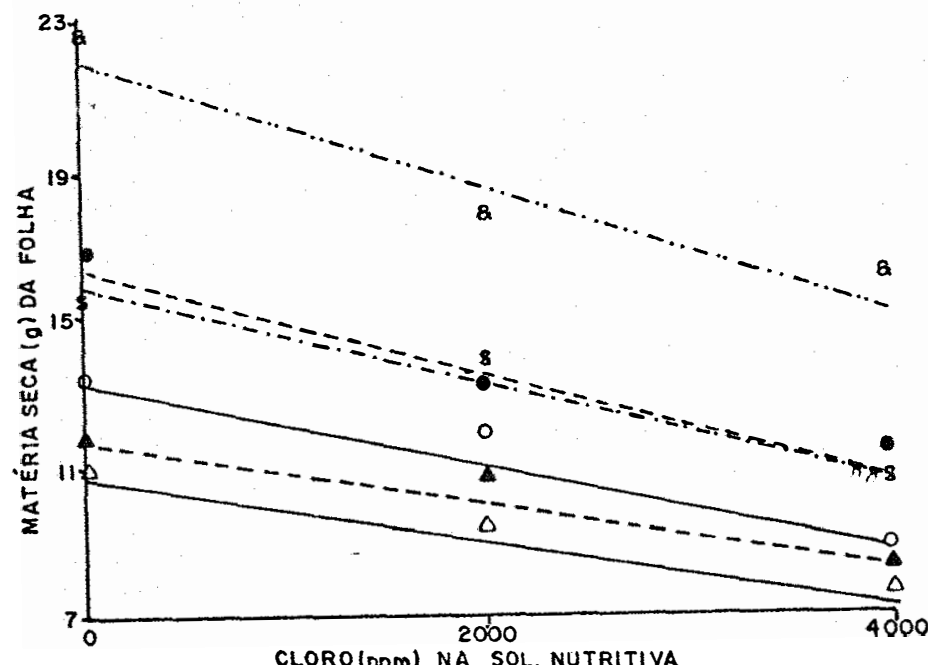

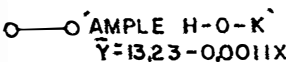

$r=-0.98$

$\bar{Y}=10,57-0,00085 x$

$r=-1,00$

- $0^{\circ}-501^{\circ}$

$\bar{\gamma}=16,17-0,0014 x$

$r=-0.98$

$\triangle-\triangle{ }^{\circ} \mathrm{Br}-503^{\circ}$

$\bar{Y}=11,60-0,00090 x$

$r=-0.98$

8-... $-8 \mathrm{Br}-602^{\circ}$

$\bar{Y}=15,39-0,0012 x$

$r=-0,98$

a-... IPA-7301218

$\bar{Y}=21,96-0,0017 X$

$r=-0.97$

CLORO (PPM) NA SOL. NUTRITIVA

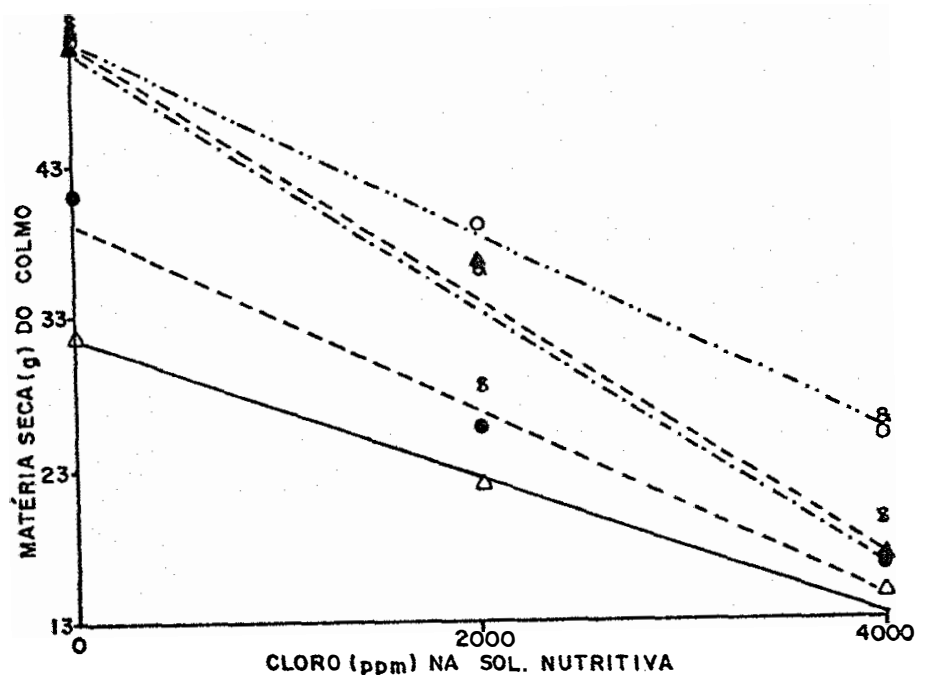

O- OAMPLE $H-0-K^{\circ}$

$r=-100$

$\triangle \mathrm{CMS}-X S-616^{\circ}$

$r=-1,00$

Br -501

$\bar{Y}=39,27-0,0062 x$

$r=-0,99$

$\mathrm{Br}-503^{\circ}$

$\bar{\gamma}=50,18-0,0083 x$

$r=-0,99$

8-.. $0 r-602^{\circ}$

$\bar{\gamma}=49,13-0,0083 X$

$r=-0,97$

Q-..-Q IPA-7301218

$\bar{Y}=50.13-0.0064 X$

$r=-0,99$

Figura 4 - Matéria seca (g) de raiz, de colmo e de folhas em função dos niveis de cloreto na solução nutritiva. 


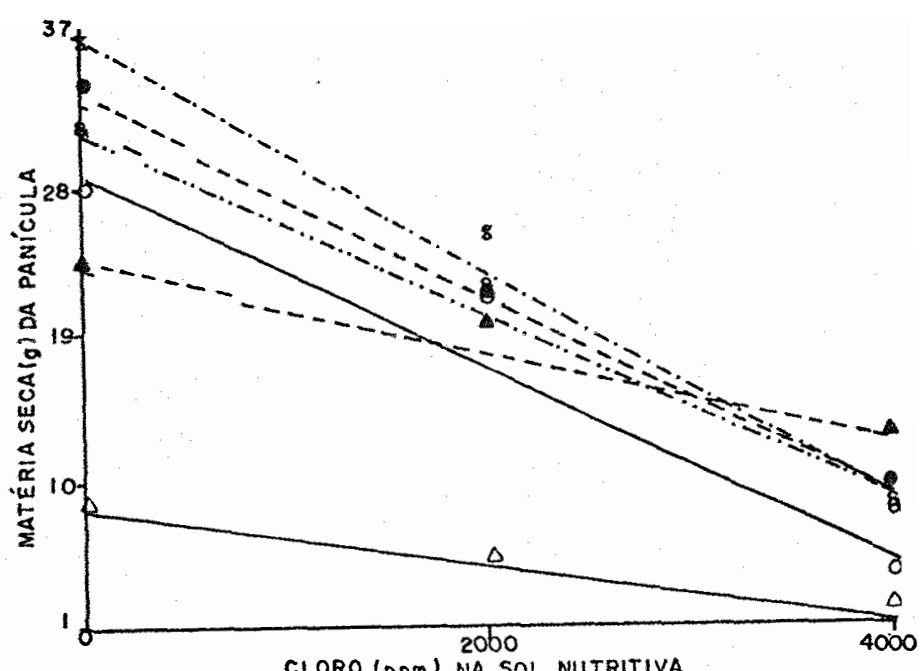

42.

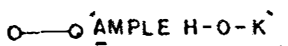

$\bar{Y}=28,42-0,0058 x$

$\triangle \triangle^{\circ} C M S-X S-616^{\circ}$

$\bar{\gamma}=7.62-0.0016 \mathrm{x}$

$r=-0,97$

-... $\mathrm{Br}-50 i^{\circ}$

$\bar{Y}=33,13-0,0062 x$

$r=-1,00$

$\triangle--\triangle B r-503^{\circ}$

$\bar{Y}=22,70-0.0026 X$

$r=-1,00$

$8--88^{\circ} \mathrm{Br}-602^{\circ}$

$\bar{Y}=36,67-0,0071 x$

B- $Q$ Q $I P A-7301218^{\circ}$

$\bar{Y}=31.58-0.0059$

$r=-0,98$

$r=-0,99$

$r=-0,99$

CLORO (PPM) NA SOL. NUTRITIVA

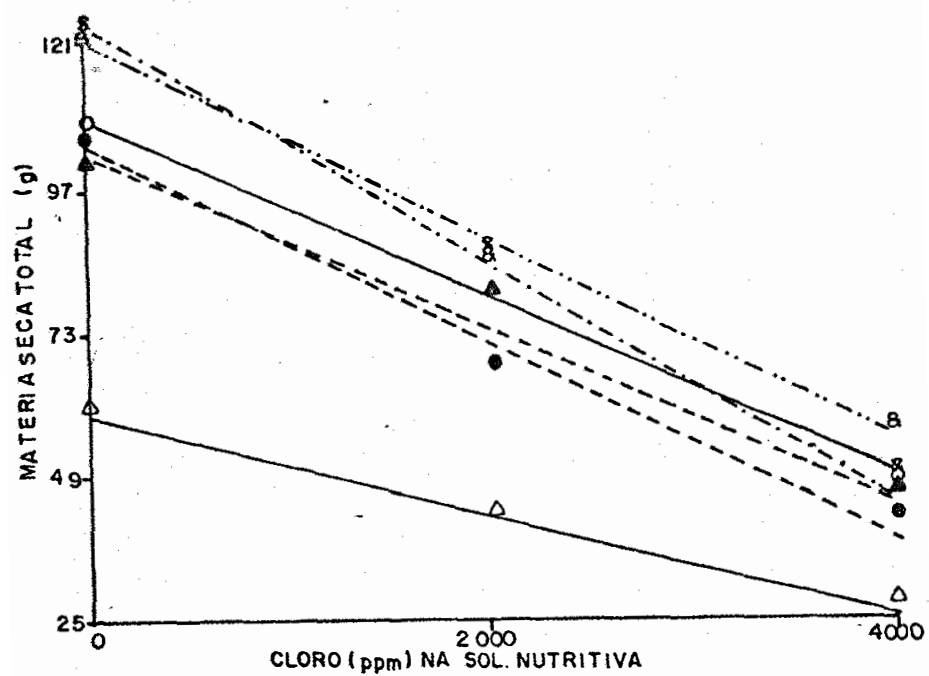

O OAMPLE $H-O-K^{\circ}$

$\bar{\gamma}=108.83-0.015 X$

$r=-0.99$

$\triangle \triangle{ }^{\prime} C M S-X S-616^{\circ}$

$\bar{\gamma}=58,49-0.0082 X$

$r=-7,00$

-..- $\mathrm{Br}_{\mathrm{r}}-501$

$\bar{\gamma}=101,70-0,016 \mathrm{X}$

$r=-0.99$

$\triangle-\triangle \mathrm{Br}-503$

$\bar{Y}=100,22-0.014 x$

$r=-0.99$

8-. $8 r-602$

$\bar{Y}=120,25-0,020 X$

$r=-1,00$

Q.-. Q $0^{\circ}$ IPA - $7301218^{\circ}$

$\bar{Y}=118.57-0.016 X$

$r=-1.00$

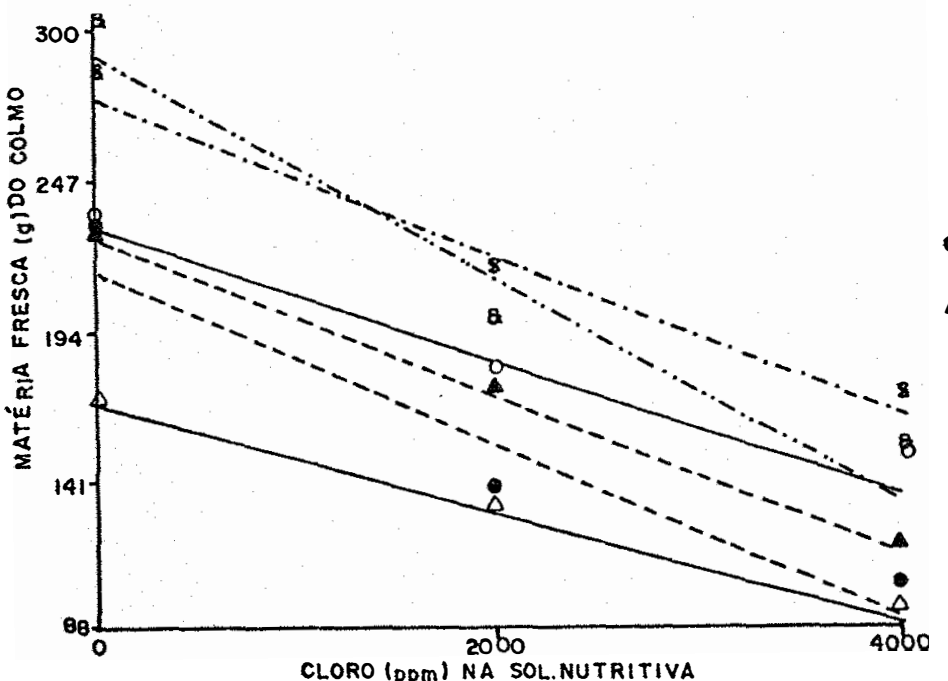

$p=-0,99$

$\bar{Y}=226,57-0,021 X$

$\triangle \triangle \triangle^{\circ} M M S-X S-616^{\circ}$

$\bar{\gamma}=163,67-0.019 x$

$r=-1,00$

- - Br $-50 i$

$\bar{Y}=213,35-0,031 X$

$r=-0.97$

$\triangle-\Delta_{\mathrm{Br}-503^{\circ}}^{\circ}$

$\bar{\gamma}=224,61-0.028 x$

$r=-1,00$

$8+. .8 r-602^{\circ}$

$\bar{\gamma}=278.55-0.028 x$

$r=-0,99$

a-- - Q IPA $-7301218^{\circ}$

$\bar{Y}=290,91-0,039 x$

$r=-0.98$

CLORO (PPM) NA SOL.NUTRITIVA

Figura 5 - Matéria seca (g) de panicula, matéria seca (g) total e matéria fresca (g) de colmo, em função dos niveis de cloreto na solução nutritiva. 
Verifica-se nesta Figura, que as produções de colmos frescos sofreram redução linear em função dos niveis crescentes de cloreto em todas as cultivares, com os coeficientes de correlação: -0,99 (Ample-H-O-K) , -1,0 (CMS-XS-616), -0,97 (Br-501), -1,0 (Br-503), $-0,99(\mathrm{Br}-602)$ e $-0,98$ (IPA-7301218).

Analisando-se a Tabela 14, nota-se que dentro do nivel zero as maiores produções referem-se às cultivares Br-602 e IPA-7301218, enquanto nos niveis 2.000 e 4.000 ppm, isto ocorreu para es tas cultivares mais a cultivar Ample-H-O-K.

\subsubsection{4 - Comentārio Geral}

A redução no crescimento da planta em função da salinidade tem sido discutida por diversos pesquisadores. Em sintese, a salinidade afeta diretamente o crescimento das plantas glicófitas de vido: ao aumento na pressão osmötica do meio onde se encontram (BERNS TEIN e HAYWARD, 1958; EATON, 1941); ao ajustamento osmótico (SLATYER, 1961; BERNSTEIN, 1961 e 1963); à acumulação de certos íons no tecido vegetal em concentração tóxica (EPSTEIN, 1975) que diminuem o crescí mento independente do efeito osmótico, podendo causar deficiências de outros nutrientes (ALLISON, 1964) e alterações do estado nutricional. Conforme STROGONOV (1964), a salinidade devida ao cloreto causa redução na diferenciação do tecido condutor de água e diminuição no diâmetro interno dos vasos da planta, e de acordo com OERTLI (1968) e ACEVES-N et alii (1975), a redução no crescimento ocorre também em função da modificação na atividade metabólica das paredes celulares. 
Conforme FENN et alii (1968), a redução de ärea fotos sintētica e a energia gasta para acumulação de cloreto dentro das cé lulas são as causas provāveis da redução no crescimento da planta sob condições salinas.

SEIFERT Jr. et alii (1975), trabalıando com sorgo gra nifero submetido a 450, $800,1.600$ e 2.400 ppm de sais na água de irrigação, fornecidos como $\mathrm{NaCl}, \mathrm{CaCl}_{2}$ e $\mathrm{MgSO}_{4}$, observaram redução sig nificativa no crescimento e produção da matéria seca do sorgo granifero. Resultados semelhantes nesta cultivar foram obtidos por EATON (1942) usando 50 e $150 \mathrm{meq} / 1$ de cloreto e por GARCIA e MORARD (1976) usando 36 e $72 \mathrm{meq} / 1$, fornecidos como cloreto de sódio. PRISCO et alii (1975), trabalhando com os potenciais $-2,-3,-4,-5$ e -6 bares

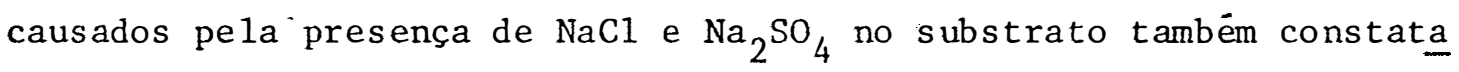
ram redução no crescimento de plāntulas de sorgo.

Conforme HAN et alii (1965), na Argentina, solos apre sentando condutividade elétrica de 4,7 mmos/cm e $11,8 \%$ como sódio trocāvel, permitem bom desenvolvimento do sorgo sacarino.

A redução no peso da matéria seca do sorgo encontrada pelos pesquisadores anteriormente citados são concordantes com os dados obtidos no presente trabalho.

As variações ocorridas no crescimento das cultivares dentro de um mesmo nivel são provavelmente decorrentes dos fatores genéticos e/ou climáticos que possam modificä-las quanto ao seu desenvolvimento, hája visto a cultivar IPA-7301218 obtida na região Nor deste, com um ciclo em torno de 110 dias*, mostrou-se com um ciclo

* Informação dada pelo Engo-Agrọ, M.Sc. João Emanuel Fernandes Bezer ra, da Empresa Pernambucana de Pesquisa Agropecuária - IPA, Recifé, Pe, 1983. 
de 150 dias.

Embora tenham ocorrido reduções significativas no cres cimento de todas as cultivares, em função dos niveis de cloreto, è provável que efeitos maiores tivessem ocorrido caso os tratamentos fossem dados em fase inicial de crescimento das flantas, pois segun do Maliawal e Paliwal (1967), citados por TAYLOR et alii (1975), as plantas são mais susceptiveis à salinidade na germinação e estädio inicial de desenvolvimento, apesar de que outros estádios possamtam bém ser afetados.

Pelas razões expostas no item 4.1 é possivel que os dados obtidos no presente trabalho sejam resultado de efeito conjun to entre os ions $\mathrm{Cl}^{-}$e $\mathrm{Na}^{+}$, o que serà objeto de discussão posterior.

\subsection{3 - Teores de nutrientes e de sōdio na matéria seca}

Os dados referentes aos teores de nutrientes e de södio contidos no colmo e folhas das cultivares estudadas, em função dos niveis de cloreto na solução nutritiva, encontram-se nas Tabelas 15 a 40 (Apêndice) e nas Figuras 6 a 18. A utilização do teste de Tú key a $5 \%$ permitiu constatar mudanças significativas no teor de cada elemento, numa mesma parte amostrada, conforme o tratamento e cultivar. Houve também variações no teor de cada elemento entre as partes amostradas de uma mesma cultivar. 


\subsubsection{1 - Nitrogēnio}

Nas Tabelas 15 e 16 (Apēndice) encontram-se as concen trações de nitrogênio contidas no colmo e folhas respectivamente. Os valores de $\mathrm{F}$ foram significativos para cultivar e nivel no caso de colmo, enquanto para folha houve significância devido a sintomas e interações cultivar $x$ nível, alèm dos jämencionados. Na Figura 6 , encontram-se as representações dos teores desse elemento no colmo e folhas, construidas em função dos niveis de cloreto, utilizando-se as equações de regressão polinomial de 19 e 29 graus.

A observação da Tabela 15 mostra que os niveis de nitrogênio no colmo das cultivares Ample-H-0-K, Br-501, Br-503 e Br-602 não aiferiram nos niveis estudados, e as variações dos dados obtidos obedecem a regressão do 20 grau (Figura 6). Na cultivar IPA-7301218, houve um aumento linear do nitrogênio em função da dose, enquanto na cụltivar CMS-XS-616 houve uma redução apenas no nível 2.000 ppm.

Examinando-se ainda a Figura 6, nota-se que nas foThas com sintomas leves ou com sintomas acentuados das cultivares IPA-7301218, Br-501, Br-503 e Ample-H-0-K houve redução no teor de nitrogēnio em função dos níveis de cloreto na solução nutritiva, ten do isto ocorrido linearmente para as 3 primeiras cultivares. Comportamento inverso verificou-se nas cultivares CMS-XS-616 e Br-602. FoThas com sintomas leves contiveram sempre teores superiores do elemento em questão, quando comparados àquelas com sintomas acentuados, dentro de cada tratamento, com relação às cultivares Ample-H-O-K, Br- 

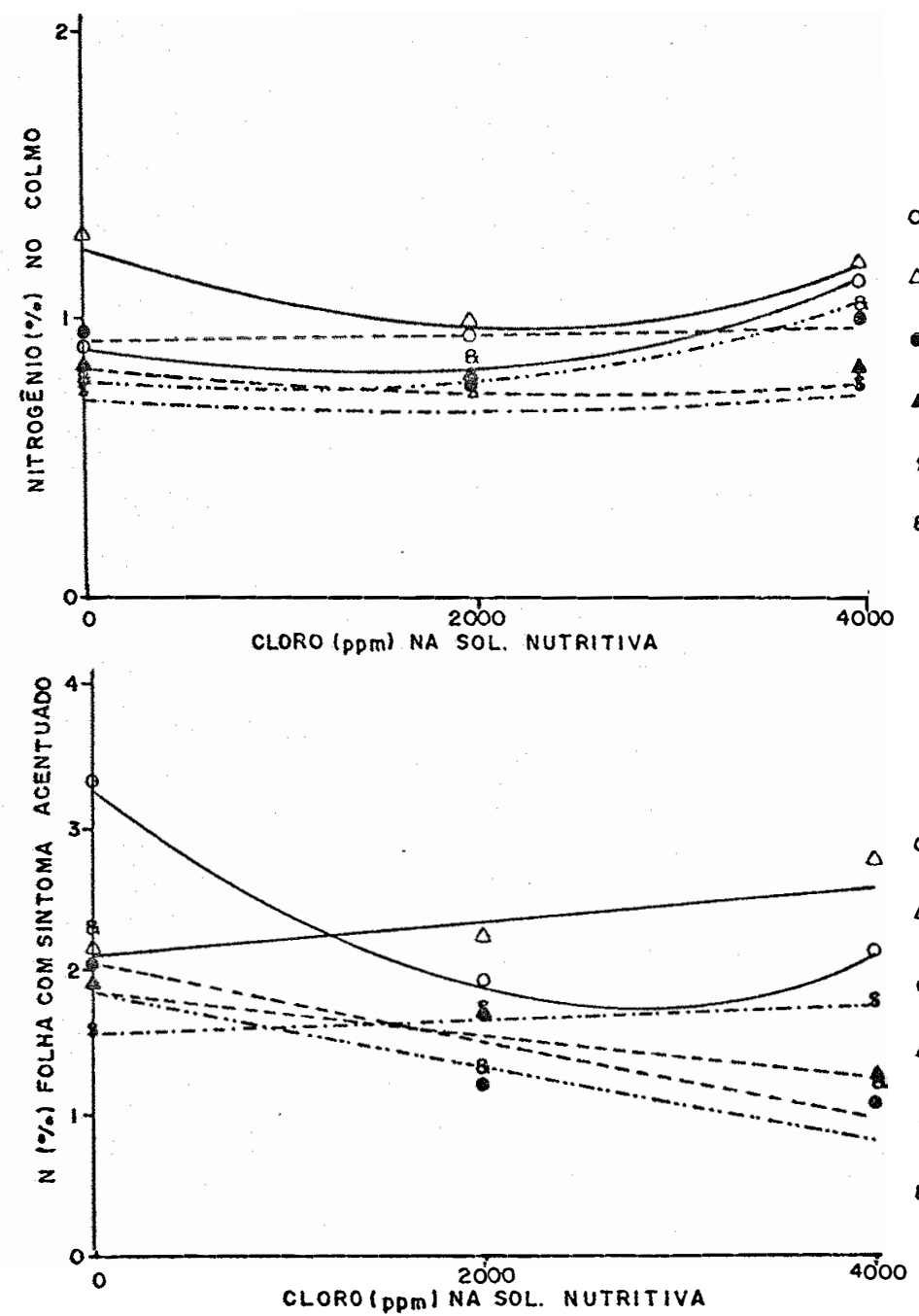

○AMPLE H-O-K

$\bar{\gamma}=0,86-0,000092 X+0,000000034 X^{2} K^{2}=100 \%$

$\triangle \triangle^{\prime} C M S-X S-616^{\circ}$

$\bar{\gamma}=122-0.00026 x+0,000000058 X^{2} R^{2}=100 \%$

- $B \mathrm{r}-500^{\circ}$

$\bar{Y}=087-0,0000050 X+0,0000000033 x^{2} R^{2}=100 \%$

$\triangle \mathrm{Br}-503^{\circ}$

$\bar{Y}=0.79-0000082 x+0,000000016 X^{2} R^{2}=100 \%$

8-...8 $8 \mathrm{~B}-602^{\circ}$

$\bar{Y}=0,66-0,000018 x+0,0000000058 x^{2} R^{2}=100 \%$

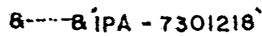

$\bar{Y}=0,66+0,000070 X$

$r=0.92$

OAMPLE H-O-K.
$\bar{Y}=3,21-0,00107 X+0,000000195 X^{2} \quad R^{2}=100 \%$

$\triangle \triangle$ CMS - XS - 616

$\bar{\gamma}=1,99+0,000147 x$

$r=0,91$

- $\mathrm{Br}-501$

$\bar{\gamma}=181-0,000237 x$

$r=-0,93$

A Br - $503^{\circ}$

$\bar{\gamma}=1.81-0.000144 X \quad r=-0.97$

$8-\cdots \mathrm{Br}-602^{\circ}$

$\bar{Y}=1,50+0,000046 \mathrm{X}$

$r=0,98$

Q-.... B IPA - $7301218^{\circ}$

$\bar{\gamma}=2,06-0,000280 x$

$r=-0,92$

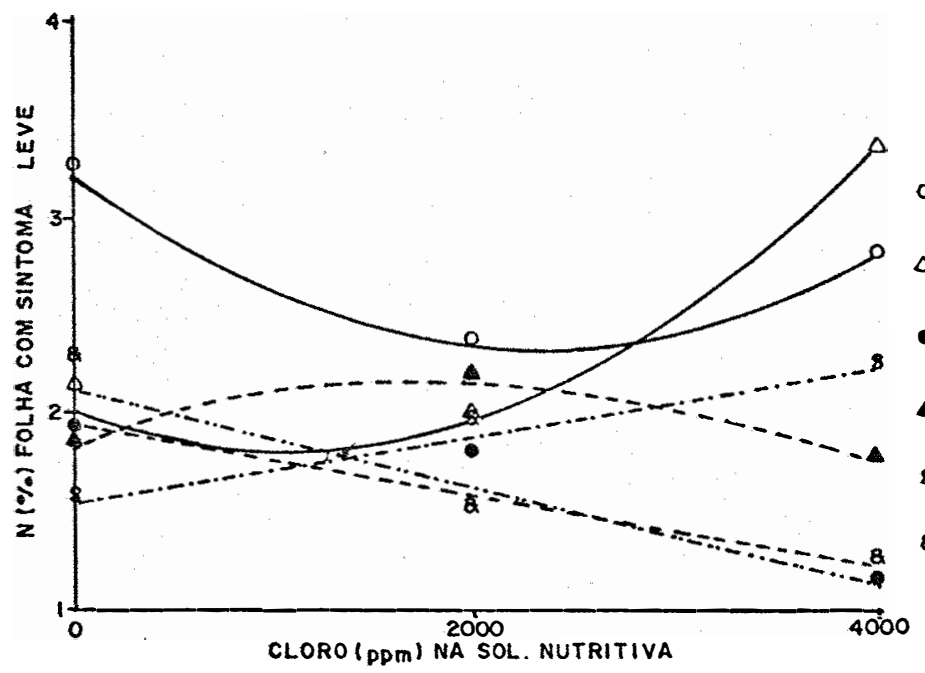

$\sim$ 'AMPLE $H-O-K^{\circ}$

$\bar{Y}=3,200-0,000777 x+0,000000167 \dot{x}^{2} \quad R^{2}=100 \%$

$\triangle \triangle^{\prime}{ }^{\prime} M S-X S-616^{\circ}$

$\bar{Y}=2.077-0.000442 X+0.000000188 X^{2} \quad R^{2}=100 \%$

$\bullet-\cdots \circ \mathrm{Br}-501^{\circ}$

$\bar{\gamma}=1,98-0,000192 x$

$r=-0,94$

$\triangle-\cdots{ }^{\circ}$ Br $-503^{\circ}$

$\bar{Y}=1,82+0,00033 X-0,0000000912 X^{2} \quad R^{2}=100 \%$

8-...-8 $8 \mathrm{Br}-602^{\circ}$

$\bar{Y}=1.51+0,000177 X$

$r=100$

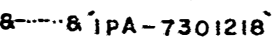

$\bar{Y}=2,13-0,00025 X$

$r=-0,96$

Figura 6 - Concentração de nitrogēnio (\%) no colmo, nas : folhas com sintomas leves e nas folhas com sintomas acentuados, em função dos niveis de cloreto na solução nutritiva. 
-503 e Br-602, verdadeiro também para a cultivar Br-501 dentro do tra tamento 2.000 ppm (Tabela 16).

En todas as cultivares e tratamentos as folhas contiveram maior concentração de nitrogênio.

O efcito depressivo do cloreto de sódio sobre o nitro gênio observado nas cultivares IPA-7301218, $\mathrm{Br}-501, \mathrm{Br}-503$ e AmpleH-0-K foi também constatado por WEBER (1983) estudando os níveis 0, $69,138,207$ e 276 ppm de södio fornecidos como $\mathrm{Na}_{2} \mathrm{SO}_{4}$ e $\mathrm{NaCl}$ em cin co cultivares de cana-de-açúcar. Este autor afirma que o fornecimento de $\mathrm{NaCl}$ se caracterizou pelo efeito predominantemente negativo so bre os teores de nitrogênio nas folhas das cultivares. SYED e EL-SWAIFY (1973) verificaram o mesmo efeito trabalhando com cana-de-açücar na presença de $\mathrm{NaCl}$ nas concentrações de $2,4,6 \mathrm{e}^{\circ} 8$ mmhos/cm. Estes resultados concordam ainda com os obtidos por WADIEIGH e GAUCH (1942) e TENÓRIO (1981), os quais observaram que a adição de cloreto de sōdio ao substrato está associada com a diminuição de $\mathrm{N}$ em plantas de feijão. Conforme STROGONOV (1964) a salinidade reduz o teor de nitrogénio no tecido vegetal, alterando o metabolismo desse elemento, principalmente dos aminoäcidos, havendo acumulação de substâncias tó xicas tais como a amônia, acarretando efeitos adversos sobre os processos fisiológicos da planta.

Por outro lado, o aumento do teor de nitrogènio em fun ção da salinidade, ocorrido nas cultivares CMS-XS-616 e Br-602, foi tambëm observado por JOSHI e NAIK (1980) trabalhando com cana-de-açü car, cultivada sob condutividade elétrica de 10 mmos/cm causadapor 
$\mathrm{NaCl}, \mathrm{Na}_{2} \mathrm{SO}_{4}, \mathrm{MgCl}_{2}$ e $\mathrm{MgSO}_{4}$, coincidindo com a estimulação da reduta se de nitrato. O mesmo foi observado ainda em feijão por WADLEIGH e AYERS (1942), em tomate, por HAYWARD e LONG (1943), e em cevada por GAUCH e EATON (1942).

GARCIA e MORARD (1976), pesquisande sobre o assunto com o sorgo granifero, observaram que 6 meq/1 de $\mathrm{NaCl}$ causaram aumen to nos teores de nitrogênio, enquanto 36 e 72 meq/1 causaram reduções .

\subsubsection{2 - Fósforo}

Os dados referentes aos teores de fósforo na matéria seca do colmo e folha encontram-se nas Tabelas 17 e 18 (Apêndice), e na Figura 7 acham-se as anälises de regressão polinomial traduzidas por equação do 19 e 29 graus. Houve efeito de cultivar, nível e inte ração, no caso de colmo, enquanto para folha houve efeito devido a sintomas e interação cultivar x sintomas, além dos jā mencionados.

A observação dos dados constantes nas Tabelas 17 e 18 permite verificar que houve diferença entre os teores de fósforo no colmo e na folha, em função dos niveis de cloreto, comparando-se as médias pelo teste de Tukey a $5 \%$.

Quando se correlacionaram doses de cloreto com os teo res de fósforo do colmo, ficou evidenciado que o cloreto deprimiu a concentração do elemento em questão dentro do níve1 2.000 ppm nas cul tivares Ample-H-0-K, $\mathrm{Br}-501$, e que nas cultivares $\mathrm{Br}-602$ e IPA-7301218 
houve acúmulo de fósforo dentro do nível 4.000 ppm, sugerindo, portanto, efeito de diluição (Figura 7). Nos níveis 0 e 2.000 ppm a cul tivar CMS-XS-616 mostrou os mais altos teores de fósforo, diferindo das demais cultivares (Tabela 17), que por sua vez mostraram teores semelhantes estatisticamente.

Ainda na Figura 7, percebe-se que os teores de fósforo nas folhas com sintomas leves ou com sintomas acentuados foram re duzidos em função dos niveis de cloreto e com altos coeficientes de correlação, embora em alguns casos isto não tenha ocorrido significa tivamente.

Nos niveis 2.000 e $4.000 \mathrm{ppm}$, folhas com sintomas acentuados pertencentes às cultivares CMS-XS-616, Br-501 e Br-503 con tiveram menorés teores de fósforo do que folhas com sintomas leves (Tabela 18). Isto se verificou também nas cultivares Ample-H-O-K e Br-602, dentro dos niveis 2.000 e 4.000 ppm respectivamente.

Os teores de fósforo do colmo foram sempre inferiores aos das folhas em todas as cultivares.

A influência da salinidade sobre os teores de fósforo da planta è bastante controvertida, havendo redução ou acréscimo nes tes teores, dependendo da espécie ou cultivar.

HEILMAN (1974), trabalhando com as variedades de sorgo granifero ATX-399 e RS-671, submetidas a uma condutividade de 0,3 a $9 \mathrm{mmhos} / \mathrm{cm}$ causada pelo $\mathrm{NaCl}$, observaram aumento no teor de fósforo da raiz e parte aérea de ambas as variedades. PATEL (1973) consta 


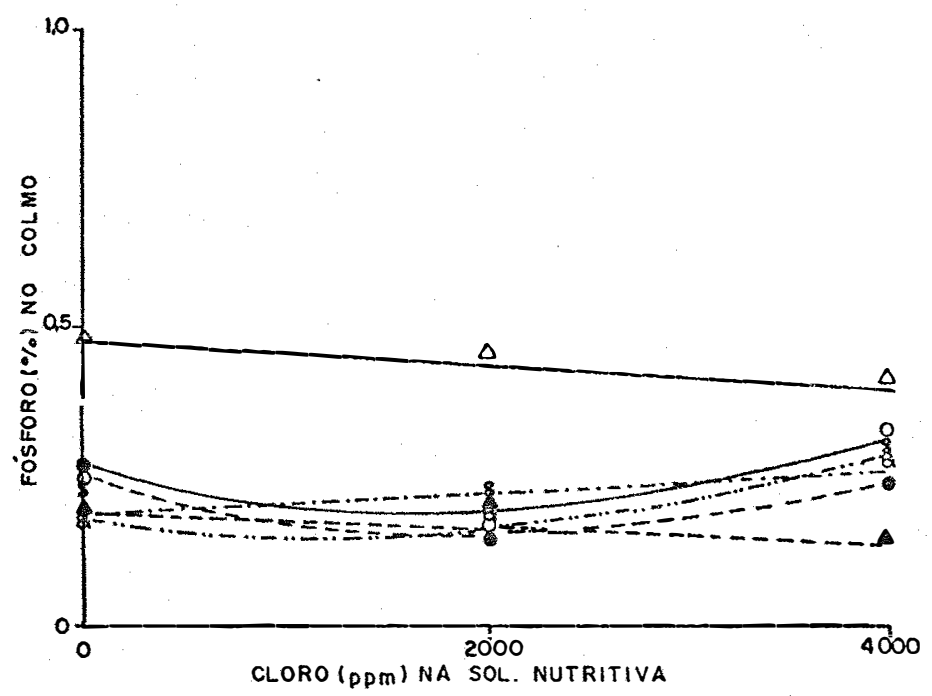

51.
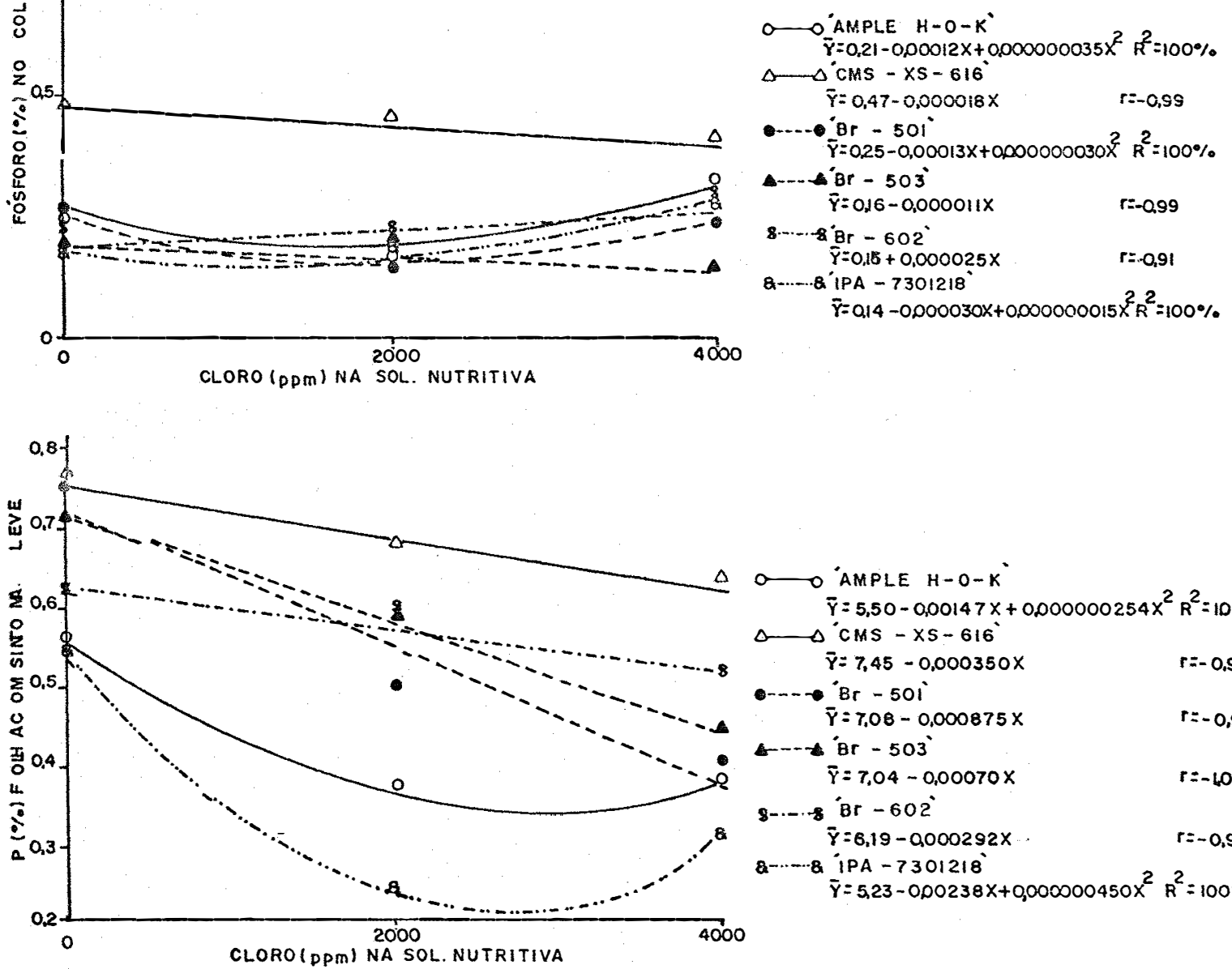

$\sim$ 'AMPLE $H-O-K^{\circ}$

$\bar{Y}=5,50-0,00147 X+0,000000254 X^{2} R^{2}=100 \%$

$\triangle \triangle \triangle^{\prime} C M S-X S-616^{\circ}$

$\bar{\gamma}=7,45-0,000350 x \quad r=-0.98$

$\longrightarrow \cdots \mathrm{Br}-50 i^{\circ}$

$\bar{Y}=7,08-0,000875 X \quad r=-0,96$

- Br $-503^{\circ}$

$\bar{\gamma}=7,04-0,00070 x \quad r=-100$

8-... Br $-602^{\circ}$

$\bar{\gamma}=6,19-0,000292 x . \quad r=-0,96$

Q-..-8 IPA $-7301218^{\circ}$

$\bar{Y}=5,23-0,00238 x+0,000000450 x^{2} \quad R^{2}=100 \%$

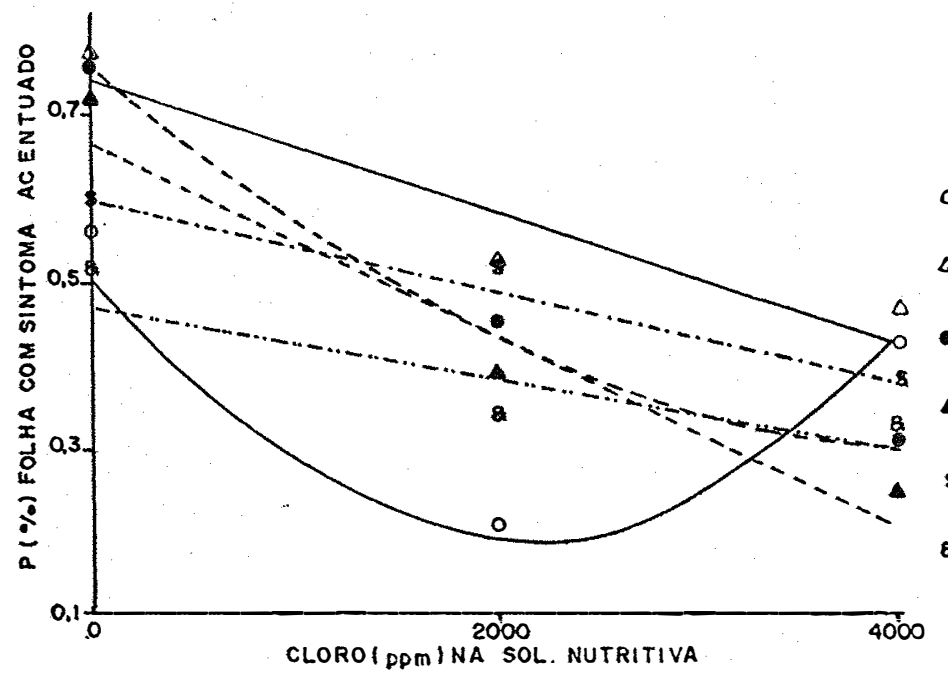

$\sim \sim_{-}^{\circ}$ AMPLE H-O-K'

$\bar{\gamma}=5,43-0,0032 x+0,00000070 X^{2} \quad R^{2}=100 \%$

$\triangle \triangle \Delta^{\circ} \mathrm{CMS}-\mathrm{XS}-616^{\circ}$

$\bar{Y}=7.21-0,00077 x$

$r=-0,95$

$-\cdots \mathrm{Br}^{\circ}-501^{\circ}$

$\bar{Y}=7.40-0.0020 X+0,00000021 x^{2} R^{2}=100 \%$

A Br $-503^{\circ}$

$\bar{y}=6,63-0,0012 x$

$r=-0,98$

$8-8^{\circ} \mathrm{Br}-602^{\circ}$

$\bar{\gamma}=5,91-0,00055 \mathrm{X}$

Q.-... $8^{\circ}$ IPA $-7301218^{\circ}$

$\bar{\gamma}=4,73-0,00050 x$

$r=-0,99$

$r=-0,91$

Figura 7 - Concentração de fósforo (\%) no colmo, nas folhas com sin tomas leves e nas folhas com sintomas acentuados, em função dos niveis de cloreto na solução nutritiva. 
tou aumento no teor de fósforo, de sorgo, milho e trigo, à medidaque aumentava a salinidade no substrato. GARCIA e MORARD (1976), estudan do os niveis 6,36 e $72 \mathrm{meq} / 1$ de $\mathrm{NaCl}$ no substrato de cultivo do sor go granifero, reportam aumentos significativos nos teores de fósforo das diversas partes da planta em função da salinidade.

WEBER (1983), trabalhando com cana-de-açúcar, observou que até $72,7 \mathrm{ppm}$ de sódio fornecido ao substrato como $\mathrm{NaCl}$ houve redução no teor desse elemento nas folhas da cultivar RB-70194, e a partir daí houve aumento no teor de fósforo com o aumento da salinidade; o mesmo ocorreu nas cultivares RB-725828, NA-56-79 e CP-51-22, a partir da concentração 107,5 ppm de sódio, enquanto na cultivar CB 45-3 houve um efeito predominantemente negativo, em todos os niveis estudados. Com esta cultura, SYED e EL-SWAIFY (1973) constataram que a presença de $\mathrm{NaCl}$ até 8 mmhos/cm aumentou significativamenteo teor de fósforo na cultivar H-507209, não o fazendo na cultivar NCo310. Re dução no teor de fósforo em função da salinidade. foi tambám observado por HASSAN et alii (1970a), trabalhando com cevada, e por HASSAN et alii (1970b), estudando o assunto em milho.

\subsubsection{3 - Potássio}

Nas Tabelas 19 e 20 (Apêndice) encontram-se os teores médios para potássio no colmo e folhas, respectivamente, onde,median te a utilização do teste de Tukey a $5 \%$, permitiu constatar que a adi ção dedoses crescentes de $\mathrm{NaCl}$ acarretaram mudanças significativas nos teores do elemento em questão, tanto para colmo como para folhas.Hou 
ve efeito de cultivar, nivel e interação para colmo devido a sintomas e interações para folha, além dos jā mencionados.

Na Figura 8 tem-se as correlações entre os niveis de cloreto e os teores de potāssio, no colmo, folhas com sintomas leves e com sintomas acentuados, respectivamente, nas quais acham--se as anālises de regressão polinomial traduzidas por equações do 19 e 2 ? graus.

Examinando-se a Figura 8 percebe-se que a adição de cloreto na solução nutritiva reduziu o teor de potảssio no colmo das cultivares $\mathrm{Br}-501, \mathrm{Br}-503, \mathrm{Br}-602$, nos diferentes niveis, e da culti var IPA-7301218 com relação ao nivel $2.000 \mathrm{ppm}$. No nivel zero os teo res de potássio no colmo das cultivares $\mathrm{Br}-501$ e $\mathrm{Br}-602$ foram semè1hantes estatisticamente ao das CMS-XS-616 e $\mathrm{Br}-503$, variando de 1,33 a $1,61 \%$ (Tabela 19). Dentro do nível 2.000 ppm estas duas últimas cal tivares não diferiram entre si. estatisticamente, contendo os mais altos teores desse elemento, enquanto no nivel 4.000 ppm isto ocorreu entre estas cultivares, IPA-7301218 e Ample-H-0-K.

Analisando-se outra vez a Figura 8, nota-se que os teo res de $\mathrm{K}$ nas folhas com sintomas leves das Ample-H-0-K, Br-503, IPA-7301218 e CMS-XS-616 foram reduzidos linearmente em função da adição de cloreto na solução nutritiva. Esta redução linear ocorreu ain da nas folhas com sintomas acentuados das duas primeiras cultivares, e de forma quadrātica nesta ültima. Entretanto, na cultivar Br-501, aconteceu o conträrio. Dentro do nivel $2.000 \mathrm{ppm}$ folhas com sintomas 


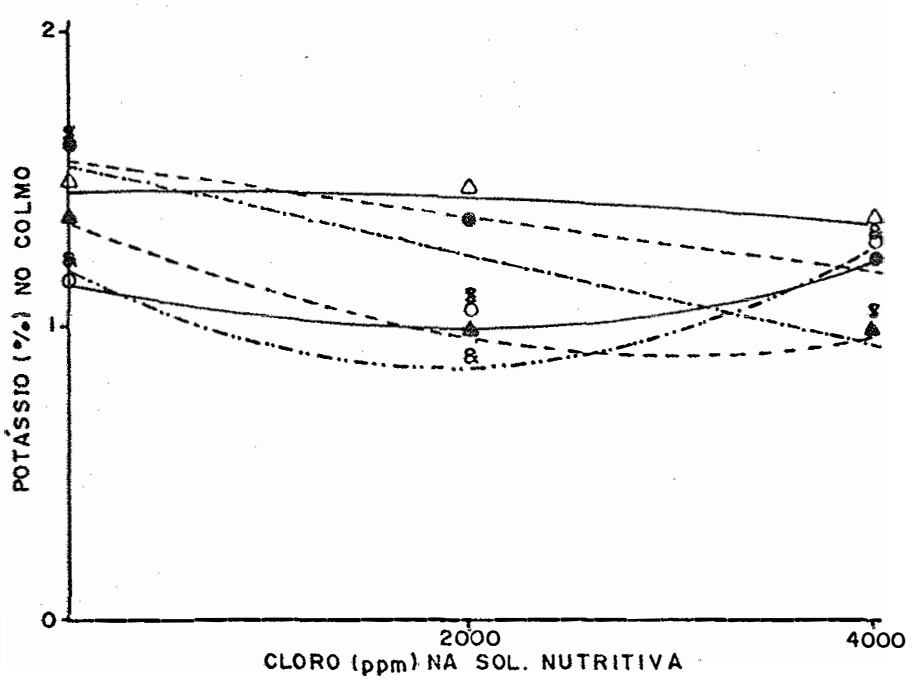

54.

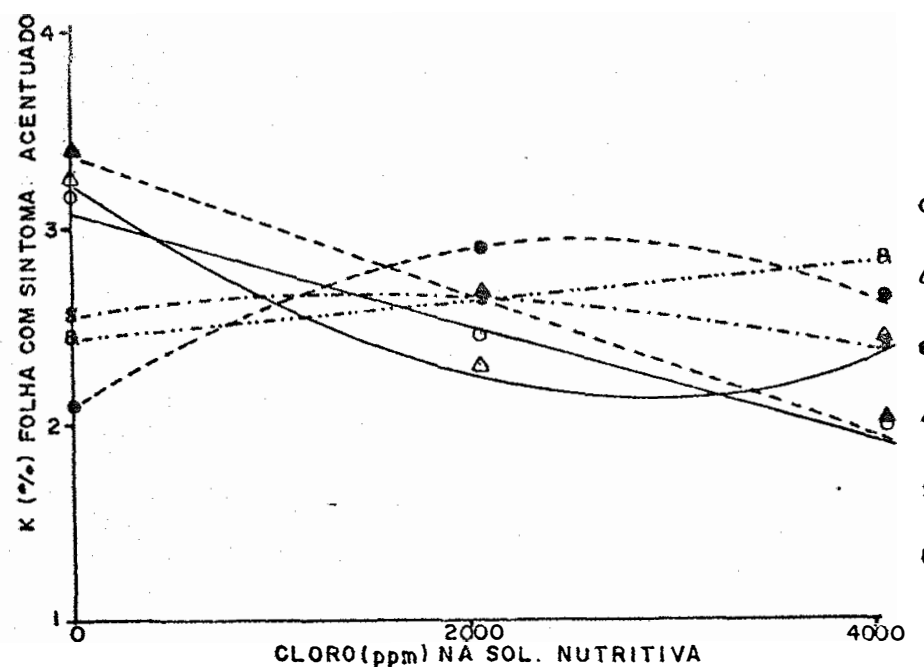

$\bigcirc$ ○ AMPLE H-O-K'

$\bar{\gamma}=1,12-0,00015 X+0,000000044 X^{2} \quad R^{2}=100 \%$

$\triangle \triangle$ CMS - XS - $616^{\circ}$

$\bar{Y}=1,44+0,000011 x-0,00000011 x^{2} R^{2}=100 \%$

- B Br - $50 i^{\circ}$

$\bar{Y}=1,55-0,000095 x \quad r=-0,97$

$\triangle \gamma^{\circ}-503^{\circ}$

$\bar{\gamma}=133-0,00029 x+0,000000048 x^{2} \quad R^{2}=100 \%$

8-.- $-88^{\circ} B-602^{\circ}$

$\bar{\gamma}=1,53-0,00015 X \quad r=0,90$

Q..... $0^{\circ}$ IPA $-7301218^{\circ}$

$\bar{\gamma}=1,18-0,00036 x+0,000000097 X^{2} R^{2}=100 \%$

$\sim$ O AMPLE H-O-K'

$\bar{\gamma}=3,04-0,00028 X$

$r=-0.99$

$\triangle \Delta^{\prime} C M S-X S-616^{\circ}$

$\bar{Y}=3.19-0,00076 X+0,00000014 X^{2} \quad R^{2}=100 \%$

-... $\mathrm{Br}-501^{\circ}$

$B r-501$
$\bar{Y}=202+0,00066 x-0,00000013 X^{2} \quad R^{2}=100 \%$

A $B r-503^{\circ}$

$\bar{\gamma}=3.31-0.00034 x \quad r=-100$

8...- 8 B $\mathrm{Br}-602^{\circ}$

$\tilde{\gamma}=2.50+0,000137 X-0,0000000475 X^{2} R^{2}=100 \%$

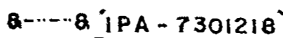

$\bar{\gamma}=2.39+0.000085 x \quad r=1,00$

CLORO $(P P M)$ NA SOL. NUTRITIVA

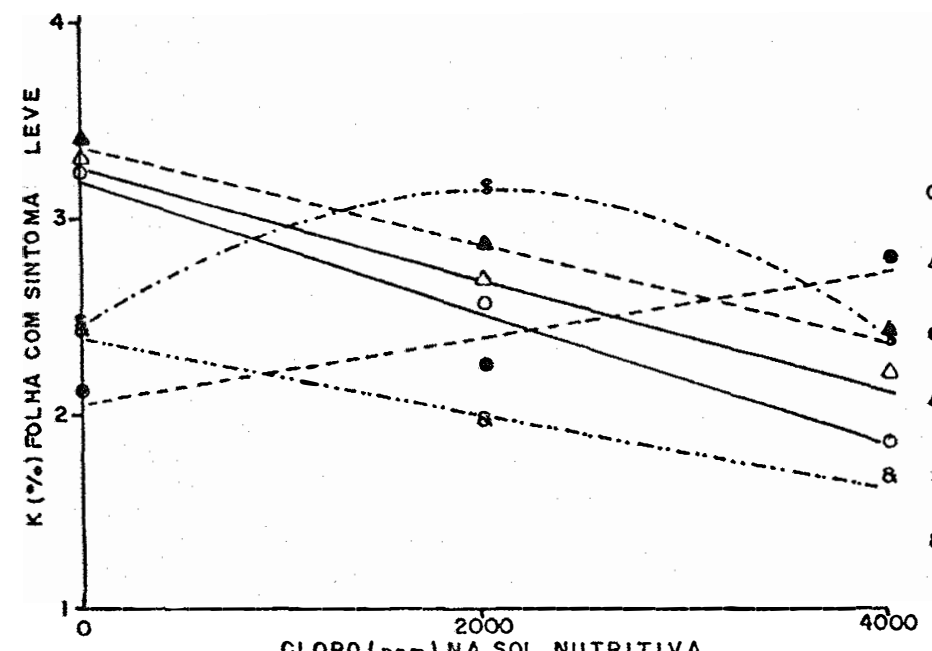

0 -

$\bar{\gamma}=3,16-0,000347 X \quad r=-1,00$

$\triangle \triangle C M S-X S-616^{\circ}$

$\bar{Y}=3,21-0,000284 X \quad r=-100$

- - - 8 Br $-501^{\circ}$

$\bar{\gamma}=1,97+0.000163 x \quad r=0.94$

$\triangle \cdots \mathrm{Br}-503^{\circ}$

$\bar{Y}=3,30-0,000252 x$

$r=-100$

s-...-8 $B r-602^{\circ}$

$\bar{\gamma}=2,49+0,00065 x-0,00000018 x^{2} \quad h^{2}=100 \%$

8-.-. ' $1 P A-7301218^{\circ}$

$\bar{\gamma}=2,36-0,00021 X$

$r=-0,99$

CLORO IPPMINA SOL. NUTRITIVA

Figura 8 - Concentração de potássio (\%) no colmo, nas folhas com sin tomas leves e nas folhas com sintomas acentuados, em função dos niveis de cloreto na solução nutritiva. 
leves das cultivares CMS-XS-616 e Br-602 contiveram teores de potās sio significativamente superiores aos de folhas com sintomas acentua dos, ocorrendo o inverso com relação às cultivares Br-501 e IPA-7301218 (Tabela 20), constatando-se o mesmo dentro do nivel 4.000 ppm para esta cultivar e $\mathrm{Br}-503$.

A presença de $\mathrm{NaCl}$ na solução nutritiva, em niveis elevados, diminuem os àcidos orgānicos das plantas de sorgo (GARCIA e MORARD, 1976), os quais são importantes em manter o equilíbrio inter no entre cảtions e ānions (MORARD et alii, 1974). Em geral, o aumento de salinidade no substrato causa redução na absorção e/ou nos teo res de potāssio da planta (GAUCH e WADLEIGH, 1945; EHRLER, 1960; HAS SAN et alii, 1970a,b; GREENWAY, 1962; SMITH e MIDLETON, 1980; PATHAMANABHAN e RAO, 1976).

Pesquisas sobre o mecanismo de absorção do potāssio em presença dos ions cloreto de sódio têm sido discutidas por RAINS (1972). Conforme este autor, em baixas concentrações o cloreto mostra pouca influência sobre a absorção do potássio. Na presença de $\mathrm{NaCl}$ em doses baixas sugere-se a possibilidade de um sinergismo intracelular $\mathrm{K}^{+}-\mathrm{Na}^{+}$(GARCIA e MORARD, 1976); em doses elevadas o sódio compete com o potássio (HELAL, 1980; EPSTEIN, 1975), dependendo do mecanismo de bombeamento de prótons, no plasmalema e tonoplasto, dis cutida por RAINS (1972). O aumento na absorção do sōdio reduz a absorção do potảssio (BANGE, 1959).

Dependendo da espécie, o sódio pode substituir parcialmente o potàssio (MALAVOLTA, 1980). 
GARCIA e MORARD (1976), trabalhando com sorgo granife ro, observaram que houve um efeito depressivo nos teores de potássio, em função da salinidade.

WEBED (1983), estudando este aspecto em cana-de-açūcar, verificou que à salinidade provocada pelo $\mathrm{NaCl}$ causou aumentos marcantes nos teores de potássio das folhas das cinco cultivares estudadas. O mesmo foi observado por OLIVEIRA (1983) em plantas de arroz, submetidas aos niveis $2.000,4.000,6.000$ e $8.000 \mathrm{ppm}$ de sais, fornecidos como $\mathrm{NaCl}(50 \%), \mathrm{NaHCO}_{3}(15 \%), \mathrm{CaSO}_{4}(15 \%), \mathrm{MgSO}_{4}(10 \%)$ e $\mathrm{CaCl}_{2}$ (10\%); entretanto, verificou também que a quantidade armazenada pela planta foi reduzida.

MARTIN e BINGHAM (1954) informam que a adição de sódio pode resultar em grande transferência de potássio das raízes para a parte aérea.

\subsubsection{4 - Cálcio}

A adição de cloreto de sódio na solução nutritiva per mitiu constatar, mediante a utilização do teste de Tukey a 5\%, a ocor rência de mudanças significativas nos teores de cálcio do colmo e da folha, conforme se pode observar nas Tabelas 21 e 22 (Apêndice), res pectivamente. Houve efeito de cultivar, nivel e interação para colmo, enquando no caso da folha houve efeito devido a sintomas, e interações cultivar x nível e nível x sintomas, além dos já mencionados. 
Utilizando-se a anālise de regressão polinomial, foi construída a Figura 9, correspondendo às correlações entre teores des se elemento no colmo, folhas com sintomas leves e com sintomas acentuados, e niveis de cloreto na solução.

A Figura 9 permite visualizar que nos teores de cálcio no colmo das cultivares $\mathrm{Br}-501$ e $\mathrm{Br}-602$ houve uma redução, ocorrendo de forma quadrätica, em função dos níveis de cloreto, não se alterando estatisticamente nas demais cultivares.

Dentro do nível zero, os teores do elemento em questão foram maiores no colmo da cultivar Br-501 que, por sua vez, foi similar à cultivar Br-602. Dentro dos niveis 2.000 e $4.000 \mathrm{ppm}$ não - houve diferenças entre as cultivares.

Nas folhas com sintomas leves ou com sintomas acentua dos das cultivares Ample-H-0-K, Br-501, Br-503 e Br-602 os teores de cálcio sofreram redução em função dos níveis de cloreto, conforme se verifica na Figura 9. Isto ocorreu ainda na cultivar IPA-7301218, no caso de folhas com sintomas leves. Este tipo de folhas conteve maiores concentrações de cálcio do que folhas com sintomas acentuados com relação à cultivar Ample H-0-K, dentro do nível 2.000 ppm, ocorrendo o inverso nas cultivares $\mathrm{Br}-501, \mathrm{Br}-503$ e IPA-7301218 (Tabe1a 22). Is to foi verdadeiro dentro do nivel $4.000 \mathrm{ppm}$ para esta ültima cultivar.

Os resultados obtidos por GARCIA e MORARD (1976) mostram que os teores de cálcio em sorgo granífero foram reduzidos com 
58.
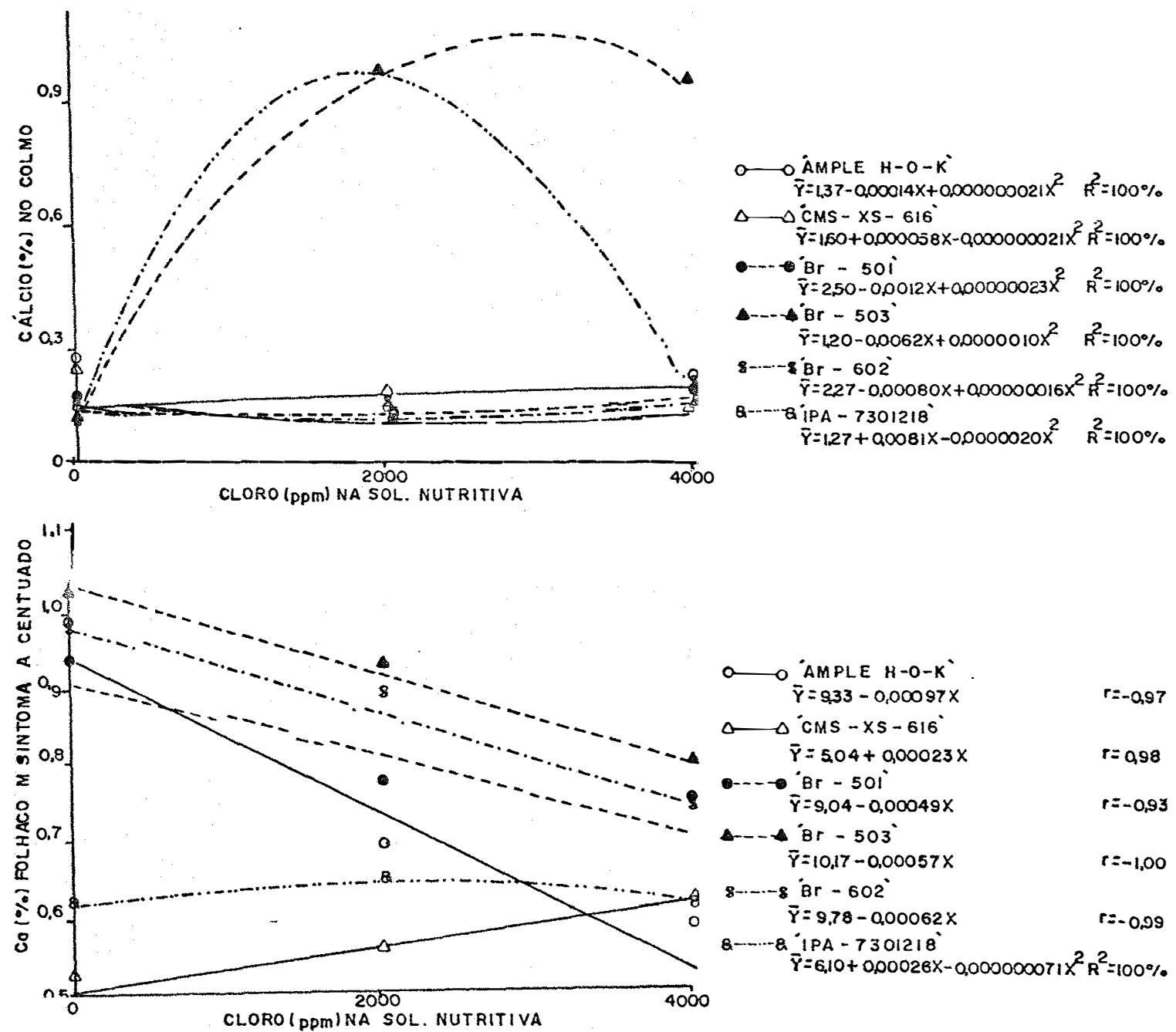

○ $\bigcirc$ AMPLE $H-O-K^{\circ}$

$\bar{\gamma}=9,33-0,00097 X$

$r=-0,97$

$\triangle \triangle \triangle^{\circ} C M S-X S-616^{\circ}$

$\bar{\gamma}=5,04+0,00023 x$

$r=0,98$

- $\mathrm{Br}-501^{\circ}$

$\bar{\gamma}=9,04-0,00049 x$

$r=-0,93$

$\triangle-1 B r-503^{\circ}$

$\bar{\gamma}=10,17-0,00057 \mathrm{X}$

$r=-1,00$

8-.--8 Br $-602^{\circ}$

$\bar{\gamma}=9,78-0,00062 x$

6-..-2 ${ }^{\circ} 1 P A-7301218^{\circ}$

$r=-0,99$

$\bar{Y}=6,10+0,00026 X-0,000000071 X^{2} R^{2}=100 \%$

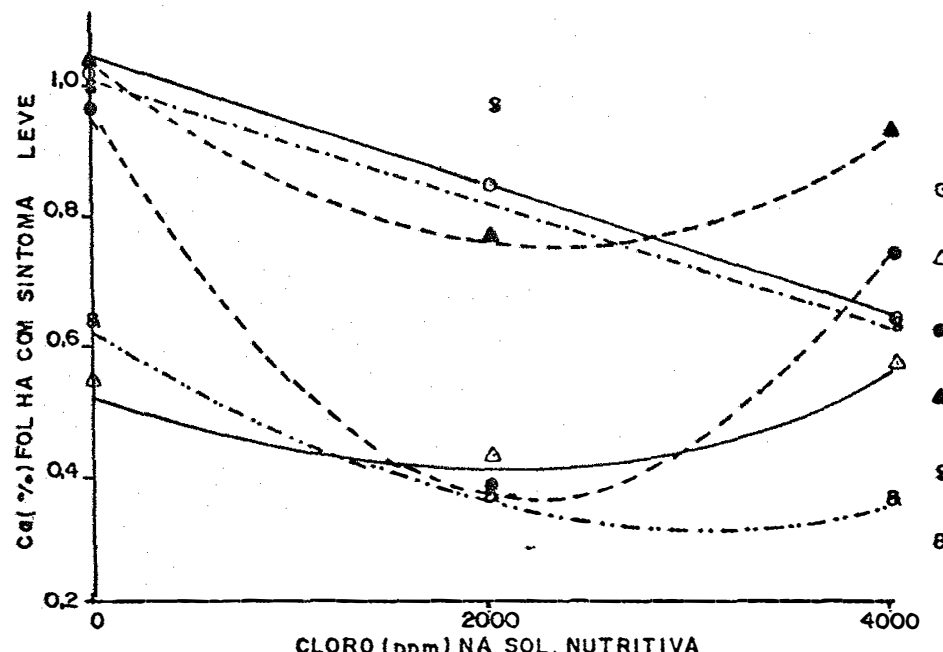

0 ○ AMPLE $H-O-K^{\prime}$

$\vec{\gamma}=9,84-0,00091 X$

$\triangle \triangle$ CMS - XS - 616

$r=-0,99$

$\bar{\gamma}=5,23-00013 x+0,00000033 X^{2} R^{2}=100 \%$

$\cdots \mathrm{Br}^{\circ}-501^{\circ}$

$\bar{\gamma}=8,40-0,0053 x+0,0000012 x^{2} \quad R^{2}=100 \%$

A-..- $\mathrm{Ar}-503^{\circ}$

$\bar{Y}=10,10-0,0024 X+0,00000053 X^{2} R^{2}=100 \%$

8-...-8 $\mathrm{Br}-602^{\circ}$

$\bar{\gamma}=10,28-0,00093 x$

Q-....

$r=-0.21$

$\bar{\gamma}=617-0,0021 x+0,00000036 x^{2} \cdot R^{2}=100 \%$

CLORO (DPM) NA SOL. NUTRITIVA

Figura 9 - Concentração de cālcio (\%) no colmo, nas folhas com sintomas leves e nas folhas com sintomas acentuados, em função dos niveis de cloreto na solução nutritiva. 
o aumento da salinidade. Efeito antagônico entre sódio e cálcio foi também observado por ELZAM (1970) em raízes de cevada.

Em cana-de-açücar, SYED e EL-SWATHY (1973) mostram que o NaCl diminuiu o toor de cálcio nas cultivares NCo-310 e H5-7209. Com esta cultura, WEBER (1983) afirma que o NaCl afetou a concentração de cálcio nas folhas predominantemente no sentido de diminuir sua concentração, em todas as cultivares estudadas.

Conforme OLIVEIRA (1983), os teores de cälcio nas plan tas de arroz aumentaram em função da salinidade; o mesmo foi observa do por HASSAN et aZii (1970a) em folhas e caule de milho. Entretanto em ambos os trabalhos a absorção de cālcio foi reduzida.

Em ültima anālise, o comportamento do cảlcio neste tra balho foi variável conforme a parte amostrada e cultivar.

\subsubsection{5 - Magnés io}

Os estudos realizados entre niveis de cloreto na solu ção e teores de magnésio no colmo e folhas, das diferentes cultivares, evidenciaram efeito de cultivar, no primeiro caso, e ainda efei to de nivel, sintoma e interações. O teste de Tukey a $5 \%$ revelou diferenças significativas nos teores de magnésio das partes amostradas em função dos niveis de cloreto, como pode ser constatado nas Tabelas 23 e 24 (Apēndice). Na Figura 10 tem-se a correlação entre estes fatores, sendo construída mediante a utilização das anälises de regressão polinomial de 19 e 20 graus. 
Examinando-se a Figura 10, observa-se que os teores de magnésio contidos no colmo da cultivar Br-501 sofreu redução em função dos níveis de cloreto, permanecendo inalterado estatisticamente, nos colmos das demais cultivares. Os mais altos teores de magnésio fo ram contidos na cultivar CMS-XS-616, dentro dos três níveis estudados (Tabela 23).

Analisando-se ainda a Figura 10 , se verifica que os teo res de magnésio nas folhas com sintomas leves foram reduzidos em fun ção dos níveis de cloreto, nas cultivares Ample-H-0-K, Br-501,Br-602 e IPA-7301218, ocorrendo o mesmo nas folhas com sintomas acentuados das duas primeiras cultivares. Aconteceu o inverso nas folhas comsin tomas leves da cultivar $\mathrm{Br}-602$ no nivel $2.000 \mathrm{ppm}$.

Os teores de magnēsio nas folhas com sintomas leves foram maiores quando comparados às folhas com sintomas acentuados, na cultivar Br-602 dentro do nivel 2.000 ppm, acontecendo o contrário nas cultivares Br-501 dentro desse mesmo nível, e IPA-7301218, dentro do nivel 4.000 ppm (Tabela 24).

GARCIA e MORARD (1976) relatam aumento dos teores de magnẻsio em função da salinidade provocada pelo cloreto de sódio, em sorgo.

WEBER (1983) obteve diferentes respostas com relação aos teores de magnésio nas folhas das diferentes cultivares de cana-de-açúcar, afetando positivamente a Na-5679 e negativamente a CP-5122 . 

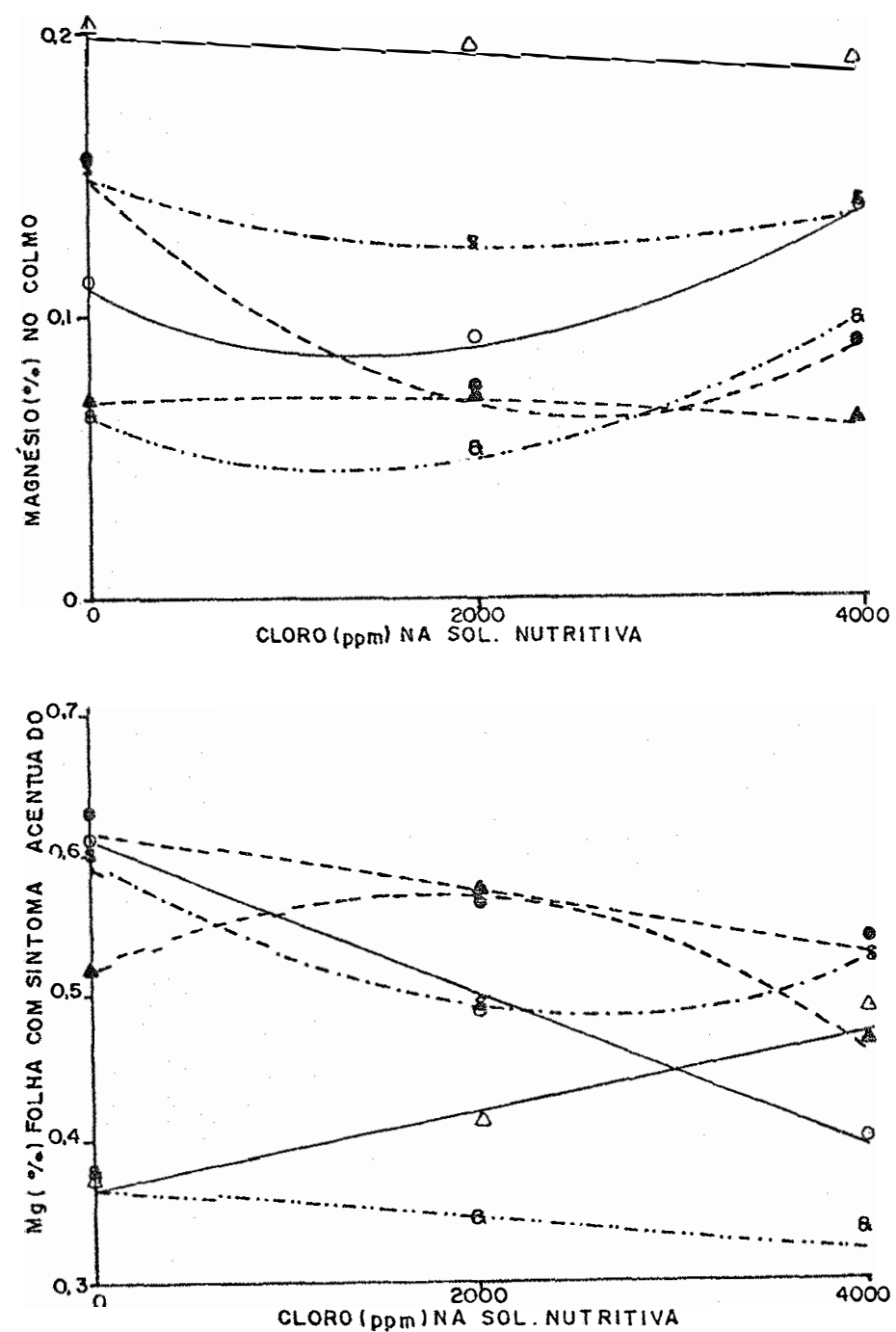

0 OAMPLE $H-0-K^{2}$
$\bar{\gamma}=107-0.00027 x+0.000000083 x^{2} \quad R^{2}=100 \%$ $\Delta \Delta D^{\circ}$ CMS - XS - $616^{\circ}$ $\bar{\gamma}=1,97-0,000033 x \quad r=-1,00$

-... Br - $50 i$ $\bar{Y}=1,47-0,00061 x+0,00000011 x^{2} \quad R^{2}=100 \%$

ABr - $503^{\circ}$ $\bar{Y}=0,67-0,000025 x+0000000012 x^{2} R^{2}=100 \%$ $8-\cdots 8^{\circ} \mathrm{Br}-602^{\circ}$ $\bar{Y}=1,43-0,00021 X+0,000000046 X^{2} k^{2}=100 \%$ Q.... IPA - $7301218^{\circ}$ $\bar{Y}=0.63-0.00024 X+0.000000079 X^{2} R^{2}=100 \%$

$\bigcirc$ OAMPLE $H-O-K^{\circ}$

$\bar{Y}=5,98-0,00053 X$

$r=-100$

$\triangle{ }^{\circ} \mathrm{CNS}-X S-616^{\circ}$

$\bar{Y}=3.57+0.00029 x$

$r=0,98$

- $\mathrm{Br}-501^{\circ}$

$\bar{Y}=6,12-0,00022 X$

$r=-0,95$

$\triangle-\Delta^{\circ} \mathrm{Br}-503^{\circ}$

$\bar{Y}=5.10+0.00063 X-0,00000019 X^{2} R^{2}=100 \%$

$8-\cdots 8^{\circ} \mathrm{Br}-602^{\circ}$

$\bar{Y}=5,83-0,00087 X+0,00000017 X^{2} R^{2}=100 \%$

a-. Q $\quad$ IPA $-7301218^{\circ}$
$\bar{Y}=3,59-0,000032$

$r=-0.94$

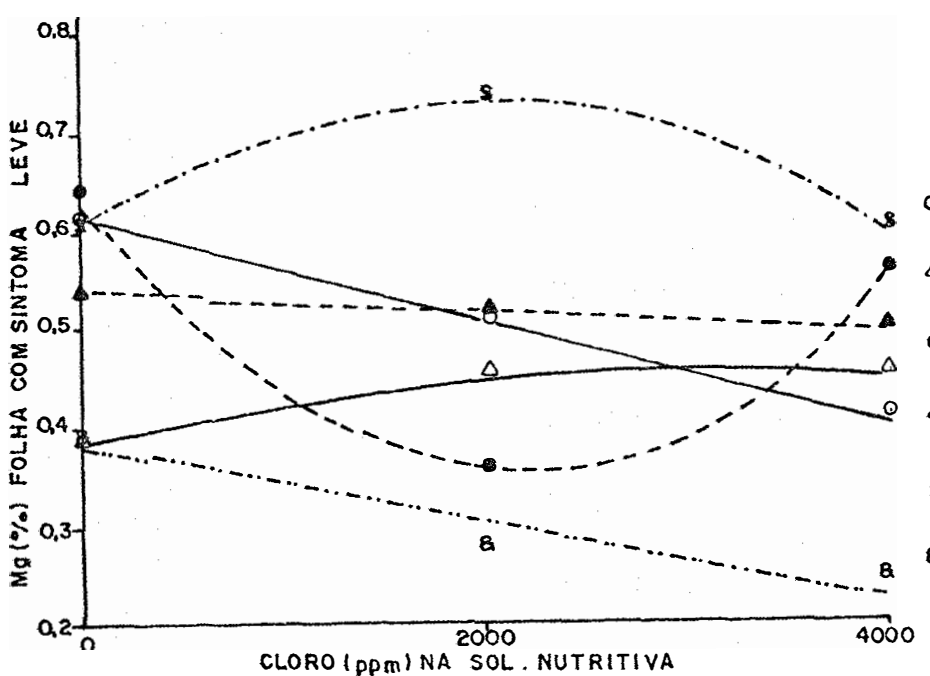

0 OAMPLE H-O-K'
$\bar{Y}=5,98-0,00050 X$

$r=-1,00$

$\triangle \longrightarrow \Delta^{\circ}$ CMS - XS - $616^{\circ}$

$\bar{Y}=3,73+0,00053 X-0,000000092 X^{2} R^{2}=100 \%$

- B $\mathrm{B}-501^{\circ}$

$\bar{Y}=6,30-0,0026 X+0,00000060 X^{2} R^{2}=100 \%$

A $8 \mathrm{Br}-503^{\circ}$

$\bar{Y}=5,23-0,000083 X \quad r=-1,00$

$8 \cdots-8^{\circ} B r-602^{\circ}$

$\bar{\gamma}=5,93+0.0013 x-0,00000033 x^{2} \quad R^{2}=100 \%$

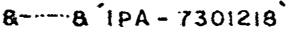

$\bar{Y}=3,62-0,00035 X$

$r=-0,94$

CLORO IPPMINA SOL. NUTRITIVA

Figura 10 - Concentração de magnésio (\%) no colmo, nas folhas com sin tomas leves e nas folhas com sintomas acentuados, em função dos niveis de cloreto na solução nutritiva. 


\subsubsection{6 - Enxofre}

Os teores de enxofre determinados no colmo e folhas das cultivares variaram estatisticamente conforme se verifica nas Ta belas 25 e 26 (Apêndice). Houve efeito de cultivar e nível para colmo e folhas, e interações cultivar $x$ nivel, cultivar $x$ sintomas, nive1 x sintomas, para folhas.

As correlações entre teores de enxofre no colmo e foThas encontram-se na Figura 11, construída mediante utilização das anālises de regressão polinomial de 19 e 2 ? graus.

Na Figura 11 percebe-se que os teores do elemento em questão no colmo da cultivar Br-501 sofreram reduções em função dos niveis de cloreto na solução, tendo isto ocorrido de forma quadrática. Na cultivar Br-602 isto ocorreu com relação ao nivel 2.000 ppm. Dentro dos níveis 0 e 2.000 ppm os teores dé enxofre variaram estatisticamente entre as cultivares, enquanto no níve1 $4.000 \mathrm{ppm}$ isto não aconteceu (Tabela 25).

Nas folhas com sintomas leves, nota-se que os teores de enxofre foram reduzidos em função dos niveis de cloreto, de todas as cultivares, enquanto nas folhas com sintomas acentuados isto se verificou apenas nas cultivares Ample-H-0-K, Br-503 e Br-602, confor me se constata na Figura 11. Folhas com sintomas leves contiveram es tatisticamente menores teores do que folhas com sintomas acentuados na cultivar IPA-7301218, enquanto nas outras cultivares is to não foi significativo (Tabela 26). 

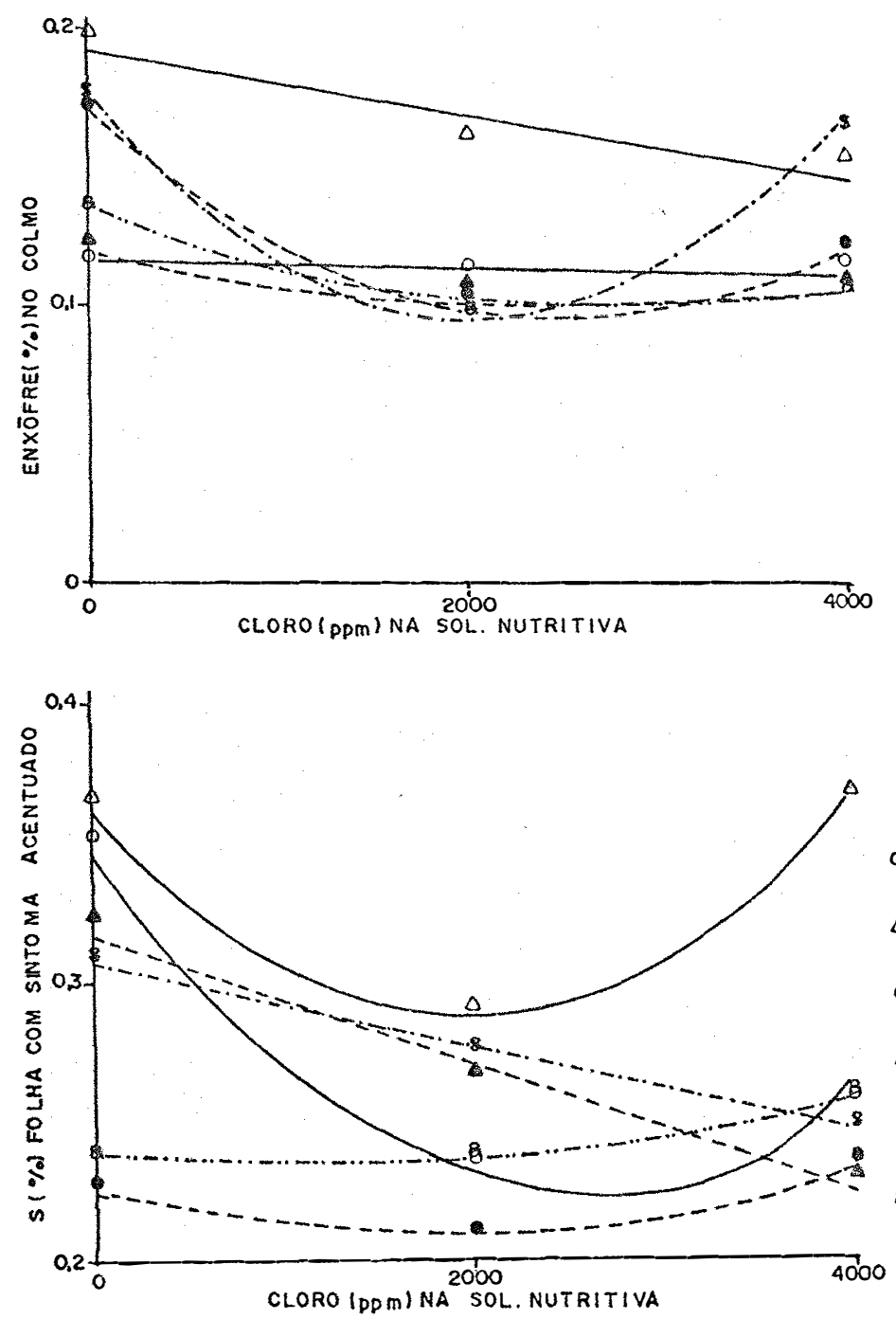

$\sim$ AMPLE $H-O-K$
$\bar{Y}=L, 13-0,000025 X+0,0000000042 X^{2} R^{2}=100 \%$

$\triangle \triangle \dot{C} M S-X S-616^{\circ}$ $\bar{\gamma}=1,89-0,00012 x$ $r=-0,95$

- $\mathrm{Br}-501^{\circ}$

$\hat{\gamma}=1,67-0,00057 x+0,00000011 x^{2} \quad R^{2}=100 \%$

1- Br - $503^{\circ}$

$\bar{Y}=120-0,00015 X+0,000000 \cdot 25 X^{2} R^{2}=100 \%$

s-.. s $^{\circ}-602^{\circ}$

$\bar{Y}=1,73-0,00077 X+0,00000018 x^{2} R^{2}=100 \%$

Q- $Z^{\circ}$ IPA-7301218

$\dot{\gamma}=1,33-0,00026 x+0000000050 x^{2} R^{2}=100 \%$

O O 'AMPLE $H-O-K^{\circ}$

$\bar{Y}=3,47-0,00093 x+0,00000017 X^{2} \quad R^{2}=100 \%$

$\triangle \triangle$ CMS - X.S - $616^{\circ}$

$\bar{Y}=3,63-0,00077 x+0,00000019 x^{2} R^{2}=100 \%$

C. Br $-501^{\circ}$

$\bar{\gamma}=2,23-0,00018 x+0,000000050 x^{2} R^{2}=100 \%$

$\triangle \mathrm{Br}-503^{\circ}$

$\bar{\gamma}=3,17-0,00023 x$

$r=-0,99$

$8-\cdots 8^{\circ} B r-602^{\circ}$

$\bar{Y}=3,06-0,00016 \mathrm{X}$

8-..... $8^{\circ} 1 P A-7301210^{\circ}$

$r=-1,00$

$\bar{Y}=2.37-0,000075 x+0,000000029 X^{2} R^{2}=100 \%$

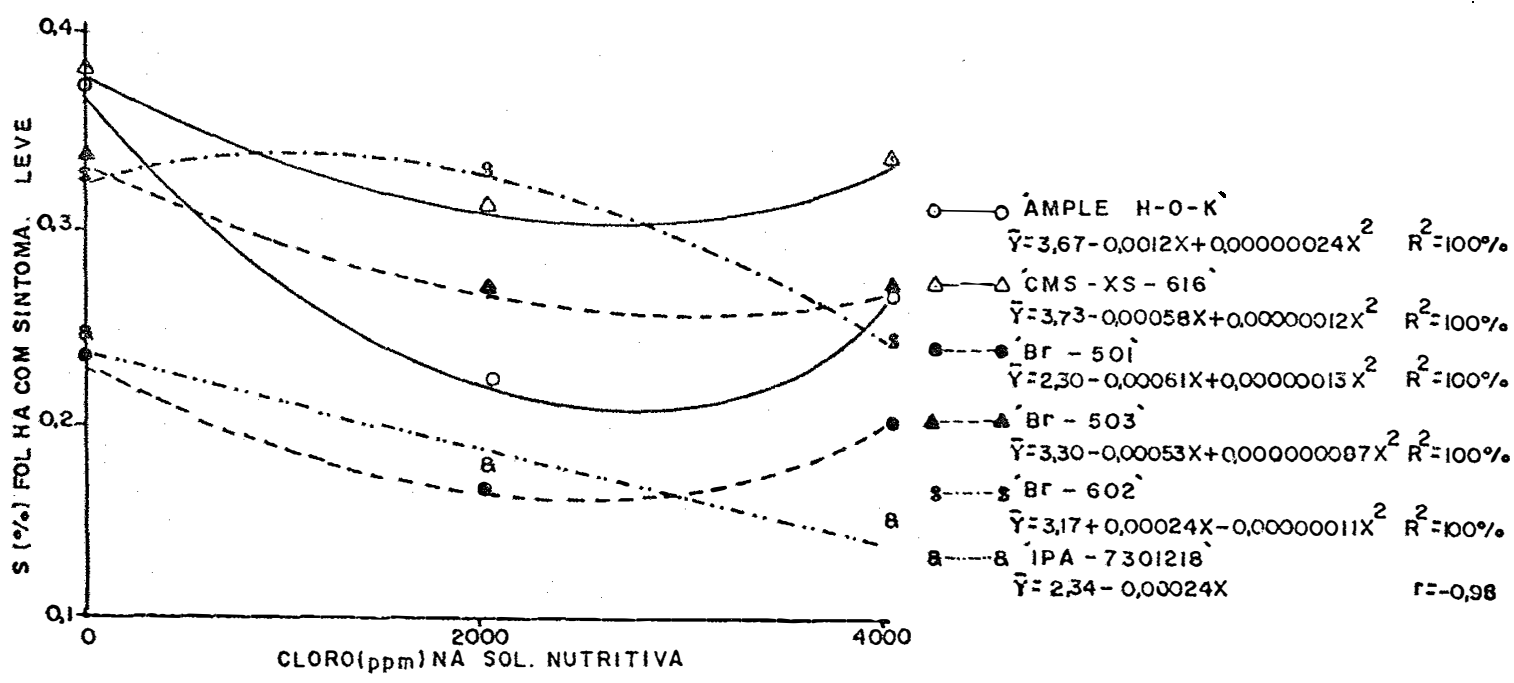

Figura 11 - Concentração de enxofre (\%) no colmo, nas folhas com sintomas leves e nas folhas com sintomas acentuados, em função dos níveis de cloreto na solução nutritiva. 
GARCIA e MORARD (1976) constataram aumento no teor de enxofre de plantas de sorgo quando em presença de 36 e 72 meq/1 de NaC1. WEBER (1983), trabalhando com cana-de-açūcar, verificou efeito diferenciado entre as cultivares, na presença de NaCl. Nas folhas das cultivares NA-5679 e CP-51-22 ocorreu redução nos teores de enxofre, enquanto nas cultivares RB-70194 e RB-725828 houve acréscimo até 67 ppm de $\mathrm{Na}$, acima do qual houve efeito inverso. Na cultivar CB-45-3 houve efeito depressivo até 53,2 ppm de Na. SYED e EL-SWAIGY (1973) observaram que o NaCl reduziu os teores de $\mathrm{S}$ nas folhas da cana-de-açücar, sugerindo um possivel antagonismo entre $\mathrm{Cl}^{-}$e $\mathrm{SO}_{4}^{-2}$. Isto tem sido comentado também por MALAVOLTA (1980).

\subsubsection{7 - Boro}

Encontram-se nas Tabelas 27 e 28 (Apêndice) os resultạ dos médios obtidos para teores de boro no colmo e folhas, respectivamente. A anālise de variância determinou efeito de cultivar, nivel e interação, para colmo e folhas. O teste de Tukey a 5\% permitiu eviden ciar mudanças significativas nos teores desse elemento em função dos niveis de cloreto na solução.

Na Figura 12 tem-se as correlações entre teores de boro do colmo e folhas em função dos níveis de cloreto na solução nutri tiva, construída utilizando-se anālise de regressão polinomial do 19 e 2 graus. 


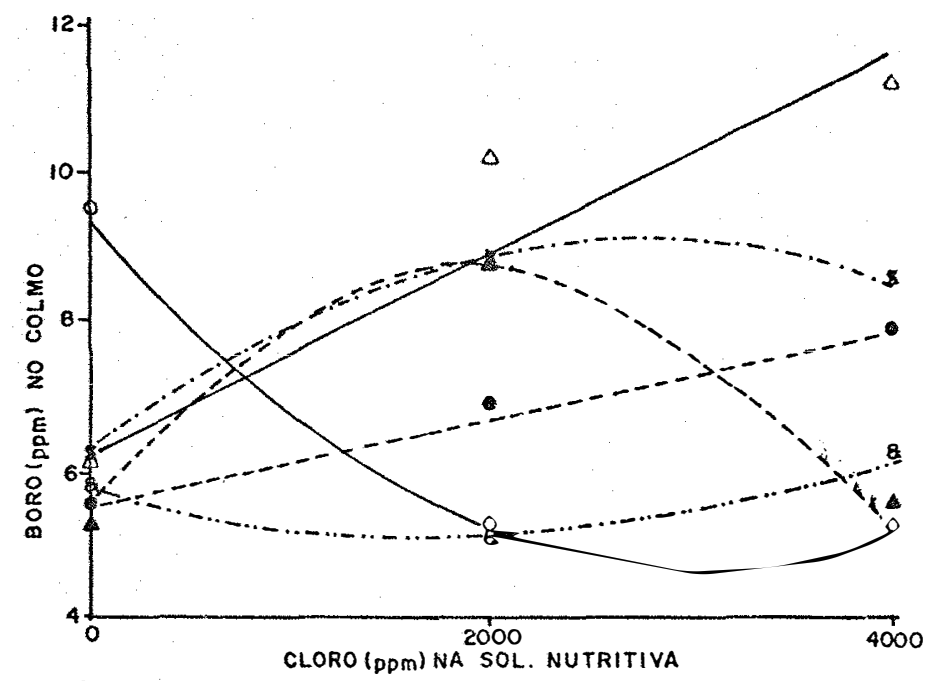

65.

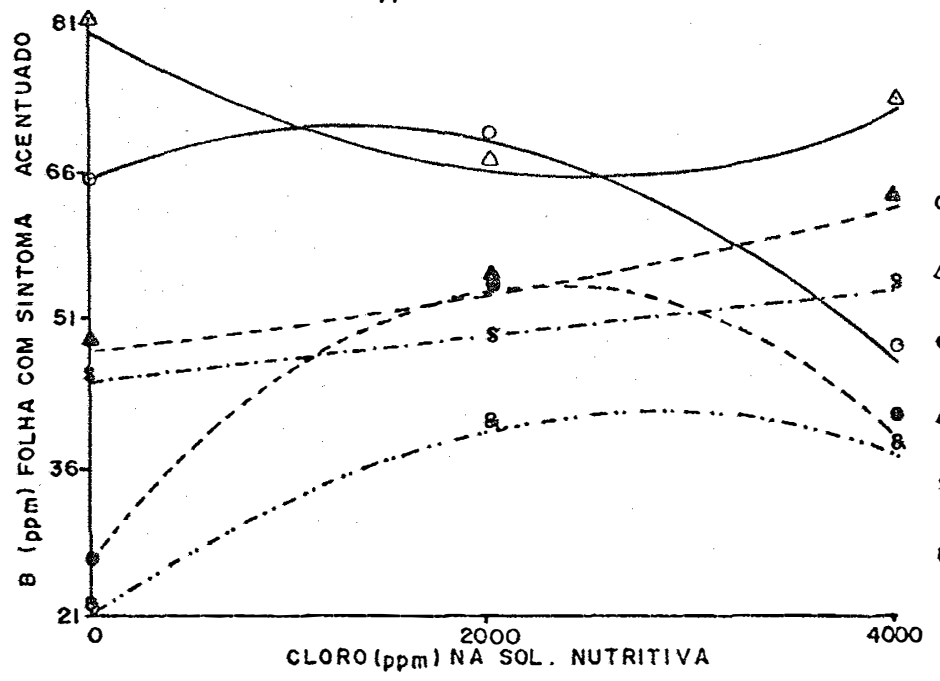

$\longrightarrow$ AMP PLE H-O-K
$\hat{\hat{\gamma}}=9,33-0,0032 X+0,00000054 X^{2} \quad R^{2}=100 \%$

$\triangle \triangle \Delta^{\circ} M S-X S-616^{\circ}$

$\bar{Y}=5,94+0,0014 x \quad r=0,94$

- B B $-501^{\circ}$

$\bar{Y}=5,11+0,00067 X \quad r=0,99$

$\Delta--1 B r-503^{\circ}$

$\bar{Y}=5,00+0,0036 x-0,00000087 x^{2} \quad R^{2}=100 \%$

8- - - 8 B $\mathrm{Br}-602^{\circ}$

$\bar{Y}=600+0,0021 X-0,00000037 x^{2} \quad K^{2}=100 \%$

8..... 8 IPA $-7301218^{\circ}$

$\bar{\gamma}=5,67-0,00075 x+0,00000021 x^{2} R^{2}=100 \%$

0 O AMPLE $H-O-K^{\circ}$

$\bar{\gamma}=64,00+0,0087 x-0,0000033 K^{2} \quad k^{2}=100 \%$

$\triangle D_{\bar{Y}} C M S-X S-616^{\circ}$
${ }^{\circ}=80,00-0,012 X+0,0000026 X^{2} \quad R^{2}=100 \%$

- o Br - $50 i^{\circ}$

$\bar{y}=25,33+0,023 x-0,0000049 x^{2} \quad R^{2}=100 \%$

$\quad B r-503^{\circ}$
$\bar{Y}=47,33+0,0023 x+0,00000033 X^{2} \quad R^{2}=100 \%$

$8--8^{\circ} \mathrm{Br}-602^{\circ}$

$\bar{Y}=43,44+0,0023 x \quad r=1,00$

Q-..... Q $Q^{\circ} I P A-7301218^{\circ}$

$\bar{\gamma}=21,00+0.014 x-0,0000026 X^{2} \quad R^{2}=100 \%$

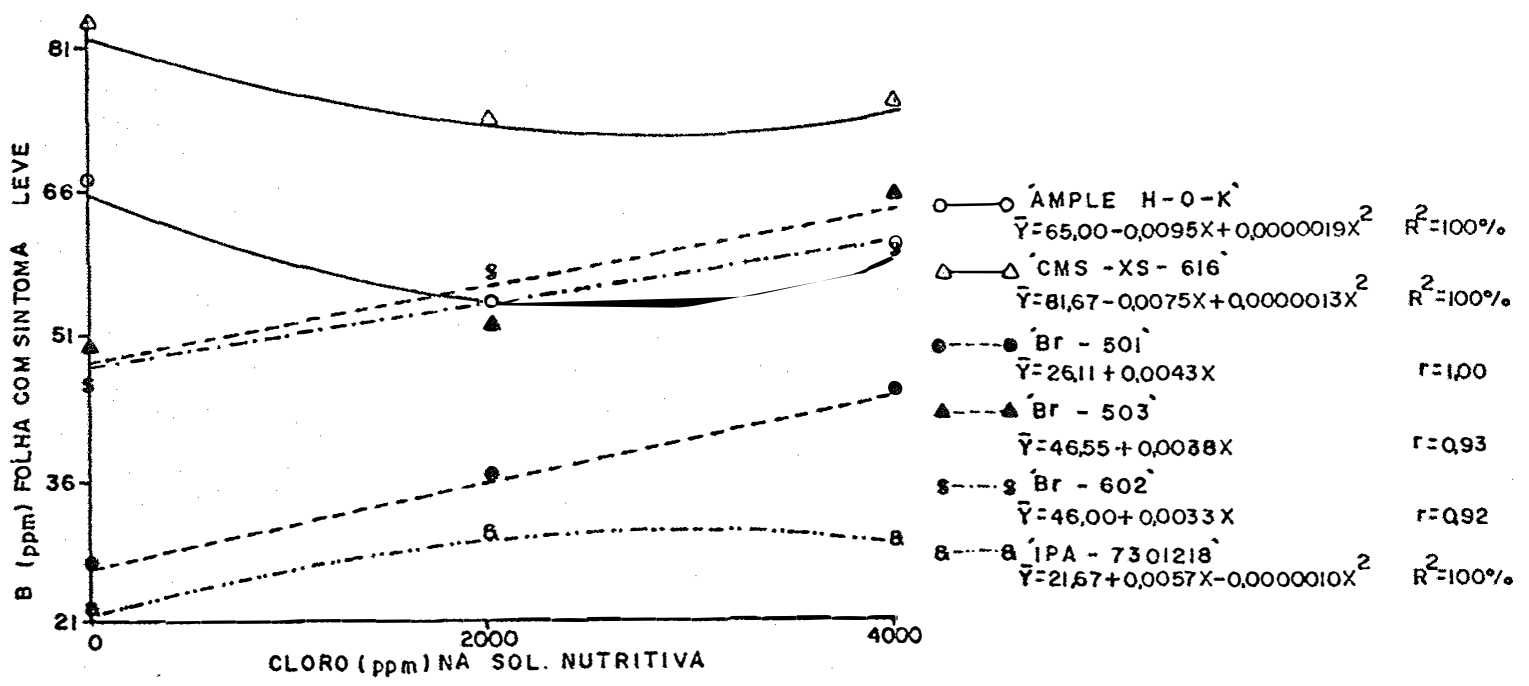

Figura 12 - Concentração de boro (ppm) no colmo, nas folhas com sintomas leves e nas folhas com sintomas acentuados, em fun ção dos niveis de cloreto na solução nutritiva. 
Houve redução nos teores de boro do colmo da AmpleH-O-K devida à adição de cloreto, ocorrendo o inverso nas cultivares CMS-XS-616 e Br-501, conforme se verifica na Figura 12.

Examinando-se ainda esta Figura, nota-se que nas foThas com sintomas leves houve aumento dos teores de boro em função dos niveis de cloreto, nas cultivares $\mathrm{Br}-501$ e $\mathrm{Br}-503$. Isto foi verdadeiro ainda para folhas com sintomas acentuados da primeira cultivar e IPA-7301218. Folhas com sintomas acentuados contiveram signifi cativamente maiores teores de boro do que folhas com sintomas leves, nas cultivares Ample-H-O-K e Br-501 dentro do nivel 2.000 ppm (Tabela 28).

A salinidade inibe a absorção de nutrientes pela plan ta, todavia, o mecanismo deste efeito não é totalmente esclarecido (HELAL, 1980; BERNSTEIN e HAYWARD, 1958).

WEBER (1983) afirma que o NaCl aumentou a concentração de boro nas folhas de diferentes cultivares de cana-de-açücar.

\subsubsection{8 - Cobre}

Os teores de cobre no colmo e folhas encontram-se, res pectivamente, nas Tabelas 29 e 30 (Apēndice). Houve efeito de cultivar e interação cultivar $x$ dose para colmo, enquanto para folhas, além desses, houve efeito ainda devido a sintomas e interação nivel $x$ sintomas.

Na Figura 13 tem-se as correlações entre os teores de cobre de colmo e folhas, das diferentes cultivares em função dos niveis de cloreto. 

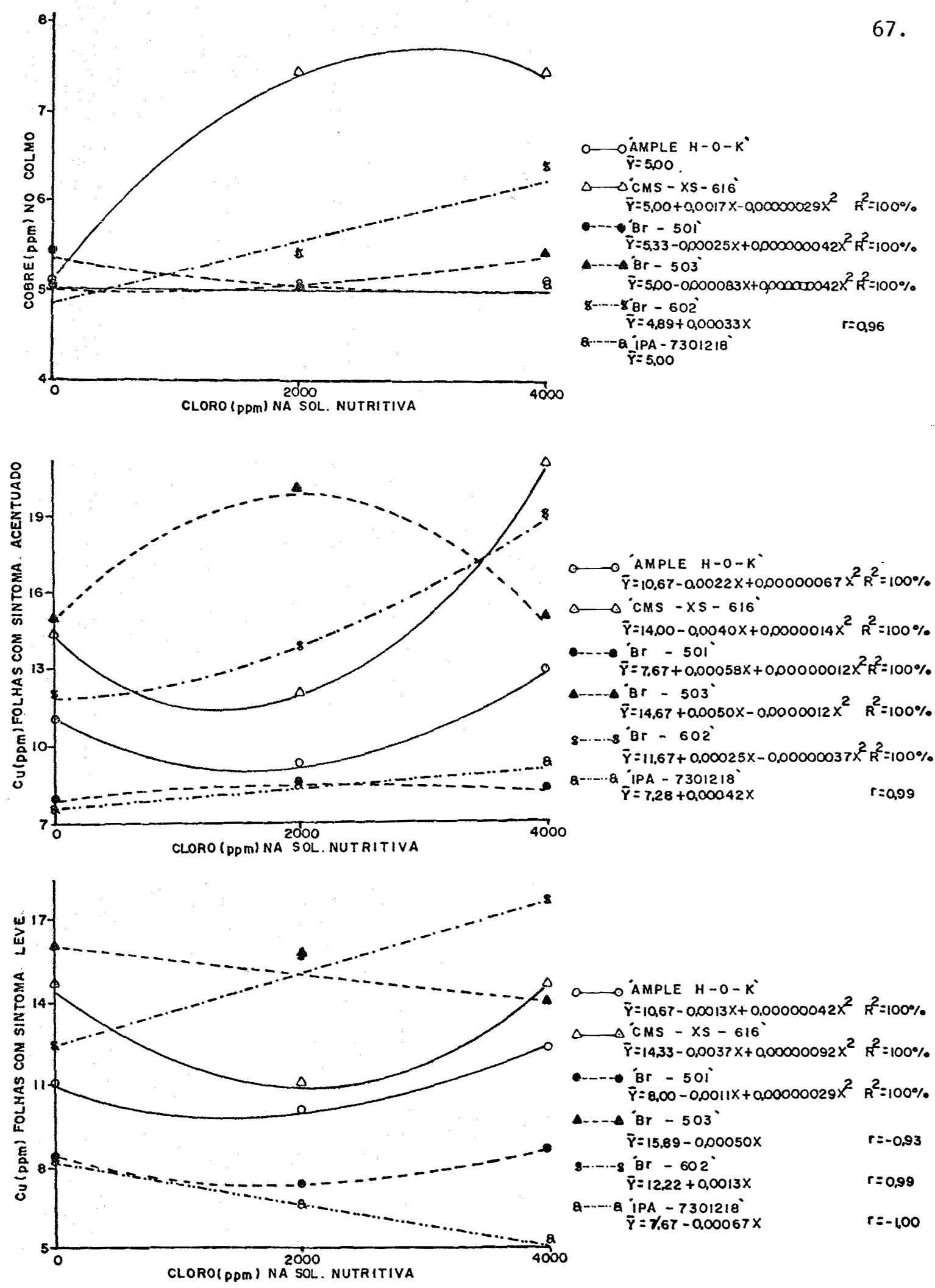

Figura 13 - Concentração de cobre (ppm) no colmo, nas folhas com sin tomas leves e nas folhas com sintomas acentuados, em fun ção dos niveis de cloreto na solução nutritiva. 
A Figura 13, referente à concentração de cobre no coll mo, mostra a ocorrência de aumento nos teores desse elemento em função dos niveis de cloreto nas cultivares CMS-XS-616 e Br-602. Houve variação nos teores entre as cultivares apenas dentro dos niveis 2.000 e $4.000 \mathrm{ppm}$ (Tabela 29).

Nas folhas com sintomas leves não houve variação estạ tística dos teores de cobre em função dos níveis, excetuando-se a cul tivar Br-602, na qual ocorreu aumento em função dos niveis de cloreto (Figura 13), o que foi verdadeiro também nas folhas com sintomas acentuados desta cultivar e das cultivares Ample H-0-K e CMS-XS-616. Folhas com sintomas acentuados da cultivar $\mathrm{Br}-503$ contiveram maiores teores de cobre quando comparadas com folhas com sintomas leves, den tro do nivel $2.000 \mathrm{ppm}$. Isto se verificou também para as cultivares CMS-XS-616 e IPA-7301218 dentro do nível 4.000 ppm (Tabela 30).

HASSAN et alii (1970b) constatou redução na absorção de cobre em plantas de milho cultivado sob condições salinas, embora a concentração deste elemento nas diferentes partes da planta tenha aumentado em função da salinidade.

\subsubsection{9 - Ferro}

A adição de $\mathrm{NaCl}$ na solução nutritiva ocasionou mu danças estatisticamente significativas sobre a concentração de ferro do colmo e folhas, conforme se verifica nas Tabelas 31 e 32 , respectivamente, através do teste de Tukey a 5\%. Houve efeito de cultivar, 


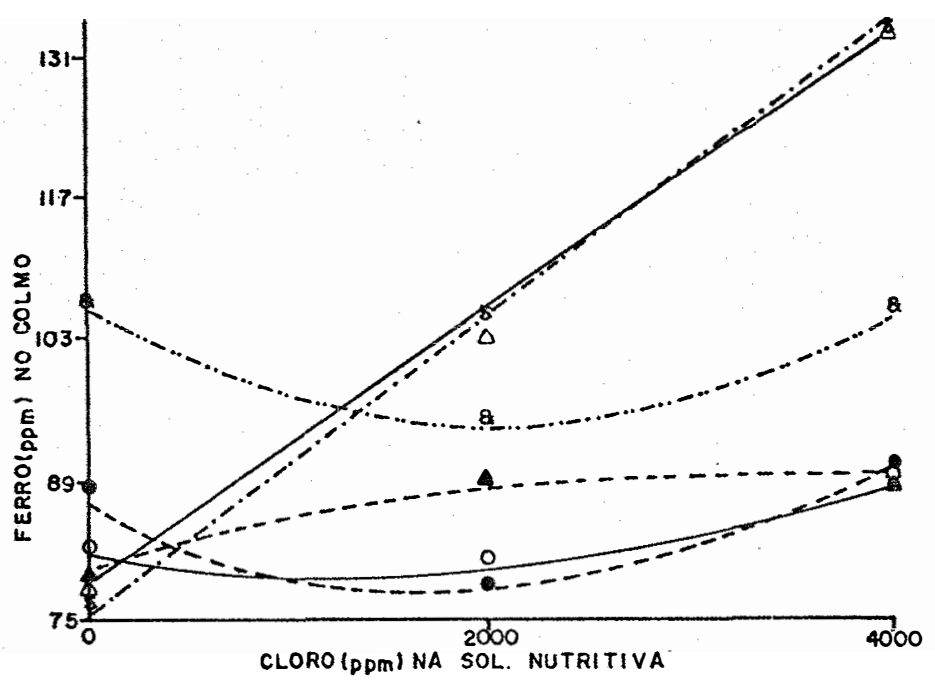

69.

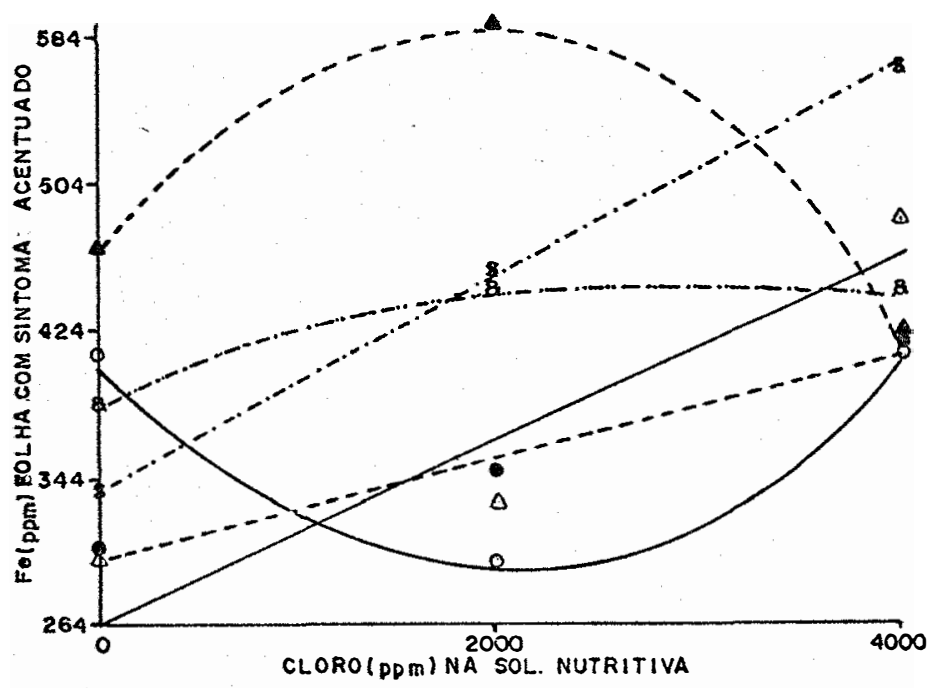

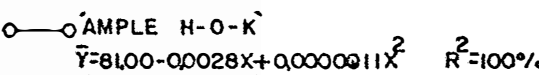

$\triangle \triangle \mathrm{CMS}-\mathrm{XS}-616^{\circ}$

$\bar{Y}=78,44+0,013 x$

$r=0,99$

- $\operatorname{Br}-500^{\circ}$

$\bar{Y}=86,67-0,0098 x+0,0000026 x^{2} \quad k^{2}=100 \%$

$48 r-503^{\circ}$

$\bar{\gamma}=78,33+0.0066 x-0,0000010 x^{2} \quad R^{2}=100 \%$

$8-8^{\circ} B r-602^{\circ}$

$\bar{Y}=75,05+0,014 X \quad r=1,00$

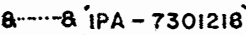

$\bar{\gamma}=105,33-0.011 x+0,0000028 x^{2} \quad R^{2}=100 \%$

0 OAMPLE $H-O-K^{\circ}$
$\bar{Y}=398,66-0.11 X+0,000027 X^{2} \quad R^{2}=100 \%$

$\triangle \triangle^{\circ} \mathrm{CMS}-X S-616^{\circ}$

$\bar{\gamma}=264,05+0,048 X \quad r=0,94$

-..- Br - $501^{\circ}$

$\bar{Y}=291,61+0,029 x$

$r=0,99$

Br $-503^{\circ}$
$\bar{y}=45500+0,14 X-0,000037 X^{2} \quad R^{2}=100 \%$

$8 \cdots-8 \mathrm{Br}-602^{\circ}$

$\bar{\gamma}=332,38+0,056 x \quad r=100$

8-.... $1 P A-7301218^{\circ}$
$\bar{Y}=375,00+0,052 x-0,0000092 x^{2} R^{2}=100 \%$

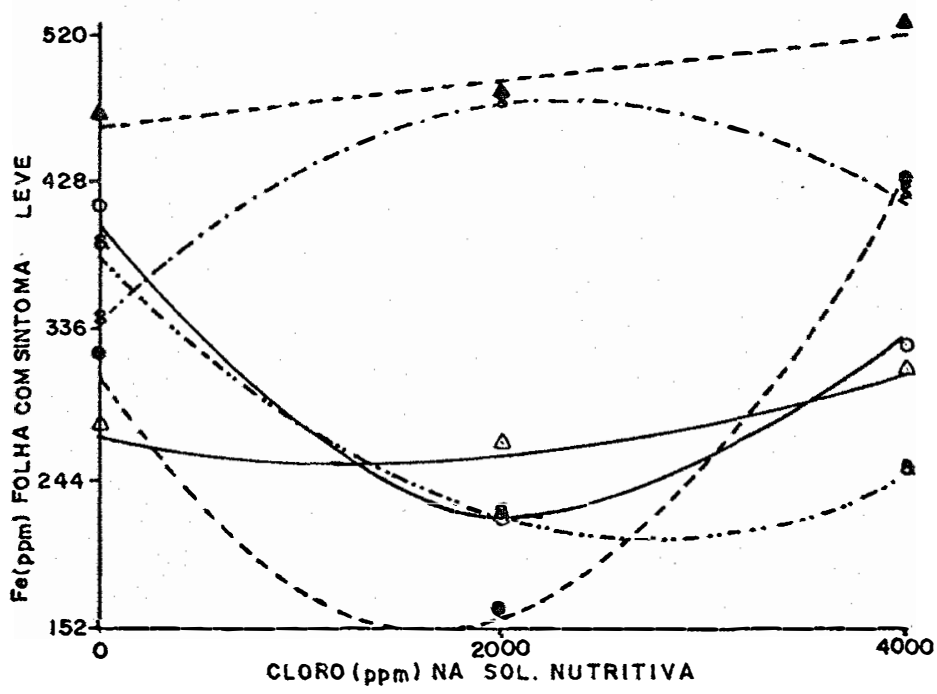

$O$ A AMPLE $H-O-K^{\circ}$

$\bar{\gamma}=400,66-0,17 x+0,000036 x^{2} \quad R^{2}=100 \%$

$\triangle \triangle^{\circ} C M S-X S-616^{\circ}$

$\bar{Y}=279,33-0.028 x+0,0000085 X^{2} R^{2}=100 \%$

$\bullet-{ }^{\circ} \mathrm{Br}-501^{\circ}$

$\bar{\gamma}=311,00-0,18 x+0,000053 x^{2} \quad R^{2}=100 \%$

a $\mathrm{Br}-503^{\circ}$

$\bar{\gamma}=454.72+Q 015 x$

$r=0,97$

$8 \cdots-8^{\circ} B r-602^{\circ}$

$\bar{\gamma}=334,33+0,12 X-0,000025 X^{2} \quad R^{2}=100 \%$

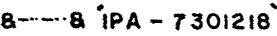

$\bar{\gamma}=380,66-0.13 x+0,000023 x^{2} \quad R^{2}=100 \%$

Figura 14 - Concentração de ferro (ppm) no colmo, nas folhas com sin tomas leves e nas folhas com sintomas acentuados, em fun ção dos niveis de cloreto na solução nutritiva. 
nive1, e interação para colmo e folhas e, ainda, devido a sintomas e interações cultivar $\mathrm{x}$ sintomas, nivel $\mathrm{x}$ sintomas para folhas.

Em razão das significāncias encontradas mediante a uti 1ização das anālises de regressão polinomial de 1؟̆ e 2 ̣ graus, foi obtida a Figura 14 .

Na Figura 14, onde se correlacionaram teores de ferro no colmo com niveis de cloreto, verificou-se efeito favorável do clo reto sobre o ferro, nas cultivares CMS-XS-616 e Br-602.

Dentro do nivel zero, apenas a cultivar Br-503 diferiu das demais, mostrando os menores teores desse elemento. Por sua vez, dentro do nive1 $2.000 \mathrm{ppm}$, as cultivares contiveram teores seme 1hantes estatisticamente (Tabela 31 ). Dentro do nive1 $4.000 \mathrm{ppm}$, as cultivares Br-503, CMS-XS-616 e IPA-7301218 contiveram os mais altos teores de ferro no colmo, sendo semelhantes estatisticamente (Tabela 31).

Nas folhas com sintomas leves (Figura 14), nota-se que na cultivar IPA-7301218, Ample-H-0-K e Br-501 houve efeito depressivo do cloreto, sendo que nestas duas ültimas cultivares isto foi ver dadeiro apenas no nivel $2.000 \mathrm{ppm}$. Houve efeito favorável nas cultivares $\mathrm{Br}-602(2.000$ e $4.000 \mathrm{ppm})$ e $\mathrm{Br}-501$ (4.000 ppm). Nas folhas com sintomas acentuados houve aumento nos teores de ferro nas cultivares CMS-XS-616 e Br-501, no nive1 4.000 ppm, e Br-503, no nive1 2.000 ppm; na IPA-7301218 isto se verificou em ambos os niveis. O efeito foi in verso na Ample-H-0-K no nivel 2.000 ppm (Figura 14). 
Comparando-se os dois tipos de folhas de uma mesma cul tivar, aquelas com sintomas acentuados contiveram teores mais elevados de ferro, nas cultivares Ample-H-0-K, CMS-XS-616 e Br-602 no nive1 4.000 ppm e culitivares $\mathrm{Br}-501$ e $\mathrm{Br}-503$, no nive1 2.000 ppm, na IPA-7301218 isto ocurreu em ambos os níveis (Tabela 32).

WEBER (1983), trabalhando com cana-de-açúcar, constạ tou que os niveis de $\mathrm{NaCl}$ fornecidos ao substrato afetaram apenas as cultivares RB-70194 e RB-725828 das cinco cultivares utilizadas. Segundo este autor, atē 63,5 ppm de $\mathrm{Na}$ a concentração de Fe nas folhas foi aumentada, e acima da mesma ocorreu efeito depressivo.

HASSAN et alii (1970a), trabalhando com cevada, concluiram que os sais $\mathrm{Na}_{2} \mathrm{SO}_{4}, \mathrm{MgSO}_{4}$ e $\mathrm{CaCl}_{2}$ no solo provocando $\mathrm{CE}$ de $16 \mathrm{mmhos} / \mathrm{cm}$ causaram aumento na concentração de ferro, embora tenha havido redução na absorção.

Em sorgo granífero, HEILMAN (1974) observou que o $\mathrm{NaCl}$ provocou aumento na concentração de ferro em plantas de sorgo, com o aumento de salinidade, embora a absorção total tenha se reduzi do em função da" redução no crescimento.

\subsubsection{0 - Manganês}

Os teores de manganēs contidos no colmo e folhas encontram-se, respectivamente, nas Tabelas 33 e 34 (Apêndice), onde atravēs do teste de Tukey a $5 \%$ constatam-se mudanças significativas nos teores desse elemento, em ambas as partes amostradas, devido à 
adição de cloreto. Houve efeito de nivel, cultivar e interação para folha, enquanto para colmo houve efeito de cultivar e interação nível $\mathrm{x}$ cultivar.

As correlações entre teores desse slemento no colmo e folhas com sintomas leves ou acentuados encontram-se na Figura 15, sendo construída mediante utilização de análise de regressão polinomial de 19 e 29 graus.

Os teores de manganês no colmo da CMS-XS-616 sofreram redução de forma quadrática em função dos niveis de cloreto, enquanto na Br-602 isto se verificou inversamente, de forma linear (Figura 15), permanecendo inalterado estatisticamente nas demais cultivares (Tabela 33).

Nas folhas com sintomas leves (Figura 15) verifica-se um aumento no teor de manganēs das cultivares Br-503 (quadraticamente) e Br-602 (linearmente), em função do cloreto; o mesmo aconteceu nas folhas com sintomas acentuados da primeira cultivar, enquanto nes ta ültima isto foi verdadeiro apenas no nivel 4.000 ppm. Aliās, neste nivel, as cultivares CMS-XS-616 e Br-501 também mostraram acrésci mos .

Folhas com sintomas leves da CMS-XS-616 contiveram me nores teores de Mn do que folhas com sintomas acentuados, no nivel $4.000 \mathrm{ppm}$, ocorrendo o inverso com a Br-602 (Tabela 34).

Em folhas de cana-de-açúcar, WEBER (1983) observou que o NaCl provocou elevação na concentração de manganês, nas folhas das 


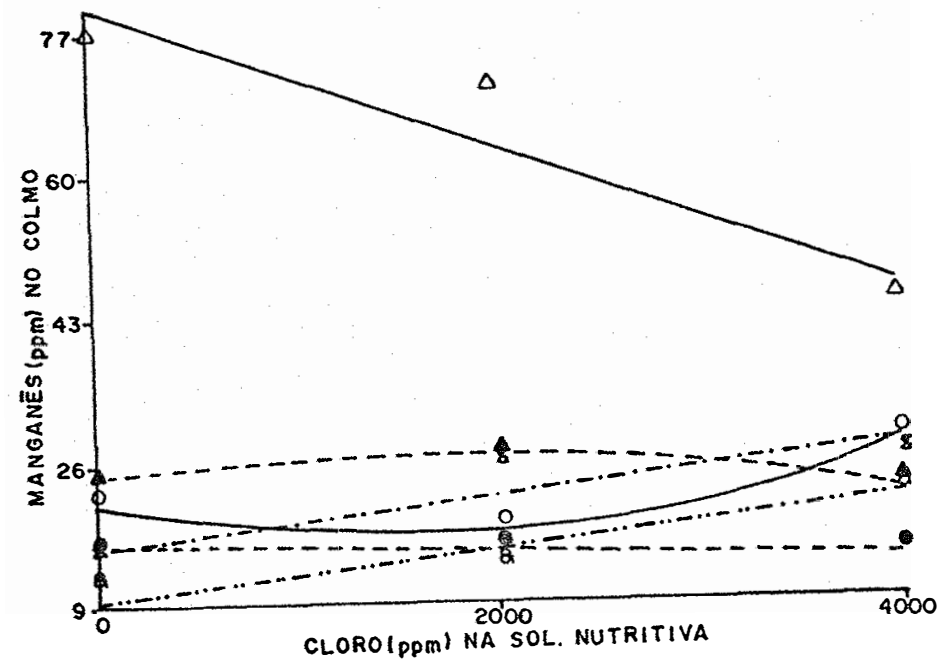

73.
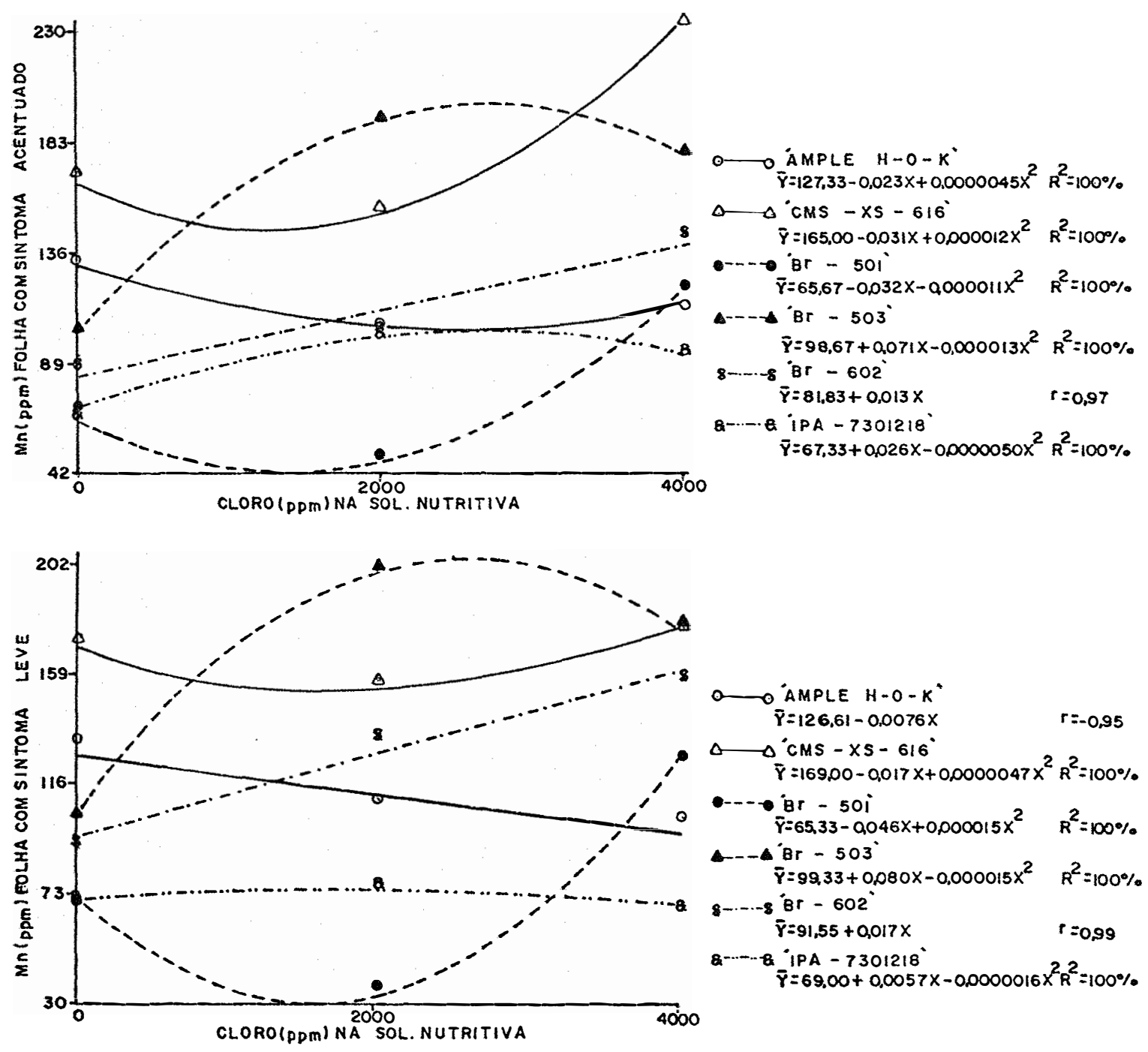

Figura 15 - Concentração de manganês (ppm) no colmo, nas folhas com sintomas leves e nas folhas com sintomas acentuados, em função dos niveis de cloreto na solução nutritiva. 
diferentes cultivares; em milho, HASSAN et alii (1970b) verificaram reduções na absorção desse elemento, no caule e folhas, quando estas plantas foram cultivadas sob concentração de $16 \mathrm{mmhos} / \mathrm{cm}$, induzida por $\mathrm{Na}_{2} \mathrm{SO}_{4}$ e $\mathrm{CaCl}_{2}$.

\subsubsection{1- Zinco}

Na Tabela 35 encontram-se os teores de zinco contidos no colmo das cultivares em função da adição de cloreto de sódio.

O fornecimento de cloreto de sódio na solução nutriti va ocasionou mudanças estatisticamente significativas sobre os teores de zinco das folhas das cultivares, conforme se observa na Tabe1a 36 (Apêndice). Houve efeito de cultivar, nivel e interações culti $\operatorname{var} x$ nivel, cultivar $x$ sintomas. Com relação ao colmo houve efeito apenas de cultivar.

As correlações entre teores de zinco no colmo e foThas e niveis de cloreto encontram-se na Figura 16, construida com auxílio da análise de regressão polinomial do 19 e 2 g graus.

Analisando-se a Tabela 35 percebe-se que as variações nos teores de zinco do colmo das cultivares não sofreu alteração estatística, em função dos níveis de cloreto, com exceção da cultivar Br-501, no nível 2.000 ppm, a qual mostra redução no teor desse elemento.

$\mathrm{Na}$ Figura 16 constata-se que os teores de zinco nas folhas com sintomas leves aumentaram em função do cloreto nas cul 


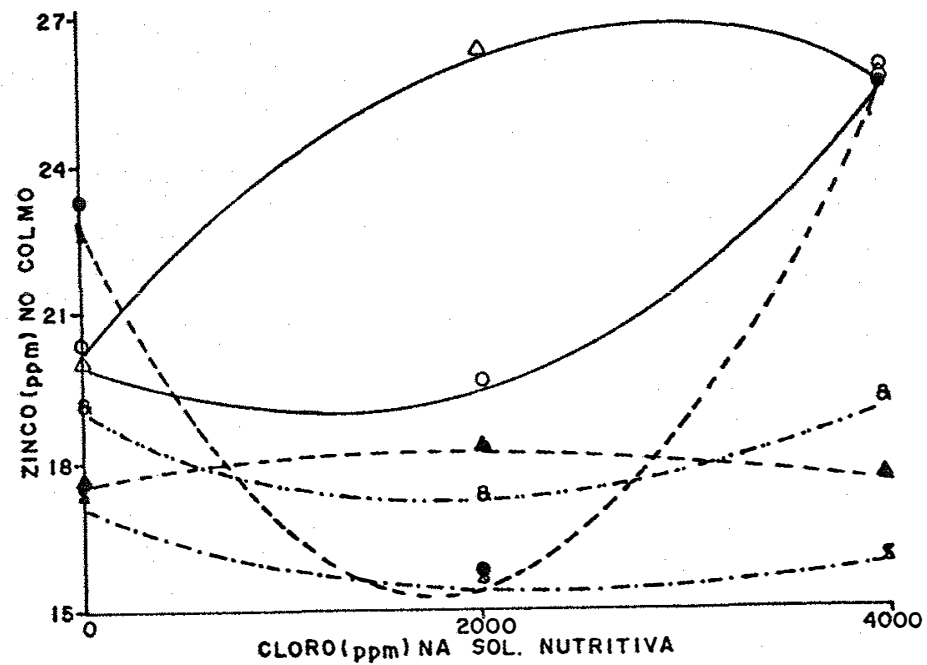

OAMPLE $H-0-K^{*}$
$\bar{Y}=2000-0.0021 X+0,00000087 X^{2} \quad \hat{f}^{2}=100 \%$ $\triangle \triangle \triangle^{\circ} M S-X S-616^{\circ}$

$\bar{Y}=19,67+0,0048 x-0,00000083 x^{2} \quad \hat{R}^{2}=100 \%$

- o Br - $501^{\circ}$

$\bar{\gamma}=2300-0.0082 x+0.0000022 x^{2} \quad R^{2}=100 \%$

$\quad B r-503$
$\bar{Y}=7,33+0,00067 x-0,00000017 X^{2} R^{2}=100 \%$

$8-8^{\circ} B r-602^{\circ}$

$\bar{Y}=17,00-0,0013 x+0,00000025 x^{2} R^{2}=100 \%$

B. - $-8 i P A-7301218^{\circ}$
$\hat{\gamma}=1200-0,0020 X+0,00000050 X^{2}{ }^{2}=100 \%$

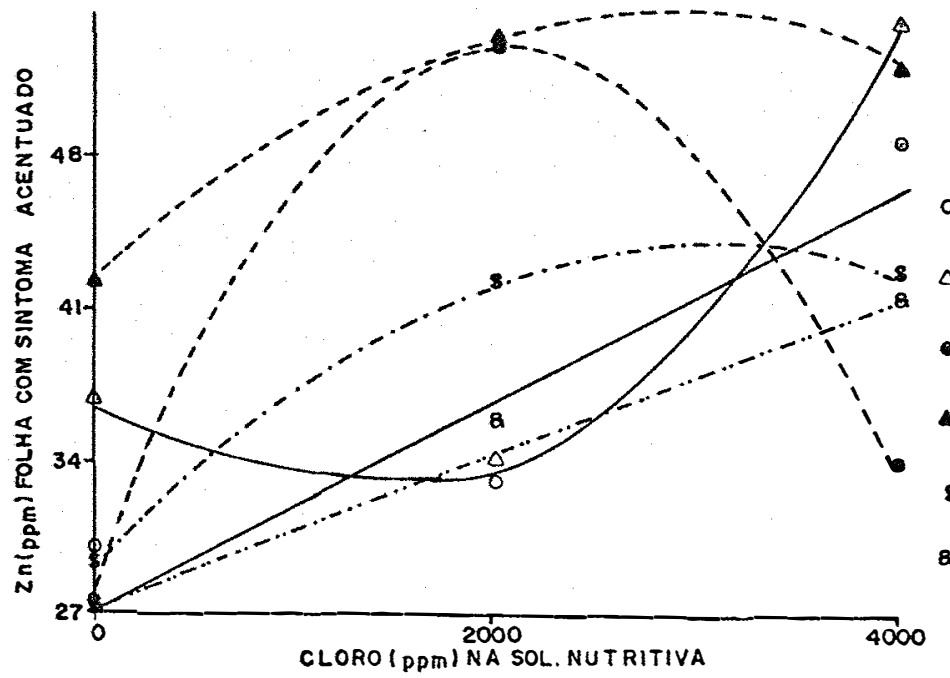

○ $\bigcirc$ AM PLE $H-0-K^{\circ}$

$\bar{\gamma}=27.22+0.0047 x$

$r=0,93$

$\triangle \triangle \Delta^{\prime} C M S-X S-616^{\circ}$

$\bar{\gamma}=36,00-0,0070 x+0,0000028 x^{2} R^{2}=100 \%$

- $-1 \mathrm{Br}-501^{\circ}$

$\bar{y}=27,00+0.024 x-0,0000055 x^{2} R^{2}=100 \%$

$\triangle-1 \mathrm{Br}-503^{\circ}$

$\bar{Y}=41,33+0,0088 X-0,0000016 X^{2} R^{2}=100 \%$

$8-\cdots-8$ "Br $-602^{\circ}$

$\bar{\gamma}=28,67+0.0097 X-0.0000016 X^{2} R^{2}=100 \%$

8--..-8 IPA - $7301218^{\circ}$

$\bar{\gamma}=27,44+0.0035 x$

$r=0,99$

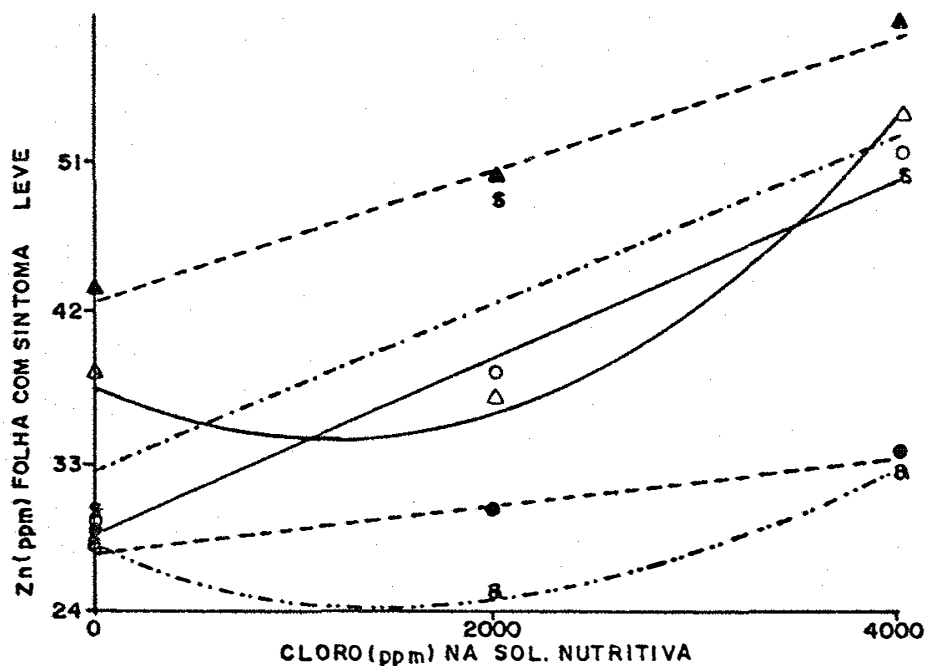

O $O$ AMPLE $H-O-K^{\circ}$

$\bar{\gamma}=20,17+0,0054 X$

$\triangle \triangle^{\circ}$ CHS $-X S-616^{\circ}$

$r=0,99$

$\bar{\gamma}=37,33-0,0052 x+0.0000023 x^{2} R^{2}=100 \%$

- Br - $501^{\circ}$

$\bar{\gamma}=27,33+0.0013 x$

$r=0,98$

- $8 \mathrm{Br}-503^{\circ}$

$\bar{\gamma}=41,89+0,0040 x$

$8--8^{\circ} B r-602^{\circ}$

$\bar{\gamma}=32.11+0.0050 X$

Q-.-B IPA - 7301218

$\bar{\gamma}=28,00-0,0044 x+0,0000014 x^{2} R^{2}=100 \%$

Figura 16 - Concentração de zinco (ppm) no colmo, nas folhas com sin tomas leves e nas folhas com sintomas acentuados, em fun ção dos niveis de cloreto na solução nutritiva. 
tivares Ample-H-0.K, CMS-XS-616, Br-503, no nivel 4.000 ppm, e na Br-602 em ambos os niveis. Nas folhas com sintomas acentuados, as duas primeiras cultivares, IPA-7301218 e Br-602 mostram os respectivos comportamentos, anteriormente citados. A Br-503 também mostrou au mento nesse nutriente, em ambos os niveis, enquanto a $\mathrm{Br}-501$ o fez com relação ao nivel $2.000 \mathrm{ppm}$.

Folhas com sintomas acentuados pertencentes à cultivar IPA-7301218 contiveram teores mais elevados de zinco quando comparados àqueles com sintomas leves (Tabela 36). Is to ocorreu aindana Br-501, no nivel $2.000 \mathrm{ppm}$.

Folhas contiveram teores mais elevados de zinco do que colmo.

En sorgo granifero, HEILMAN (1974) constatou que a pre sença de $\mathrm{NaCl}$ causcu aumento de zinco na parte aérea da variedade ATX-399, ocorrendo o inverso na variedade RS-671. Em cana-de-açūcar, WEBER (1983) verificou que o uso de NaCl caracterizou-se por elevar a concentração de zinco nas folhas das cultivares CB-45-3, RB-70194 e $R B-725828$. 


\subsubsection{2 - Cloro}

Nas Tabelas 37 e 38 (Apêndice), encontram-se os dados referentes a teores de cloreto no colmo e folhas, respectivamente. A observação dos dados permite estabelecer, mediante a utilização do teste de Tukey a 5\%, que a adição de cloreto na solução nutritiva ocasionou mudanças significativas nos teores de cloreto da matéria seca de ambas as partes amostradas. Houve efeito de cultivar, nível e interação para colmo e folhas, sendo que nesta ültima parte houve ainda efeito devido a sintomas e interações nível x sintomas e cultí var $\mathrm{x}$ sintomas.

Na Figura 17 encontram-se as correlações entre este elemento na matéria seca de colmo e folhas, e os niveis do mesmo na solução nutritiva.

Examinando-se estas figuras percebe-se que os teores de cloreto na matéria seca de colmo, folhas com sintomas leves ou acentuados, aumentaram 1 inearmente, em função da adição deste elemento na solução nutritiva, com altos coeficientes de correlação.

No nivel zero os teores de cloreto do colmo não diferiram estatisticamente (Tabela 37), enquanto nos níveis 2.000 e 4.000 ppm a $\mathrm{Br}-501$ conteve os maiores teores.

Folhas com sintomas leves contiveram menores teores de cloreto do que aquelas com sintomas acentuados, em todas as cultivares (Tabela 38). 


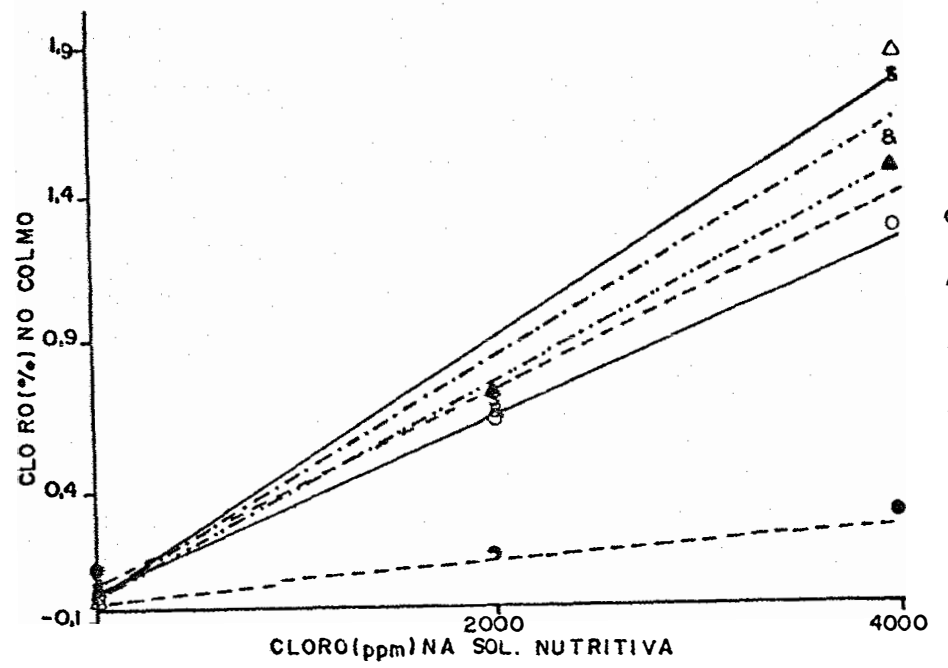

O OAMPLE $H-0-K^{\circ}$

$\bar{Y}=0,24+0,0029 X$

$\triangle \triangle \triangle^{\circ} C M S-X S-616^{\circ}$

$\bar{Y}=-0.13+0,0043 x$

$r=\infty 0$

-... Dr -501

$\bar{Y}=-0.0022+0.00062 X$

$r=1,00$

$\triangle 1.0 \dot{B r}-503$

$\bar{\gamma}=0,15+0,0033 x$

$r=0.99$

2...-.

$\overline{\mathrm{Y}}=-0,39+0,0041 \mathrm{X}$

8-1.-6. $1 P A-7301218^{\circ}$

$\bar{Y}=0,078+0,0036 \mathrm{X}$

$r=0,97$

$r=0,99$

$r=0,94$

$r=0,99$

$r=0,97$

$r=0,98$

$r=0,98$

$r=0,97$

CLORO (DPM) NA 200 SOL. NUTRITIVA

$\bar{Y}=-0,036+0,00010 X$

'IPA - $7301218^{\circ}$

$\bar{\gamma}=-0.15+0.0010 x$

$-1]$ CLOROIDPMINA SOL. NUTRITIVA

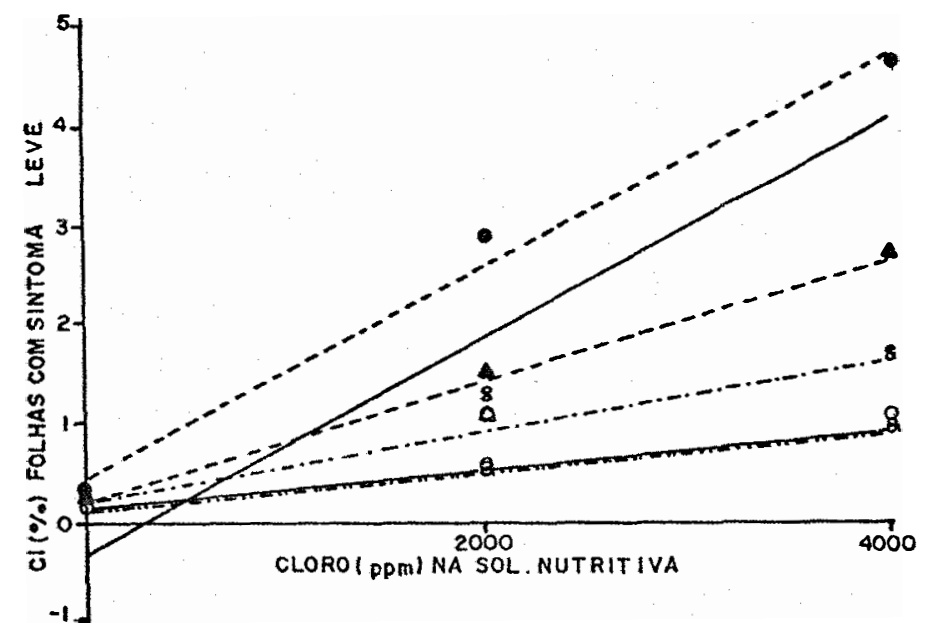

0 OAMPLE $H-O-K{ }^{\prime}$

$\bar{Y}=0.13+0,00018 X$

$\triangle \triangle^{\circ} \mathrm{CMS}-X S-616^{\circ}$

$r=0,98$

$\bar{Y}=-0,27+0,0011 x$

$r=0,94$

0 Br $-501^{\circ}$

$\bar{\gamma}=0,41+0,0010 x$

$r=1,00$

$\Delta \dot{B} r-503^{\circ}$
$\bar{Y}=0.16+0,00060 X$

$8 \cdots-8^{\circ}$ Br $-602^{\circ}$

$\bar{Y}=0,24+0,00034 X$

Q-.... \& $1 P A-7301218^{\circ}$

$\bar{Y}=0.11+0,00018 x$

$r=1,00$

$r=0,98$

$r=0,99$

Figura 17 - Concentração de cloro (\%) no colmo, nas folhas com sinto mas leves e nas folhas com sintomas acentuados, em função dos níveis de cloreto na solução nutritiva. 
De um modo geral os teores mëdio de cloreto nas folhas são superiores aos do colmo em todas as cultivares (Tabelas 37 e 38). OLIVEIRA (1983), trabalhando com a cultura do arroz sob condições salinas observou que $u$ colmo foi a parte da planta que apresentou maior teor de cloro. GARCiA e MORARD (1976) verificou que os órgãos mais jo vens de plantas de sorgo cultivadas sob condições salinas são mais rí cos em cloro.

Os teores de cloreto obtidos no presente trabalho mostram-se bem superiores aos niveis tóxicos relatados por EATON (1942) no sorgo grańifero, e por CLEMENTS (1980) em cana-de-açūcar.

0 mecanismo de toxidez do cloreto não è bem conhecido (BERNSTEIN e HAYWARD, 1958), entretanto, sabe-se que o mesmo mostra efeito inibidor sobre os ions nitrogēnio e fösforo (EVANS, 1950). Sua presença como cloreto de sódio diminuem os ácidos orgânicos de plantas de sorgo (GARCIA e MORARD, 1976), os quais são importantes em man ter o equilíbrio interno entre cátions eânions (visto no ítem 4.2.3.3). Estes autores constataram que $6 \mathrm{meq} / 1$ de $\mathrm{NaCl}$ no substrato de cultivo foi benéfico para o desenvolvimento desta cultura, enquanto que as doses de 36 e 72 meq/1 foram depressivas.

0 ion cloreto acumula-se principalmente na parte aérea (FENN et alii, 1970). O nivel de acumulação de cloreto que desenvolve sintomas típicos não é bem definido (BERNSTEIN e AYERS, 1953; BROWN et alii, 1953). Conforme RIZK e NORMAND (1969), o maior grau de toxidez de um sal pode ser devido a fatores do meio ambiente e inerentes à cultivar. 
80.

MALAVOLTA et aZii (1979), estudando salinidade em sor go sacarino cultivado em solução nutritiva, contendo $50 \mathrm{ml} / 1 \mathrm{de} \mathrm{NaClM}$, constataram que folhas inferiores contiveram 3,85\% de cloreto, enquan to as superiores contiveram $2,37 \%$ deste ion. Estec teores, de certa forma, são concordantes com os obtidos neste trabə1ho.

\subsubsection{3 - Sódio}

Os teores de sódio no colmo e folhas das cultivares va riaram estatisticamente. Mediante a utilização do teste de Tukey a $5 \%$, foi permitido constatar que a adição de $\mathrm{NaCl}$ na solução acarretou mudanças significativas nos teores de sódio das partes amostra das, conforme Tabelas 39 e 40 (Apêndice). Houve efeito de cultivar, nivel, e interação para colmo e folhas, sendo que nesta ültima parte amostrada houve ainda efeito devido a sintomas e interação nível $x$ sintomas e cultivar $\mathrm{x}$ sintomas.

As correlações entre teores de sódio no colmo e fo1has, e níveis de cloreto na solução nutritiva encontram-se na Figura 18, construída mediante utilização da equação regressão do 1 Q grau.

Analisando-se a Figura 18, referente a teores desse elemento no colmo, constata-se que em todas as cultivares ocorreu au mento linear do sódio em função dos níveis de cloreto, com altos coe ficientes de correlação. A cultivar Br-501 conteve o maior teor de sódio, sendo similar, estatisticamente, à cultivar CMS-XS-616, nos niveis 2.000 e 4.000 ppm (Tabela 39). 
Examinando-se a Figura 18 , no que se relaciona a teores de sódio nas folhas em função dos niveis de cloreto, verifica-se que nas folhas com sintomas leves ou acentuados de todas as cultivares houve aumento 1 inear nos teores de sódio em função dos niveis de cloreto na solução, com altos coeficientes de correlação, igualmente ao colmo. Comparando-se os dois tipos de folhas, aquelas com sinto mas leves contem menores teores de sódio, estatisticamente, do que aquelas com sintomas acentuados (Tabela 40).

Em sorgo granifero, GARCIA e MORARD (1976) observaram que o teor de sódio na matéria seca aumenta em todas as partes vegetais com o aumento da concentração de $\mathrm{NaCl}$ na solução nutritiva, entretanto, os maiores teores são encontrados em örgãos mais velhos.

Neste trabalho observa-se que os teores de sódio contidos nas folhas são superiores aos encontrados no colmo. OLIVEIRA (1983) verificou que os colmos de plantas de arroz cultivadas sob condições salinas contiveram os mais altos teores de sódio quando com paradas às demais partes da planta. O mesmo foi constatado por HASSAN et alii (1970b) utilizando plantas de milho.

Pesquisas feitas por MORARD (1981) usando ${ }^{24} \mathrm{Na}$ em sor go, mostram que este ín foi translocado rapidamente para todos os órgãos da planta, após sua absorção radicular, se acumulando no teci do condutor e particularmente raízes, acarretando baixos teores de sódio nas folhas, contrārio portanto ao cloreto (ítem 4.1.2). A plan ta pode suportar altos niveis de sódio por excluir sua absorção ou secretá-1o no vacuólo (RAINS, 1972; CLARKSON e HANSON, 1980). 


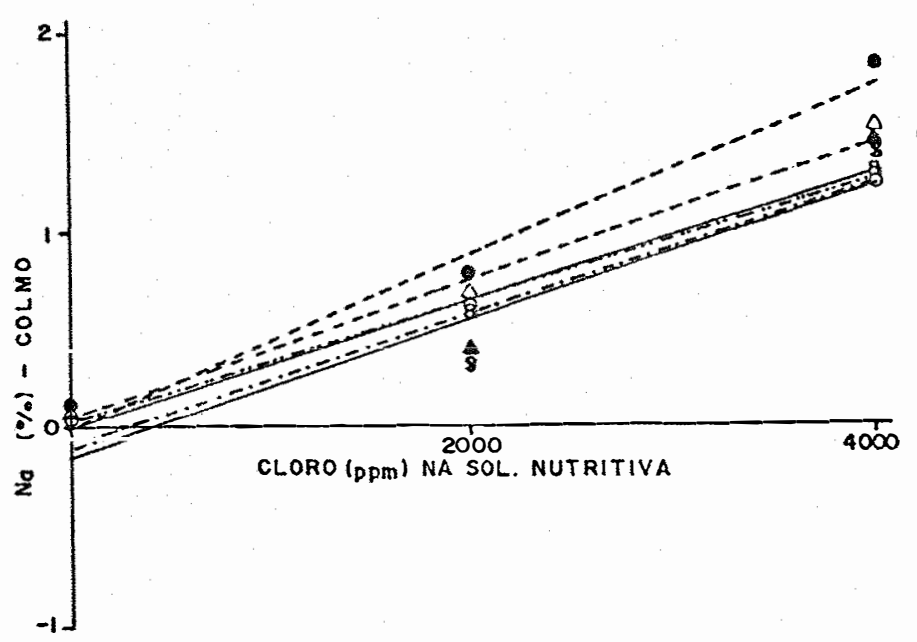

82.

0 'AMPLE $\mathrm{H}-\mathrm{O}-\mathrm{K}^{\circ}$

$\bar{Y}=-0,022+0,000291 X$

$r=1,00$

$\triangle \quad{ }^{\circ} \mathrm{CMS}-\mathrm{XS}-616^{\circ}$

$\bar{Y}=-0,032+0,000359 x$

$r=0.99$

-... Br - $501^{\circ}$

$\bar{\gamma}=-0.054+0.00043 x$

$r<0,99$

A... Br $-503^{\circ}$

$\bar{\gamma}=-0,11+0,00034 x$

$r=0,95$

$8-8^{\circ}$ Br $-602^{\circ}$

$\bar{\gamma}=-0.14+0.000325 x$

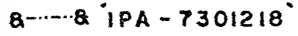

$\bar{Y}=-0,0039+0,00030 x$

$r=0,93$

$r=100$

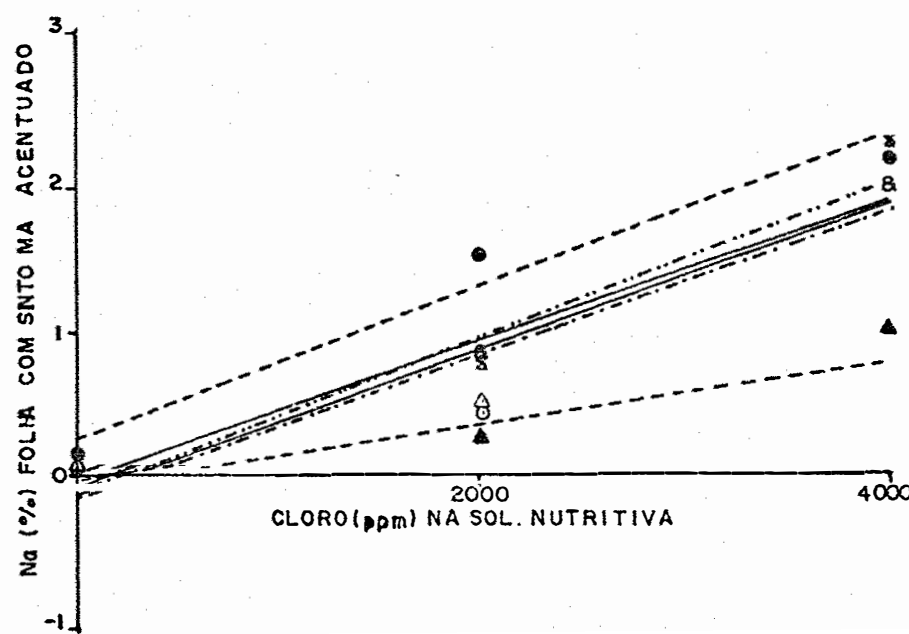

$\bigcirc$ 'AMPLE H-O-K'

$\bar{Y}=-0,22+0,00051 X$

$r=0.93$

$\triangle \triangle D^{\circ} C M S-X S-616^{\circ}$

$\bar{Y}=-0.21+0.00054 x$

$r=0,94$

•-... ${ }^{\circ} \mathrm{Br}-501^{\circ}$

$\bar{Y}=-0,12+0,00054 X$

$r=0,98$

$\triangle-18 r-503^{\circ}$

$\bar{\gamma}=-0.090+0.00022 x$

$r=0,93$

8-.-.8 Br - $602^{\circ}$

$\bar{Y}=-0.13+0.00054 X$

8-...8 IPA - $7301218^{\circ}$

$r=0,98$

$r=0,99$

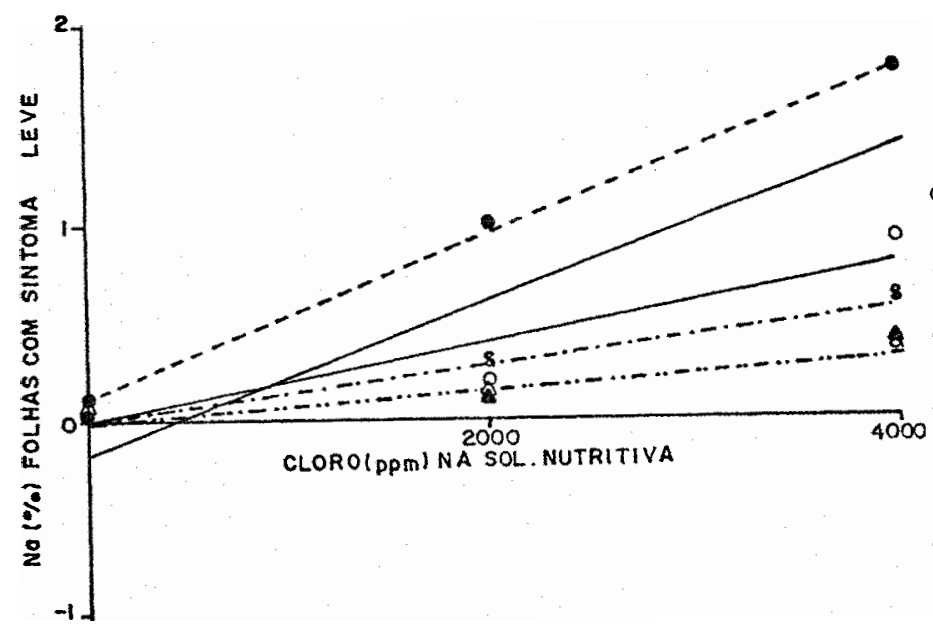

$\bigcirc-O^{\circ}$ AMPLE H-O-K'

$\bar{Y}=-0,080+0,00020 X$

$\triangle \triangle^{\circ} \mathrm{C} M S-X S-616^{\circ}$

$\bar{Y}=-0,23+0,00042 X$

$r=0.93$

- - B $-501^{\circ}$

$\bar{Y}=0,024+0,00043 x$

$\triangle--\triangle^{\circ}$ Br $-503^{\circ}$

$\bar{\gamma}=-0.024+0.000071 \mathrm{X}$

$8-.-8 \mathrm{Br}-602^{\circ}$

Q-... Q ' IPA - 7301218

$\bar{y}=-0.038+0,000080 \mathrm{x}$

$r=0.90$

$r=1,00$

$r=0,92$

$r=0.99$

$r=0.89$

Figura 18 - Concentração de sódio (\%) no colmo, nas folhas com sinto mas leves e nas folhas com sintomas acentuados, em função dos niveis de cloreto na solução nutritiva. 

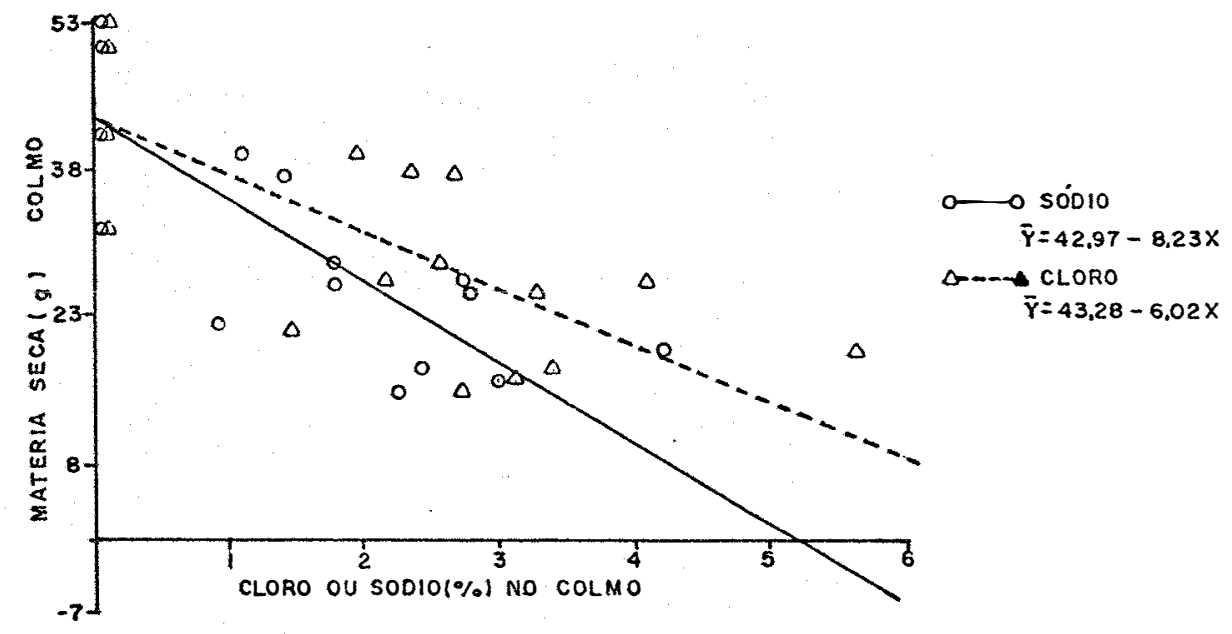

$r=-0.81$

$r=-0,76$
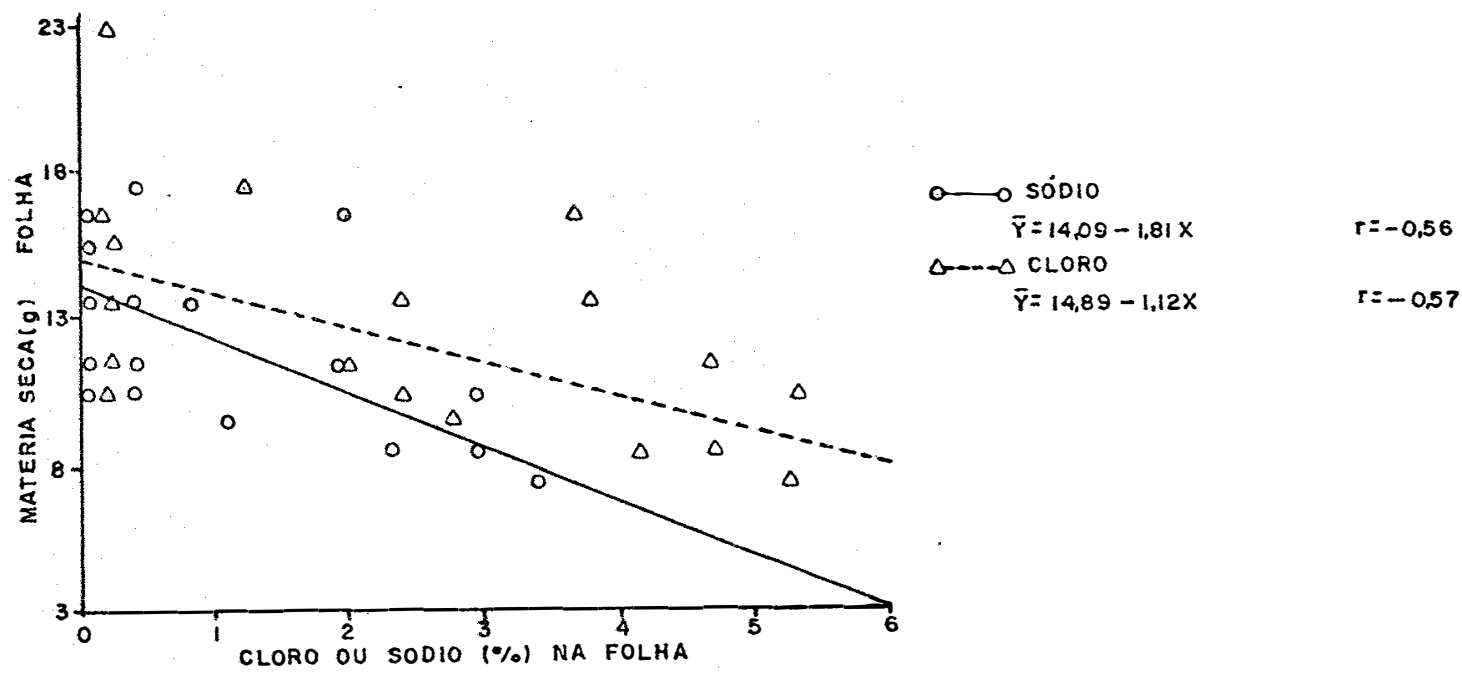

Figura 19 - Correlação entre teores de sódio (\%) e de cloro (\%) no colmo e nas folhas, e matéria seca (g) de folhas e de colmo. 
O sódio é reconhecidamente menos tóxico às plantas que o ion cloro (STROGONOV, 1964), e dependendo da concentração usada no substrato de cultivo pode ser benéfico para o desenvolvimento das mes mas (LUNT, 1966; GARCIA e MORARD, 1976).

Utilizando-se os teores de cloro e de sódio contidos no colmo e nas folhas das cultivares, bem como os pesos de matéria seca ( $g$ ) de colmo e folhas em função dos niveis de cloreto na solução nutritiva, foi construída a Figura 19, através da análise de regressão polinomial de 19 grau. Analisando-se esta figura, percebe-se que tanto no caso de colmo como para folhas, o ion cloro mostrou-se menos tóxico que o íon sódio.

\subsection{4 - Teores de nutrientes no caldo}

Os dados atinentes à concentração de nutrientes no cal do acham-se nas Tabelas 41 a 53 (Apêndice). As anālises de variância dos dados originais revelaram efeito de cultivar, nível e interação, para sódio e todos os nutrientes analisados, excetuando-se o boro. A adição de cloreto na solução nutritiva permitiu constatar, mediante a utilização do teste de Tukey a $5 \%$, a ocorrência de mudanças sig nificativas nos teores de sódio e de todos os nutrientes com exceção do boro.

As Figuras 20 a 24 mostram as representações gräficas construídas utilizando-se anälise de regressão polinomial do 19 e 2 9 graus. 


\subsubsection{1 - Nitrogēnio}

Examinando-se a Figura 20 nota-se que o fornecimento de cloreto acarretou redução nos teores de nitrogênio das cultivares, de forma quadrätica na cultivar Ample-H-0-K, enquanto nas demais isto ocorreu linearmente.

A cultivar CMS-XS-616 conteve os maiores teores desse elemento no caldo, diferindo estatisticamente das demais, em todos os niveis, sendo que no nivel 4.000 ppm foi similar à cultivar Ample H-0-K (Tabela 41 do Apēndice).

o efeito negativo do cloreto de sódio sobre a concentração de nitrogênio do caldo ocorreu igualmente na matéria seca das folhas das cultivares IPA-7301218, Br-501, Br-503 e Ample H-0-K, como foi discutido no item 4.3.1. Por sua vez, as folhas das cultivares Br-602 e CMS-XS-616 apresentaram efeito inverso ao ocorrido no caldo. Em todas as cultivares os teores de nitrogênio contidos no cal do foram inferiores aos encontrados no colmo ou folhas.

A faixa de teores de $\mathrm{N}$ encontrados no caldo das culti vares (518-2.794 mg/1), è superior à encontrada por SILVA (1983),tra balhando com a Brandes (457 a $838 \mathrm{mg} / 1)$.

\subsubsection{2 - Fósforo}

Observando-se ainda a Figura 20 , nota-se que os teores de fösforo no caldo das cultivares CMS-XS-616 e Br-503 foram reduzidos linearmente em função da adição de cloreto na solução,enquan 
to no caldo das cultivares $\mathrm{Br}-501$, Ample-H-0-K e IPA-7301218 isto ocorreu inversamente de forma quadrática na primeira e linearmente nas duas ültimas. Na Br-602 houve redução apenas no nivel 4.000 ppm.

Os tcores de fósforo contidos na cultivar CMS-XS-616 diferiram estatisticamente das demais, sendo os mais altos, em todos os níveis estudados (Tabela 42, Apēndice).

0 aumento da concentração de fósforo no caldo da IPA-7301218 aconteceu igualmente na matéria seca do colmo, e inversamen te nas folhas; nas demais cultivares também ocorreu variação quando se comparou teores de $\mathrm{P}$ na matéria seca com os do caldo. Como foi vis to no item 4.2.3.2, os teores de fósforo na planta, em função da salinidade, variam em função da parte amostrada e da cultivar (HEIrMAN, 1974; GARCIA e MORARD, 1976; WEBER, 1983).

A faixa de teores de fósforo encontrada no caldo dessas cultivares (299-1.326 mg/1) è superior à encontrada por SILVA (1983), sendo 52 a $170 \mathrm{mg} / 1$.

\subsubsection{3 - Potāssio}

A adição de cloreto de sódio na solução nutritiva pro vocou aumentos significativos nos teores de potássio do caldo de todas as cultivares (Tabela 43 do Apêndice) de forma quadrática nas cul tivares $\mathrm{Br}-501$ e $\mathrm{Br}-503$, e linearmente nas demais, conforme se verifica na Figura 20.

Dentro do nível zero, as cultivares Ample-H-0-K, CMSXS-616 e Br-501 foram similares estatisticamente, contendo os mais 


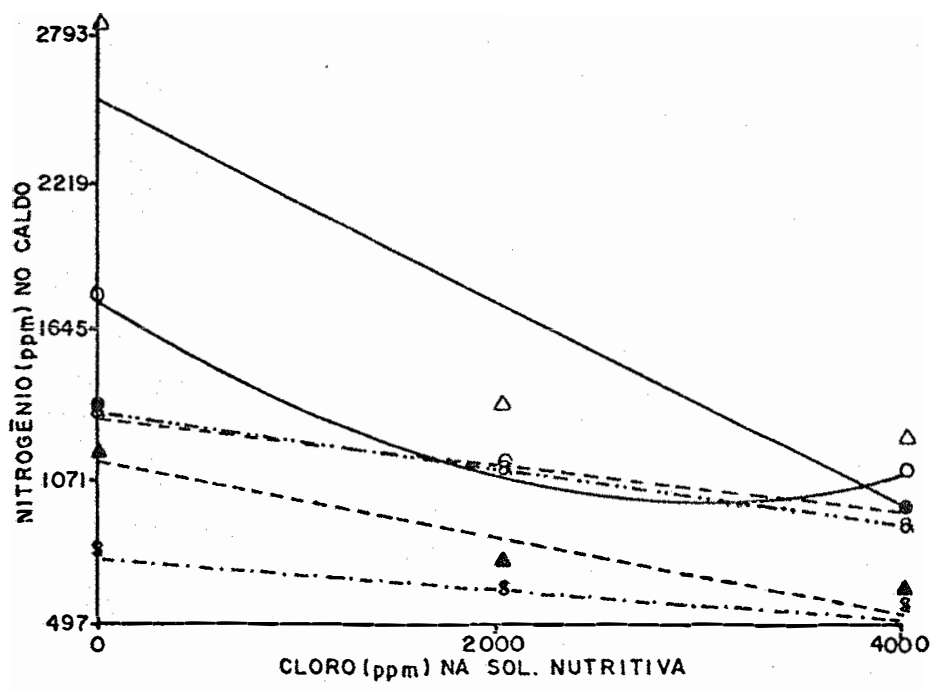

87.
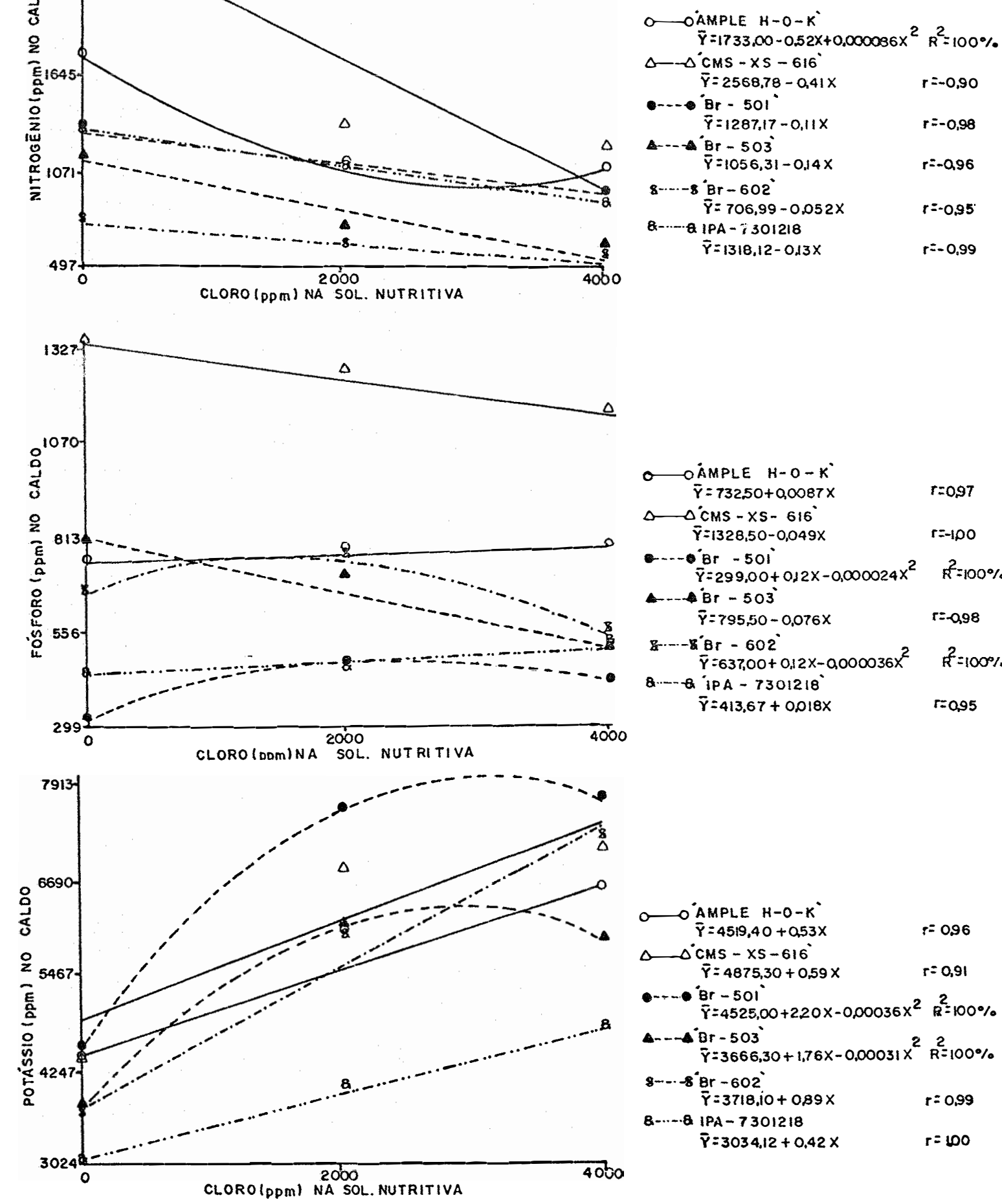

$\circ \quad$ OAMPLE $\quad K-0-K^{\circ}$
$\bar{Y}=732.50+0,0087 X \quad t=097$

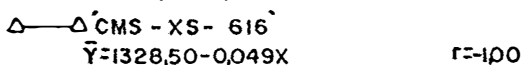

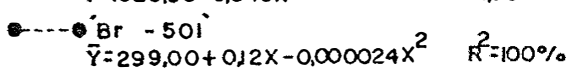

Br $-503^{\circ}$

$\bar{\gamma}=795,50-0,076 \mathrm{X} \quad r=-0,98$

R- $-\gamma^{\circ}{ }^{\circ} \mathrm{Br}-602^{\circ}$

$\bar{\gamma}=637,00+0,12 X-0,000036 X^{2} \quad R^{2}=100 \%$

Q.- IPA - $7301218^{\circ}$

$\bar{\gamma}=413,67+0.018 x \quad r=0,95$

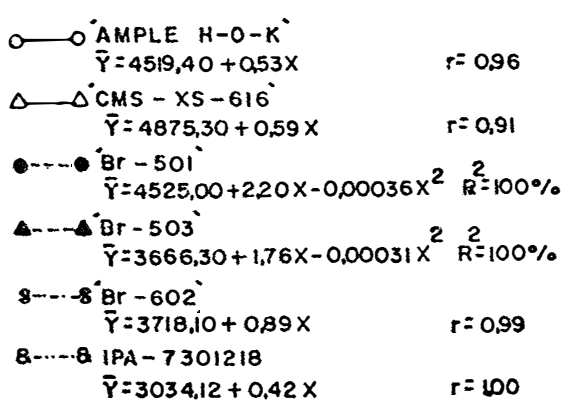

Figura 20 - Concentrações de nitrogênio (ppm), fósforo (ppm) e de potässio (ppm), no caldo de sorgo sacarino, em função dos niveis de cloreto na solução nutritiva. 
88.

altos teores desse elemento, enquanto nos niveis 2.000 e 4.000 ppm is to ocorreu apenas com esta ültima cultivar; neste ültimo nível a Br503 foi similar à cultivar Br-602 (Tabela 43).

O comportamento do potássio frente ao $\mathrm{NaCl}$ no caldo das cultivares foi inverso ao que ocorreu no colmo e folhas (Tabela 19 e 20), excetuando-se folhas da cultivar Br-501. Em geral a presen ça de salinidade acarreta depressão nos teores de potássio, conforme resultados obtidos por diversos pesquisadores em várias culturas, in clusive sorgo, como foi discutido no item 4.2.3.2. Entretanto, WEBER (1983), trabalhando com cana-de-açücar, OLIVEIRA (1983), com arroz e HASSAN et alii (1970b), com milho, constataram que a salinidade acar retava aumento nos teores de potássio semelhantes ao que ocorreu no caldo das cultivares, nesta pesquisa.

A faixa de teores encontrada no caldo dessas cultivares no nível zero ( 3.022 a $4.565 \mathrm{mg} / 1$ ) foi superior à encontrada por SILVA (1983), a qual variou de 1.426 a $2.456 \mathrm{mg} / 1$.

\subsubsection{4 - Cálcio}

Examinando-se a Figura 21, verifica-se que a presença de cloreto de sódio na solução nutritiva ocasionou redução linear nos teores de cálcio do caldo de todas as cultivares, com exceção da cul tivar IPA-7301218, onde isto ocorreu de forma quadrätica.

Dentro dos niveis 0 e $4.000 \mathrm{ppm}$, as cultivares $\mathrm{Br}-602$, Ample-H-0-K e Br-501 não diferiram estatisticamente, contendo os maio 
res teores de cálcio no caldo, acontecendo isto, ainda, com as duas primeiras, dentro do nível 2.000 ppm (Tabela 44).

A redução nos teores de cálcio no caldo foram mais con sistentes do que as verificadas no colmo ou folhas (Tabelas 21 e 22). É provável que o aumento de potássio no caldo em f́unção da salinidade tenha favorecido este fato, em virtude do antagonismo existente en tre estes ions (MALAVOLTA, 1980). Saliente-se ainda que a própria sa linidade contribui para reduzir os teores de cálcio na planta (GARCIA e MORARD, 1976; SYED e EL-SWAIFY, 1973; WEBER, 1983), principa1mente pela presença antagônica do íon sódio (ELZAM, 1970).

A faixa de teores encontrada no caldo dessas cultivares no nível zero $(296-571 \mathrm{mg} / \mathrm{ml})$ apresenta-se inferior à obtida por SILVA (1983), trabalhando com a Brandes (477-783 mg/1).

\subsubsection{5 - Magnésio}

Analisando-se a Figura 21 constata-se que a adição de cloreto na solução ocasionou redução linear nos teores de magnésio do caldo das cultivares, com exceção da cultivar IPA-7301218, onde isto ocorreu de forma quadrātica.

A cultivar CMS-XS-616 conteve os mais altos teores de magnésio no caldo, diferindo das demais, estatisticamente, em todos os niveis estudados (Tabela 45).

A diminuição dos teores de magnésio ocorrida no caldo das cultivares foi igualmente observada no colmo da cultivar Br-501 e folhas com sintomas leves das cultivares Ample-H-O-K, Br-501 e Br- 
90.

-602 e IPA-7301218. Provavelmente a presença do potássio favoreceu a redução no teor de magnèsio do caldo, conforme. foi visto no item 4.2.4.5, embora a salinidade contribua para esta redução, dependendo da cultivar, constaíado por WEBER (1983), discutido no item 4.2.3.5.

\subsubsection{6 - Enxofre}

A análise da correlação entre niveis de cloreto e teo res de enxofre no caldo acusou redução linear nos teores deste último nutriente, em todas as cultivares, excetuando-se a cultivar Br-602 na qual isto se processou quadraticamente, ainda conforme a Figura 21. Estas reduções significativas em função dos niveis de cloreto(Ta bela 46) sugerem um efeito neǵativo do cloreto sobre o enxofreda mes ma forma observado no presente trabalho, para os teores de $\mathrm{Ca}$ e $\mathrm{Mg}$ no caldo.

Dentro dos niveis 0 e 2.000 ppm, as cultivares CMS-XS616 e Ample-H-0-K foram semelhantes estatisticamente, contendo as mais altas concentrações de enxofre no caldo, enquanto no nive1 4.000 ppm isto aconteceu entre estas cultivares e a cultivar Br-503.

Observa-se que esta redução nos teores de enxof re do caldo em função da salinidade ocorreu igualmente nas folhas de todas as cultivares e colmo da Br-501. SYED e EL-SWAIFY (1973) sugerem um provável antagonismo entre o $\mathrm{Cl}^{-}$e $\mathrm{SO}_{4}^{--}$ 


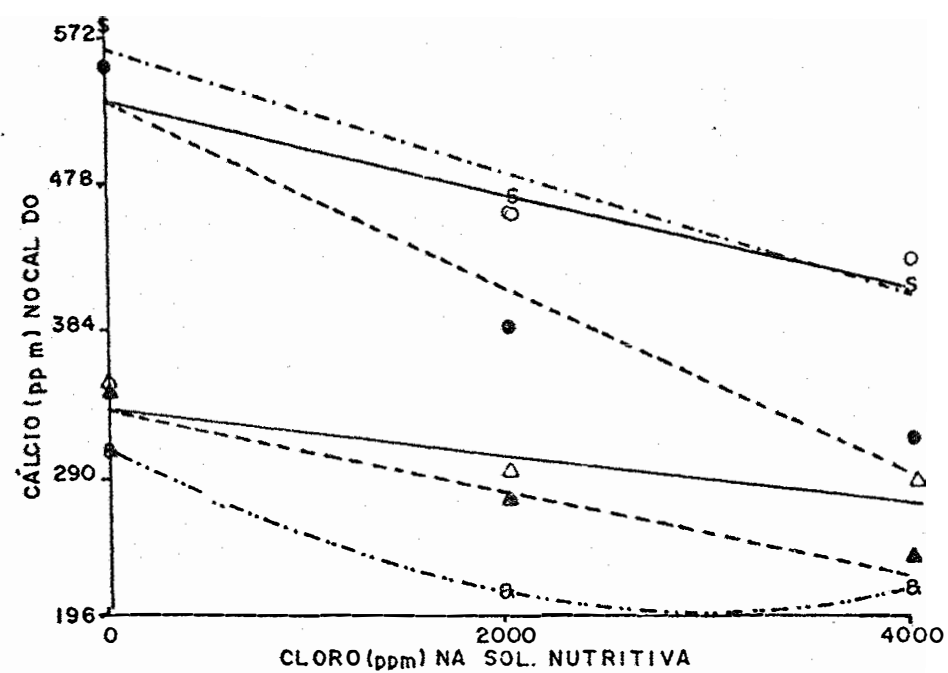

91.

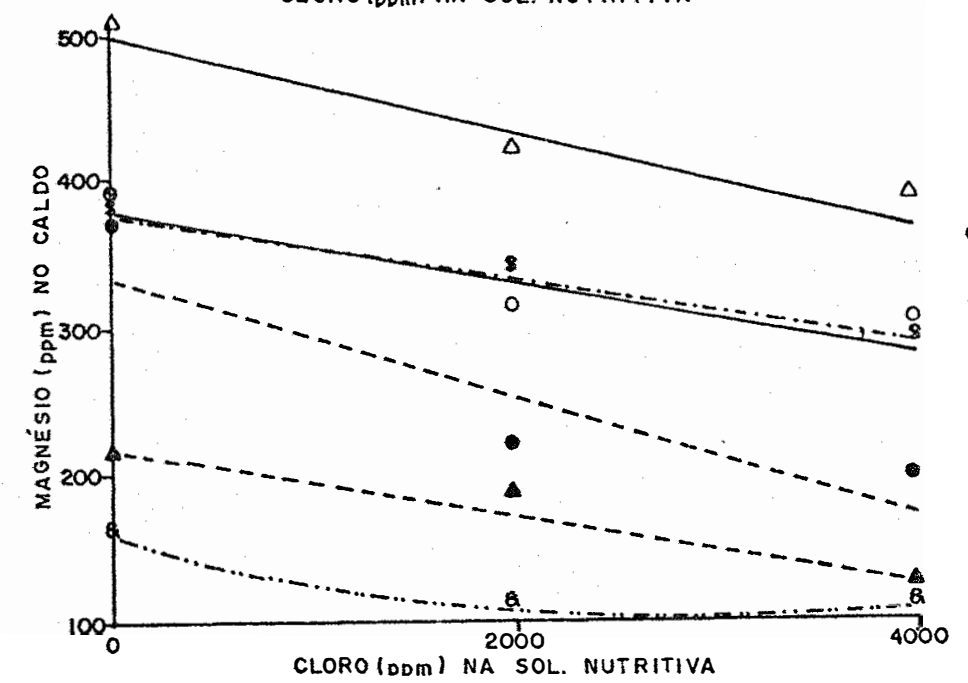

O OAMPLE H-O-K'

$\bar{\gamma}=531,83-0.033 \mathrm{X}$

$\triangle \triangle C_{M S}-X S-616$

$\bar{Y} \leq 327,50-0,016 x$

$1=-096$

$0 . \mathrm{Br}-501$

$\bar{\gamma}=528,00-0,061 x \quad r=-a 98$

A. B $\mathrm{Br}-503^{\circ}$

$\bar{Y}=326,67-0,027 x$

$r=-0.98$

8-.- $-\mathrm{g}^{\circ} \mathrm{Br}-602^{\circ}$

$\bar{Y}=563,17-0,044 X$

Q-. 8 iPA $-7301218^{\circ}$

$\hat{Y}=296,00-0,066 x+0,000011 X^{2}$

$r=-0,99$

$R^{2}-100 \%$

$\bigcirc$ OAMPLE $H-O-K^{\circ}$

$\bar{Y}=371,50-0,022 X$

$r=-0,90$

$\triangle \triangle^{\circ} C M S-X S-616^{\circ}$

$\bar{\gamma}=419,94-0,031 x \quad r=-0,97$

-... ${ }^{\circ} \mathrm{Br}-501^{\circ}$

$\bar{\gamma}=338,38-0,043 x \quad r=-0,91$

A- -4 Br $-503^{\circ}$

$\bar{\gamma}=212,38-0.023 x \quad r=-0,98$

8-.. s $^{\circ} \mathrm{Br}-602^{\circ}$

$\bar{\gamma}=371,05-0,022 x$

$r=-0.99$

Q-.)-Q. IPA - 7301218

$\bar{\gamma}=16:, 00-0,039 X+0,0000064 X^{2} R^{2}=100 \%$

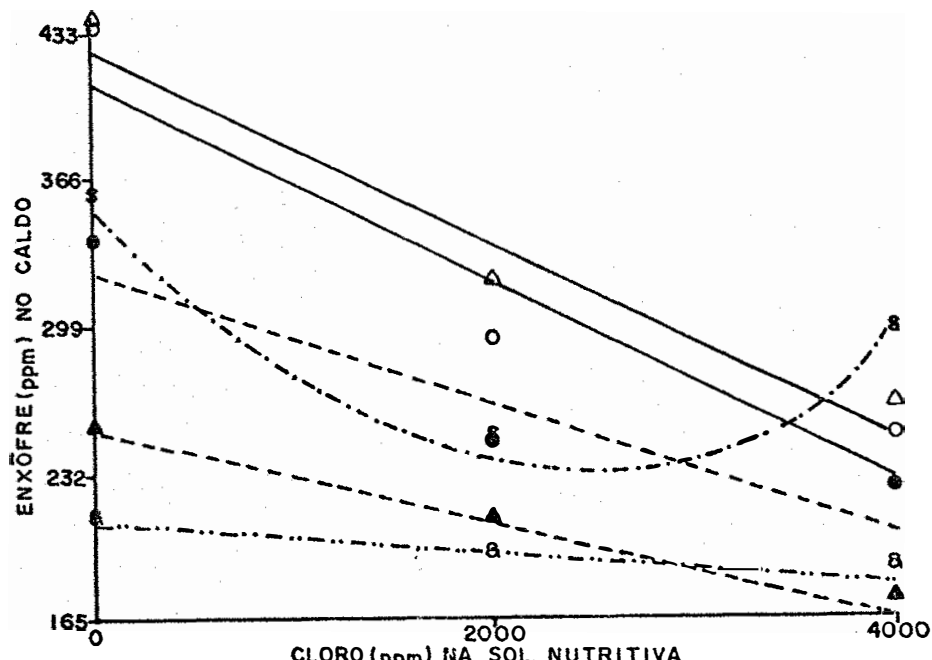

O OAMPLE $H-O-K^{\circ}$

$\bar{\gamma}=413,55-0,047 X$

$r=-0,96$

$\triangle \triangle^{\circ} C M S-X S-616^{\circ}$

$\bar{Y}=422.94-0.045 X$

$r=-0,98$

-.- Br - $501^{\circ}$

$\bar{\gamma}=319,94-0.028 x \quad r=-0.95$

$\triangle--\triangle^{\circ} B r-503^{\circ}$

$\bar{Y}=246,39-0,020 x$

$r=-1,00$

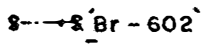

$\bar{Y}=353.33-0.097 x+0,00002.0 x^{2} R^{2}=100 \%$

Q.- $1 P A-7301218$

$\bar{\gamma}=207.49-0,0066 x \quad r=-0.97$

CLORO (PDM) INA SOL. NUTRITIVA

Figura 21 - Concentrações de cälcio (ppm), magnēsio (ppm) e de enxofre (ppm) no caldo de sorgo sacarino, em função dos niveis de cloreto na solução nutritiva. 


\subsubsection{7 - Boro}

Os teores médios desse nutriente no caldo das diferen tes cultivares não apresentaram variação em função dos niveis ou entre cultivares, conforme se verifica na Tabela 47 e Figura 22. Estes teores são bem inferiores aos encontrados no colmo e folhas das culti vares, conforme foi visto no item 4.2.3.7.

\subsubsection{8 - Cobre}

Analisando-se a Figura 22, no que se refere a teores de cobre no caldo em função da salinidade, nota-se que a presença de cloreto de sódio causou aumento nos níveis de cobre do caldo de todas as cultivares.

Entre as cultivares, dentro do nivel zero, as cultiva res $\mathrm{Br}-501$, Ample-H-0-K, Br-503 e CMS-XS-616 foram similares estatis ticamente, contendo os mais altos teores de cobre no caldo, enquanto no níve1 $2.000 \mathrm{ppm}$ isto aconteceu apenas com estas duas últimas cultivares (Tabela 48). No nive1 4.000 ppm, a cultivar Ample-H-0-K destacou-se, mostrando os mais altos teores de cobre.

Este aumento no teor de cobre do caldo foi igualmente observado no colmo das cultivares CMS-XS-616 e Br-602, e folhas desta última cultivar. HASSAN et alii (1970b) observou o mesmo em milho.

Os teores médios de cobre contidos no caldo das culti vares foram inferiores aos encontrados no colmo e folhas, em todas as cultivares (Tabelas 29 e 30 ). 
A faixa de teores contidos no caldo destas cultivares (0,5 a 4,7 mg/1) é comparàvel à obtida por SILVA (1983), analisando a cultivar Brandes (1,1-2,1 mg/1).

\subsubsection{9 - Ferro}

Os teores de ferro no caldo das cultivares Ample-H-O-K, IPA-7301218, Br-501 e Br-602 foram reduzidos, linearmente: nas duas primeiras, e quadraticamente nas duas ültimas, em função dos níveis de cloreto na solução nutritiva, conforme se constata na Figura 22 , onde se relacionam níveis de ferro contidos no caldo e concentração de cloreto na solução nutritiva.

As cultivares $\mathrm{Br}-602$, Ample-H-O-K e CMS-XS-616 foram semelhantes estatisticamente, nos niveis 2.000 e 4.000 ppm, contendo as mais altas concentrações de ferro. Isto foi verdadeiro com relação às duas primeiras cultivares no nível zero (Tabela 49).

O efeito do $\mathrm{NaCl}$ sobre o ferro nas diversas partes amostradas das cultivares foi variāvel, como também variou em função do nível e cultivar (Tabelas 31,32 e 49).

Os teores de ferro contidos no caldo das cultivares fo ram inferiores aos encontrados no colmo ou folhas.

WEBER (1983), estudando a influência do NaCl sobre os teores de ferro, em folhas de cana-de-açúcar, também constatou varia ções conforme o nível e cultivar (visto no item 4.2.3.9). Entretanto, HEILMAN (1974), trabalhando com sorgo granifero, verificou apenas a- 

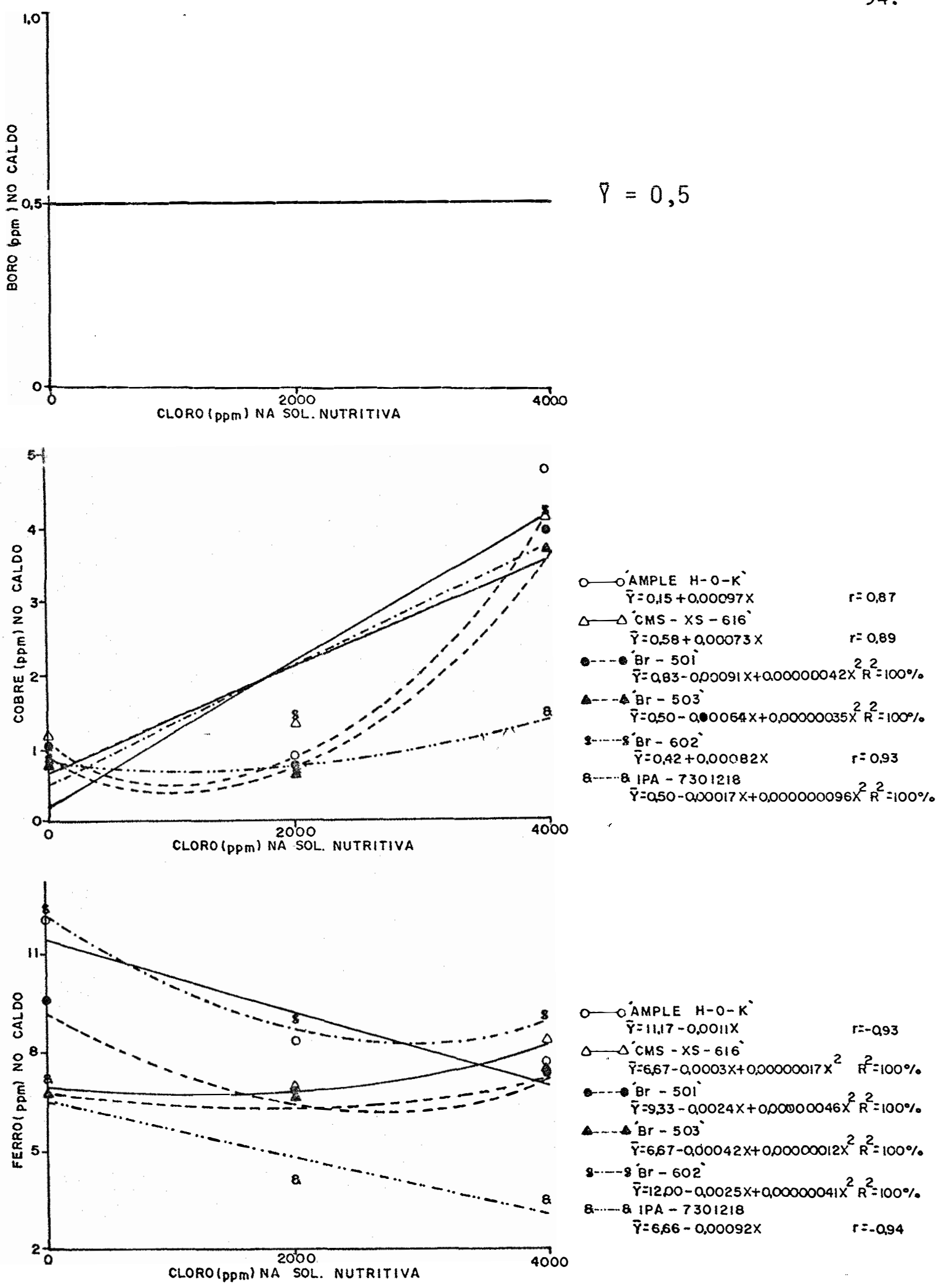

Figura 22 - Concentrações de boro (ppm), cobre (ppm) e de ferro (ppm) no caldo do sorgo sacarino, em função dos niveis de clore to na solução nutritiva. 
créscimos nos teores de ferro, em função dos níveis de $\mathrm{NaCl}$ no substrato, mesmo tendo utilizado cultivares ferro-eficiente e ferro-ineficiente.

Estas variações encontradas podem ser devidas a fatores genéticos e/ou ambientais que possam modificá-las quanto à ab sorção desse nutriente.

Os teores de ferro encontrados no caldo das cultivares no presente trabalho, no nivel zero $(6,7$ a $11,7 \mathrm{mg} / 1)$, foram inferiores aos encontrados por SILVA (1983), na cultivar Brandes (19$34 \mathrm{mg} / 1)$.

\subsubsection{0 - Manganês}

Na Figura 24, onde se relaciona a concentração de man ganês no caldo em função dos niveis de cloreto, nota-se que os teo res desse nutriente nas cultivares Ample-H-0-K, Br-501 e Br-503 foram reduzidos, ocorrendo o inverso na IPA-7301218.

Nos niveis de cloreto estudados, a CMS-XS-616 conteve os maiores teores de Mn, diferindo estatisticamente das demais, sendo que no nível 4.000 ppm ela foi também similar à Ample H-0-K (Tabe 1a 50).

Os teores de manganés contidos no caldo das cultivares em função dos niveis de cloreto, foram inferiores aos respectivos teores contidos no colmo ou folhas. A presença do $\mathrm{NaCl}$ na solução nutritiva causou efeito variável na concentração desse nutriente, conforme a cultivar e parte amostrada de uma mesma cultivar (Tabelas 33,34 e 50), como no caso do ferro. 
Trabalhando com cana-de-açücar, WEBER (1983) notou que a presença de $\mathrm{NaCl}$ causou apenas aumentos nos teores de Mn nas folhas das cultivares. HASSAN et alii (1970b) verificou que a salinida de causou acréscimos nos teores desse elemento em folhas de milho.

A faixa de teores de manganès encontrada no caldo das cultivares, neste trabalho (2,7 a $14 \mathrm{mg} / 1)$, no nivel zero (Tabela 50), foi inferior à obtida por SILVA (1983), com a cultivar Brandes (25 $35 \mathrm{mg} / 1)$.

\subsubsection{1 .. Zinco}

Os teores de zinco no caldo das cultivares $\mathrm{Br}-501$ e Br-602 aumentaram com a presença de cloreto no nivel 4.000 ppm, ocor rendo o mesmo em ambos os niveis com a IPA-7301218, conforme a Figura 23 , onde se relacionam teores de zinco no caldo e niveis de clore to na solução nutritiva.

Entre as cultivares, a CMS-XS-616 mostrou os maiores teores de zinco, diferindo estatisticamente das demais, em todos os níveis, sendo que no nível 4.000 ppm foi também similar à Ample-H-0-K (Tabela 51).

Os teores de zinco contidos no caldo das cultivares foram inferiores aos apresentados pelo colmo ou folhas (Tabelas 35, 36 e 51).

Semelhante ao que ocorreu no caso do ferro, manganēs e cobre, a interferência do $\mathrm{NaCl}$ no teor de zinco das cultivares de sor go sacarino foi variảvel conforme o nivel, cultivar e parte amostra- 


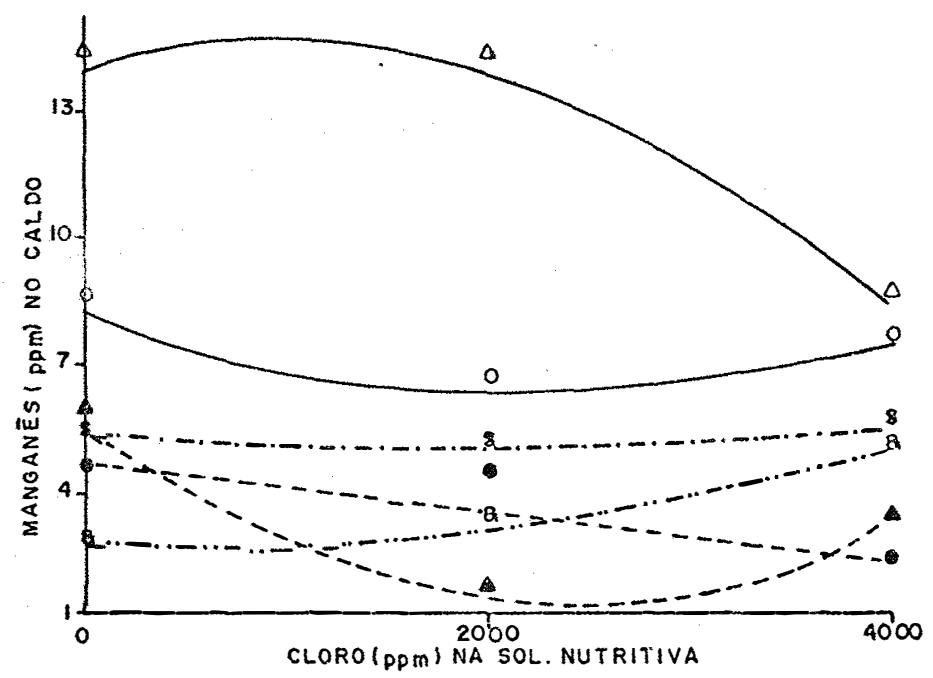

0 OAMPLE $H-O-K^{\circ}$

$\bar{Y}=8,33-0,0017 X+0.00000037 X^{2} R^{2}=100 \%$

$\triangle \triangle^{\circ} \mathrm{CMS}^{\prime} \mathrm{XS}-616^{\circ}$

$\bar{y}=14,00+0,0014 x-0,00000071 x^{2} h^{2}=100 \%$

- Br -501

$\bar{Y}=4,61-0.00056 x \quad r=-0,92$

$\Delta$ - $\Delta \mathrm{Br}-503^{\circ}$

$\bar{\gamma}=5.67-0.0037 x+0,00000075 X^{2} R^{2}=100 \%$

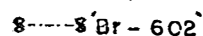

$\bar{Y}=5,00-0,00042 X+0,00000012 X^{2} R^{2}=100 \%$ Q-.... 8 IPA -7301218

$\bar{\gamma}=2,67-0,00017 x+0,00000017 X^{2} R^{2}=100 \%$

CLORO(PDI) NA SOL. NUTRITIVA

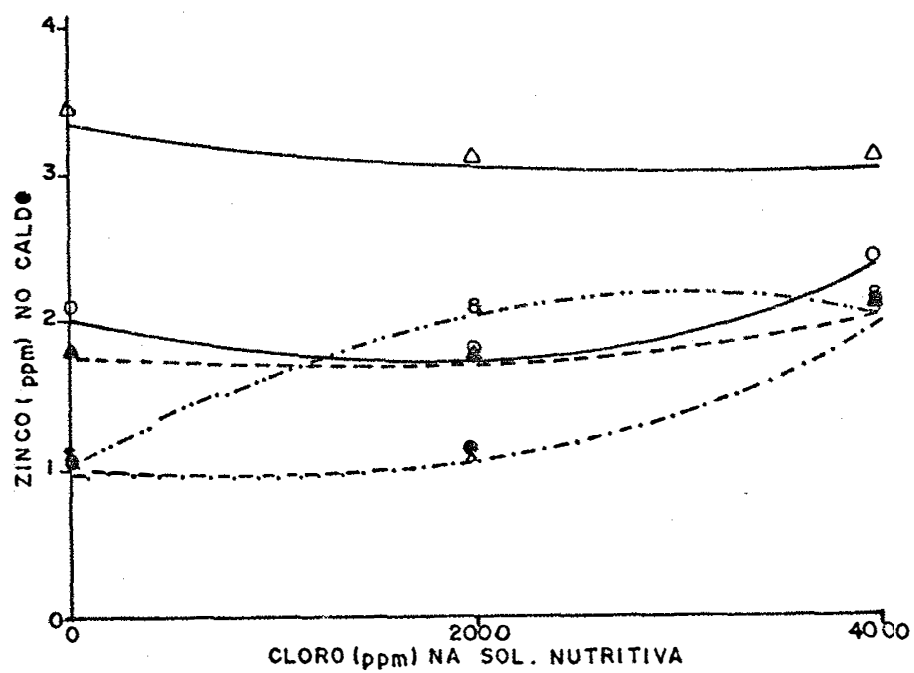

O- $\triangle A M P L E ~ H-O-K^{\circ}$

$\bar{\gamma}=2,00-0,00042 x+0,00000012 X^{2} R^{2}=100 \%$

$\triangle \triangle^{\circ} C M S-X S-616^{\circ}$

$\bar{Y}=3,33-0,00025 x+0,000000042 x^{2} R^{2}=100 \%$

- Br $-50 i^{\circ}$

$\bar{Y}=100-0,00025 x+0,00000012 x^{2} R^{2}=100 \%$

$\triangle \mathrm{Br}-503^{\circ}$

$\bar{Y}=1,67-0,000083 x+0,000000042 X^{2} R^{2}=100 \%$

8- $-8^{\circ} \mathrm{Br}-602^{\circ}$

$\bar{\gamma}=100-0200025 x+0,00000012 x^{2} k^{2}=100 \%$

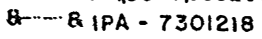

$\bar{Y}=100+0,00075 x-0,00000012 x^{2} R^{2}=100 \%$

Figura 23 - Concentrações de zinco (ppm), e de manganês (ppm) nocaldo do sorgo sacarino, em função dos niveis de cloreto na solução nutritiva. 
98.

da de uma mesma cultivar. HEILMAN (1974), estudando sorgo granifero, também constatou que o teor de zinco em função do NaC1 variou confor me a cultivar.

A faixa de teores de zinco encontrada no caldo das cul tivares, no nivel zero $(1,0-3,3 \mathrm{mg} / 1)$ è inferior à encontrada por SILVA (1983), na cultivar Brandes (3,2 a 8,6 mg/1).

\subsubsection{2 - Cloro}

A anālise de variância dos teores de cloro do caldo, em função dos niveis de cloro na solução nutritiva, indicou valores de F significativos para cultivar, nível e interação.

Percebe-se, na Figura 24, que os teores de cloreto no caldo aumentaram linearmente em função dos niveis de cloreto na solu ção nutritiva, em todas as cultivares.

No nive1 $2.000 \mathrm{ppm}$ os teores de cloreto contidos nas cultivares CMS-XS-616, Br-501 e IPA-7301218 foram semelhantes estatisticamente, enquanto no nive1 $4.000 \mathrm{ppm}$ houve superioridade apenas da ültima cultivar (Tabela 52).

Os teores de cloreto no caldo são inferiores aos contidos no colmo ou folhas (Tabelas 37,38 e 52). 

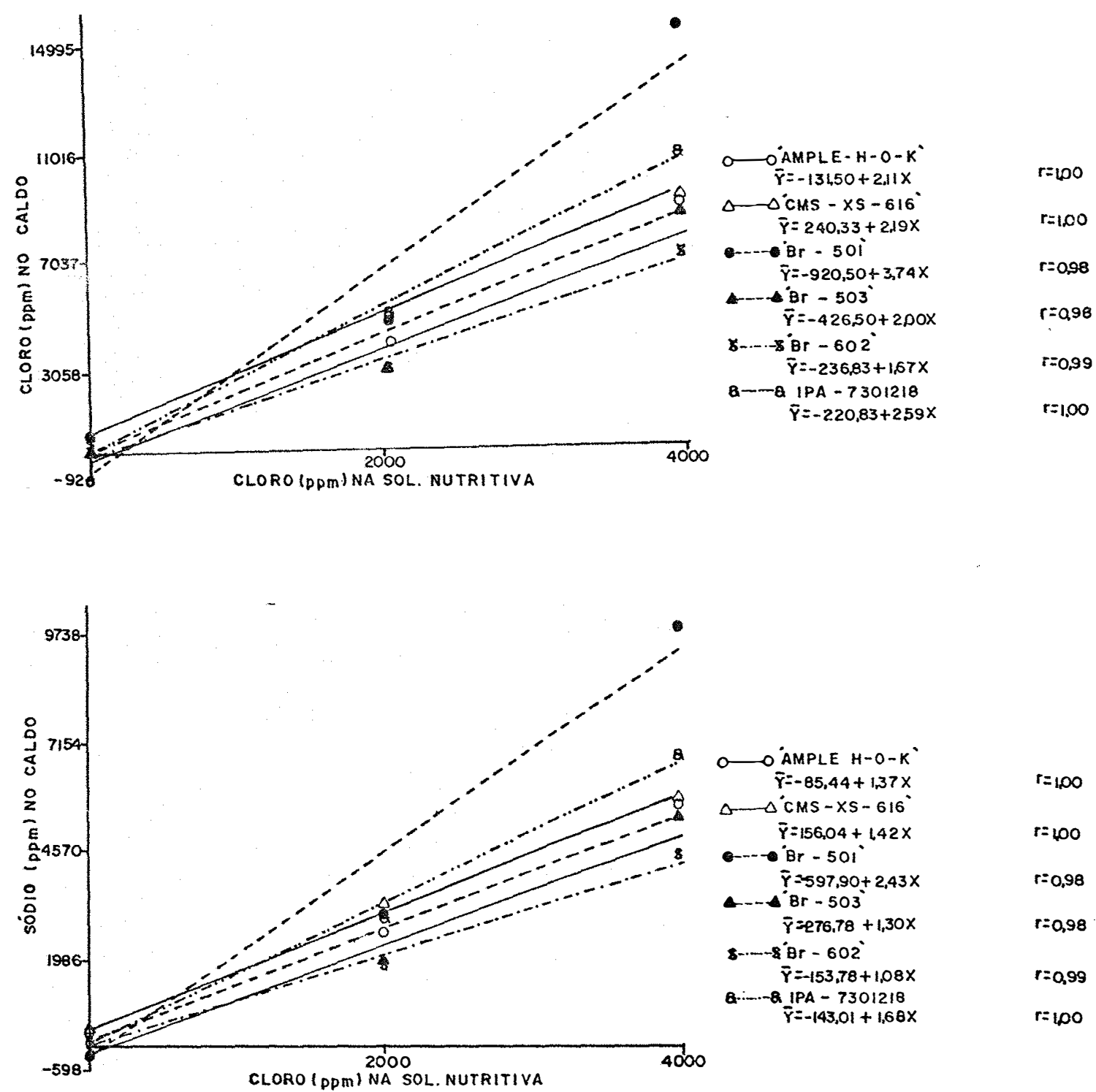

$0 \quad \underset{\bar{\gamma}=-85,44+1,37 X \quad r=1,00}{\circ}$

$\triangle \triangle \triangle^{\circ} C M S-X S-616^{\circ}$

$r=200$

$\bar{Y}=156,04+142 X$

$r=\infty 0$

$\bar{Y}=597,90+2,43 x$

$r=0,98$

$4 \mathrm{Br}-503$

$\bar{Y}=276,78+1,30 X \quad r=0,98$

$8--8^{\circ} \theta r-602^{\circ}$

$\bar{\gamma}=-153,78+1,08 x \quad r=0,99$

Q.-- -8 IPA -7301218

$\bar{\gamma}=-143,01+1,68 x$

$r=100$

Figura 24 - Concentrações de cloro (ppm) e de sódio (ppm) no caldo do sorgo sacarino, em função dos niveis de cloreto na solução nutritiva. 
A anālise de variância dos teores de sódio contidos no caldo em função dos niveis de cloreto na solução nutritiva mostra que houve efeito de cultivar, nivel e interação.

As correlações entre teores de sódio no caldo das cul tivares e niveis de cloreto evidenciam que os teores de sódio aumentaram linearmente em função dos níveis de cloreto, em todas as cultí vares, com altos coeficientes de correlação, conforme se verifica na Figura 24.

Dentro do nível $2.000 \mathrm{ppm}$, as cultivares CMS-XS-616, Br-602 e Br-501 não diferiram estatisticamente, contendo os mais a1tos teores de sódio, enquanto no nível $4.000 \mathrm{ppm}$ isto ocorreu apenas na cultivar Br-501 (Tabela 53).

Os teores de sódio contidos no caldo são inferiores aos encontrados no colmo ou folhas, em todas as cultivares (Tabelas $39,40$ e 53$)$.

\subsection{5 - Características tecnológicas}

Os dados referentes aos valores de ${ }^{\circ}$ Brix (v/v), ART\%, AR\% e sacarose \% do caldo e da fibra das diferentes cultivares desor go sacarino, obtidos em função dos niveis 0, 2.000 e 4.000 ppm de clo reto na solução nutritiva, encontram-se nas Tabelas 54 a 58 (Apêndice). A utilização do teste de Tukey a $5 \%$ permitiu constatar que os 
niveis estudados causaram mudanças significativas nas caracteristicas tecnológicas das cultivares.

Nas Figuras 25 e 26 tem-se as curvas referentes aos pa râmetros examinados, sendo construídas mediante a utilização das anā lises de regressão polinomial de 19 e 29 graus.

\subsubsection{1 $-{ }^{{ }^{O}}$ Brix}

A adição de doses crescentes de cloreto na solução nutritiva acarretou mudanças estatisticamente significativas sobre os valores de ${ }^{\circ}$ Brix do caldo das cultivares, conforme pode ser observado na Tabela 54. Em razão das significâncias encontradas, mediante a utilização da análise de regressão do 19 grau, foi possível obter altos coeficientes de correlação, indicando que os valores do

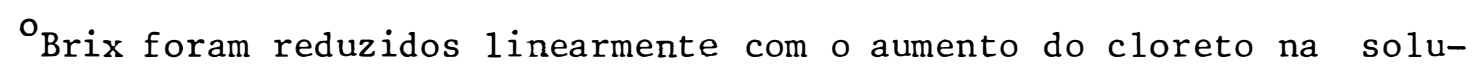
ção (Figura 25). Dentro dos níveis zero e 2.000 ppm, a cultivar Ample-H-0-K foi semelhante estatisticamente à cultivar CMS-XS-616 e su perior às demais (Tabela 54). Isto aconteceu também no nível 4.000 ppm, mas nesse caso, foi similar à cultivar IPA-7301218. As maiores reduções ocorreram nas cultivares Br-501 e CMS-XS-616.

Este efeito depressivo do sal sobre os teores de sóli dos solúveis ( ${ }^{\circ}$ Brix) foi tambëm observado por ZERBAN (1913), trabaThando com cana-de-açücar, constatando que $0,23 \%$ de sais no solo cor respondeu valor ${ }^{\circ}$ Brix de 21,0 , sendo reduzido para 19,3 quando a por centagem de sais aumentou para 0,46\%. 0 mesmo foi verificado por MA- 
NOFF (1939), nesta mesma cultura, segundo o qual 0,025, 0,090,0,120 e $0,245 \%$ de sais no solo corresponderam respectivamente os valores seguintes de ${ }^{\circ}$ Brix no caldo: $17,26,16,73,16,37$ e 15,92. Resultado semelhante foi ainda encontrado por POEY (1942), em cana-de-açúcar, relatando que $0,062,0,145$ e $0,147 \%$ de sais no solo reduziram o valor do ${ }^{\circ}$ Brix para $21,2,21,0$ e 19,0, respectivamente. Este autor sugere inclusive o não cultivo desta cultura em regiões onde os teores de $\mathrm{NaCl}$ no solo sejam superiores a $0,15 \%$.

\subsubsection{2 - Açūcares redutores totais (ART)}

Ao se estudar a correlação existente entre os teores de ART no caldo com os níveis de cloreto na solução, foi evidenciado que a equação de regressão significativa foi a de 19 grau para to das as cultivares, ou seja, houve redução linear do ART, com os níveis de cloreto adicionados, com altos coeficientes de correlação, conforme se observa na Figura 25. Dentro dos niveis 0 e 2.000 ppm, as cultivares IPA-7301218, CMS-XS-616 e Ample H-O-K não diferiram estatisticamente, sendo superiores às demais, enquanto no níve1 $4.000 \mathrm{ppm}$ houve superioridade apenas da primeira cultivar (Tabela 54). Percebe-se ainda que as cultivares CMS-XS-616 e Br-501 foram as mais afetadas, relacionando-se o nível mais alto de cloreto com o controle.

Alguns pesquisadores, reportando-se aos teores de ART do caldo de sorgo sacarino observaram variações de 14-18\% (SCHAEFFER e BORGONOVI, 1980), 13-15\% (ESTEVES et alii, 1981) e 14-17\% (SILVA, 1983). Nenhum deles, todavia, se refere à influência dos sais sobre 
a concentração dos açücares totais no caldo. Entretanto, por este tra balho, ficou evidenciado que aumentando-se os niveis de sal houve re dução na concentração de açücares, bem como, observou-se, igualmente, comportamento diferencial entre as variedades, conforme se pode cons tatar através da Tabela 55. Este efeito se verifica provavelmente de vido à inibição provocada pelo sal sobre a absorção de alguns nutrientes (BERNSTEIN e HAYIARD, 1958; STROGONOV, 1964), tais como o nitrogênio e o fósforo, que exercem influência na acumulação de açúcares no colmo. Conforme EVANS (1959), a redução do rendimento industrial em cana cultivada em solos salinos está relacionada aos baixos teores de nitrogênio e fósforo na folha, resultante do efeito inibi dor do ion cloreto sobre a absorção destes nutrientes. Aliás, neste trabalho este fato ocorreu em algumas cultivares, conforme foi visto no item 4.2.3.1 e 4.2.3.2. Some-se a isto as necroses provocadas pelo cloreto de sódio nas folhas, o que reduz drasticamente a área fotossintética (FENN et alii, 1968) e consequentemente a concentração de ART.

\subsubsection{3 - Açūcares redutores (AR)}

Os resultados atinentes aos teores de $\mathrm{AR}$ no caldo em função dos niveis de cloreto, permitem constatar variações explicáveis por equações de regressão polinomial do 29 grau, para as cultivares Ample-H-0-K e CMS-XS-616, e do 19 grau para as de mais cultivares. 


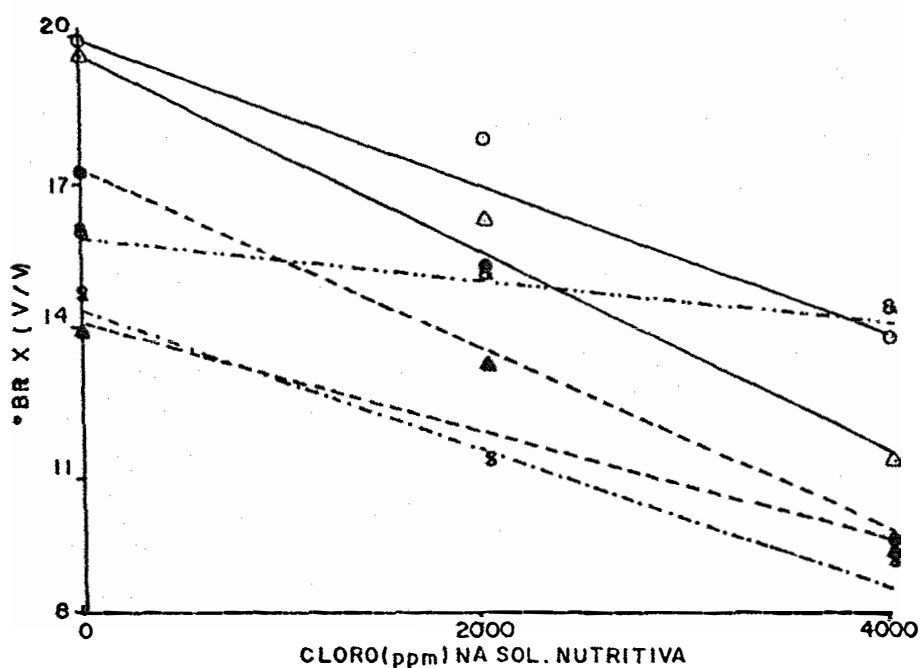

104.

O ÁMPLE H-O-K०

$\bar{Y}=19,90-0,00157 X$

$r=-0,98$

$\Delta \quad \Delta{ }^{\prime} C M S-X S-616^{\circ}$

$\bar{\gamma}=19,49-0,00212 X \quad r=-1,00$

-..- or - $801^{\circ}$

$\bar{\gamma}=17,49-0,00192 x \quad r=-0,97$

$\triangle-18 \mathrm{Br}-503^{\circ}$

$\bar{Y}=14.14-0,0012 X \quad r=-0,94$

$8 \cdots-8$ " $\mathrm{Br}-602^{\circ}$

$\bar{\gamma}=14,31-0,00147 x$

$r=-0,99$

Q...... Q IPA $-7301218^{\circ}$

$\bar{\gamma}=15.67-0,000469 x$

$r=-100$

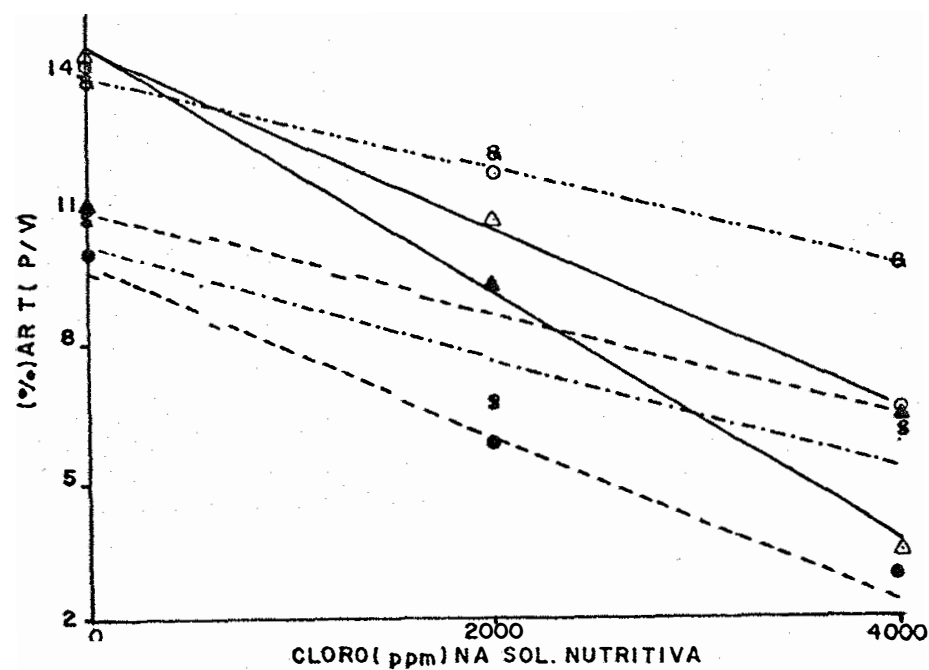

0 'AMPLE $H-O-K$

$\bar{Y}=14,44-0,00198 X$

$r=-0,98$

$\triangle \triangle^{\circ} \mathrm{CMS}-X S-616^{\circ}$

$\bar{\gamma}=14,67-0,00273 x$

$r=-0,98$

CBr $-501^{\circ}$

$\bar{Y}=2,50-0,00175 x$

$r=-0,99$

$\triangle--\Delta \mathrm{Br}-503^{\circ}$

$\bar{Y}=10,89-0,00119 x \quad r=-0,99$

8-..-8 $\mathrm{Br}-602^{\circ}$

$\bar{Y}=9,97-0,00125 X$

$r=-0,94$

a-.... $1 P A-7301218^{\circ}$

$\bar{\gamma}=13,67-0,00105 x$

$r=-0.99$

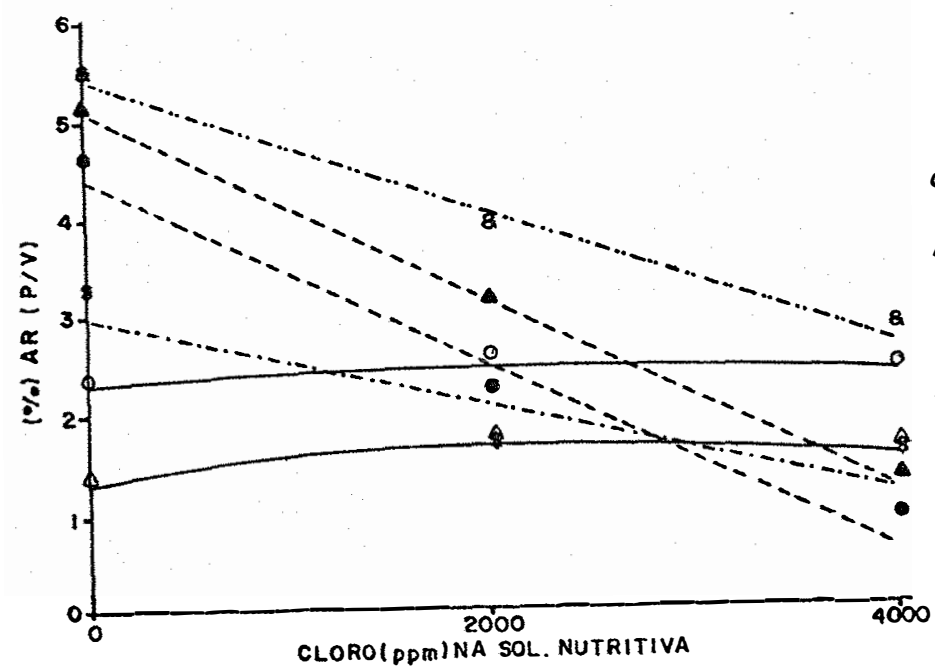

0 - $O$ AMPLE $\mathrm{H}-\mathrm{O}-\mathrm{K}^{\circ}$

$\bar{\gamma}=2,25+0.00015 X-0,000000032 X^{2} \quad R^{2}=100 \%$

$\triangle \triangle^{\circ} \mathrm{CMS}-\mathrm{XS}-616^{\circ}$

$\bar{Y}=122+0,00033 X-0,000000065 X^{2} \quad R^{2}=100 \%$

$\ldots \ldots \circ \mathrm{Br}-501^{\circ}$

$\bar{Y}=4,29-0,00093 X$

$r=-0,99$

$\triangle \mathrm{Br}-503^{\circ}$

$\bar{\gamma}=4,99-0,00096 \mathrm{X} \quad r=-100$

$8-\cdots 8^{\circ}$ Br $-602^{\circ}$

$\bar{Y}=2,91-0,00045 X$

$r=-0.90$

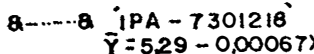

$r=-0,99$

Figura 25 - ${ }^{\circ} \operatorname{Brix}(v / v)$, teores (\%) de açúcares redutores totais (ART) e de açúcares redutores (AR) dó caldo de sorgo sacarino,em função dos niveis de cloreto na solução nutritiva. 
Observando-se a Figura 25 , nota-se que houve redução 1inear nos teores de AR das cultivares Br-501, Br-503, IPA-7301218 e $\mathrm{Br}-602$, enquanto nas demais cultivares ocorreu um pequeno acréscimo embora não significativo pelo teste de Tukey. Por sua vez, as três primeiras cultivares foram similares estatisticamente e superiores às demais, dentro do nível zero (Tabela 56). A cultivar IPA-7301218 não diferiu das cultivares $\mathrm{Br}-503$ e Ample-H-0-K dentro dos niveis 2.000 e 4.000, respectivamente, sendo superioces às demais cultivares. A cultivar Br-501 sofreu a maior redução com relação ao controle.

A redução nas caracteristicas tecnológicas da cana-de-açúcar em solos salinos, como foi visto, está relacionada aos baixos teores de nitrogênio e fósforo na folha, resultante do efeito inibidor do íon cloreto sobre a absorção desses nutrientes (EVANS, 1959).

\subsubsection{4 - Sacarose}

Ao se estudar a correlação existente entre os teores de sacarose no caldo com as doses crescentes de cloreto, foi evidenciado que a equação de regressão significativa foi a de 19 grau, para as cultivares Ample-H-0-K, CMS-XS-616, Br-501 e Br-602, apresentando altos coeficientes de correlação, enquanto nas demais cultivares o fenōmeno foi explicado por equação de regressão polinomial do 29 grau, conforme se verifica na Figura 26.

Destes resultados se infere que os teores de sacarose do caldo foram reduzidos em consequéncia do fornecimento de cloreto, 
em todas as cultivares. Dentro do nível zero as cultivares Ample-H-0-K e CMS-XS-616 não diferiram, apresentando os mais altos teores de saca rose no caldo, sendo que dentro do nível $2.000 \mathrm{ppm}$ estes cultivares mostraram o mesmo comportamento, não diferindo tarubém da cultivar IPA-7301218 (Tabela 57). Saliente-se que esta culitivar apresentou leve redução com relação ao controle, enquanto a CMS-XS-616 mostrou redução mais acentuada.

ZERBAN (1913) verificou que os teores de sacarose de cana-de-açúcar baixavam de 18,3 para $15,5 \%$ quando a salinidade do so1o aumentava de 0,23 para $0,46 \%$.

MANOFF (1939), estudando o efeito dos teores de sais no solo sobre a qualidade tecnológica da cana-de-açúcar constatou que $0,025,0,090,0,120$ e $0,245 \%$ de sais no solo corresponderam, respecti vamente aos teores $14,38,13,83,13,28,12,87 \%$ de sacarose. POEY(1942), trabalhando com esta cultura, verificou que $0,062,0,145$ e $0,147 \%$ de sais no solo conduziram a $20,14,19,18$ e $16,08 \%$ de sacarose, respecti vamente.

De acordo com FOGLIATA e ASO (1965), o teor de sacarose diminui drasticamente quando a condutividade elétrica do solo é sü perior a 1,20 mmos $/ \mathrm{cm}(0,102 \%$ de sais $)$ e que esta característica não é afetada quando a $C E$ do solo era inferior a $0,73 \mathrm{mmhos} / \mathrm{cm}(0,043 \%$ de sais).

MARETZKI et alii (1972) observou elevação no teor de sacarose em cana-de-açúcar, acompanhada pela baixa concentração de acúcares redutores e por um decréscimo da atividade da invertase, quan do o potencial osmótico do solo era diminuído. 
Entretanto, convém lembrar que a salinidade afeta a absorção de íons (BERNSTEIN e HAYWARD, 1958; RAINS, 1972; MENGEL e KIRKBY, 1982) como no caso do nitrogênio e do fósforo (visto no ítem 4.2.5.4) e outros íns como por exemplo o potássic (EPSTEIN, 1975), causando deficiência à planta e, nestas condições, há reduçãonos teo res de açúcares do caldo, o que está de acordo com HART (1934), HUMBERT (1968) e HAAG (1961).

\section{$4.2 .5 .5-$ Fibra}

Os dados referentes à fibra do colmo, das diferentes cultivares obtidos em função dos níveis de cloreto encontram-se na Tabela 58. A análise de variância revelou valores de F significativos para cultivar, nível e interação, e o teste de Tukey a $5 \%$ permitiu constatar mudanças significativas no parâmetro analisado em todas as cultivares.

Na Figura 26 se correlacionou fibra com os níveis de cloreto, evidenciando-se que para a cultivar $\mathrm{Br}-503$ ajustou-se equação de regressão do 29 grau, com alto coeficiente de correlação, enquanto para as demais cultivares a equação de regressão significativa foi a de 19 grau, com altos coeficientes de correlação.

0 exposto mostra que houve um aumento no teor de fibra dos colmos de todas as cultivares, decorrente da adição de clore to. Dentro do nível zero, a cultivar Br-503 conteve o maior teor de fibra, entretanto, dentro do nivel 2.000 ppm não diferiu dos teores apresentados pelas cultivares $\mathrm{Br}-602$ e IPA-7301218, e ainda, dentro 

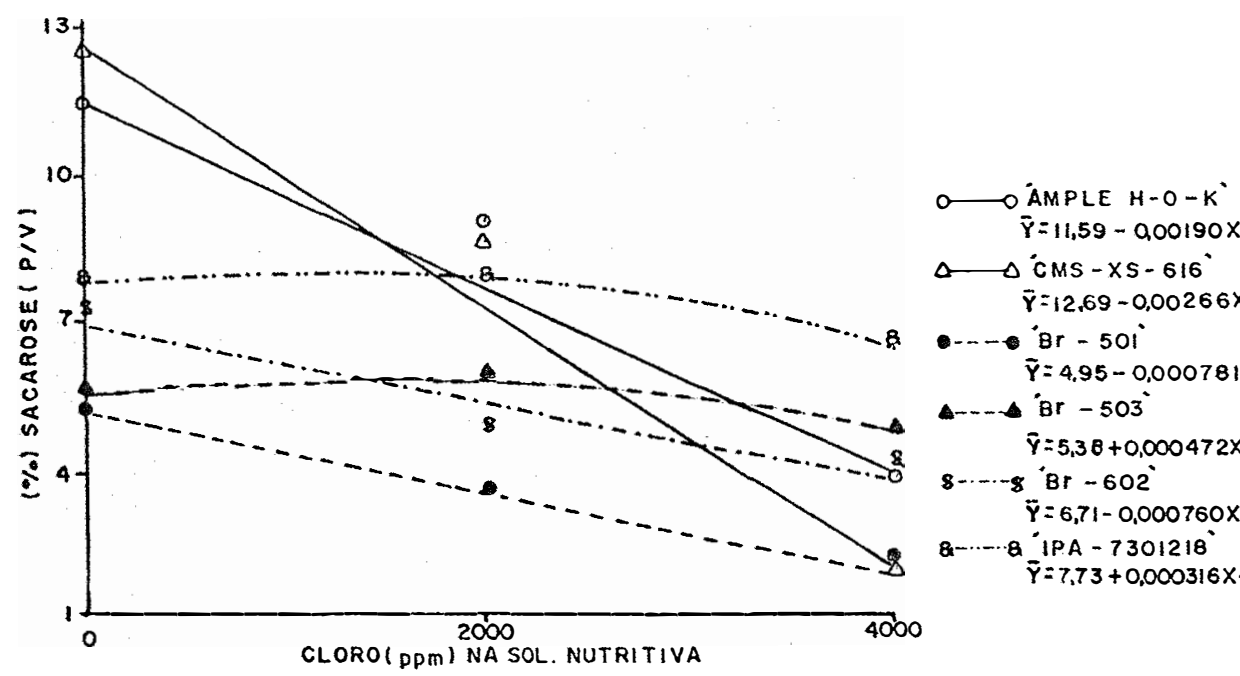

$\bar{Y}=11,59-0,00190 X$

$\triangle \triangle \triangle^{\prime} C M S-X S-616^{\circ}$

$r=-0,99$

$\bar{\gamma}=12,69-0,00266 \mathrm{X}$

$r=-1,00$

-.. Br - B $501^{\circ}$

$\bar{Y}=4.95-0.000781 X$

$\triangle \mathrm{Br}-503^{\circ}$

$\bar{Y}=5,38+0,000472 X-0,000000171 X^{2} R^{2}=100 \%$ $8+\cdots 8^{\circ} \mathrm{Br}-602^{\circ}$

$\tilde{Y}=6,71-0,000760 X$

8-.... $8^{\circ} 1 P A-7301218^{\circ}$

$r=-0,96$

$\bar{Y}=7.73+0,000316 X-0,000000168 X^{2} R^{2}=100 \%$

CLORO (PPM) NA SOL. NUTRITIVA

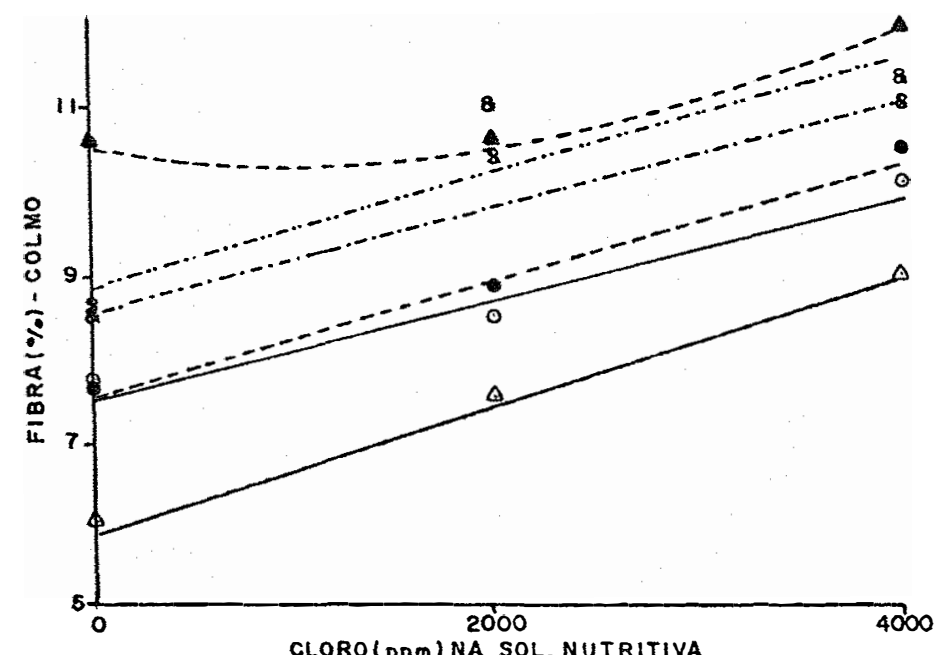

O $O A M P L E$ H-O-K

$\bar{\gamma}=7,45+0,00055 X$

$r=0,98$

$\triangle \Delta^{\circ} \mathrm{CMS}-X S-616^{\circ}$

$\bar{Y}=5,93+0,00070 X$

$r=1,00$

-... $\mathrm{Br}-50 \mathrm{O}^{\circ}$

$\bar{\gamma}=7.45+0.00067 X$

$r=1,00$

$\triangle-\cdots{ }^{\circ} \mathrm{Br}-503^{\circ}$

$\bar{\gamma}=10.42-0.00033 x+0,00000016 X^{2} R^{2}=100 \%$

$8-\cdots-8^{\circ} \mathrm{Br}-602^{\circ}$

$\bar{\gamma}=8,63+0,00057 x$

$r=0,96$

Q-..-B $1 P A-7301218^{\circ}$

$\bar{\gamma}=8.81+0,00064 X$

$r=0,91$

Figura 26 - Teores (\%) de sacarose no caldo e de fibra no colmo do sorgo sacarino, em função dos niveis de cloreto na solu ção nutritiva. 
do nivel 4.000 ppm foi semelhante estatisticamente apenas com relação a esta última cultivar (Tabela 58). A cultivar CMS-XS-616 mostrou o maior acréscimo no teor de fibra.

As variações encontradas nos teores de fibra são, em parte, decorrentes das diferenças constatadas nos teores de sólidos solúveis, considerando-se que a fibra foi calculada em função dos va lores do ${ }^{\circ}$ Brix. Note-se que hã una relação inversa entre os valores do ${ }^{\circ}$ Brix e os teores de fibra. Entretanto, os resultados da literatu ra indicam efeito da salinidade sobre o processo nutricional da plan ta (BERNSTEIN e HAYWARD, 1958; EPSTEIN, 1975; RAINS, 1970), causando distúrbios fisiológicos, alteração na estrutura anatomo-morfológica e, consequentemente, redução no crescimento. Confome STROGONOV(1964), o cloreto afeta especificamente o tecido condutor de água, díficultando portanto as relações hidricas da planta. $\bar{E}$ provável que todos estes aspectos favoreçam redução na quantidade de caldo do sorgo sacarino, aumentando, portanto, o teor de fibra.

\subsection{6 - Produção estimada de ālcool}

Na Tabela 59 encontram-se os resultados obtidos para produção de matéria fresca de colmos, em tonelada/ha, das diferentes cultivares, em função dos niveis de cloreto, para uma população esti mada de 50.000 plantas/ha. Tem-se ainda a produção estimada de à1cool por tonelada de colmos, e a quantidade total (1/ha), em função dos niveis de cloreto. 
A anālise de variância destes dados acusou valores de F significativos para cultivar, nivel e interação para todos os parâa metros analisados.

A adição de doses crescentes de cloreto na solução nu tritiva permitiu constatar, mediante a utilização do teste de Tukey a $5 \%$, a ocorrência de mudanças significativas na produção estimada de älcool (1/t de colmo e $1 / \mathrm{ha}$ ).

As correlações entre niveis de cloreto e produção de colmo (t/ha), produção estimada de àlcool, em $1 /$ t de colmo e em $1 /$ ha encontram-se respectivamente na Figura 27 , obtidas utilizando-se os dados originais e através da análise de regressão polinomial do 19 grau.

Estes resultados indicam que a produção estimada de àlcool (1/t de colmo e $1 / \mathrm{ha}$ ), bem como a produção de colmo ( $t / \mathrm{ha}$ ) foi reduzida linearmente, em função dos niveis de cloreto, com altos coe ficientes de correlação. Para um mesmo parâmetro e nivel analisado, houve comportamento diferente entre as variedades, o que resulta,pro vavelmente, dos fatores genéticos e/ou climáticos que possam modificá-las quanto ao seu desenvolvimento e características tecnológicas, além das alterações provocadas pelo cloreto de sódio (visto no item 4.2.5).

Examinando-se a Tabela 59 , percebe-se que no nivel ze ro, a maior produção de colmo foi apresentada pela cultivar IPA7301218, a qual não diferiu estatisticamente da cultivar $\mathrm{Br}-502$, mos trando consequentemente, a maior produção estimada de álcool em $1 /$ ha 

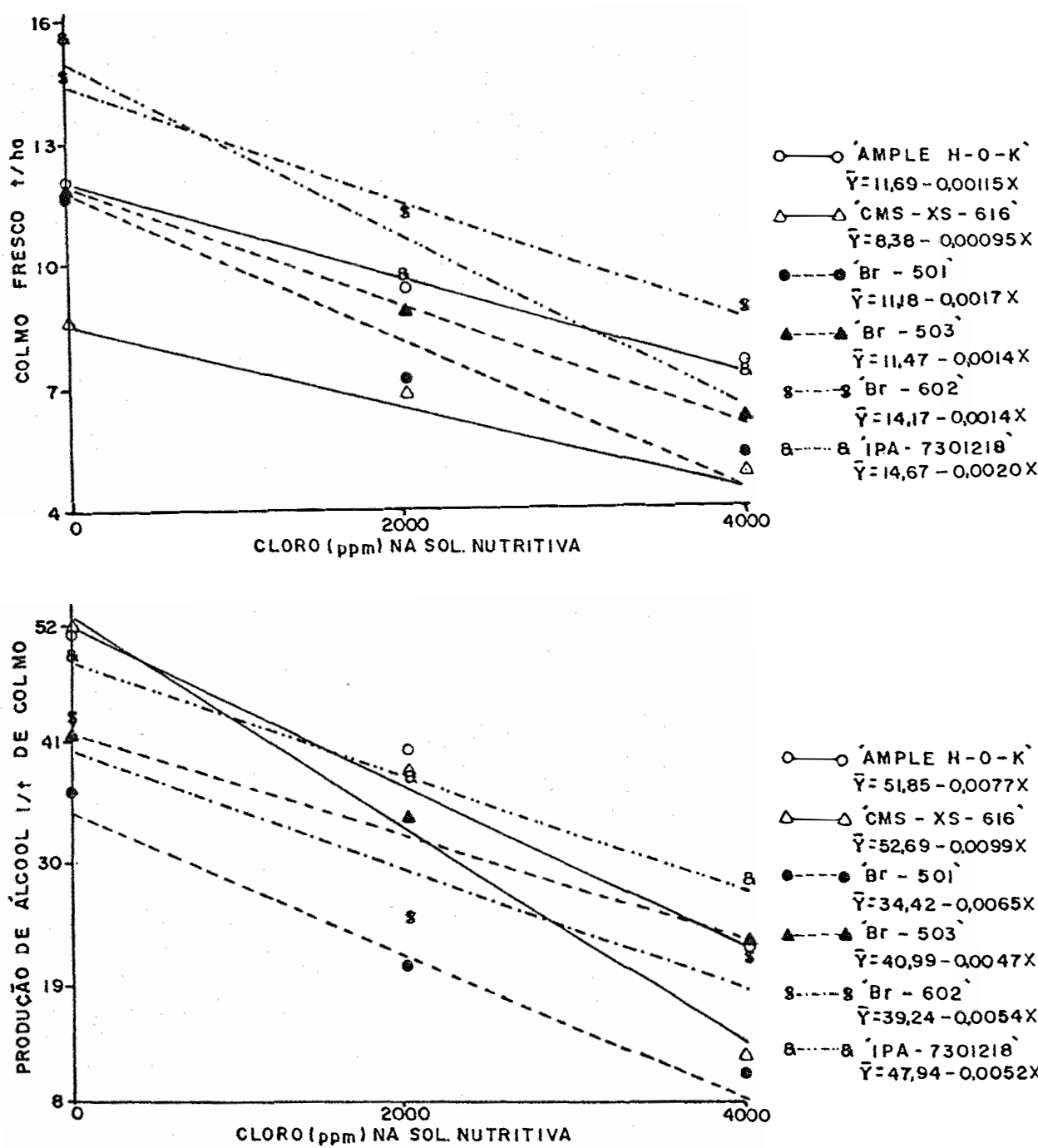

a $O$ AMPLE $\mathrm{H}-\mathrm{O}-\mathrm{K}^{\circ}$ $\bar{Y}=51,85-0,0077 X$ $\bar{\gamma}=52,69-0.0099 x$

$r=-0,98$

- B́r - $501^{\circ}$

$\bar{\gamma}=34,42-0,0065 X$

$r=-0,99$

-. 'Br - $503^{\circ}$

$\bar{\gamma}=40,99-0,0047 x$

$r=-0,99$

8-..-8 8 "Br -602

$\bar{Y}=39,24-0,0054 X$

$r=-0,95$

Q-..-Q IPA - $7301218^{\circ}$

$\bar{Y}=47,94-0,0052 X$

$r=-100$

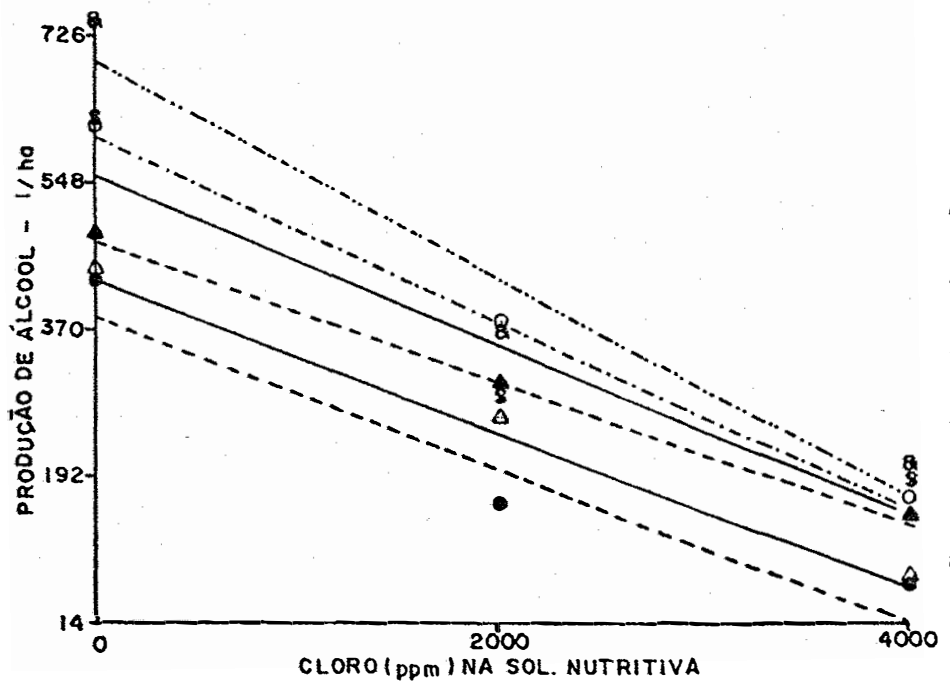

O O ÁMPLE H-O-K'

$\bar{\gamma}=591,46-0,11 X$

$r=-1,00$

$\Delta \Delta^{\circ}$ CMS - XS - 616

$\overline{\mathbf{y}}=424,26-0.093 x$

$r=-1,00$

- Br - $501^{\circ}$

$\bar{\gamma}=38183-0,092 x$

$r=-0.96$

- $-18 r-503^{\circ}$

$\bar{\gamma}=460,64-0,085 x$

$r=-1,00$

$8-\cdots-8$ Br -602

$\bar{Y}=555,02-0,11 X$

$r=-0.96$

Q-.... 8 iPA -7301218

$\bar{\gamma}=689,74-0,13 x$

$r=-0.97$

Figura 27 - Produção do colmo ( $t /$ ha), produção estimada de ālcool (1/ $t$ de colmo e em $1 /$ ha), em função dos niveis de cloreto na solução nutritiva. 
Ressalte-se que a cultivar CMS-XS-616, embora tendo apresentado a mais baixa produção de colmos/ha, está entre as mais produtivas quan to à produção estimada de àlcool em $1 / t$ de colmo, devido ao seu elevado teor de ART (item 4.2.5.2).

A cultivar IPA-7301218 mostrou as maiores reduções de produção de colmo e de àlcool em função da salinidade.

A produção estimada de àlcool em $1 /$ t de colmo e $1 /$ ha encontrada para as diferentes cultivares neste trabalho no nivel zero encontra-se um pouco abaixo dos resultados apresentados por COUTI NHO (1982), o qual apresenta variação de 63,0 a 69,6 1 de álcool/t de colmo e 1.845 a 3.809 1/ha, relativo à cultivar Brandes.

A redução na produção de colmo em tonelada por hectare, em funç̃̃o da salinidade, è uma consequéncia da diminuição no cres cimento da planta provocado pelo cloreto de sódio, conforme foi visto no item 4.2.2. Por sua vez, a diminuição occirrida na produção estimada de álcool è provavelmente decorrente deste fator e tambèm das variações constatadas nas caracteristicas tecnológicas das cultivares, provocadas pelo cloreto de sódio (item 4.2.5).

\subsection{7 - Tolerância Relativa}

Na Tabela 60 tem-se a tolerância relativa das cultiva res, cujo cálculo foi efetuado com base no peso das matérias secas de colmos e de grãos no nivel 2.000 ppm, com relação ao controle,con siderando-se o ciclo ou não. 
Examinando-se a Tabela anteriormente citada, nota-se que, com relação ao colmo, as cultivares CMS-XS-616 e IPA-7301218 apresentaram aproximadamente o mesmo indice de tolerância, sem incluir o ciclo e que a cultivar Ample-H-O-K foi a mais tolerante; entretanto, considerando-se produção de grãos, a Br-503 mcstrou-se superior às demais.

PATHAMANABHAN e RAO (1976), pesquisando a tolerância de cultivares de sorgo granifero à salinidade, observaram que as variedades mais tolerantes continham teores mais elevados de potássio na matéria seca. O mesmo foi constatado por GAUCH e WADLËIGH (1945), em arroz. No presente trabalho, os teores de potássio encontrados no colmo das cultivares Br-503 e Ample-H-O-K (Tabela 19) não confirmam o resultado obtido por estes autores, entretanto, os teores médios deste elemento nas folhas com sintomas leves ou acentuados destas cultivares dentro do nivel zero (Tabela 20) foram os mais altos.

Percebe-se ainda neste trabalho, que a duração do ciclo alterou o indice de tolerância das cultivares.

Em ültima análise, a presença de NaCl na solução nutritiva foi prejudicial às produções de colmo e de grãos das cultiva res, as quais mostraram tolerâncias diferentes entre as mesmas e numa mesta cultivar, conforme a parte amostrada. 
Tabela 60 - Tolerāncia relativa das cultivares, considerando-se o ci clo ou não, com base no peso seco de colmo e de grãos, no nive1 $2.000 \mathrm{ppm}$.

\begin{tabular}{|c|c|c|c|c|c|}
\hline \multirow{2}{*}{ CULT IVARES } & & \multicolumn{2}{|c|}{ COLMO } & \multicolumn{2}{|c|}{ GRÃOS } \\
\hline & Sem & cic 10 & Com ciclo & Sem ciclo & Com ciclo \\
\hline Ample-H-O-K & & 78 & 0,65 & 74 & 0,61 \\
\hline CMS-XS-616 & & 70 & 0,58 & 55 & 0,46 \\
\hline $\mathrm{Br}-501$ & . & 62 & 0,52 & 61 & 0,50 \\
\hline $\mathrm{Br}-503$ & & 73 & 0,61 & 83 & 0,69 \\
\hline $\mathrm{Br}-602$ & & 52 & 0,46 & 67 & 0,55 \\
\hline IPA-7301218 & & 69 & 0,46 & 69 & 0,46 \\
\hline
\end{tabular}


115.

5. CONCLUSOES

Os resultados obtidos permitiram tirar as seguintes conclusões :

5.1 - Sintomas

5.1 .1 - Os sintomas de toxidez provocados pelo cloreto de só dio nas cultivares Ample-H-0-K, CMS-XS-616, Br-501, Br-503, Br-602 e IPA-7301218 são concordantes com os sintomas gerais em plantas com toxidez destes elemen tos e principalmente com aqueles obtidos por outros pesquisadores trabalhando com esta cultura.

5.1.2 - Os sintomas se manifestam primeiramente na parte aérea. 
5.1.3 - A dosagem de $4.000 \mathrm{ppm} \mathrm{de} \mathrm{Cl}^{-}$como $\mathrm{NaCl}$ retardou o florescimento e causou abortamento de flores, em to das as cultivares.

5.1.4 - A cultivar Br-501 foi a mais afetada.

5.1 .5 - 4.000 ppm de cloreto como $\mathrm{NaCl}$ causa secamento ráp $\underline{i}$ do das folhas mais velhas em plantas de sorgo sacarino, enquanto $2.000 \mathrm{ppm}$ não $\mathrm{o}$ faz.

\section{2 - Crescimento}

5.2.1 - o cloreto de sódio reduziu linearmente a altura, com primento da panícula e diâmetro do colmo de todas as cultivares.

5.2 .2 - Houve redução linear na matéria seca de todas as par tes das cultivares influindo na matéria seca total de cada uma delas.

5.2.3 - o cloreto de sódio prejudicou a produção de matéria seca na seguinte ordem: panícula $>$ raiz $>$ colmo $>$ fo Thas.

5.2.4 - A produção de colmos verdes foi afetada negativamente, em todas as cultivares.

5.2.5 - As cultivares $\mathrm{Br}-501$ e CMS-XS-616 foram as mais afetadas. 


\section{3 - Nutrição}

5.3.1 - Houve comportamento diferenciado entre as cultivares, em função da salinidade.

5.3.2 - o cloreto de sódio causou alteração nos teores de ma cro e mitronutrientes das folhas, colmo e caldo, com as seguintes tendências:

\begin{tabular}{|c|c|c|c|c|c|c|}
\hline \multirow{2}{*}{ CULTIVARES } & \multicolumn{3}{|c|}{ ACRÉSCIMOS NOS TEORES } & \multicolumn{3}{|c|}{ DECREESCIMOS NOS TEORES } \\
\hline & Folha & Colmo & Caldo & Folha & Colmo & Ca1do \\
\hline Ample $\mathrm{H}-\mathrm{O}-\mathrm{K}$ & - & $\mathrm{N}$ & $\begin{array}{c}\mathrm{K}, \mathrm{P}, \\
\mathrm{Cu}\end{array}$ & $\begin{array}{c}\mathrm{N}, \mathrm{K}, \\
\mathrm{Ca}, \mathrm{Mg}, \\
\mathrm{S}\end{array}$ & B & $\begin{array}{l}\mathrm{N}, \mathrm{P}, \\
\mathrm{Ca}, \mathrm{Mg}, \\
\mathrm{S}, \\
\mathrm{Fe}, \mathrm{Mn}\end{array}$ \\
\hline CMS-XS-616 & $\mathrm{N}$ & $\begin{array}{l}\mathrm{B}, \mathrm{Cu}, \\
\mathrm{Fe}\end{array}$ & $\mathrm{K}, \mathrm{Cu}$ & $\mathrm{K}$ & $\mathrm{Mn}$ & $\begin{array}{c}\mathrm{N}, \mathrm{Ca}, \\
\mathrm{Mg}, \mathrm{S}, \\
\mathrm{P}, \mathrm{Fe}\end{array}$ \\
\hline $\mathrm{Br}-501$ & B & $\mathrm{B}$ & $\underset{\mathrm{Cu}}{\mathrm{K}, \mathrm{P},}$ & $\underset{\mathrm{Mg}}{\mathrm{N},}$ & $\begin{array}{l}\mathrm{K}, \mathrm{Ca}, \\
\mathrm{Mg}, \mathrm{S}\end{array}$ & $\begin{array}{l}\mathrm{N}, \mathrm{Ca}, \\
\mathrm{Mg}, \mathrm{S}, \\
\mathrm{Fe}, \mathrm{Mn}\end{array}$ \\
\hline $\mathrm{Br}-503$ &, $\mathrm{Mn}$ & ; & $\mathrm{K}, \mathrm{Cu}$ & $\begin{aligned} \mathrm{N}, \mathrm{K} & \\
\mathrm{Ca}, & \mathrm{S}\end{aligned}$ &, $\mathrm{K}$ & $\begin{array}{c}\mathrm{N}, \mathrm{Ca}, \\
\mathrm{Mg}, \mathrm{S}, \\
\mathrm{P}, \mathrm{Fe}, \\
\mathrm{Mn}\end{array}$ \\
\hline $\mathrm{Br}-602$ & $\mathrm{~N}, \mathrm{Cu}$ & $\underset{\mathrm{Mn}}{\mathrm{Cu}, \mathrm{Fe}}$ & $\mathrm{K}, \mathrm{Cu}$ & $\mathrm{Ca}, \mathrm{S}$ & $\mathrm{K}, \mathrm{Ca}$ & $\begin{array}{c}\mathrm{N}, \mathrm{Ca}, \\
\mathrm{Mg}, \mathrm{S}, \\
\mathrm{Fe}\end{array}$ \\
\hline IPA-7301218 & - & - & $\begin{array}{c}\mathrm{K}, \mathrm{P}, \\
\mathrm{Cu}, \mathrm{Mn}, \\
\mathrm{Zn}\end{array}$ & $\mathrm{N}$ & - & $\begin{array}{c}\mathrm{N}, \mathrm{Ca}, \\
\mathrm{Mg}, \mathrm{S}, \\
\mathrm{Fe}\end{array}$ \\
\hline
\end{tabular}


5.3.3 - A variação dos teores de nutrientes no caldo das cul tivares foram mais consistentes do que aqueles correspondentes a folhas ou colmo, embora tenham se mos trado em concentrações inferiores.

5.3 .4 - o cloro e o sódio acumularam-se em maiores quantida des nas folhas, sendo que o primeiro mostrou-se menos tóxico.

5.3.5 - Os teores de cloro e de sódio nas folhas com sintomas acentuados são mais elevados do que aqueles cor respondentes às folhas com sintomas leves.

\section{4 - Anālises Tecnolögicas}

5.4.1 - A presença do cloreto de sódio causou redução no OBrix, ART\%, AR\%, sacarose \%, das cultivares, sendo mais afetadas a Br-501 e CMS-XS-616.

5.4 .2 - Os teores de fibra aumentaram em função da salinida de.

5.4.3 - A produção estimada de álcool, em 1/t de colmo, e em 1/ha, foi reduzida em função dos níveis de cloreto, consequência da diminuição nos substratos para a fer mentação contidos no caldo. 
5.5 - Tolerância Relativa

5.5.1 - A cultivar Ample-H-O-K foi a mais tolerante quando se considerou colmo, enquanto que considerando-se grãos isto ocorreu na $\mathrm{Br}-503$.

5.5.2 - A cultivar Br-602 foi a menos tolerante. 
120.

\section{LITERATURA CITADA}

ACEVES-N, E.; L.H. STOLZY e G.R. MEHUYS, 1975. Effects of soil osmotic potential produced with low salt species on plant water potential, growth and grain yield of weat. Plant Soil. The Hague, 42: 619-27.

ALLISON, L.E., 1964. Salinity in relation to irrigation. Adv. Agron. New York, 16: 139-78.

AMORIM, H.V.; E.A. ZAGO; A.J. OLIVEIRA, 1983. Métodos analiticos pa ra o controle da fermentação alcoólica e aparelhos de destilação. São Paulo. Sociedade Brasileira de Microbiologia. 127 p.

ARAUJO, N.Q.; H.F. CASTRO; A.E.S. VISCONTI, 1977. Sorgo - matéria prima renovável para produção de etanol na escalada energética na cional. Brasil Açucareiro. Rio de Janeiro, 90: 23-41. 
BANGE, G.G.J., 1959. Interactions in the potassium and sodium absor ption by intact maize seedlings. Plant and Soil. The Hague, 11: 17-29.

BERNSTEIN, L. e A.D. AYERS, 1953. Salt tolerance of five varieties of carrots. Proc. Am. Soc. Hort. Sci. St. Joseph, 61: 360-66.

BERNSTEIN, L. e H.E. HAYWARD, 1958. Physiology of salt tolerance. Ann. Rev. Plant Physiol. Palo Alto, 9: 25-46.

BERNSTEIN, L., 1961. Osmotic adjustment of plants to saline media.I. Steady State. Am. J. Bot. Lancaster, 48: 909-918.

BERNSTEIN, L., 1963. Osmotic adjustment of plant to saline media. II. Dynamic phase. Am. J. Bot. Lancaster, 50: 360-370.

BERNSTEIN, L., 1974. Crops growth and salinity. Em: J. van SCHILFGAARDE, ed. Drainage for agriculture, Madison, American Society of Agronomy, n. 17. p. 39-54.

BLACK, C.A., 1975. Relaciones suelo-planta. 1ạ ed., Buenos Aires, Editorial Hemisferio Sur, V.1. p. 391-444.

BOURRIER, E.; P. MORARD; J.P. LACOMBE e J. BEDUCOU, 1974. Etude de la nutrition potassique du sorgho. II. Incidence du replacement du potassium par le sodium sur 1 a teneur en acides organiques des fe nilles. Commun. Soil Sci. and Plant Anal., New York, 5(5):456-60.

BROWN, J.W.; C.H. WADLEIGH e H.E. HAYWARD, 1953. Foliar analysis of stone fruit and almond trees on saline substrates. Am. Soc. Hort. Sci. Proc. St. Joseph, 61: 49-55. 
CLARKSON, D.T. e J.B. HANSON, 1980. The mineral nutrition of higher plants. Ann. Rev. Plant Physio1. Palo A1to, 31: 239-98.

CLEMENTS, S.H.F., 1980. Sugarcane crop logging and crop control. Principles and practices. London. Pitman Publishing Limited . 520 p.

COLEMAN, O.H., 1975. Jarabe y azucar de sorgo dulce. Em: WALL, J.S. e W.M. ROSS. Producion y usos del sorgo. 1ạ ed., Hemisferio Sur, Cap. 11, p. 237-250.

COUTINHO, E.L.M., 1983. Efeitos da adubação nitrogenada, fosfatada e potássica na cultura do sorgo sacarino (Sorghum bicolor L. Moench), avaliada pela diagnose foliar, produção de colmos e álcool etílico. Piracicaba, ESALQ/USP. 89 p. [Tese de Doutorado].

CROCOMO, O.J.; A.M.L. NEPTUNE; H.R. ZUMETA, 1965. E1 comportamiento de las plantas en condicion salina. Em: Absorcion de iones por las. plantas. Maracaibo Ed. Univ. de la Univ. del Zulia. p. 125-40.

EATON, F.M., 1941. Water uptake and root growth as influenced by inequalities in the concentration of the substrate. Plant. Physiology. Lancaster, 16: 545-64.

EATON, F.M., 1942. Toxicity and accumulation of chloride and sulfate salts in plants. Jour. Agr. Res. Washington, 64: 357-399.

EATON, F.M., 1966. Chroline. In: CHAPMAN, H.D. Diagnostic criteria for plants and soils. Riverside. Univ. of Calif. Div. of Agric. Sci. p. 98-135.

EHRLER, W., 1960. Some effects of salinity on rice. Bot. Gaz. Chicago, 122: 102-4. 
ELZAM, O.E., 1970. Interactions between sodiun, potassium and calcium in their absorption by intact barley plants. Recent Advances in Plant Nutrition. Tel Aviv, Gordon and Breach ed., New York. 491-507.

EMPRESA BRASILEIRA DE PESQUISA AGROPECUĀRIA, 1979. Resultados do en saio nacional de sorgo sacarino, 1977/78. Bol. Tec. do Centro Nac. de Pesq. de Milho e Sorgo, Sete Lagoas, n. 2. 46 p.

EPSTEIN, E., 1975. Nutrição mineral das plantas. Princípios e perspectivas. São Paulo. Ed. da Univ. de São Paulo. 341 p.

EPSTEIN, E.; J.D. NORLYN; D.W. RUSH; R.W. KINGSBURY; D.B. KELLEY; G. A. CUNNINGHAM, 1980. Saline culture of crops: a genetic approach. Science, Washington, 210:399-404.

ESTEVES, A.L.; C.B. BAGGIO; F.A. COSTA; H.F. CASTRO, 1981. Efeitos da época de plantio em dez cultivares de sorgo sacarino. Inf. Inst. Nac. Tec. Rio de Janeiro, 14(25): 26-44.

EVANS, H., 1959. Elements other than nitrogen, potassium and phospho rus in the mineral nutrition of sugarcane. Proc. Inst. Soc. of Sugar Cane Technologists. Honolulu, 10: 473-508.

FENN, L.B.; F.T. BINGHAM e J.J. OERTLI, 1968. On the mechanism of chlo ride toxicity. Yearbook. California Avocado Society, Los Angeles. 52: $113-16$.

FENN, L.B.; J.J. OERTLI e F.T. BINGHAM, 1970. Specific chloride injury in Persea americana. Soil Sci. Soc. Am. Proc. Madison, 34: 617-20. 
FIBGE, 1978. Anuário estatístico do Brasil - Produção Vegetal. Rio de Janeiro, FIBGE. V. 39. p. 359-378.

FRANCISCO, F.E. de S., 1959. Recuperação de solos salgados no Nordeste. Rio de Janeiro, DNOCS, V. 19, p. 86-99. [Boletin no 3].

FOGLIATA, F.A.; P.J. ASO, 1964. Efectos de los sales solubles del suelo sobre el rendimiento sacarino de la caña de azucar. Boletin Estacion Experimental Agrícola de la Provincia de Tucuman, no 97. $15 \mathrm{p}$.

FOGLIATA, F.A. e P.J. ASO, 1965. The effects of soil soluble salts on sucrose yield of sugarcane. ISSCT. XII Congresso. p. 682-94.

GARCIA, M. e P. MORARD, 1976. Influence de la teneur en chlorure de sodium du milieu sur la composition minerale du sorgho. 40 Colloque International sur le Contrôle de l'alimentations des Plantes Cultivées. Comptes-Rendus. Gent. Vo1. I. p. 470-79.

GAUCH, H.G. e C.H. WADLEIGH, 1942. The influence of saline substrates upon the absorption of nutrients by bean plants. Proc. Amer. Soc. Hort. Sci. 41: 365-9.

GAUCH, G.; C.H. WADLEIGH, 1945. Effect of high concentrations of sodium, calcium, chloride and sulphate on ionic absorption by bean plants. Soil Sci. New Brunswick, 59: 139-53.

GREENWAY, H., 1962. Plant responses to saline substrates. I. Growth and ion uptake of several varieties of barley during and after sodium chloride treatment. Aust. J. Biol. Sci. Melbourne, 15:16-38. 
GULLO, J.L.; P. MORARD; J. BERDUCOU, 1972. InfJuence of progressive substitution of potassium by sodium on the mineral composition of grain sorghum. Agrochimica 16(4-5): 310-318. In: Soil and Ferti1izer Abstracts, Harpenden, 1972. 35(6): 751 (Ref. 5430).

HAAG, H.P., 1961. Estudos de nutrição mineral na cana-de-açúcar ( $S a$ ccharion officinarion L.) variedade CB 41-76 cultivada em solução nutritiva. Piracicaba. ESALQ/USP. 100 p. [Tese de Livre-Docéncia].

HAJRASUIHA, S., 1980. Accumulation and toxicity of chloride in bean plants. Plant: and Soil, The Hague, 5j: 133-138.

HAN, F.; P.J. ASO e F.A. FOGLIATA, 1965. Estudio sobre salinidad en algunos suelos cultivados con caña de azucar del departamento leales, Tucuman. Rev. Agrono. Noroeste Argentino. Tucuman. 4(2):16580 .

HARTT, C.E., 1934. Some effects of potassium upon the amounts of pro tein and amino from nitrogen, sugar and enzime activity of sugar cane. Plant Physiol., Lancaster, 9: 453-490.

HASSAN, N.A.K.; J.V. DREW; D. KNUDSEN e R.A. OLSON, 1970a. Influence of soil salinity on production of dry matter and uptake and distri buition of nutrients in Barley and Corn: I. Barley (Hordeum vulgare L. ). Agronomy Journa1, Madison, 62:43-5.

HASSAN, N.A.K.; J.V. DREW; D. KNUDSEN e R.A. OLSON, 1970b. Influence of soil salinity on production of dry matter and uptake and distribution of nutrients in Barley and Corn: II. Corn (Zea mays L.). Agron. Journal. Madison, 62: 46-48.

HAYWARD, H.E. e E.M. LONG, 1943. Some effects of sodium salts on the growth of the tomato. Plant Physiology. Lancaster, 18: 556-69. 
HAYWARD, H.E. e C.H. WADLEIGH, 1949. Plant growth on saline and a1kali soils. Advances in Agronomy. New York, 1: 1-38.

HEILMAN, M.D., 1974. Salinity and iron effects on nutrients uptake by sorghum (Sorghom bicolor L. Moench). Dissertation Abstracts International. Ann-Arbor, Michigan, 34(12): 5774-B.

HELAL, H.M., 1980. Interaction of potassium nutrition and salt tole rance in higher plants. In: SAURAT, A. e M.M. EL-FOURY (Ed.). Role of potassium in crop production. Proc. of the Inter. Workshop. Cairo, Inter. Potash Inst. p. 125-130.

HUMBERT, R.P., 1968. The growing of sugar cane. Amsterdan. E1sevier Publishing Company. 779 p.

HUMBERT, R.P., 1973. Caña de azucar: los problemas de salinidad en su cultivo. Agricultura de las Americas, Kansas, 3: 14, 15, 4.3, 44 e 45 .

IVENGAR, E.R.R.; J.B. PANDYA; B.R. MEHTA, 1977. Effect of salinity of diluted seawater on two varieties of sugarcane. Salt Research \& Industry, Bhavngar, 13(1-2): 41-46.

JANARDHAN, K.V.; S. PANCHAKSHARAIAH; K.B. RAO e B.N. PATIL, 1979. Effect of varying $K$ : Na ratios in saline irrigation water on grain yield and ionic composition of wheat. Current Science. Bangalore, 48(16): $739-41$.

JOHNSON, C.M.; P.R. STOUT; T.C. BROYER e A.B. CARLTON, 1.957. Comparative chlorine requirements of different plant species. Plant and. Soil. The Hague, VIII, no 4, 337-53. 
JOSHI, G.V. e G.R. NAIK, 1980. Response of sugarcane to different types of salt stress. Plant and Soil, the Hague, 56: 255-63.

LEHR, J.J., 1942. The importance of sodium for plant nutrition. III. The equilibrium of ration in the beet. Soil Sci, Baltimore, 53: 399-411.

LUNT, O.R., 1966. Sodium. In: CHAPMAN, H.D. Diagnostic criteria for plants and soil. Riverside. Univ. of Calif. Div. of Agric. Sci. p. 409-432.

MALAVOLTA, E., 1975. Práticas de nutrição mineral de plantas. Piracicaba, ESALQ/USP. 65p. (mimeografado).

MALAVOLTA, E.; E.L.M. COUTINHO; G.C. VITTI; N.V. ALEJO; N.J. NOVAES; V.L. FURLANI NETO, 1979. Estudos sobre a nutrição mineral do sorgo sacarino (Sorghum bicolor L. (Moench)). I. Deficiência de macro e micronutrientes e toxidez de alumínio, cloro e manganês. Anais da Esc. Sup. de Agric. "Luiz de Queiroz". Piracicaba, 36: 173-202.

MALAVOLTA, E., 1980. Elementos de Nutrição Mineral de Plantas. Ed. Agron. Ceres. 251p.

MANNOF, I., 1939. Las aguas salitrosas del rio Sali, su origemy sus efectos. Boletin E stação Experimental Agricola de la Provincia de Tucumān, ne 29, 17p.

MARETZKI, A.; M. THOM e L.G. NICKELL, 1972. Influence of osmotic potencials on the growth and chemical composition of sugarcane cell cultures. Hawaiian Planter's Record, Honolulu, 58(15) : 183-99.

MARTIN, J.P. e F.T. BINGHAM, 1954. Effect of various exchangeable ca tions ratios in soils on growth and chemical composition of avoca do seedlings. Soil Science, New Brunswick, 78: 349-60.

MATSUI, E., 1978. Origem e dinâmica de classificação da āgua do Nordeste brasileiro. Bacia do Rio Pajeú, PE. Piracicaba, ESALQ/USP, 64p. (Tese de Doutoramento). 
MEDEIROS, O.P. de, 1982. Efeitos da aplicação do cloreto de sódio no desenvolvimento e composição mineral do feijão macassar [Vigna unguiculata (L.) Walp]. Areia, CCA/UFPb, 63 p. [Dissertação de Mes trado].

MENGEL, K. e E.A. KIRKBY, 1982. Principles of Plant Nutrition. 3ạ ed. Bern. International Potash Institute. 655 p.

MORARD, P.; J.P. LACOMBE; M. GARCIA e J. BERDUCOU, 1974. Etude de la nutrition potassique du sorgho. III. Relations entre les teneurs en cations et la composition en acides organiques des feuilles. Soil Sci. Plant Analysis, New York, 5: 461-73.

MORARD, P., 1981. Distribution of radioative sodium in the various organs of sorghum after root absorption. Comptes Rendus Hebdomadaires des Séances de 1 'Académie des Sciences. III. Toulouse, 292 (23): 1231-1236. In: Soils and Fertilizers.Abstracts. 1972. Harpenden, $45(4): 375$ (Ref. 4654$)$.

OGRA, R.K. e B.D. BAIJAL, 1978. Tolerance of some sorghum varieties to salt stress at ear $1 y$ seedling stage. Indian J. Agric. Sci. New Delhi, 48(12): 713-7.

OERTLI, J.J., 1968. Effects of external salt concentrations on water relations in plants. V. Significance of external water potential and salt transport kinetics on rate of cell expansion. Soil Sci., Baltimore, 105: 216-21.

OLIVEIRA, F.A. de, 1983. Efeito da salinidade da água de irrigação sobre algumas características do solo e da cultura do arroz [Oryza sativa (L.)]. Piracicaba, ESALQ/USP, 139 p. [Tese de Doutora mento]. 
PATEL, P.M., 1973. Salinity-fertility interactions for five different crops in relation to yield and chemical composition. Disser tation Abstracts International, Riverside, 34(1): 20-21. In: Field Crops Abstract, Aberystwith, 1975. 28(9): 542 (Ref. 5613).

PATEL, P.M.; A. WALLACE; E.F. WALLIHAN, 1975. Influence of salinity and N-P fertility levels on mineral content and growth of sorghum in sand culture. Agronomy Journal. Riverside, 67(5): 622-625.

PATHAMANABHAN, G. e J.S. RAO, 1976. Note on potassium as a possible index for screening sorghum varieties for salt tolerance. Indian Journal Agric. Sci. New Delhi, 46(8): 392-4.

PATHMANABHAN, G.; J. SAKHARAMARAO, 1977. Effect of salinity on the nutrient uptake in sorghum at seedling stage. Current Research, Coimbatore, $\underline{6}(4): 62-65$. In: Soils and Fertilizers, Harpenden, 1978. 41(4): 220 (Ref. 2057).

PIMENTEL GOMES, F., 1973. Curso de Estatistica Experimental. 5ạ ed. São Paulo, Nobel. 430 p.

POEY, F., 1942. Sales solubles en el suelo dañinas a la caña. In: XVI Congresso de la Association de Tecnicos Azucareros de Cuba, Cuba, p. 55-64.

PRISCO, J.T.; L. BARBOSA; L.G.R. FERREIRA, 1975. Efeitos da salini dade na germinação e vigor de plântulas de Sorghıon bicolor L. Moench. Cienc. Agron. Fortaleza, 5 (1-2): 13-17.

RAINS, D.W., 1972. Salt transport by plants in relation to salinity. Ann. Rev. Plant Physiol. Palo Alto, 23: 367-88. 
RATHERT, G., 1982. Influence of extreme K: Na ratios and high substrate salinity on plant metabolism of crops differing in salt to lerance. V. Ion specific salinity effects on invertase in leaves of bush bean and sugarbeet plants. Journal of Plant Nutrition, Philadelphia, $\underline{5}(2)$ : 97-109.

RICHARDS, L.A., 1974. Diagnostico y rehabilitacion de suelos salinos y sodicos. 6ạ ed., Mexico, Editorial Limusa. 160 p.

RIZK, T.Y. e W.C. NORMAND, 1969. Effects of salinity on Louisiania Sugarcane. International Sugar Journal, Manchester, 71(848): 22730 .

ROSOLEM, C.A., 1979. Contribuição ao estudo da nutrição mineral e adubação do sorgo sacarino [Sorghrom bicolor (L.) Moench]. Piraci caba, ESALQ/USP, 126 p. [Tese de Doutorado].

SALATI, E.; J.M. LEAL e M.M. CAMPOS, 1979. Isótopos ambientais apli cados a um estudo hidrogeológico do Nordeste Brasileiro. Recife, SUDENE, 55 p. (Hidrogeologia, 58).

SARRUGE, J.R. e H.P. HAAG, 1974. Anälises quimicas em plantas. Piracicaba, Depto de Química da ESALQ/USP. 56 p.

SEIFFERT Jr., W.J.; E.A. HILER e T.A. HOWELL, 1975. Trickle irrigation with water of different salinity levels. Trans. Am. Soc. Agric. Engers. St. Joseph, 18(1): 89-94.

SERRA, G.E., 1977. O sorgo sacarino como matéria prima para produção de álcool etílico. I Simpósio Brasileiro de Sorgo. EMBRAPA. Brasilia. 
SCHAFFERT, R.E. e R.A. BORGONOVI, 1982. Perspectivas do sorgo sacarino para produção de etanol. Em: Anais do Simpósio sobre o $\overline{1}$ cool. Publ. da Acad. de Ciên. do Est. de São Paulo. São Paulo, nọ 27. p. 69-84.

SILVA, H., 1983. Efeitos da adubação do sorgo sacarino [Sorghum bicolor (L.) Moench] na qualidade do caldo para multiplicação de le veduras e fermentação alcoölica. Piracicaba, ESALQ/USP. 295 p. [Tese de Doutorado].

SLATYER, R.O., 1961. Effects of several osmotic substrates on water relationships of tomato. Aust. J. Biol. Sci. Melbourne, 14:519540.

SMITH, G.S.; K.R. MIDDLETON e A.S. EDMONDS, 1980a. Sodium nutrition of pasture plants. I. Translocation of sodium and potassium in relation to transpiration rates. New Phytol. Cambridge, 84:603-12.

SMITH, G.S.; K.R. MIDDLETON e A.S. EDMONDS, 1980b. Sodium nutrition of pasture plants. II. Effect of sodium chloride on growth, chemical composition and the reduction of nitrate nitrogen. New Phytol. Cambridge, 84:613-22.

STROGONOV, B.P., 1964. Physiological bases of salt tolerance of plants. Jerusalem, Israel Program for Scientific Translations Ltd. 279 p.

SYED, M.M. e S.A. EL-SWAIFY, 1973. Effect of saline water irrigation on NCo 310 and H50-7209 cultivars of sugarcane. II. Chemical composition of plants. Tropical Agriculture. Trinidad, 50(1): 45.

TANIMOTO, T., 1964. The press method of cane analysis. Hawaiian Planters Record, 57(2): 133-50. 
TAYLOR, R.M.; E.F. YOUNG Jr. e R.L. RIVERA, 1975. Salt tolerance in cultivars of grain sorghum. Crop Science, Madison, 15:734-5.

TEIXEIRA, C.G.; M.J. PURCHIO; T.J.B. MENEZES; A.M. SALES; P.R. DE LA MO e ARAKAKI, 1977. Produção de álcool etílico de sorgo sacarino. Anais do I Simpósio Brasileiro de Sorgo. Brasilia. p. 99-104.

TENORIO, Z., 1981. Crescimento e concentração de nutrientes e de só dio em Vigna sinensis (L.) Endl. "Seridō" cultivada em solução nu tritiva com variação no fornecimento de potássio, cálcio, magnésio e södio. Piracicaba, ESALQ/USP, 84 p. [Tese de Doutoramento].

WADLEIGH, C.H. e H.G. GAUCH, 1942. Assimilation in bean plants of nitrogen from saline solutions. Proc. Amer. Soc. Hort. Sci., College Park, Ma. 41: 360-64.

WADLEIGH, C.H. e A.D. AYERS, 1945. Growth and biochemical composition of bean plants as conditioned by soil moisture tension and salt concentration. Plant Physiology, Lancaster, 20: 106-32.

WEBER, H., 1983. Fontes e doses de södio no crescimento e na concentração de nutrientes em cultivares de cana-de-açúcar (Saccharom spp). Piracicaba, ESALQ/USP. 71 p. [Tese de Doutoramento].

ZAGATTO, E.A.G.; A.O. JACINTHO; B.F. REIS; F.J. KRUG; H. BERGAMIN FO; L.C.R. PESSENDA; J. MORTATTI; M.F. GINÉ, 1981. Manual de anälises. de plantas e águas empregando sistemas de injeção em fluxo. Piracicaba, CENA/ESALQ-USP, 45 p.

ZERBAN, F.W., 1913. Los sales existentes en las marismas y su relacion con la produccion de caña. Boletin Estacion Experimental Agricola de Puerto Rico, no 4, 44 p. 
133.

7. $A P E N D I C E$ 
134.

Tabela 5 - Produção de matéria seca (g/planta) do colmo das diferentes cultivares de sorgo sacarino, em função dos niveis de cloreto na solução nutritiva.

$\mathrm{Cl}$

\begin{tabular}{cllllll}
$(\mathrm{ppm})$ & Ample H-O-K & CMS-XS-616 & $\mathrm{Br}-501$ & $\mathrm{Br}-503$ & $\mathrm{Br}-602$ & IPA-7301218 \\
\cline { 2 - 6 } & $33,80 \mathrm{Ab}$ & $19,25 \mathrm{Ac}$ & $38,66 \mathrm{Aab}$ & $34,10 \mathrm{Ab}$ & $42,69 \mathrm{Aa}$ & $42,69 \mathrm{Aa}$ \\
3.000 & $25,62 \mathrm{Ba}$ & $15,90 \mathrm{ABb}$ & $25,04 \mathrm{Ba}$ & $26,92 \mathrm{Ba}$ & $27,31 \mathrm{Ba}$ & $29,35 \mathrm{Ba}$ \\
6.000 & $11,67 \mathrm{Ca}$ & $12,38 \mathrm{Ba}$ & $14,22 \mathrm{Ca}$ & $9,41 \mathrm{Ca}$ & $10,31 \mathrm{Ca}$ & $11,49 \mathrm{Ca}$ \\
\hline
\end{tabular}

C.v. $(\%)=9,92$

D.M.S. (Tukey 5\%): Cultivar $=2,87$

Cultivar d. Nive1 $=4,96$

Nivel $=1,65$

Nivel d. Cultivar $=4,05$

Tabela 6 - Altura (m) de diferentes cultivares de sorgo sacarino em função dos niveis de cloreto na solução nutritiva.

$\mathrm{Cl}$

\begin{tabular}{ccccccc}
$(\mathrm{ppm})$ & Ample H-0-K & CMS-XS-616 & $\mathrm{Br}-501$ & $\mathrm{Br}-503$ & $\mathrm{Br}-602$ & IPA-7301218 \\
\cline { 2 - 7 } & $2,28 \mathrm{Abc}$ & $1,93 \mathrm{Acd}$ & $1,87 \mathrm{Ac}$ & $2,63 \mathrm{Aa}$ & $2,25 \mathrm{Ab}$ & $2,75 \mathrm{Aa}$ \\
2.000 & $1,94 \mathrm{Bbc}$ & $1,72 \mathrm{Bcd}$ & $1,54 \mathrm{Bd}$ & $2,28 \mathrm{Ba}$ & $1,99 \mathrm{Bb}$ & $2,28 \mathrm{Ba}$ \\
4.000 & $1,61 \mathrm{Ca}$ & $1,28 \mathrm{Ccb}$ & $1,10 \mathrm{Cb}$ & $1,73 \mathrm{Ca}$ & $1,57 \mathrm{Ca}$ & $1,65 \mathrm{Ca}$ \\
\hline
\end{tabular}

C.V. $(\%)=6,25$

D.M.S. (Tukey $5 \%$ ): Cultivar $=0,08$ Nivel $=0,14$

Letras maiúsculas comparan colunas e letras minúsculas comparam linhas. Médias seguidas pela mesma letra não diferem entre si. 
Tabela 7 - Comprimento da panicula $(\mathrm{cm})$ de diferentes cultivares de sorgo sacarino, em função dos niveis de cloreto na solução nutritiva.

\begin{tabular}{|c|c|c|c|c|c|c|}
\hline \multirow{2}{*}{$\begin{array}{c}\mathrm{Cl} \\
(\mathrm{ppm})\end{array}$} & \multicolumn{6}{|c|}{ C U L T I V A R E S } \\
\hline & Ample $\mathrm{H}-\mathrm{O}-\mathrm{K}$ & CMS-XS-616 & $\mathrm{Br}-501$ & $\mathrm{Br}-503$ & $\mathrm{Br}-602$ & IPA-7301218 \\
\hline 0 & $22,33 \mathrm{Abc}$ & $11,67 \mathrm{Ae}$ & 20,17 Acd & $18,33 \mathrm{Ad}$ & $23,83 \mathrm{Ab}$ & $34,50 \mathrm{Aa}$ \\
\hline 2.000 & $17,67 \mathrm{Bbc}$ & $10,00 \mathrm{Ad}$ & $17,50 \mathrm{Bbc}$ & $16,13 \mathrm{BC}$ & $20,00 \mathrm{Bb}$ & $28, \mathrm{OOBa}$ \\
\hline 4.000 & $11,83 \mathrm{Cc}$ & $5,67 \mathrm{Bd}$ & $15.83 \mathrm{Bb}$ & $10,33 \mathrm{Cc}$ & $16,00 \mathrm{Cb}$ & $24,83 \mathrm{Ca}$ \\
\hline
\end{tabular}

C. V. $(\%)=6,09$

D.M.S. (Tukey 5\%): Cultivar $=1,56$

Cultivar d. Nivel $=2,70$

Nivel $=0,89$

Nivel d. Cultivar $=2,19$

Tabela 8 - Diâmetro do colmo $(\mathrm{cm})$ de diferentes cultivares de sorgo sacarino, em função dos níveis de cloreto na solução nutritiva.

\begin{tabular}{ccccccc}
\hline \multirow{2}{*}{$\begin{array}{c}\text { C1 } \\
(\mathrm{ppm})\end{array}$} & Ample H-0-K CMS-XS-616 & Br-501 & Br-503 & Br-602 & IPA-7301218 \\
\cline { 2 - 7 } & $1,67 \mathrm{Abc}$ & $1,47 \mathrm{Ad}$ & $1,83 \mathrm{Aab}$ & $1,55 \mathrm{Acd}$ & $2,00 \mathrm{Aa}$ & $1,87 \mathrm{Aa}$ \\
\hline 0 & $1,43 \mathrm{Bab}$ & $1,32 \mathrm{Bb}$ & $1,45 \mathrm{Bab}$ & $1,35 \mathrm{Bab}$ & $1,52 \mathrm{Ba}$ & $1,47 \mathrm{Bab}$ \\
2.000 & $1,17 \mathrm{Cab}$ & $1,00 \mathrm{Cb}$ & $1,28 \mathrm{Ca}$ & $1,07 \mathrm{Cb}$ & $1,28 \mathrm{Ca}$ & $1,30 \mathrm{Ca}$ \\
4.000 & 0 & & & & &
\end{tabular}

C.V. $(\%)=4,75$

D.M.S. (Tukey 5\%): Cultivar $=0,10$

Cultivar d. Nivel $=0,17$

Nive1 $=0,06$

Nivel d. Cultivax $=0,14$

Letras maiüsculas comparam colunas e letras minúsculas comparam linhas.

Médias seguidas pela mesma letra não diferem entre si. 
Tabela 9 - Produção de matéria seca (g/planta) das raizes de diferentes cultivares de sorgo sacarino, em função dos niveis de cloreto na solução nutritiva.

\begin{tabular}{ccccccc}
\hline \multirow{2}{c}{$\begin{array}{c}\text { C1 } \\
(\mathrm{ppD})\end{array}$} & Ample H-0-K CMS-XS-616 & $\mathrm{Br}-501$ & $\mathrm{Br}-503$ & $\mathrm{Br}-602$ & IPA-7301218 \\
\cline { 2 - 7 } & $17,02 \mathrm{Aab}$ & $10,15 \mathrm{Ad}$ & $13,77 \mathrm{Ac}$ & $15,25 \mathrm{Abc}$ & $19,62 \mathrm{Aa}$ & $15,40 \mathrm{Abc}$ \\
0 & $13,65 \mathrm{Ba}$ & $6,95 \mathrm{Bc}$ & $7,60 \mathrm{Bc}$ & $11,02 \mathrm{Bab}$ & $11,62 \mathrm{Bab}$ & $9,31 \mathrm{Bbc}$ \\
2.000 & $8,77 \mathrm{Ca}$ & $3,95 \mathrm{Cc}$ & $5,30 \mathrm{Cbc}$ & $5,17 \mathrm{Cbc}$ & $7,02 \mathrm{Cab}$ & $5,81 \mathrm{Cbc}$ \\
\hline
\end{tabular}

C.V. $(\%)=12,63$

D.M.S. (Tukey 5\%): Cu1tivar $=1,59$

Cultivar d. Nivel $=2,75$

Nivel $=0,92$

Nivel d. Cultivar $=2,24$

Tabela 10 - Produção de matéria seca (g/planta) dos colmos de diferentes culti vares de sorgo sacarino, em função dos niveis de cloreto na solução nutritiva.

$\mathrm{C} 1$

C U L T I V A R E S

$(\mathrm{ppm})$

Ample H-O-K CMS-XS-616 Br-501 Br-503

Br -602

$I P A-7301218$

$\begin{array}{cllllll}0 & 49,50 \mathrm{Aa} & 30,53 \mathrm{Ac} & 40,29 \mathrm{Ab} & 49,04 \mathrm{Aa} & 51,66 \mathrm{Aa} & 51,03 \mathrm{Aa} \\ 2.000 & 38,14 \mathrm{Ba} & 21,06 \mathrm{Bc} & 24,83 \mathrm{Bbc} & 35,77 \mathrm{Ba} & 27,42 \mathrm{Bb} & 35,56 \mathrm{Ba} \\ 4.000 & 24,37 \mathrm{Ca} & 13,74 \mathrm{Cb} & 15,47 \mathrm{Cb} & 15,68 \mathrm{Cb} & 18,41 \mathrm{Cb} & 25,49 \mathrm{Ca}\end{array}$

C.V. $(\%)=8,01$

D.M.S. (Tukey 5\%): Cultivar $=3,05$

Cultivar d. Nivel $=5,29$

Nível $=1,76$

Nivel d. Cultivar $=4,31$

Letras maiúsculas comparam colunas. e letras minúsculas comparam linhas. Médias seguidas pela mesma letra não diferem entre si. 
Tabela 11 - Produção de matēria seca ( $\mathrm{g} / \mathrm{planta)}$ das folhas de diferentes cultivares de sorgo sacarino, em função dos niveis de cloreto na solução nutritiva.

C1

(ppr)

Ample

C U L T I V A R E S

\begin{tabular}{ccccccc}
\hline 0 & $12,95 \mathrm{Ac}$ & $10,52 \mathrm{Ad}$ & $16,50 \mathrm{Ab}$ & $11,37 \mathrm{Acd}$ & $15,10 \mathrm{Ab}$ & $22,47 \mathrm{Aa}$ \\
2.000 & $11,52 \mathrm{Abc}$ & $8,95 \mathrm{Ad}$ & $12,75 \mathrm{Bb}$ & $10,26 \mathrm{Bcd}$ & $13,57 \mathrm{Ab}$ & $17,57 \mathrm{Ba}$ \\
4.000 & $8,42 \mathrm{Bcd}$ & $7,11 \mathrm{Bd}$ & $10,99 \mathrm{cb}$ & $7,77 \mathrm{Cd}$ & $10,27 \mathrm{Bbc}$ & $15,73 \mathrm{Ca}$ \\
\hline
\end{tabular}

C.V. $(\%)=8,05$

$\begin{aligned} \text { D.M.S. (Tukey 5\%): Cultivar } & =1,21 & & \text { Cultivar d. Nivel }=2,09 \\ \text { Nivel } & =0,70 & & \text { Nivel d. Cultivar }=1,71\end{aligned}$

Tabela 12 - Produção de matéria seca (g/planta) das panículas de diferentes cu1 tivares de sorgo sacarino, em função dos niveis de cloreto na solução nutritiva.

C1

\begin{tabular}{ccccccc}
\cline { 2 - 6 }$(\mathrm{ppm})$ & Ample H-0-K & CMS-XS-616 & $\mathrm{Br}-501$ & $\mathrm{Br}-503$ & $\mathrm{Br}-602$ & IPA-7301218 \\
\hline 0 & $26,85 \mathrm{Ac}$ & $7,70 \mathrm{Ac}$ & $33,27 \mathrm{Ab}$ & $22,12 \mathrm{Ad}$ & $35,82 \mathrm{Aa}$ & $30,80 \mathrm{Ab}$ \\
2.000 & $19,92 \mathrm{Bb}$ & $4,27 \mathrm{Bc}$ & $20,45 \mathrm{Bb}$ & $18,55 \mathrm{Bb}$ & $24,07 \mathrm{Ba}$ & $21,20 \mathrm{Bb}$ \\
4.000 & $3,55 \mathrm{Cc}$ & $1,31 \mathrm{Cc}$ & $8,50 \mathrm{Cb}$ & $11,54 \mathrm{Ca}$ & $7,25 \mathrm{Cb}$ & $7,35 \mathrm{Cb}$ \\
\hline
\end{tabular}

C.V. $(\%)=7,75$

$\begin{aligned} \text { D.M.S. (Tukey 5\%): Cultivar } & =1,58 & & \text { Cultivar d. Nivel }=2,74 \\ \text { Nivel } & =0,91 & & \text { Nivel d. Cultivar }=2,24\end{aligned}$

Letras maiúsculas comparam colunas e letras minúsculas comparam linhas.

Médias seguidas pela mesma letra não diferem entre si. 
Tabela 13 - Produção de matëria seca total (g/planta) de diferentes cultivares de sorgo sacarino, em função dos níveis de cloreto na solução nutritiva.

C1

C. U L T I V A R E S

\section{(ppm)}

Ample H-O-K CMS-XS-616 Br-501

$\operatorname{Br}-503$

$\mathrm{Br}-602$

IPA-7301218

\begin{tabular}{crrrrrr}
\hline 0 & $106,32 \mathrm{Ab}$ & $58,90 \mathrm{Ac}$ & $103,84 \mathrm{Ab}$ & $97,79 \mathrm{Ab}$ & $122,21 \mathrm{Aa}$ & $119,70 \mathrm{Aa}$ \\
2.000 & $83,24 \mathrm{Ba}$ & $41,28 \mathrm{Bc}$ & $65,66 \mathrm{Bb}$ & $76,29 \mathrm{Ba}$ & $76,69 \mathrm{Ba}$ & $83,64 \mathrm{Ba}$ \\
4.000 & $45,12 \mathrm{Cb}$ & $26,12 \mathrm{Cc}$ & $40,27 \mathrm{Cb}$ & $40,17 \mathrm{Cb}$ & $42,96 \mathrm{Cb}$ & $54,39 \mathrm{Ca}$ \\
\hline
\end{tabular}

C.V. $(\%)=5,87$

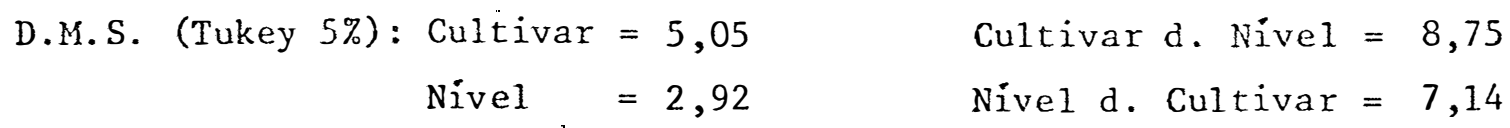

Tabela 14 - Produção de colmos frescos (g/planta) de diferentes cultivares de sorgo sacarino, em função dos niveis de cloreto na solução nutritiva.

Cl

C U L T I V A R E S

(ppm)

Ample H-0-K CMS-XS-616

$\mathrm{Br}-501$

Br -503

$\mathrm{Br}-602$

IPA-7301218

\begin{tabular}{clrllll}
0 & $229,83 \mathrm{Ab}$ & $163,93 \mathrm{Ac}$ & $222,52 \mathrm{Ab}$ & $224,80 \mathrm{Ab}$ & $282,41 \mathrm{Aa}$ & $299,43 \mathrm{Aa}$ \\
2.000 & $177,00 \mathrm{Babc}$ & $125,96 \mathrm{Bd}$ & $132,85 \mathrm{Bcd}$ & $168,40 \mathrm{Bbcd}$ & $213,92 \mathrm{Ba}$ & $195,73 \mathrm{Bab}$ \\
4.000 & $143,74 \mathrm{Bab}$ & $89,52 \mathrm{Bd}$ & $98,15 \mathrm{Bcd}$ & $113,15 \mathrm{Cbcd}$ & $168,61 \mathrm{Ca}$ & $141,15 \mathrm{Cabc}$ \\
\hline
\end{tabular}

C.V. $(\%)=12,15$

$\begin{aligned} \text { D.M.S. (Tukey 5\%): Cultivar } & =26,02 & & \text { Cultivar d. Nivel }=45,07 \\ \text { Nível } & =15,02 & & \text { Nivel d. Cultivar }=36,78\end{aligned}$

Letras maiúsculas comparam colunas e letras minúsculas comparam linhas. Médias seguidas peḷa mesma letra não diferem entre si. 
139.

Tabela 15 - Concentração de nitrogênio (\%) nos colmos de diferentes cultivares de sorgo sacarino, em função dos niveis de cloreto na solução nutritiva.

\begin{tabular}{ccccccc}
\hline \multirow{2}{c}{$\begin{array}{c}\text { C } \\
(p p m)\end{array}$} & Ample H-0-K CMS-XS-616 & Br-501 & Br-503 & Br-602 & IPA-7301218 \\
\cline { 2 - 7 } & $0,86 \mathrm{Ab}$ & $1,22 \mathrm{Aa}$ & $0,87 \mathrm{Ab}$ & $0,79 \mathrm{Ab}$ & $0,66 \mathrm{Ab}$ & $0,69 \mathrm{Bb}$ \\
0 & $0,82 \mathrm{Aa}$ & $0,93 \mathrm{Ba}$ & $0,88 \mathrm{Aa}$ & $0,69 \mathrm{Aa}$ & $0,65 \mathrm{Aa}$ & $0,73 \mathrm{ABa}$ \\
2.000 & $1,04 \mathrm{Aab}$ & $1,11 \mathrm{ABa}$ & $0,91 \mathrm{Aabc}$ & $0,71 \mathrm{Abc}$ & $0,68 \mathrm{Ac}$ & $0,97 \mathrm{Aabc}$ \\
4.000 & & & & & & \\
\hline
\end{tabular}

C.V. $(\%)=16,12$

D.M.S. (Tukey 5\%): Cultivar $=0,19$

Cultivar d. Nivel $=0,33$

Nivel $=0,11$

Nivel d. Cultivar $=0,27$

Letras maiúsculas comparam colunas e letras minüsculas comparam linhas. Médias seguidas pela mesma letra não diferem entre si. 
Tabela 16 - Concentração de nitrogênio (\%) nas folhas de dicerentes cultivares de sorgo sacarino, em função dos níveis de cloreto na solução nutritiva.

$\mathrm{C} 1$

C U L T I V A R E S

(ppro)

Ample H-O-K CMS-XS-616

Br -501

Br -503

$\mathrm{Br}-602$

IPA-7301218

SINTOMAS LEVES (SUPERIORES)

$\begin{array}{ccccccc}0 & 3,20 \mathrm{~A} & 2,08 \mathrm{~B} & 1,90 \mathrm{~A} & 1,82 \mathrm{AB} & 1,49 \mathrm{~B} & 2,22 \mathrm{~A}, \\ 2.000 & 2,31 \mathrm{C} & 1,94 \mathrm{~B} & 1,76 \mathrm{~A} & 2,13 \mathrm{~A} & 1,89 \mathrm{~A} & 1,48 \mathrm{~B} \\ 4.000 & 2,76 \mathrm{~B} & 3,31 \mathrm{~A} & 1,13 \mathrm{~B} & 1,71 \mathrm{~B} & 2,20 \mathrm{~A} & 1,23 \mathrm{~B}\end{array}$

SINTOMAS ACENTUADOS (INFERIORES)

$\begin{array}{ccccccc}0 & 3,21 \mathrm{~A} & 2,06 \mathrm{~B} & 1,91 \mathrm{~A} & 1,77 \mathrm{~A} & 1,49 \mathrm{~A} & 2,20 \mathrm{~A} \\ 2.000 & 1,84 \mathrm{~B} & 2,13 \mathrm{~B} & 1,12 \mathrm{~B} & 1,61 \mathrm{~A} & 1,61 \mathrm{~A} & 1,24 \mathrm{~B} \\ 4.000 & 2,03 \mathrm{~B} & 2,66 \mathrm{~A} & 0,96 \mathrm{~B} & 1,19 \mathrm{~B} & 1,67 \mathrm{~A} & 1,10 \mathrm{~B}\end{array}$

C.V. (\%) Parcelas

$=6,98$

C.V. (\%) Subparcelas

$=8,44$

D.M.S. (Tukey 5\%): Nivel d. Cultivar d. Sintoma $=0,32$

Cultivar d. Nivel d. Sintoma $=0,39$

Sintoma d. Cultivar d. Nivel $=0,26$

Letras maiüsculas comparam colunas.

Médias seguidas pela mesma letra não diferem entre si. 
Tabela 17 - Concentração de fósforo (\%) nos colmos de diferentes cultivares de sorgo sacarino, em função dos niveis de cloreto na solução nutritiva.

\begin{tabular}{ccccccc}
\hline \multirow{2}{*}{$\begin{array}{c}\text { C1 } \\
(\mathrm{ppm})\end{array}$} & Ample H-O-K CMS-XS-616 T I V A R E S & $\mathrm{Br}-501$ & $\mathrm{Br}-503$ & $\mathrm{Br}-602$ & IPA-7301218 \\
\cline { 2 - 6 } & $0,21 \mathrm{Ab}$ & $0,47 \mathrm{Aa}$ & $0,25 \mathrm{Ab}$ & $0,16 \mathrm{Ab}$ & $0,16 \mathrm{Bb}$ & $0,14 \mathrm{Bb}$ \\
0 & $0,11 \mathrm{Bb}$ & $0,44 \mathrm{Aa}$ & $0,11 \mathrm{Bb}$ & $0,14 \mathrm{Ab}$ & $0,17 \mathrm{AB}$ & $0,14 \mathrm{Bb}$ \\
2.000 & $0,29 \mathrm{Aab}$ & $0,39 \mathrm{Aa}$ & $0,21 \mathrm{Abc}$ & $0,12 \mathrm{Ac}$ & $0,26 \mathrm{Ab}$ & $0,26 \mathrm{Ab}$ \\
4.000 & $\vdots$ & & & & & \\
\hline
\end{tabular}

C.V. $(\%)=22,09$

D.M.S. (Tukey 5\%): Cultivar $=0,07$

Cultivar d. Nivel $=0,12$

Nivel $=0,04$

Nivel d. Cultivar $=0,09$

Letras maiúsculas comparam colunas e letras minúsculas comparam linhas. Médias seguidas pela mesma letra não diferem entre si. 
Tabela 18 - Concentração de fósforo (\%) nas folhas de diferentes cultivares de sorgo sacarino, em função dos niveis de cloreto na solução nutritiva.

\begin{tabular}{|c|c|c|c|c|c|c|}
\hline \multirow{2}{*}{$\begin{array}{c}\mathrm{Cl} \\
(\mathrm{ppm})\end{array}$} & \multicolumn{6}{|c|}{$C$ U L T I V A R E S } \\
\hline & Ample $\mathrm{H}-\mathrm{O}-\mathrm{K}$ & CMS-XS-616 & $\mathrm{Br}-501$ & $\mathrm{Br}-503$ & $\mathrm{Br}-602$ & IPA-7301218 \\
\hline & \multicolumn{6}{|c|}{ SINTOMAS LEVES (SUPERIORES) } \\
\hline 0 & $0,55 \mathrm{~A}$ & $0,75 \mathrm{~A}$ & $0,74 \mathrm{~A}$ & $0,69 \mathrm{~A}$ & $0,61 \mathrm{~A}$ & $0,52 \mathrm{~A}$ \\
\hline 2.000 & $0,36 \mathrm{~B}$ & $0,66 \mathrm{~A}$ & $0,48 \mathrm{~B}$ & $0,57 \mathrm{~A}$ & $0,58 \mathrm{~A}$ & $0,23 B$ \\
\hline 4.000 & $0,37 \mathrm{~B}$ & $0,61 \mathrm{~A}$ & $0,39 \mathrm{~B}$ & $0,42 \mathrm{~B}$ & $0,49 \mathrm{~A}$ & $0,29 B$ \\
\hline
\end{tabular}

SINTOMAS ACENTUADOS (INFERIORES)

$\begin{array}{ccccccc}0 & 0,54 \mathrm{~A} & 0,75 \mathrm{~A} & 0,74 \mathrm{~A} & 0,69 \mathrm{~A} & 0,58 \mathrm{~A} & 0,52 \mathrm{~A} \\ 2.000 & 0,19 \mathrm{~B} & 0,51 \mathrm{~B} & 0,43 \mathrm{~B} & 0,37 \mathrm{~B} & 0,50 \mathrm{AB} & 0,32 \mathrm{~B} \\ 4.000 & 0,40 \mathrm{~A} & 0,44 \mathrm{~B} & 0,29 \mathrm{~B} & 0,23 \mathrm{~B} & 0,36 \mathrm{~B} & 0,30 \mathrm{~B}\end{array}$

c.v. (\%) Parcelas

$=20,01$

C.v. (\%) Subparcelas

$=13,68$

D.M.S. (Tukey 5\%): Nivel d. Cultivar d. Sintoma $=0,14$

Cultivar d. Nivel d. Sintoma $=0,18$

Sintoma d. Cultivar d. Nivel $=0,12$

Letras maiúsculas comparam colunas.

Médias seguidas pela mesma letra não diferem entre si. 
143.

Tabela 19 - Concentração de potássio (\%) nos colmos de diferentes cultivares de sorgo sacarino, em função dos niveis de cloreto na solução nutritiva.

\begin{tabular}{ccccccc}
\hline \multirow{2}{*}{$\begin{array}{c}\text { C } 1 \\
\text { ppd }\end{array}$} & \multicolumn{7}{c}{ C U L T I V A R E S } \\
\cline { 2 - 7 } & Ample H-0-K CMS-XS-616 & Br-501 & Br-503 & Br-602 & IPA-7301218 \\
\hline 0 & $1,12 \mathrm{Ac}$ & $1,44 \mathrm{Aab}$ & $1,57 \mathrm{Aa}$ & $1,33 \mathrm{Aabc}$ & $1,61 \mathrm{Aa}$ & $1,18 \mathrm{Abc}$ \\
2.000 & $1,00 \mathrm{Ac}$ & $1,42 \mathrm{Aa}$ & $1,31 \mathrm{Bab}$ & $0,94 \mathrm{Bc}$ & $1,06 \mathrm{Bbc}$ & $0,83 \mathrm{Bc}$ \\
4.000 & $1,22 \mathrm{Aab}$ & $1,31 \mathrm{Aa}$ & $1,19 \mathrm{Babc}$ & $0,93 \mathrm{Bc}$ & $1,01 \mathrm{Bbc}$ & $1,26 \mathrm{Aab}$ \\
\hline
\end{tabular}

C.V. $(\%)=9,75$

$\begin{aligned} \text { D.M.S. (Tukey 5\%): Cultivar } & =0,17 & & \text { Cultivar d. Nivel }=0,29 \\ \text { Nivel } & =0,09 & & \text { Nivel d. Cultivar }=0,23\end{aligned}$

Letras maiúsculas comparam colunas e letras minúsculas comparam linhas. Médias seguidas pela mesma letra não diferem entre si. 
Tabela 20 - Concentração de potássio (\%) nas folhas de diferentes cultivares de sorgo sacarino em função dos níveis de cloreto na solução nutritiva.

$\mathrm{Cl}$

(ppm)

C U L T I V A R E S

\begin{tabular}{lllll}
\hline Ample H-0-K CMS-XS-616 & Br-501 & Br-503 & Br-602 & IPA-7301218
\end{tabular}

SINTOMAS LEVES (SUPERIORES)

$\begin{array}{ccccccc}0 & 3,17 \mathrm{~A} & 3,24 \mathrm{~A} & 2,04 \mathrm{~B} & 3,32 \mathrm{~A} & 2,49 \mathrm{~B} & 2,40 \mathrm{~A} \\ 2.000 & 2,44 \mathrm{~B} & 2,58 \mathrm{~B} & 2,16 \mathrm{~B} & 2,75 \mathrm{~B} & 3,09 \mathrm{~A} & 1,87 \mathrm{~B} \\ 4.000 & 1,78 \mathrm{C} & 2,10 \mathrm{C} & 2,69 \mathrm{~A} & 2,31 \mathrm{C} & 2,27 \mathrm{~B} & 1,57 \mathrm{~B}\end{array}$

SINTOMAS ACENTUADOS (INFERIORES)

$\begin{array}{ccccccc}0 & 3,10 \mathrm{~A} & 3,19 \mathrm{~A} & 2,02 \mathrm{~B} & 3,33 \mathrm{~A} & 2,50 \mathrm{~A} & 2,39 \mathrm{~A} \\ 2.000 & 2,37 \mathrm{~B} & 2,22 \mathrm{~B} & 2,81 \mathrm{~A} & 2,56 \mathrm{~B} & 2,58 \mathrm{~A} & 2,56 \mathrm{~A} \\ 4.000 & 1,96 \mathrm{~B} & 2,33 \mathrm{~B} & 2,56 \mathrm{~A} & 1,96 \mathrm{C} & 2,29 \mathrm{~A} & 2,73 \mathrm{~A}\end{array}$

C.V. (\%) Parcelas $=10,81$

C.V. (\%) Subparcelas $=8,27$

D.M.S. (Tukey 5\%): Nivel d. Cultivar d. Sintoma $=0,41$

Cultivar d. Nivel d. Sintoma $=0,51$

Sintoma d. Cultivar d. Nivel $=0,34$

Letras maiüsculas comparam colunas.

Médias seguidas pela mesma letra não diferem entre si. 
Tabela 21 - Concentração de cálcio (\%) nos colmos de diferentes cultivares de sorgo sacarino,em função dos niveis de cloreto na solução nutritiva.

\begin{tabular}{ccccccc}
\hline \multirow{2}{*}{$\begin{array}{c}\mathrm{C} 1 \\
\mathrm{ppm})\end{array}$} & \multicolumn{7}{c}{ C U L T I V A R E S } \\
\cline { 2 - 7 } & Ample H-0-K & CMS-XS-616 & Br-501 & Br-503 & Br-602 & IPA- 7301218 \\
\hline 0 & $0,14 \mathrm{Ac}$ & $0,16 \mathrm{Abc}$ & $0,25 \mathrm{Aa}$ & $0,12 \mathrm{Ac}$ & $0,23 \mathrm{Aab}$ & $0,13 \mathrm{Ac}$ \\
2.000 & $0,12 \mathrm{Aa}$ & $0,16 \mathrm{Aa}$ & $0,10 \mathrm{Ba}$ & $0,09 \mathrm{Aa}$ & $0,13 \mathrm{ABa}$ & $0,09 \mathrm{Aa}$ \\
4.000 & $0,11 \mathrm{Aa}$ & $0,15 \mathrm{Aa}$ & $0,14 \mathrm{Ba}$ & $0,09 \mathrm{Aa}$ & $0,16 \mathrm{Ba}$ & $0,12 \mathrm{Aa}$ \\
\hline
\end{tabular}

C.V. $(\%)=24,45$

D.M.S. (Tukey 5\%): Cultivar $=0,05$

Cultivar d. Nivel $=0,08$

Nivel $=0,03$

Nivel d. Cultivar $=0,07$

Letras maiúsculas comparam colunas e letras minúsculas comparam linhas. Médias seguidas pela mesma letra não diferem entre si. 
Tabela 22 - Concentração de cālcio (\%) nas folhas de diferentes cultivares de sor go sacarino, em função dos niveis de cloreto na solução nutritiva.

\begin{tabular}{|c|c|c|c|c|c|c|}
\hline \multirow{2}{*}{$\begin{array}{c}\mathrm{C1} \\
(\mathrm{ppm})\end{array}$} & \multicolumn{6}{|c|}{ C U L T I V A R E S } \\
\hline & Ample $\mathrm{H}-\mathrm{O}-\mathrm{K}$ & CMS-XS-616 & $\mathrm{Br}-501$ & $\mathrm{Br}-503$ & $\mathrm{Br}-602$ & IPA-7301218 \\
\hline & \multicolumn{6}{|c|}{ SINTOMAS LEVES (SUPERIORES) } \\
\hline 0 & $0,97 \mathrm{~A}$ & $0,52 \mathrm{~A}$ & $0,94 \mathrm{~A}$ & $1,01 \mathrm{~A}$ & $0,98 \mathrm{~A}$ & $0,62 \mathrm{~A}$ \\
\hline 2.000 & $0,82 \mathrm{~A}$ & $0,40 \mathrm{~A}$ & $0,35 \mathrm{C}$ & $0,74 \mathrm{~B}$ & $0,94 \mathrm{~A}$ & $0,33 B$ \\
\hline \multirow[t]{2}{*}{4.0000} & $0,61 B$ & $0,54 \mathrm{~A}$ & $0,71 B$ & $0,90 \mathrm{AB}$ & $0,61 B$ & $0,34 \mathrm{~B}$ \\
\hline & \multicolumn{6}{|c|}{ SINTOMAS ACENTUADOS (INFERIORES) } \\
\hline 0 & $0,96 \mathrm{~A}$ & $0,51 \mathrm{~A}$ & $0,93 \mathrm{~A}$ & $1,01 \mathrm{~A}$ & $0,97 \mathrm{~A}$ & $0,61 \mathrm{~A}$ \\
\hline 2.000 & $0,68 \mathrm{~B}$ & $0,54 \mathrm{~A}$ & $0,76 \mathrm{AB}$ & $0,91 \mathrm{~A}$ & $0,87 \mathrm{AB}$ & $0,63 \mathrm{~A}$ \\
\hline 4.000 & $0,57 \mathrm{~B}$ & $0,60 \mathrm{~A}$ & $0,73 B$ & $0,79 B$ & $0,72 B$ & $0,60 \mathrm{~A}$ \\
\hline $\mathrm{P}$ & & $=12,71$ & & & & \\
\hline (\%) Su & celas & $=12,00$ & & & & \\
\hline
\end{tabular}

D.M.S. (Tukey 5\%): Nivel d. Cultivar d. Sintoma $=0,17$

Cultivar d. Nivel d. Sintoma $=0,21$

Sintoma d. Cultivar d. Nivel $=0,14$

Letras maiūsculas comparam colunas.

Mëdias seguidas pela mesma letra não diferem entre si. 
Tabela 23. - Concentração de magnésio (\%) nos colmos de diferentes cultivares de sorgo sacarino, em função dos niveis de cloreto na solução nutritiva.

\begin{tabular}{ccccccc}
\hline \multirow{2}{c}{$\begin{array}{c}\text { C U L T I V A R E S } \\
(\mathrm{ppm})\end{array}$} & Ample H-O-K & CMS-XS-616 & Br-501 & Br-503 & Br-602 & IPA-7301218 \\
\cline { 2 - 7 } & $0,11 \mathrm{Abc}$ & $0,20 \mathrm{Aa}$ & $0,15 \mathrm{Aab}$ & $0,07 \mathrm{Abc}$ & $0,14 \mathrm{Aabc}$ & $0,06 \mathrm{Ac}$ \\
0 & $0,09 \mathrm{Ab}$ & $0,19 \mathrm{Aa}$ & $0,07 \mathrm{Bb}$ & $0,07 \mathrm{Ab}$ & $0,12 \mathrm{Aab}$ & $0,05 \mathrm{Ab}$ \\
4.000 & $0,13 \mathrm{Aab}$ & $0,18 \mathrm{Aa}$ & $0,08 \mathrm{ABb}$ & $0,06 \mathrm{Ab}$ & $0,13 \mathrm{Aab}$ & $0,09 \mathrm{Ab}$ \\
\hline
\end{tabular}

C.V. $(\%)=29,66$

D.M.S. (Tukey 5\%): Cultivar $=0,05$

Cultivar $\mathrm{d}$. Nivel $=0,08$

Nivel $=0,03$

Nive1 d. Cultivar $=0,06$

Letras maiüsculas comparam colunas e letras minúsculas comparam linhas. Médias seguidas pela mesma letra não diferem entre si. 
Tabela 24 - Concentração de magnésio (\%) nas folhas de diferentes cultivares de sorgo sacarino, em função dos niveis de cloreto na solução nutritiva.

$\mathrm{C} 1$

(ppm)

C U L T I V A R E S

\begin{tabular}{lllll}
\hline Ample H-0-K CMS-XS-616 & Br-501 & Br-503 & Br-602 & IPA-7301218
\end{tabular}

SINTOMAS LEVES (SUPERIORES)

$\begin{array}{ccccccc}0 & 0,60 \mathrm{~A} & 0,37 \mathrm{~A} & 0,63 \mathrm{~A} & 0,52 \mathrm{~A} & 0,59 \mathrm{~B} & 0,38 \mathrm{~A} \\ 2.000 & 0,49 \mathrm{~B} & 0,44 \mathrm{~A} & 0,35 \mathrm{~B} & 0,51 \mathrm{~A} & 0,72 \mathrm{~A} & 0,26 \mathrm{~B} \\ 4.000 & 0,40 \mathrm{~B} & 0,44 \mathrm{~A} & 0,55 \mathrm{~A} & 0,49 \mathrm{~A} & 0,59 \mathrm{~B} & 0,24 \mathrm{~B}\end{array}$

SINTOMAS ACENTUADOS (INFERIORES)

$\begin{array}{ccccccc}0 & 0,60 \mathrm{~A} & 0,36 \mathrm{~B} & 0,62 \mathrm{~A} & 0,51 \mathrm{~A} & 0,58 \mathrm{~A} & 0,36 \mathrm{~A} \\ 2.000 & 0,48 \mathrm{~B} & 0,40 \mathrm{AB} & 0,55 \mathrm{~A} & 0,56 \mathrm{~A} & 0,48 \mathrm{~A} & 0,33 \mathrm{~A} \\ 4.000 & 0,39 \mathrm{~B} & 0,48 \mathrm{~A} & 0,53 \mathrm{~A} & 0,46 \mathrm{~A} & 0,52 \mathrm{~A} & 0,33 \mathrm{~A}\end{array}$

C.V. (\%) Parcelas

$=15,81$

C.V. (\%) Subparcelas

$=11,03$

D.M.S. (Tukey 5\%): Nivel d. Cultivar d. Sintoma $=0,10$

Cultivar d. Nivel $d:$ Sintoma $=0,12$

Sintoma d. Cultivar d. Nivel $=0,08$

Letras maiúsculas comparam colunas.

Médias seguidas pela mesma letria não diferem entre si. 
Tabela 25 - Concentração de enxofre (\%) nos colmos de diferentes cultivares de sorgo sacarino, em função dos niveis de cloreto na solução nutritiva.

$\mathrm{Cl}$.

C U L T I V A R E S

\begin{tabular}{ccccccc}
\cline { 2 - 6 }$(\mathrm{ppm})$ & Arple H-0-K & CMS-XS-616 & $\mathrm{Br}-501$ & $\mathrm{Br}-503$ & $\mathrm{Br}-602$ & IPA-7301218 \\
\hline 0 & $0,11 \mathrm{Ab}$ & $0,19 \mathrm{Aa}$ & $0,17 \mathrm{Aab}$ & $0,12 \mathrm{Ab}$ & $0,17 \mathrm{Aab}$ & $0,13 \mathrm{Aab}$ \\
2.000 & $0,11 \mathrm{Aab}$ & $0,16 \mathrm{Aa}$ & $0,10 \mathrm{Bab}$ & $0,10 \mathrm{Aab}$ & $0,09 \mathrm{Bb}$ & $0,10 \mathrm{Aab}$ \\
4.000 & $0,11 \mathrm{Aa}$ & $0,15 \mathrm{Aa}$ & $0,12 \mathrm{Ba}$ & $0,10 \mathrm{Aa}$ & $0,16 \mathrm{Aa}$ & $0,10 \mathrm{Aa}$ \\
\hline
\end{tabular}

C.v. $(\%)=19,60 \%$

$\begin{aligned} \text { D.M.S. (Tukey 5\%): Cultivar } & =0,03 & & \text { Cultivar d. Nivel }=0,06 \\ \text { Nivel } & =0,02 & & \text { Nivel d. Cultivar }=0,05\end{aligned}$

Letras maiúsculas comparam colunas e letras minüsculas comparam linhas. Médias seguidas pela mesma letra não diferem entre si. 
Tabela 26 - Concentração de enxofre (\%) nas folhas de diferentes cultivares de sorgo sacarino, em função dos niveis de cloreto na solução nutritiva.

$\mathrm{Cl}$

C U L T I V A R E S

(ppm)

Ample H-0-K CMS-XS-616

$\mathrm{Br}-501$

Br-503

Br-602

IPA-7301218

SINTOMAS LEVES (SUPERIORES)

$\begin{array}{lllllll}0 & 0,37 \mathrm{~A} & 0,37 \mathrm{~A} & 0,23 \mathrm{~A} & 0,33 \mathrm{~A} & 0,32 \mathrm{~A} & 0,24 \mathrm{~A}\end{array}$

2.000

$0,21 \mathrm{~B} \quad 0,30 \mathrm{~B}$

$0,16 \mathrm{~B}$

$0,26 \mathrm{~B}$

$0,32 \mathrm{~A}$

$0,17 \mathrm{~B}$

4.000

$0,26 B$

$0,33 \mathrm{AB}$

$0,19 \mathrm{AB}$

$0,26 B$

$0,23 \mathrm{~B}$

$0,14 \mathrm{~B}$

\section{SINTOMAS ACENTUADOS (INFERIORES)}

$\begin{array}{ccccccr}0 & 0,35 \mathrm{~A} & 0,36 \mathrm{~A} & 0,22 \mathrm{~A} & 0,32 \mathrm{~A} & 0,31 \mathrm{~A} & 0,24 \mathrm{~A} \\ 2.000 & 0,23 \mathrm{~B} & 0,29 \mathrm{~B} & 0,21 \mathrm{~A} & 0,26 \mathrm{AB} & 0,27 \mathrm{AB} & 0,23 \mathrm{~A} \\ 4.000 & 0,25 \mathrm{~B} & 0,36 \mathrm{~A} & 0,23 \mathrm{~A} & 0,23 \mathrm{~B} & 0,24 \mathrm{~B} & 0,25 \mathrm{~A}\end{array}$
$\mathrm{C}$

C.V. (\%) Subparcelas

$=15,57$

$=10,75$

D.M.S. (Tukey 5\%): Nivel d. Cultivar d. Sintoma $=0,06$

Cultivar d. Nivel d. Sintoma $=0,07$

Sintoma d. Cultivar d. Nivel $=0,05$

Letras maiúsculas comparam colunas.

Médias seguidas pela mesma letra não diferem entre si. 
Tabela 27 - Concentração de boro (ppm) nos colmos de diferentes cultivares de sorgo sacarino, em função dos niveis de cloreto na solução nutritiva.

\begin{tabular}{|c|c|c|c|c|c|c|}
\hline \multirow{2}{*}{$\begin{array}{c}\mathrm{Cl} \\
(\mathrm{ppm})\end{array}$} & \multicolumn{6}{|c|}{$C \mathrm{U} L \mathrm{~T} I \mathrm{~V} A \mathrm{R} \mathrm{ES}$} \\
\hline & Ample $\mathrm{H}-\mathrm{O}-\mathrm{K}$ & CMS-XS-616 & $\mathrm{Br}-501$ & $\mathrm{Br}-503$ & $\mathrm{Br}-602$ & IPA-7301218 \\
\hline 0 & $9,3 \mathrm{Aa}$ & $5,3 \mathrm{Bb}$ & $5, \mathrm{OBb}$ & $5,0 \mathrm{Bb}$ & $6,0 \mathrm{Bb}$ & $5,6 \mathrm{Ab}$ \\
\hline 2.000 & $5, \mathrm{OBC}$ & $10,0 \mathrm{Aa}$ & $6,6 \mathrm{ABbc}$ & $8,6 \mathrm{Aab}$ & $8,6 \mathrm{Aab}$ & $5,0 \mathrm{Ac}$ \\
\hline 4.000 & $5,0 B c$ & $11,0 \mathrm{Aa}$ & $7,6 \mathrm{Abc}$ & $5,3 \mathrm{BC}$ & $8,3 \mathrm{ABab}$ & $6,0 A b c$ \\
\hline
\end{tabular}

C.V. $(\%)=17,15$

D.M.S. (Tukey 5\%): Cultivar $=1,67$

Cultivar $d$. Nivel $=2,90$

Nivel $=0,96$

Nivel d. Cultivar $=2,35$

Letras maiúsculas comparam colunas e letras minúsculas comparam linhas. Médias seguidas pela mesma letra não diferem entre si. 
Tabela 28 - Concentração de boro (ppm) nas folhas de diferentes cultivares de sorgo sacarino, em função dos niveis de cloreto na solução nutritiva.

\begin{tabular}{|c|c|c|c|c|c|c|}
\hline \multirow{2}{*}{$\begin{array}{c}\mathrm{Cl} \\
(\mathrm{ppm})\end{array}$} & \multicolumn{6}{|c|}{$C$ U L T I V A RE S } \\
\hline & Ample $\mathrm{H}-0-\mathrm{K}$ & CMS-XS-616 & Br-501 & $\mathrm{Br}-503$ & $\mathrm{Br}-602$ & IPA-7301218 \\
\hline & \multicolumn{6}{|c|}{ SINTOMAS LEVES (SUPERIORES) } \\
\hline 0 & $65 \mathrm{~A}$ & $82 \mathrm{~A}$ & $26 \mathrm{~B}$ & $48 B$ & $44 \mathrm{~A}$ & $22 \mathrm{~A}$ \\
\hline 2.000 & $54 \mathrm{~A}$ & $72 \mathrm{~A}$ & $35 \mathrm{AB}$ & $51 \mathrm{AB}$ & $56 \mathrm{~A}$ & $29 \mathrm{~A}$ \\
\hline \multirow[t]{2}{*}{4.000} & $58 \mathrm{~A}$ & $73 \mathrm{~A}$ & $43 \mathrm{~A}$ & $64 \mathrm{~A}$ & $58 \mathrm{~A}$ & $28 \mathrm{~A}$ \\
\hline & \multicolumn{6}{|c|}{ SINTOMAS ACENTUADOS (INFERIORES) } \\
\hline 0 & $64 \mathrm{~A}$ & $80 \mathrm{~A}$ & $25 B$ & $47 \mathrm{~A}$ & $44 \mathrm{~A}$ & $21 B$ \\
\hline 2.000 & $68 \mathrm{~A}$ & $66 \mathrm{~A}$ & $52 \mathrm{~A}$ & $53 \mathrm{~A}$ & $48 \mathrm{~A}$ & $39 \mathrm{~A}$ \\
\hline 4.000 & $46 \mathrm{~B}$ & $72 \mathrm{~A}$ & $40 \mathrm{AB}$ & $62 \mathrm{~A}$ & $53 \mathrm{~A}$ & $37 \mathrm{~A}$ \\
\hline
\end{tabular}
C.v. (\%) Parcelas
$=18,90$
C.V. (\%) Subparcelas
$=14,50$

D.M.S. (Tukey 5\%): Nivel d. Cultivar d. Sintoma $=15$

$$
\begin{aligned}
& \text { Cultivar d. Nivel d. Sintoma }=18 \\
& \text { Sintoma d. Cultivar d. Nivel }=12
\end{aligned}
$$

Letras maiúsculas comparam colunas.

Médias seguidas pela mesma letra não diferem entre si. 
153.

Tabela 29 - Concentração de cobre (ppm) nos colmos de diferentes cultivares de sorgo sacarino, em função dos níveis de cloreto na solução nutritiva.

\begin{tabular}{|c|c|c|c|c|c|c|}
\hline \multirow{2}{*}{$\begin{array}{c}\mathrm{Cl} \\
(\mathrm{ppm})\end{array}$} & \multicolumn{6}{|c|}{$C U L T I V A R E S$} \\
\hline & Ample $\mathrm{H}-\mathrm{O}-\mathrm{K}$ & CMS-XS-616 & $\mathrm{Br}-501$ & $\mathrm{Br}-503$ & $\mathrm{Br}-602$ & IPA -7301218 \\
\hline 0 & $5,0 \mathrm{Aa}$ & $5, \mathrm{OBa}$ & $5,3 \mathrm{Aa}$ & $5,0 \mathrm{Aa}$ & $5, \mathrm{OBa}$ & $5,0 \mathrm{Aa}$ \\
\hline 2.000 & $5,0 \overline{\mathrm{Ab}}$ & $7,3 \mathrm{Aa}$ & $5,0 A b$ & $5,0 A b$ & $5,3 \mathrm{Bb}$ & $5,0 A b$ \\
\hline 4.000 & $5,0 \mathrm{Ac}$ & $7,3 \mathrm{Aa}$ & $5,0 A c$ & $5,3 \mathrm{Abc}$ & $6,3 \mathrm{Aab}$ & $5,0 \mathrm{Ac}$ \\
\hline
\end{tabular}

C.V. $(\%)=7,57$

D.M.S. (Tukey 5\%): Cultivar $=0,58$

Cultivar d. Nivel $=1,00$

Nivel $=0,33$

Nivel d. Cultivar $=0,81$

Letras maiüsculas comparam colunas e letras'minúsculas comparam linhas. Médias seguidas pela mesma letra não diferem entre si. 
Tabela 30 - Concentração de cobre (ppm) nas folhas de diferentes cultivares de sor go sacarino, em função dos niveis de cloreto na solução nutritiva.

\begin{tabular}{|c|c|c|c|c|c|c|}
\hline \multirow{2}{*}{$\begin{array}{c}\mathrm{C1} \\
(\mathrm{ppm})\end{array}$} & \multicolumn{6}{|c|}{ C U L T I VAR E S } \\
\hline & Ample $\mathrm{H}-\mathrm{O}-\mathrm{K}$ & CMS-XS-616 & $\mathrm{Br}-501$ & $\mathrm{Br}-503$ & $\mathrm{Br}-602$ & IPA-7301218 \\
\hline & \multicolumn{6}{|c|}{ SINTOMAS LEVES (SUPERIORES) } \\
\hline 0 & $11 \mathrm{~A}$ & $14 \mathrm{~A}$ & $8 \mathrm{~A}$ & $16 \mathrm{~A}$ & $12 \mathrm{~B}$ & $8 \mathrm{~A}$ \\
\hline 2.000 & $10 \mathrm{~A}$ & $11 \mathrm{~A}$ & $7 \mathrm{~A}$ & $15 \mathrm{~A}$ & $15 \mathrm{AB}$ & $6 \mathrm{~A}$ \\
\hline 4.000 & $12 \mathrm{~A}$ & $14 \mathrm{~A}$ & $8 \mathrm{~A}$ & $14 \mathrm{~A}$ & $17 \mathrm{~A}$ & $5 \mathrm{~A}$ \\
\hline
\end{tabular}

\section{SINTOMAS ACENTUADOS (INFERIORES)}

$\begin{array}{ccccccc}0 & 11 \mathrm{AB} & 14 \mathrm{~B} & 8 \mathrm{~A} & 15 \mathrm{~B} & 12 \mathrm{~B} & 7 \mathrm{~A} \\ 2.000 & 9 \mathrm{~B} & 12 \mathrm{~B} & 8 \mathrm{~A} & 20 \mathrm{~A} & 14 \mathrm{~B} & 8 \mathrm{~A} \\ 4.000 & 13 \mathrm{~A} & 21 \mathrm{~A} & 8 \mathrm{~A} & 15 \mathrm{~B} & 19 \mathrm{~A} & 9 \mathrm{~A}\end{array}$

C.V. (\%) Parcelas

$$
\begin{aligned}
& =24,87 \\
& =14,68
\end{aligned}
$$

C.V. (\%) Subparcelas

D.M.S. (Tukey 5\%): Nivel d. Cultivar d. Sintoma $=3,44$

Cultivar d. Nivel d. Sintoma $=4,24$

Sintoma d. Cultivar d. Nivel $=2,86$

Letras maiúsculas comparam colunas.

Médias seguidas pela mesma letria não diferem entre si. 
155.

Tabela 31 - Concentração de ferro (ppm) nos colmos de diferentes cultivares de sorgo sacarino, em função dos niveis de cloreto na solução nutrití va.

\begin{tabular}{ccccccc}
\hline \multirow{2}{*}{$\begin{array}{c}\mathrm{Cl} \\
(\mathrm{ppm})\end{array}$} & C U L T I V A R E S \\
\cline { 2 - 7 } & Ample H-O-K & CMS-XS-616 & Br-501 & Br-503 & Br-602 & IPA-7301218 \\
\hline 0 & $81 \mathrm{Aab}$ & $80 \mathrm{Bab}$ & $87 \mathrm{Aab}$ & $78 \mathrm{Aab}$ & $75 \mathrm{Cb}$ & $105 \mathrm{Aa}$ \\
2.000 & $80 \mathrm{Aa}$ & $101 \mathrm{Ba}$ & $77 \mathrm{Aa}$ & $87 \mathrm{Aa}$ & $104 \mathrm{Ba}$ & $94 \mathrm{Aa}$ \\
4.000 & $87 \mathrm{Ab}$ & $131 \mathrm{Aa}$ & $89 \mathrm{Ab}$ & $88 \mathrm{Ab}$ & $132 \mathrm{Aa}$ & $105 \mathrm{Aab}$ \\
\hline
\end{tabular}

C.V. $(\%)=12,56$

$\begin{array}{rlrl}\text { D.M.S. (Tukey 5\%): Cultivar } & =16,65 & & \text { Cultivar d. Nivel }=28,84 \\ \text { Nivel } & =9,54 & \text { Nivel d. Cultivar }=23,38\end{array}$

Letras maiüsculas comparam colunas e letras minüsculas comparam linhas. Médias seguidas pela mesma letra não diferem entre si. 
Tabela 32 - Concentração de ferro (ppm) nas folhas de diferentes cultivares de sor go sacarino, em função dos niveis de cloreto na solução nutritiva.

C1

C U L T I V A R E S

(ppm)

Ample H-0-K CMS-XS-616 Br-501 $\quad$ Br-503

$\mathrm{Br}-602$

IPA-7301218

SINTOMAS LEVES (SUPERIORES)

$\begin{array}{ccccccc}0 & 401 \mathrm{~A} & 279 \mathrm{~A} & 311 \mathrm{~B} & 459 \mathrm{~A} & 334 \mathrm{~B} & 381 \mathrm{~A} \\ 2.000 & 213 \mathrm{~B} & 257 \mathrm{~A} & 156 \mathrm{C} & 476 \mathrm{~A} & 472 \mathrm{~A} & 218 \mathrm{~B} \\ 4.000 & 316 \mathrm{~A} & 302 \mathrm{~A} & 424 \mathrm{~A} & 520 \mathrm{~A} & 412 \mathrm{AB} & 243 \mathrm{~B}\end{array}$

SINTOMAS ACENTUADOS (INFERIORES)

$\begin{array}{ccccccc}0 & 399 \mathrm{~A} & 283 \mathrm{~B} & 296 \mathrm{~B} & 455 \mathrm{~B} & 331 \mathrm{C} & 375 \mathrm{~A} \\ 2.000 & 293 \mathrm{~B} & 321 \mathrm{~B} & 340 \mathrm{AB} & 584 \mathrm{~A} & 448 \mathrm{~B} & 442 \mathrm{~A} \\ 4.000 & 403 \mathrm{~A} & 475 \mathrm{~A} & 411 \mathrm{~A} & 415 \mathrm{~B} & 556 \mathrm{~A} & 435 \mathrm{~A}\end{array}$

C.v. (\%) Parcelas

$=18,45$

C.v. (\%) Subparcelas

$=13,25$

D.M.S. (Tukey 5\%): Nivel d. Cultivar d. Sintoma $=98,58$

Cultivar d. Nivel d. Sintoma $=121,61$

Sintoma d. Cultivar d. Nivel $=82,02$

Letras maiúsculas comparam colunas.

Médias seguidas pela mesma letra não diferem entre si. 
Tabela 33 - Concentração de manganês (ppm) nos colmos de diferentes cultivares de sorgo sacarino, em função dos niveis de cloreto na solução nutritiva.

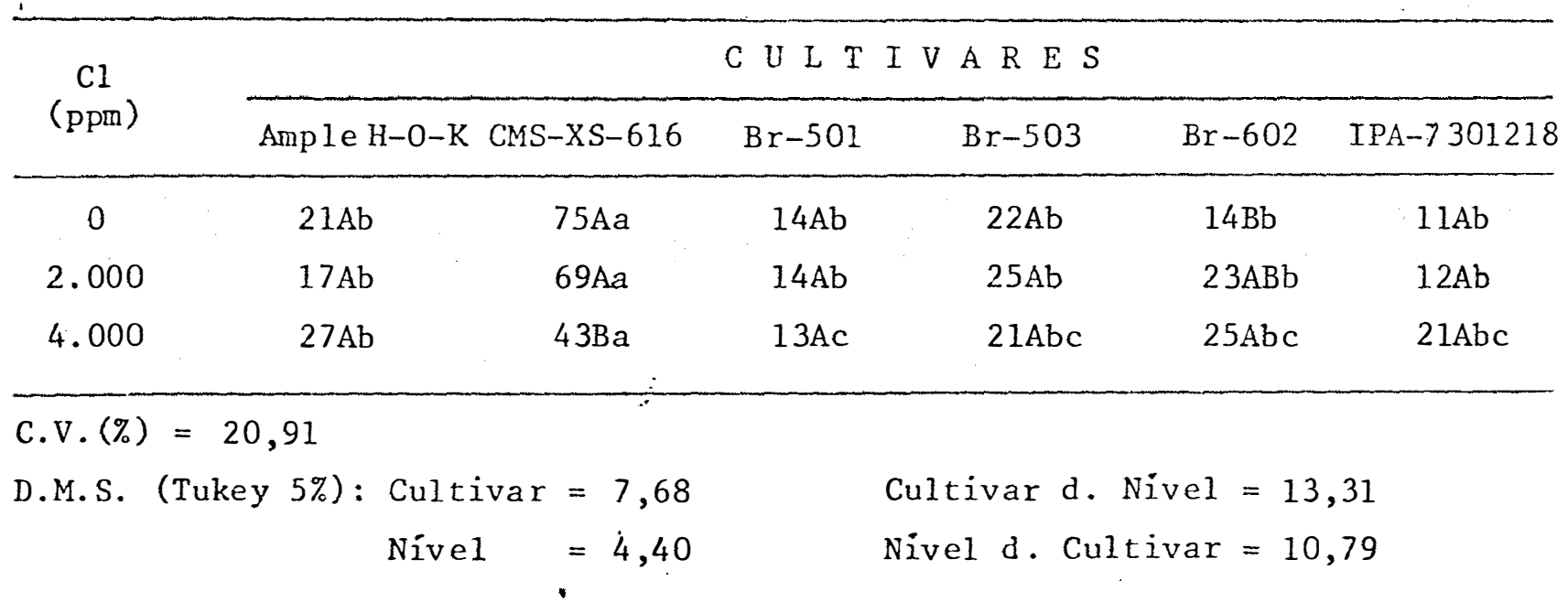

Letras maiūsculas comparam colunas e letras minúsculas comparam linhas. Mëdias seguidas pela mesma letra não diferem entre si. 
Tabela 34 - Concentração de manganês (ppm) nas folhas de diferentes cultivares de sorgo sacarino, em função dos niveis de cloreto na solução nutritiva.

\begin{tabular}{|c|c|c|c|c|c|c|}
\hline \multirow{2}{*}{$\begin{array}{c}\mathrm{Cl} \\
(\mathrm{ppm})\end{array}$} & \multicolumn{6}{|c|}{$C U L T I V A R E S$} \\
\hline & Ample $\mathrm{H}-\mathrm{O}-\mathrm{K}$ & CMS-XS-616 & $\mathrm{Br}-501$ & $\mathrm{Br}-503$ & $\mathrm{Br}-602$ & IPA-7301218 \\
\hline & \multicolumn{6}{|c|}{ SINTOMAS LEVES (SUPERIORES) } \\
\hline 0 & $129 \mathrm{~A}$ & $169 \mathrm{~A}$ & $65 B$ & $99 B$ & $88 \mathrm{~B}$ & $69 \mathrm{~A}$ \\
\hline 2.000 & $106 \mathrm{~A}$ & $153 \mathrm{~A}$ & $34 B$ & $198 \mathrm{~A}$ & $132 \mathrm{~A}$ & $74 \mathrm{~A}$ \\
\hline \multirow[t]{2}{*}{4.000} & $99 \mathrm{~A}$ & $176 \mathrm{~A}$ & $124 \mathrm{~A}$ & $175 \mathrm{~A}$ & $156 \mathrm{~A}$ & $66 \mathrm{~A}$ \\
\hline & \multicolumn{5}{|c|}{ SINTOMAS ACENTUADOS (INFERIORES) } & \\
\hline 0 & $127 \mathrm{~A}$ & $165 B$ & $66 B$ & $99 B$ & $86 B$ & $67 \mathrm{~A}$ \\
\hline 2.000 & $100 \mathrm{~A}$ & $150 B$ & $47 \mathrm{~B}$ & $188 \mathrm{~A}$ & $100 B$ & $99 \mathrm{~A}$ \\
\hline 4.000 & $108 \mathrm{~A}$ & $231 \mathrm{~A}$ & $118 \mathrm{~A}$ & $175 \mathrm{~A}$ & $140 \mathrm{~A}$ & $90 \mathrm{~A}$ \\
\hline
\end{tabular}

C.v. (\%) Parcelas

$=18,43$

C.V. (\%) Subparcelas

$=14,19$

D.M.S. (Tukey 5\%): Nivel d. Cultivar d. Sintoma $=33,54$

Cultiyar d. Nivel d. Sintoma $=41,38$

Sintoma d. Cultivar d. Nivel $=27,91$

Letras maiúsculas comparam colunas.

Médias seguidas pela mesma letra não diferem entre si. 
159.

Tabela 35 - Concentração de zinco (ppm) nos colmos de diferentes cultivares de sorgo sacarino, em função dos niveis de cloreto na solução nutriti va.

\begin{tabular}{ccccccc}
\hline \multirow{2}{*}{$\begin{array}{c}\mathrm{C} 1 \\
(\mathrm{ppm})\end{array}$} & Ample H-0-K & CMS-XS-616 & $\mathrm{Br}-501$ & $\mathrm{Br}-503$ & $\mathrm{Br}-602$ & IPA-7301218 \\
\cline { 2 - 7 } & $20 \mathrm{Aa}$ & $20 \mathrm{Aa}$ & $23 \mathrm{Aa}$ & $17 \mathrm{Aa}$ & $17 \mathrm{Aa}$ & $19 \mathrm{Aa}$ \\
\hline 0 & $19 \mathrm{Aab}$ & $26 \mathrm{Aa}$ & $15 \mathrm{Bb}$ & $18 \mathrm{Aab}$ & $15 \mathrm{Ab}$ & $17 \mathrm{Aab}$ \\
2.000 & $26 \mathrm{Aa}$ & $26 \mathrm{Aa}$ & $25 \mathrm{Aa}$ & $17 \mathrm{Aab}$ & $16 \mathrm{Ab}$ & $19 \mathrm{Aab}$ \\
4.000 & & & & & & \\
\hline
\end{tabular}

C.V. $(\%)=19,02$

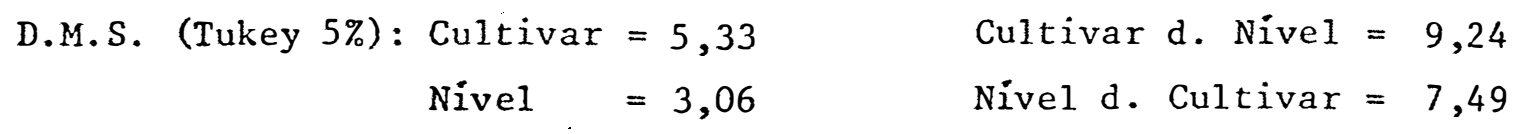

Letras maiüsculas comparam colunas e letras minüsculas comparam linhas. Médias seguidas pela mesma letra não diferem entre si. 
160.

Tabela 36 - Concentração de zinco (ppm) nas folhas de diferentes cultivares de sor go sacarino, em função dos níveis de cloreto na solução nutritiva.

Cl

C U L T I V A R E S

$(\mathrm{ppm})$

Ample H-0-K CMS-XS-616 Br-501 Br-503

$\mathrm{Br}-602$

IPA-7301218

SINTOMAS LEVES (SUPERIORES)

0

$29 B$

$37 \mathrm{~B}$

$28 \mathrm{~A}$

42B

29B

$28 A$

2.000

$37 \mathrm{~B}$

$36 \mathrm{~B}$

$29 A$

$49 A B$

$48 \mathrm{~A}$

$25 \mathrm{~A}$

4. 000

$51 \mathrm{~A}$

$53 \mathrm{~A}$

$33 \mathrm{~A}$

$58 \mathrm{~A}$

$49 \mathrm{~A}$

$32 \mathrm{~A}$

SINTOMAS ACENTUADOS (INFERIORES)

0

$29 B$

$36 \mathrm{~B}$

$27 B$

$41 B$

29B

$27 \mathrm{~B}$

2.000

$32 \mathrm{~B}$

33B

$52 \mathrm{~A}$

$53 \mathrm{~A}$

$42 \mathrm{~A}$

$35 \mathrm{AB}$

4.000

$48 \mathrm{~A}$

$53 \mathrm{~A}$

33B

$51 \mathrm{~A}$

$42 \mathrm{~A}$

$41 \mathrm{~A}$

C.V. (\%) Parcelas

$=16,75$

C.V. (\%) Subparcelas

$=12,28$

D.M.S. (Tukey 5\%): Nivel d. Cultivar d. Sintoma $=9,52$

Cultivar d. Nivel d. Sintoma $=11,74$

Sintoma d. Cultivar d. Nivel $=7,92$

Letras maiúsculas comparam colunas.

Médias seguidas pela mesma letra não diferem entre si. 
Tabela 37 - Concentração de cloro (\%) nos colmos de diferentes cultivares de sorgo sacarino, em função dos niveis de cloreto na solução nutriti va.

\begin{tabular}{ccccccc}
\hline \multirow{6}{Cl}{$\begin{array}{c}\text { C U L T I V A R E S } \\
(\mathrm{ppm})\end{array}$} & Ample H-0-K CMS-XS-616 & Br-501 & Br-503 & Br-602 & IPA-7301218 \\
\cline { 2 - 6 } & $0,04 \mathrm{Ca}$ & $0,08 \mathrm{Ca}$ & $0,05 \mathrm{Ca}$ & $0,07 \mathrm{Ca}$ & $0,07 \mathrm{Ca}$ & $0,06 \mathrm{Ca}$ \\
0 & $0,58 \mathrm{Bb}$ & $0,67 \mathrm{Bb}$ & $1,15 \mathrm{Ba}$ & $0,58 \mathrm{Bb}$ & $0,57 \mathrm{Bb}$ & $0,64 \mathrm{Bb}$ \\
2.000 & $1,22 \mathrm{Ae}$ & $1,81 \mathrm{Ab}$ & $2,55 \mathrm{Aa}$ & $1,41 \mathrm{Ade}$ & $1,72 \mathrm{Abc}$ & $1,52 \mathrm{Acd}$ \\
\hline
\end{tabular}

C.V. $(\%)=10,44$

D.M.S. (Tukey 5\%): Cultivar $=0,12$

Cultivar d. Nivel $=0,21$

Nível $=0,07$

Nivel d. Cultivar $=0,17$

Letras maiúsculas comparam colunas e letras minúsculas comparam linhas. Médias seguidas pela mesma letra não diferem entre si. 
162.

Tabela 38 - Concentração de cloro (\%) nas folhas de diferentes cultivares de sorgo sacarino, em função dos niveis de cloreto na solução nutritiva.

$\mathrm{Cl}$

(ppr)

C U L T I V A R E S

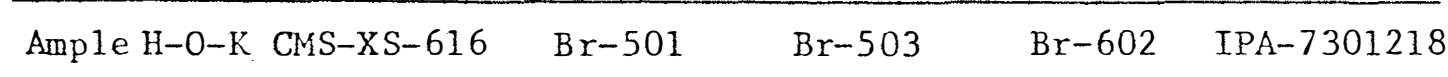

SINTOMAS LEVES (SUPERIORES)

$\begin{array}{ccccccc}0 & 0,18 \mathrm{~B} & 0,18 \mathrm{C} & 0,31 \mathrm{C} & 0,17 \mathrm{C} & 0,17 \mathrm{C} & 0,13 \mathrm{~B} \\ 2 & 0,41 \mathrm{~B} & 0,95 \mathrm{~B} & 2,72 \mathrm{~B} & 1,36 \mathrm{~B} & 1,07 \mathrm{~B} & 0,43 \mathrm{~B} \\ 4 & 0,92 \mathrm{~A} & 4,44 \mathrm{~A} & 4,51 \mathrm{~A} & 2,58 \mathrm{~A} & 1,55 \mathrm{~A} & 0,86 \mathrm{~A}\end{array}$

SINTOMAS ACENTUADOS (INFERIORES)

$\begin{array}{lllllll}0 & 0,18 \mathrm{C} & 0,17 \mathrm{C} & 0,30 \mathrm{C} & 0,16 \mathrm{C} & 0,17 \mathrm{C} & 0,13 \mathrm{C} \\ 2 & 1,02 \mathrm{~B} & 2,11 \mathrm{~B} & 3,68 \mathrm{~B} & 3,17 \mathrm{~B} & 1,56 \mathrm{~B} & 1,32 \mathrm{~B} \\ 4 & 5,07 \mathrm{~A} & 5,00 \mathrm{~A} & 5,06 \mathrm{~A} & 4,61 \mathrm{~A} & 4,16 \mathrm{~A} & 4,22 \mathrm{~A}\end{array}$

\begin{tabular}{ll}
\hline C.v. (\%) Parcelas & $=6,93$ \\
C.v. (\%) Subparcelas & $=8,48$
\end{tabular}

D.M.S. (Tukey 5\%): Nivel d. Cultivar d. Sintoma $=0,30$

Cultivar d. Nivel d. Sintoma $=0,38$

Sintoma d. Cultivar d. Nivel $=0,25$

Letras maiüsculas comparam colunas.

Médias seguidas pela mesma letra não diferem entre si. 
163.

Tabela 39 - Concentração de södio (\%) nos colmos de diferentes cultivares de sorgo sacarino, em função dos niveis de cloreto na solução nutritiva.

\begin{tabular}{cllllll}
\hline \multirow{2}{*}{$\begin{array}{c}\mathrm{C} 1 \\
(\mathrm{ppm})\end{array}$} & \multicolumn{7}{c}{ C U L T I V A R E S } \\
\cline { 2 - 7 } & Ample H-0-K CMS-XS-616 & Br-501 & Br-503 & Br-602 & IPA-7301218 \\
\hline 0 & $0,01 \mathrm{Ca}$ & $0,01 \mathrm{Ca}$ & $0,01 \mathrm{Ca}$ & $0,01 \mathrm{Ca}$ & $0,01 \mathrm{Ba}$ & $0,01 \mathrm{Ca}$ \\
2.000 & $0,50 \mathrm{Babc}$ & $0,60 \mathrm{Bab}$ & $0,69 \mathrm{Ba}$ & $0,31 \mathrm{Bbc}$ & $0,21 \mathrm{Bc}$ & $0,58 \mathrm{Bab}$ \\
4.000 & $1,17 \mathrm{Ab}$ & $1,45 \mathrm{Aab}$ & $1,75 \mathrm{Aa}$ & $1,36 \mathrm{Ab}$ & $1,31 \mathrm{Ab}$ & $1,23 \mathrm{Ab}$ \\
\hline
\end{tabular}

C.v. $(\%)=22,48$

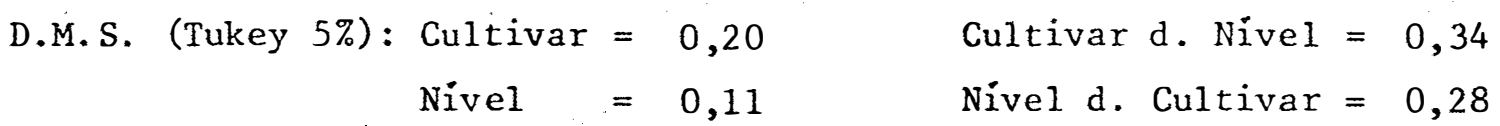

Letras maiúsculas comparam colunas e letras minüsculas comparam linhas. Médias seguidas pela mesma letra não diferem entre si. 
Tabela 40 - Concentração de sódio (\%) nas folhas de diferentes cultivares de sorgo sacarino, em função dos níveis de cloreto na solução nutritiva.

$\mathrm{Cl}$

C U L T I V A R E S

(ppn)

Ample H-0-K CMS-XS-616

Br -501

$\mathrm{Br}-503$

$\mathrm{Br}-602$

IPA-7301218

SINTOMAS LEVES (SUPERIORES)

$\begin{array}{ccccccc}0 & 0,01 \mathrm{~B} & 0,01 \mathrm{~B} & 0,01 \mathrm{C} & 0,01 \mathrm{~B} & 0,01 \mathrm{C} & 0,01 \mathrm{~B} \\ 2 & 0,14 \mathrm{~B} & 0,13 \mathrm{~B} & 0,91 \mathrm{~B} & 0,05 \mathrm{~B} & 0,22 \mathrm{~B} & 0,03 \mathrm{~B} \\ 4 & 0,83 \mathrm{~A} & 1,70 \mathrm{~A} & 1,72 \mathrm{~A} & 0,29 \mathrm{~A} & 0,53 \mathrm{~A} & 0,33 \mathrm{~A}\end{array}$

SINTOMAS ACENTUADOS (INFERIORES)

$\begin{array}{ccccccc}0 & 0,01 \mathrm{C} & 0,01 \mathrm{C} & 0,01 \mathrm{C} & 0,01 \mathrm{~B} & 0,01 \mathrm{C} & 0,01 \mathrm{C} \\ 2 & 0,35 \mathrm{~B} & 0,41 \mathrm{~B} & 1,41 \mathrm{~B} & 0,15 \mathrm{~B} & 0,66 \mathrm{~B} & 0,76 \mathrm{~B} \\ 4 & 2,06 \mathrm{~A} & 2,16 \mathrm{~A} & 2,16 \mathrm{~A} & 0,89 \mathrm{~A} & 2,16 \mathrm{~A} & 1,84 \mathrm{~A}\end{array}$

C.V. (\%) Parcelas

$=20,78$

C.V. (\%) Subparcelas

$=12,94$

D.M.S. (Tukey 5\%): Nível d. Cultivar d. Sintoma $=0,16$

Cultivar d. Nivel d. Sintoma $=0,19$

Sintoma d. Cultivar d. Nivel $=0,13$

Letras maiúsculas comparam colunas.

Médias seguidas pela mesma letra não diferem entre si. 
Tabela 41 - Concentração de nitrogênjo (mg/1) no caldo de diferentes cultivares de sorgo sacarino, em função dos níveis de cloreto na solução nutri tiva.

\begin{tabular}{clccccc}
\hline \multirow{2}{c}{$\begin{array}{c}c 1 \\
(\mathrm{ppm})\end{array}$} & C U L T I V A R E S \\
\cline { 2 - 7 } & Ample H-O-K CMS-XS-616 & Br-501 & Br-503 & Br-602 & IPA-7301218 \\
\hline 0 & $1.733 \mathrm{Ab}$ & $2.794 \mathrm{Aa}$ & $1.313 \mathrm{Ac}$ & $1.103 \mathrm{Ad}$ & $728 \mathrm{Ae}$ & $1.343 \mathrm{Ac}$ \\
2.000 & $1.044 \mathrm{Bb}$ & $1.300 \mathrm{Ba}$ & $1.023 \mathrm{Bb}$ & $685 \mathrm{Bc}$ & $561 \mathrm{Bc}$ & $1.012 \mathrm{Bb}$ \\
4.000 & $1.044 \mathrm{Bab}$ & $1.155 \mathrm{Ca}$ & $889 \mathrm{Cbc}$ & $549 \mathrm{Cd}$ & $518 \mathrm{Bd}$ & $831 \mathrm{Cc}$ \\
\hline
\end{tabular}

C.V. $(\%)=5,96$

D.M.S. (Tukey 5\%): Cultivar $=92,25$

Cultivar d. Nivel $=159,78$

Nivel $=52,88$

Nivel d. Cultivar $=129,54$

Letras maiúsculas comparan colunas e letras minüsculas comparam linhas. Médias seguidas pela mesma letra não diferem entre si. 
Tabela 42 - Concentração de fösforo (mg/1) no caldo de diferentes cultivares de sorgo sacarino, em função dos niveis de cloreto na solução nutritiva.

\begin{tabular}{ccccccc}
\hline \multirow{2}{*}{$\begin{array}{c}\text { C U L T I V A R E S } \\
(\mathrm{ppD})\end{array}$} & Ample H-0-K CMS-XS-616 & Br-501 & Br-503 & Br-602 & IPA-7301218 \\
\cline { 2 - 7 } & $730 \mathrm{Ab}$ & $1.326 \mathrm{Aa}$ & $299 \mathrm{Ac}$ & $777 \mathrm{Ab}$ & $637 \mathrm{ABb}$ & $421 \mathrm{Ac}$ \\
\hline 0 & $755 \mathrm{Ab}$ & $1.235 \mathrm{ABa}$ & $448 \mathrm{Ac}$ & $681 \mathrm{Ab}$ & $731 \mathrm{Ab}$ & $436 \mathrm{Ac}$ \\
2.000 & $765 \mathrm{Ab}$ & $1.129 \mathrm{Ba}$ & $405 \mathrm{Ac}$ & $474 \mathrm{Bc}$ & $538 \mathrm{Bc}$ & $495 \mathrm{Ac}$ \\
\hline
\end{tabular}

C. V. $(\%)=11,36$

D.M.S. (Tukey 5\%): Cultivar $=110,0$ Nive1 $=63,06$
Cultivar d. Nivel $=190,53$

Nivel d. Cultivar $=154,46$

Tabela 43 - Concentração de potássio (mg/1) no caldo de diferentes cultivares de sorgo sacarino, em função dos niveis de cloreto na solução nutritiva.

\begin{tabular}{ccccccc}
\hline \multirow{2}{*}{$\begin{array}{c}\text { Cl } \\
\text { ppm }\end{array}$} & \multicolumn{7}{c}{ C U L T I V A R E S } \\
\cline { 2 - 7 } & Ample H-0-K CMS-XS-616 & Br-501 & Br-503 & Br-602 & IPA- 7301218 \\
\hline 0 & $4.344 \mathrm{Ca}$ & $4.565 \mathrm{Ba}$ & $4.525 \mathrm{Ba}$ & $3.666 \mathrm{Bb}$ & $3.544 \mathrm{Cbc}$ & $3.022 \mathrm{Cc}$ \\
2.000 & $5.935 \mathrm{Bc}$ & $6.680 \mathrm{Ab}$ & $7.495 \mathrm{Aa}$ & $5.961 \mathrm{Ac}$ & $5.848 \mathrm{Bc}$ & $3.911 \mathrm{Bd}$ \\
4.000 & $6.472 \mathrm{Ac}$ & $6.935 \mathrm{Abc}$ & $7.617 \mathrm{Aa}$ & $5.806 \mathrm{Ad}$ & $7.106 \mathrm{Aab}$ & $4.725 \mathrm{Ae}$ \\
\hline
\end{tabular}

C.V. $(\%)=4,58$

$\begin{aligned} \text { D.M.S. (Tukey 5\%): Cultivar } & =354,53 & & \text { Cultivar d. Nivel }=614,06 \\ \text { Nivel } & =203,23 & & \text { Nivel d. Cultivar }=497,82\end{aligned}$

Letras maiúsculas comparam colunas e letras minúsculas comparam linhas. Médias seguidas pela mesma letra não diferem entre si. 
Tabela 44 - Concentração de cálcio (mg/1) no caldo de diferentes cultivares de sorgo sacarino, em função dos niveis de cloreto na solução nutrití va.

\begin{tabular}{ccccccc}
\hline \multirow{6}{C}{$\begin{array}{c}\text { C U L T I V A R E S } \\
(\mathrm{ppm})\end{array}$} & Ample H-0-K CMS-XS-616 & Br-501 & Br-503 & Br-602 & IPA-7301218 \\
\cline { 2 - 7 } & $543 \mathrm{Aa}$ & $335 \mathrm{Ab}$ & $544 \mathrm{Aa}$ & $333 \mathrm{Ab}$ & $571 \mathrm{Aa}$ & $296 \mathrm{Ab}$ \\
0 & $444 \mathrm{Ba}$ & $280 \mathrm{Bc}$ & $374 \mathrm{Bb}$ & $260 \mathrm{Bcd}$ & $459 \mathrm{Ba}$ & $208 \mathrm{Bd}$ \\
2.000 & $412 \mathrm{Ba}$ & $270 \mathrm{Bbc}$ & $300 \mathrm{Cb}$ & $225 \mathrm{Bcd}$ & $394 \mathrm{Ca}$ & $208 \mathrm{Bd}$ \\
\hline
\end{tabular}

C.V. $(\%)=5,95$

$\begin{aligned} \text { D.M.S. (Tukey 5\%): Cultivar } & =30,31 & & \text { Cultivar d. Nivel }=52,51 \\ \text { Nivel } & =17,38 & & \text { Nivel d. Cultivar }=42,57\end{aligned}$

Tabela 45 - Concentração de magnésio (mg/1) no caldo de diferentes cultivares de sorgo sacarino, em função dos niveis de cloreto na solução nutritiva.

\begin{tabular}{ccccccc}
\hline \multirow{2}{*}{$\begin{array}{c}\text { C1 } \\
\text { ppm }\end{array}$} & C U L T I V A R E S \\
\cline { 2 - 7 } & Ample H-0-K CMS-XS-616 & Br-501 & Br-503 & Br-602 & IPA-7301218 \\
\hline 0 & $384 \mathrm{Ab}$ & $501 \mathrm{Aa}$ & $360 \mathrm{Ab}$ & $207 \mathrm{Ac}$ & $368 \mathrm{Ab}$ & $161 \mathrm{Ac}$ \\
2.000 & $301 \mathrm{Bb}$ & $412 \mathrm{Ba}$ & $209 \mathrm{Bc}$ & $178 \mathrm{Acd}$ & $333 \mathrm{ABb}$ & $108 \mathrm{Ad}$ \\
4.000 & $294 \mathrm{Bb}$ & $377 \mathrm{Ba}$ & $189 \mathrm{Bc}$ & $114 \mathrm{Bcd}$ & $280 \mathrm{Bb}$ & $106 \mathrm{Ad}$ \\
\hline
\end{tabular}

C.V. $(\%)=11,53$

$\begin{array}{rlrl}\text { D.M.S. (Tukey 5\%): Cultivar } & =44,36 & & \text { Cultivar d. Nivel }=76,84 \\ \text { Nivel } & =25,43 & \text { Nivel d. Cultivar }=62,30\end{array}$

Letras maiüsculas comparam colunas e letras minúsculas comparam linhas.

Médias seguidas pela mesma letra não diferem entre si. 
Tabela 46 - Concentração de enxofre (mg/1) no caldo de diferentes cultivares de sorgo sacarino, em função dos niveis de cloreto na solução nutriti va.

\begin{tabular}{cllllll}
\hline \multirow{2}{*}{$\begin{array}{c}\text { C1 } \\
(\mathrm{ppm})\end{array}$} & Ample H-0-K CMS-XS-616 & $\mathrm{Br}-501$ & $\mathrm{Br}-503$ & $\mathrm{Br}-602$ & IPA-7301218 \\
\cline { 2 - 7 } & $430 \mathrm{Aa}$ & $434 \mathrm{Aa}$ & $331 \mathrm{Ab}$ & $248 \mathrm{Ac}$ & $353 \mathrm{Ab}$ & $209 \mathrm{Ac}$ \\
0 & $286 \mathrm{Bab}$ & $312 \mathrm{Ba}$ & $241 \mathrm{Bbc}$ & $202 \mathrm{ABc}$ & $241 \mathrm{Bbc}$ & $191 \mathrm{Ac}$ \\
4.000 & $242 \mathrm{Babc}$ & $255 \mathrm{Cab}$ & $216 \mathrm{Bbcd}$ & $167 \mathrm{Bd}$ & $290 \mathrm{Ba}$ & $183 \mathrm{Acd}$ \\
\hline
\end{tabular}

C.V. $(\%)=9,60$

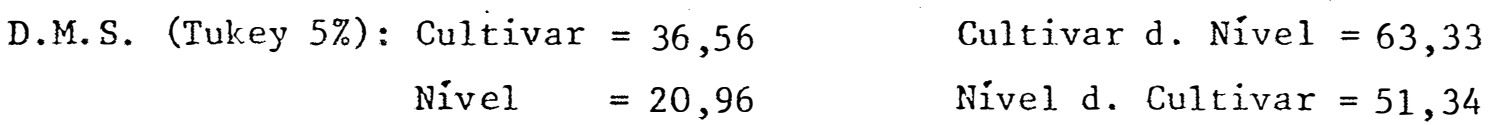

Tabela 47 - Concentração de boro (mg/1) no cảldo de diferentes cultivares de sorgo sacarino, em função dos niveis de cloreto na solução nutriti va.

C1

C U L T I V A R E S

\begin{tabular}{ccccccc} 
(ppm) & Ample H-0-K CMS-XS-616 & Br-501 & Br-503 & Br-602 & IPA-7301218 \\
\hline 0 & 0,5 & 0,5 & 0,5 & 0,5 & 0,5 & 0,5 \\
2.000 & 0,5 & 0,5 & 0,5 & 0,5 & 0,5 & 0,5 \\
4.000 & 0,5 & 0,5 & 0,5 & 0,5 & 0,5 & 0,5 \\
\hline
\end{tabular}

C. V. $(\%)=$

D.M.S. (Tukey 5\%): Cultivar $=$

Cultivar d. Nivel $=$ Nivel =

Nivel d. Cultivar $=$

Letras maiúsculas comparam colunas e letras minúsculas comparam linhas. Médias seguidas pela mesma letra não diferem entre si. 
Tabela 48 - Concentração de cobre (mg/1) no caldo de diferentes cultivares de sorgo sacarino, em função dos niveis de cloreto na solução nutritiva.

\begin{tabular}{ccccccc}
\hline \multirow{2}{c}{$\begin{array}{c}\text { C } 1 \\
(\mathrm{ppm})\end{array}$} & Ample H-0-K CMS-XS-616 & $\mathrm{Br}-501$ & $\mathrm{Br}-503$ & $\mathrm{Br}-602$ & IPA-7301218 \\
\cline { 2 - 7 } & $0,8 \mathrm{Bab}$ & $1,0 \mathrm{Ba}$ & $0,8 \mathrm{Bb}$ & $0,5 \mathrm{Bb}$ & $0,8 \mathrm{Cab}$ & $0,5 \mathrm{Bb}$ \\
0 & $0,8 \mathrm{Bbc}$ & $1,2 \mathrm{Bab}$ & $0,7 \mathrm{Bc}$ & $0,6 \mathrm{Bc}$ & $1,3 \mathrm{Ba}$ & $0,5 \mathrm{Bc}$ \\
2.000 & $4,7 \mathrm{Aa}$ & $3,9 \mathrm{Ab}$ & $3,9 \mathrm{Ab}$ & $3,6 \mathrm{Ab}$ & $4,1 \mathrm{Ab}$ & $1,3 \mathrm{Ac}$ \\
4.000 & & & & & & \\
\hline
\end{tabular}

c.V. $(\%)=11,33$

D.M.S. (Tukey 5\%): Cultivar $=0,28$

Cultivar d. Nivel $=0,48$

Nivel $=0,16$

Nivel d. Cultivar $=0,39$

Tabela 49 - Concentração de ferro (mg/1) no caldo de diferentes cultivares de sorgo sacarino, en função dos níveis de cloreto na solução nutritiva.

\begin{tabular}{ccccccc}
\hline \multirow{2}{*}{$\begin{array}{c}\mathrm{C} 1 \\
\mathrm{ppm})\end{array}$} & C U L T I V A R E S \\
\cline { 2 - 7 } & Ample H-0-K CMS-XS-616 & $\mathrm{Br}-501$ & $\mathrm{Br}-503$ & $\mathrm{Br}-602$ & IPA-7.301218 \\
\hline 0 & $11,7 \mathrm{Aa}$ & $6,7 \mathrm{Ac}$ & $9,3 \mathrm{Ab}$ & $6,7 \mathrm{Ac}$ & $12,0 \mathrm{Aa}$ & $7,0 \mathrm{Ac}$ \\
2.000 & $8,0 \mathrm{Bab}$ & $6,7 \mathrm{Aab}$ & $6,3 \mathrm{Bb}$ & $6,3 \mathrm{Ab}$ & $8,7 \mathrm{Ba}$ & $4,0 \mathrm{Bc}$ \\
4.000 & $7,3 \mathrm{Ba}$ & $8,0 \mathrm{Aa}$ & $7,0 \mathrm{Ba}$ & $7,0 \mathrm{Aa}$ & $8,7 \mathrm{Ba}$ & $3,3 \mathrm{Bb}$ \\
\hline
\end{tabular}

C.V. $(\%)=11,65$

$\begin{array}{rlrl}\text { D.M.S. (Tukey 5\%): Cultivar } & =1,24 & & \text { Cultivar d. Nivel }=2,14 \\ \text { Nivel } & =0,71 & \text { Nivel d. Cultivar }=1,74\end{array}$

Letras maiüsculas comparam colunas e letras minúsculas comparam linhas.

Médias seguidas pela mesma letra não diferem entre si. 
Tabela 50 - Concentração de manganês (mg/1) no caldo de diferentes cultivares de sorgo sacarino, em função dos níveis de cloreto na solução nutritiva.

\begin{tabular}{ccccccc}
\hline \multirow{2}{*}{$\begin{array}{c}\text { C U U T I V A R E S } \\
(\mathrm{ppm})\end{array}$} & Ample H-0-K CMS-XS-616 & $\mathrm{Br}-501$ & $\mathrm{Br}-503$ & $\mathrm{Br}-602$ & IPA-7301218 \\
\cline { 2 - 7 } & $8,3 \mathrm{Ab}$ & $14,0 \mathrm{Aa}$ & $4,3 \mathrm{Acd}$ & $5,6 \mathrm{Ac}$ & $5,0 \mathrm{Ac}$ & $2,7 \mathrm{Bd}$ \\
0 & $6,3 \mathrm{Bb}$ & $14,0 \mathrm{Aa}$ & $4,0 \mathrm{Ac}$ & $1,3 \mathrm{Cd}$ & $4,7 \mathrm{Abc}$ & $3,0 \mathrm{Bcd}$ \\
4.000 & $7,3 \mathrm{ABa}$ & $8,3 \mathrm{Ba}$ & $2,0 \mathrm{Bd}$ & $3,0 \mathrm{Bcd}$ & $5,3 \mathrm{Ab}$ & $4,7 \mathrm{Abc}$ \\
\hline
\end{tabular}

C.V. $(\%)=12,68$

D.M.S. (Tukey 5\%): Cultivar $=1,04$ Nivel $=0,60$

Cultivar d. Nivel $=1,80$

Nivel d. Cultivar $=1,46$

Tabela 51 - Concentração de zinco (mg/1) no caldo de diferentes cultivares de sór go sacarino, em função dos niveis de cloreto na solução nutritiva.

\begin{tabular}{ccccccc}
\hline \multirow{2}{*}{$\begin{array}{c}\text { C U U T I V A R E S } \\
(\mathrm{ppm})\end{array}$} & Ample H-0-K CMS-XS-616 & Br-501 & Br-503 & Br-602 & IPA-7301218 \\
\cline { 2 - 6 } & $2,0 \mathrm{Ab}$ & $3,3 \mathrm{Aa}$ & $1,0 \mathrm{Bc}$ & $1,6 \mathrm{Abc}$ & $1,0 \mathrm{Bc}$ & $1,0 \mathrm{Bc}$ \\
0 & $1,7 \mathrm{Abc}$ & $3,0 \mathrm{Aa}$ & $1,0 \mathrm{Bc}$ & $1,7 \mathrm{Abc}$ & $1,0 \mathrm{Bc}$ & $2,0 \mathrm{Ab}$ \\
2.000 & $2,3 \mathrm{Aab}$ & $3,0 \mathrm{Aa}$ & $2,0 \mathrm{Ab}$ & $2,0 \mathrm{Ab}$ & $2,0 \mathrm{Ab}$ & $2,0 \mathrm{Ab}$ \\
4.000 & & & & & & \\
\hline
\end{tabular}

C.V. $(\%)=20,58$

D.M.S. (Tukey 5\%): Cultivar $=0,55$

Cultivar d. Nivel $=0,95$

Nivel $=0,31$

Nivel d. Cultivar $=0,77$

Letras maiúsculas comparam colunas e letras minúsculas comparam linhas.

Médias seguidas pela mesma letra não diferem entre si. 
Tabela 52 - Concentração de cloro (mg/1) no caldo de diferentes cultivares de sorgo sacarino, em função dos níveis de cloreto na solução nutritiva.

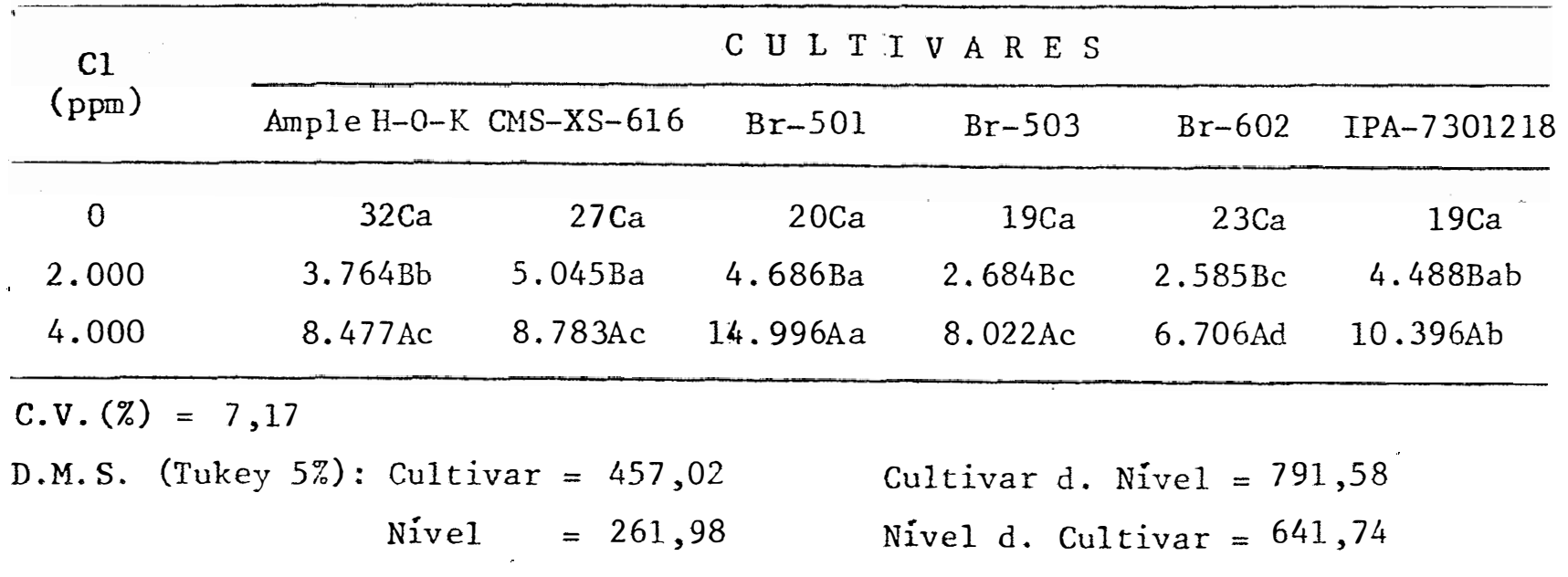

Tabela 53 - Concentração de sódio (mg/1) no caldo de diferentes cultivares de sorgo sacarino, em função dos níveis de cloreto na solução nutritiva.

\begin{tabular}{|c|c|c|c|c|c|c|}
\hline \multirow{2}{*}{$\begin{array}{c}C 1 \\
(\mathrm{ppm})\end{array}$} & \multicolumn{6}{|c|}{ C U L T I V A R E S } \\
\hline & Ample $\mathrm{H}-\mathrm{O}-\mathrm{K}$ & CMS-XS-616 & $\mathrm{Br}-501$ & $\mathrm{Br}-503$ & $\mathrm{Br}-602$ & IPA-7301218 \\
\hline 0 & $21 \mathrm{Ca}$ & $18 \mathrm{Ca}$ & $13 \mathrm{Ca}$ & $12 \mathrm{Ca}$ & $15 \mathrm{Ca}$ & $13 \mathrm{Ca}$ \\
\hline 2.000 & $2.444 \mathrm{Bb}$ & $3.276 \mathrm{Ba}$ & $3.043 \mathrm{Ba}$ & $1.743 \mathrm{BC}$ & $1.678 \mathrm{Bc}$ & $2.915 \mathrm{Bab}$ \\
\hline 4.000 & $5.405 \mathrm{Ac}$ & $5.703 \mathrm{Ac}$ & $9.738 \mathrm{Aa}$ & $5.209 \mathrm{AC}$ & 4. 354Ad & $6.751 \mathrm{Ab}$ \\
\hline
\end{tabular}

C.V. $(\%)=7,18$

D.M.S. (Tukey 5\%): Cultivar $=296,81$

Cultivar d. Nivel $=514,10$

Nivel $=170,15$

Nivel d. Cultivar $=416,78$

Letras maiúsculas comparam colunas e letras minüsculas comparam linhas.

Médias seguidas pela mesma letra não diferem entre si. 
Tabela 54 - Teores de sólidos solüveis ( ${ }^{\circ}$ Brix v/v) no caldo de diferentes cultivares de sorgo sacarino, em função dos niveis de cloreto na solu ção nutritiva.

\begin{tabular}{ccccccc}
\hline \multirow{c}{C}{$\begin{array}{c}\text { C U L T I V A R E S } \\
(\mathrm{ppm})\end{array}$} & Ample H-0-K & CMS-XS-616 & Br-501 & Br-503 & Br-602 & IPA-7301218 \\
\cline { 2 - 7 } & $19,5 \mathrm{Aa}$ & $19,2 \mathrm{Aab}$ & $16,9 \mathrm{Abc}$ & $13,6 \mathrm{Ad}$ & $14,5 \mathrm{Acd}$ & $15,7 \mathrm{Acd}$ \\
0 & $17,5 \mathrm{Ba}$ & $15,7 \mathrm{Bab}$ & $14,8 \mathrm{Bbc}$ & $12,8 \mathrm{Acd}$ & $10,9 \mathrm{Bd}$ & $14,6 \mathrm{Abc}$ \\
2.000 & $13,2 \mathrm{Cab}$ & $10,8 \mathrm{Cbc}$ & $9,2 \mathrm{Cc}$ & $9,0 \mathrm{Bc}$ & $8,7 \mathrm{Cc}$ & $13,8 \mathrm{Aa}$ \\
\hline
\end{tabular}

C.V. $(\%)=7,31$

D.M.S. (Tukey 5\%): Cultivar $=1,44$

Cultivar d. Nivel $=2,50$

Nivel $=0,83$

Nivel d. Cultivar $=2,03$

Tabela 55 - Teores de açúcares redutores totais (ART \%) no caldo de diferentes cultivares de sorgo sacarino, em função dos niveis de cloreto na solução nutritiva.

\begin{tabular}{ccccccc}
\hline \multirow{2}{c}{$\begin{array}{c}\text { C } 1 \\
(\mathrm{ppm})\end{array}$} & Ample H-0-K & CMS-XS-616 T I V A R E S & Br-501 & Br-503 & Br-602 & IPA-7301218 \\
\cline { 2 - 7 } & $13,9 \mathrm{Aa}$ & $14,1 \mathrm{Aa}$ & $9,7 \mathrm{Ab}$ & $10,7 \mathrm{Ab}$ & $10,5 \mathrm{Ab}$ & $13,5 \mathrm{Aa}$ \\
0 & $11,4 \mathrm{Bab}$ & $10,4 \mathrm{Bab}$ & $5,5 \mathrm{Bc}$ & $8,9 \mathrm{Bb}$ & $6,4 \mathrm{Bc}$ & $11,8 \mathrm{Aa}$ \\
2.000 & $6,0 \mathrm{Cb}$ & $3,1 \mathrm{Ccd}$ & $2,7 \mathrm{Cd}$ & $5,9 \mathrm{Cb}$ & $5,5 \mathrm{Bbc}$ & $9,3 \mathrm{Ba}$ \\
\hline
\end{tabular}

C.V. $(\%)=11,53$

D.M.S. (Tukey 5\%): Cultivar $=1,45$

Cultivar d. Nivel $=3,14$

Nivel $=0,83$

Nivel d. Cultivar $=2,04$

Letras maiúsculas comparam colunas e letras minúsculas comparam linhas. Médias seguidas pela mesma letra não diferem entre si. 
Tabela 56 - Teores de açúcares redutores (AR \%) no caldo de diferentes cultivares de sorgo sacarino, em função dos niveis de cloreto na solução nutritiva.

C1

$(p p r)$
0
2.000
4.000

Ample H-O-K CMS-XS-616

C U L T I V A R E S

C.V. $(\%)=18,90$

D.M.S. (Tukey 5\%): Cultivar $=0,68$ Nivel $=0,39$

$\begin{array}{llllll}2,25 \mathrm{Abc} & 1,22 \mathrm{Ac} & 4,47 \mathrm{Aa} & 5,01 \mathrm{Aa} & 3,16 \mathrm{Ab} & 5,39 \mathrm{Aa} \\ 2,41 \mathrm{Abc} & 1,62 \mathrm{Ac} & 2,07 \mathrm{Bc} & 3,01 \mathrm{Bab} & 1,49 \mathrm{Bc} & 3,76 \mathrm{Ba} \\ 2,33 \mathrm{Aab} & 1,50 \mathrm{Abc} & 0,75 \mathrm{Cc} & 1,14 \mathrm{Ca} & 1,35 \mathrm{Cbc} & 2,70 \mathrm{Ca}\end{array}$

Tabela 57 - Teores de sacarose no caldo de diferentes cultivares de sorgo sacarino, em função dos niveis de cloreto na solução nutritiva.

C1

C U L T I V A R E S

\begin{tabular}{ccccccc} 
(ppm) & Ample H-0-K & CMS-XS-616 & $\mathrm{Br}-501$ & $\mathrm{Br}-503$ & $\mathrm{Br}-602$ & IPA-7301218 \\
\cline { 2 - 6 } 0 & $11,1 \mathrm{Aa}$ & $12,2 \mathrm{Aa}$ & $5,0 \mathrm{Ac}$ & $5,4 \mathrm{Ac}$ & $7,0 \mathrm{Abc}$ & $7,7 \mathrm{Ab}$ \\
2.000 & $8,7 \mathrm{Ba}$ & $8,3 \mathrm{Ba}$ & $3,3 \mathrm{ABc}$ & $5,6 \mathrm{Abc}$ & $4,6 \mathrm{Bc}$ & $7,7 \mathrm{Aab}$ \\
4.000 & $3,5 \mathrm{Cbcd}$ & $1,5 \mathrm{Cd}$ & $1,9 \mathrm{Bcd}$ & $4,5 \mathrm{Aab}$ & $3,9 \mathrm{Bbc}$ & $6,3 \mathrm{Aa}$ \\
\hline
\end{tabular}

C.V. $(\%)=15,86$

$\begin{aligned} \text { D.M.S. (Tukey 5\%): Cultivar } & =4,26 & & \text { Cultivar d. Nivel }=4,26 \\ \text { Nivel } & =3,45 & & \text { Nivel d. Cultivar }=3,45\end{aligned}$

Letras maiúsculas comparam colunas e letras minúsculas comparam linhas. Mēdias seguidas pela mesma letra não diferem entre si. 
Tabela 58 - Teores de fibra no colmo de diferentes cultivares de sorgo sacarino, em função dos niveis de cloreto na solução nutritiva.

\begin{tabular}{|c|c|c|c|c|c|c|}
\hline \multirow{2}{*}{$\begin{array}{c}\mathrm{Cl} \\
(\mathrm{ppm})\end{array}$} & \multicolumn{6}{|c|}{ C U L T I V A R E S } \\
\hline & Ample $\mathrm{H}-\mathrm{O}-\mathrm{K}$ & CMS-XS-616 & $\mathrm{Br}-501$ & $B r-503$ & $\mathrm{Br}-602$ & IPA-7301218 \\
\hline 0 & $7,59 \mathrm{Bcd}$ & $5,91 \mathrm{Ce}$ & $7,53 \mathrm{Cd}$ & $10,42 \mathrm{Ba}$ & $8,43 \mathrm{Cbc}$ & $8,47 \mathrm{Bb}$ \\
\hline 2.000 & $8,28 \mathrm{Bb}$ & $7,36 \mathrm{BC}$ & $8,64 \mathrm{Bb}$ & $10,40 \mathrm{Ba}$ & $10,16 \mathrm{Aa}$ & $10,78 \mathrm{Aa}$ \\
\hline 4.000 & $9,78 \mathrm{Ac}$ & $8,69 \mathrm{Ad}$ & $10,21 \mathrm{Abc}$ & $11,66 \mathrm{Aa}$ & $10,70 \mathrm{Ab}$ & $11,03 \mathrm{Aab}$ \\
\hline
\end{tabular}

C.V. $(\%)=3,77$

D.M.S. (Tukey 5\%): Cultivar $=0,49$

Cultivar d. Nivel $=0,85$

Nivel $=0,28$

Nivel d. Cultivar $=0,69$

Letras maiúsculas comparam colunas e letras minúsculas comparam linhas. Médias seguidas pela mesma letra não diferem entre si. 


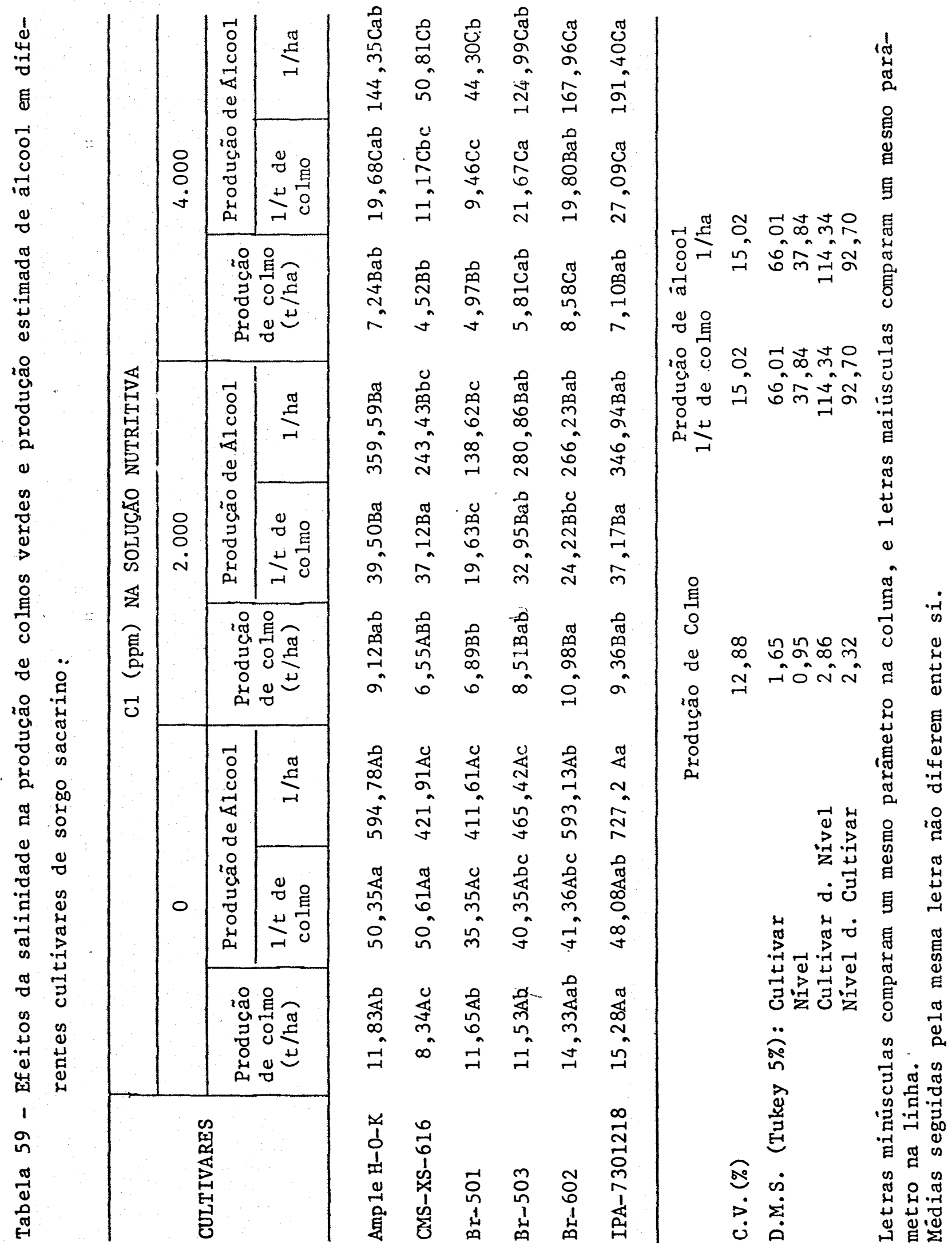

